\title{
‡USGS
}

science for a changing world

In Cooperation with Minerals Management Service, Gulf of Mexico Outer Continental Shelf Region

\section{Influence of the Houma Navigation Canal on Salinity Patterns and Landscape Configuration in Coastal Louisiana}

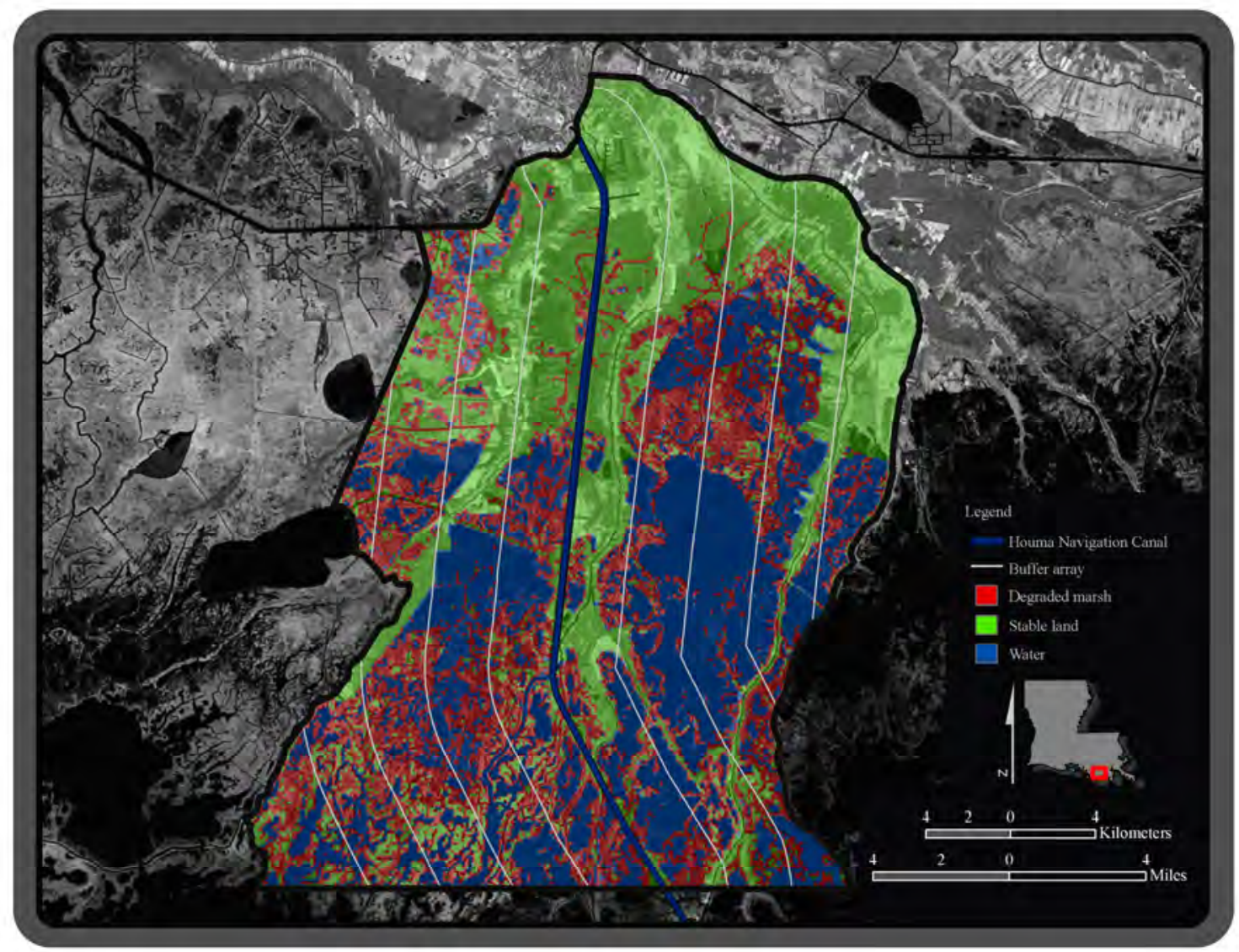

Open-File Report 2008-1127

U.S. Department of the Interior

U.S. Geological Survey 


\section{Influence of the Houma Navigation Canal on Salinity Patterns and Landscape Configuration in Coastal Louisiana}

By Gregory D. Steyer ${ }^{1}$, Charles Sasser ${ }^{2}$, Elaine Evers ${ }^{3}$, Erick Swenson ${ }^{3}$, Glenn Suir ${ }^{4}$, and Sijan Sapkota ${ }^{5}$

${ }^{1}$ U.S. Geological Survey

National Wetlands Research Center

Coastal Restoration Field Station

Baton Rouge, LA 70894

${ }^{2}$ Agricultural Center, School of Coast and Environment Louisiana State University

Baton Rouge, LA 70803

${ }^{3}$ Coastal Ecology Institute, School of Coast and Environment Louisiana State University

Baton Rouge, LA 70803

${ }^{4}$ IAP World Services, Inc.

700 Cajundome Blvd.

Lafayette, LA 70506

${ }^{5}$ U.S. Geological Survey

National Wetlands Research Center

Lafayette, LA 70506

Open-File Report 2008-1127

U.S. Department of the Interior

U.S. Geological Survey 


\section{U.S. Department of the Interior DIRK KEMPTHORNE, Secretary}

\section{U.S. Geological Survey \\ Mark D. Myers, Director}

U.S. Geological Survey, Reston, Virginia 2008

For product and ordering information:

World Wide Web: http://www.usgs.gov/pubprod

Telephone: 1-888-ASK-USGS

For more information on the USGS - the Federal source for science about the Earth, its natural and living resources, natural hazards, and the environment:

World Wide Web: http://www.usgs.gov

Telephone: 1-888-ASK-USGS

Suggested citation:

Steyer, G.D., Sasser, C., Evers, E., Swenson, E., Suir, G., and Sapkota, S., 2008, Influence of the Houma Navigation Canal on salinity patterns and landscape configuration in coastal Louisiana: an interagency collaboration: U.S. Geological Survey Open-File Report 2008-1127, $190 \mathrm{p}$.

Front cover image: The Houma Navigation Canal with 3-kilometer buffer zones on either sides of the Canal. The Houma Navigation Canal is located in Terrebonne Parish, Louisiana. Image source: 2000 Thematic Mapper imagery. Scale: 1:215,000.

Any use of trade, product, or firm names is for descriptive purposes only and does not imply endorsement by the U.S. Government.

Although this report is in the public domain, permission must be secured from the individual copyright owners to reproduce any copyrighted material contained within this report. 


\section{Contents}

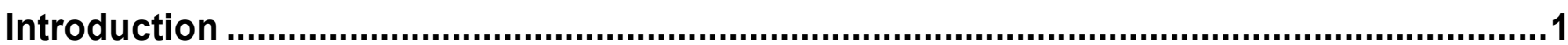

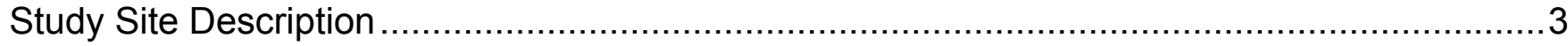

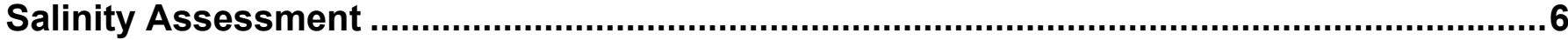

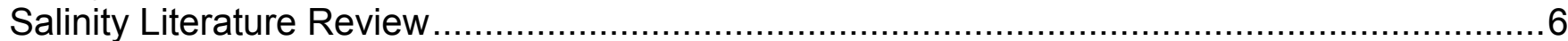

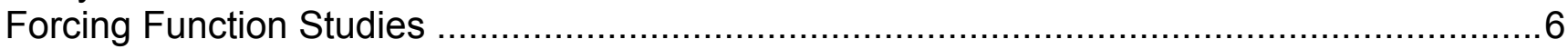

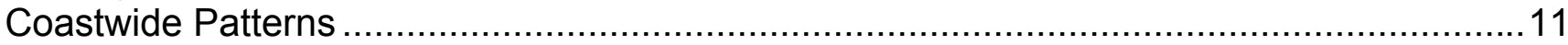

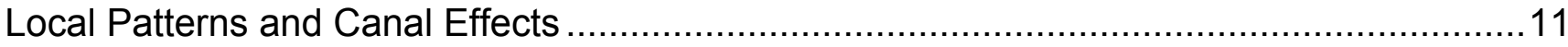

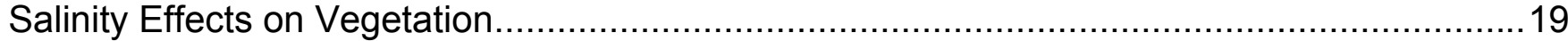

Historical Salinity Data Collection and Trend Analyses ................................................. 19

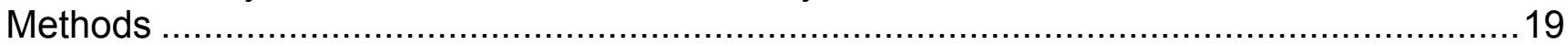

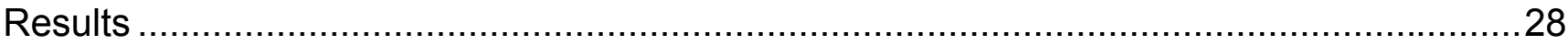

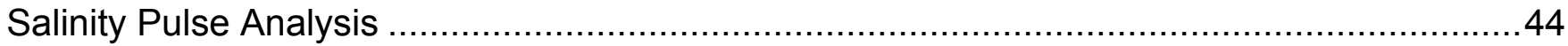

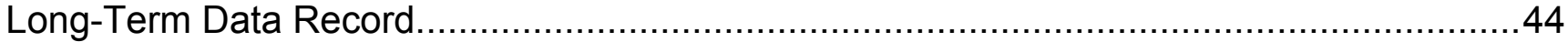

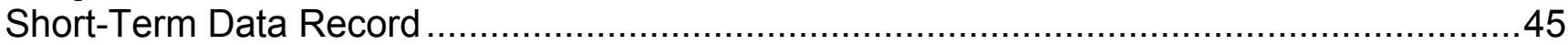

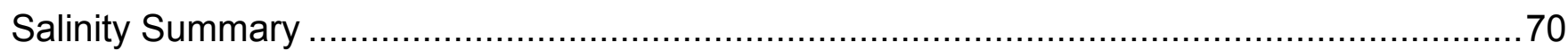

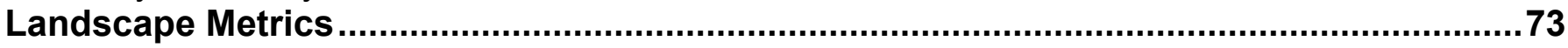

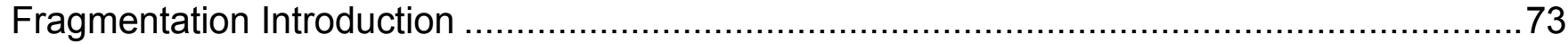

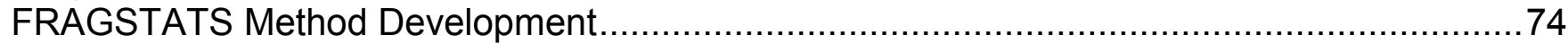

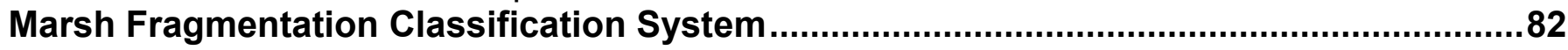

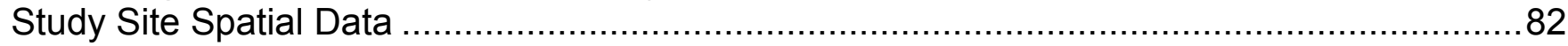

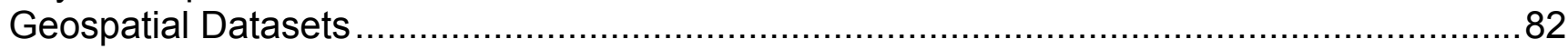

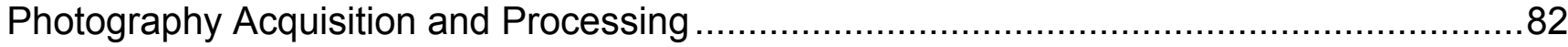

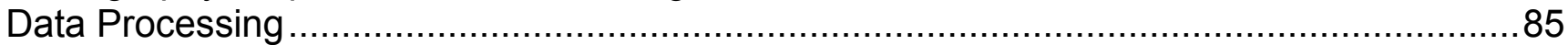

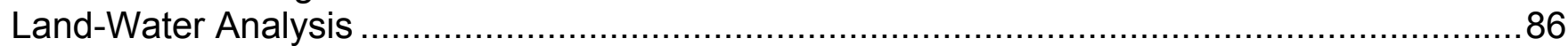

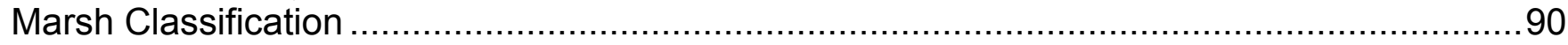

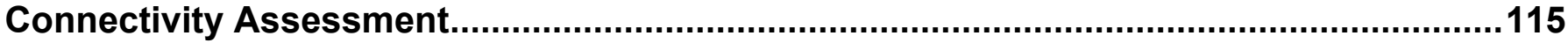

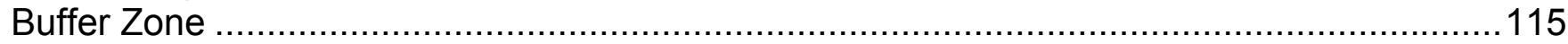

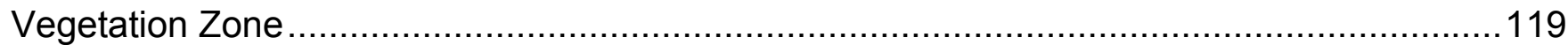

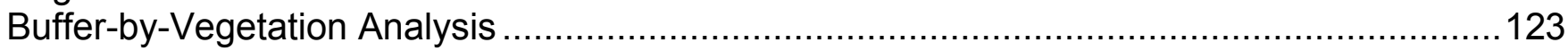

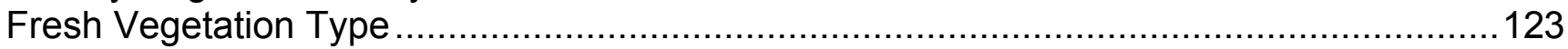

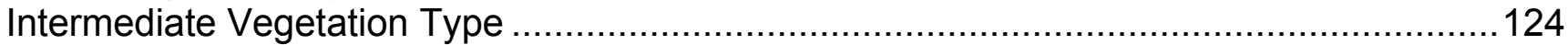

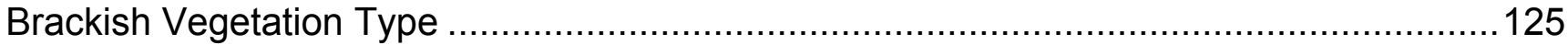

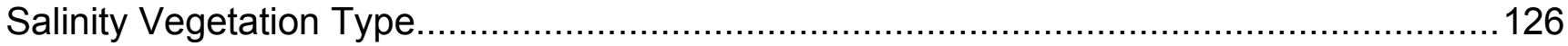

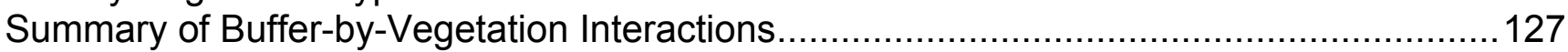

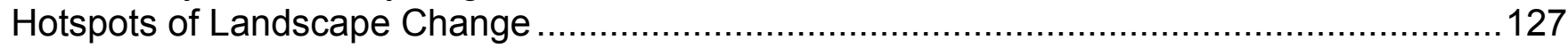

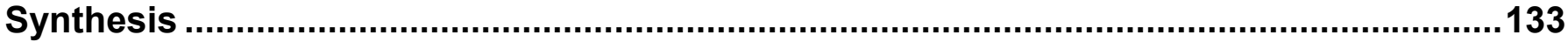

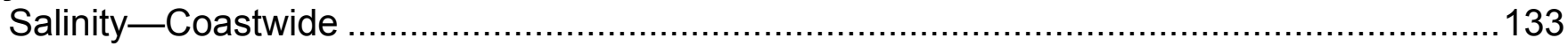

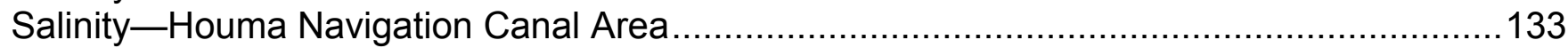

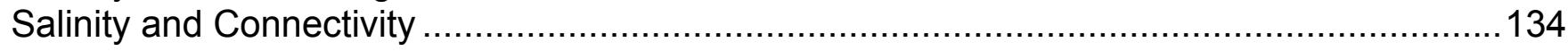

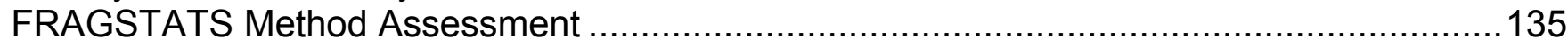

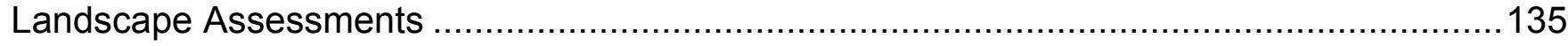

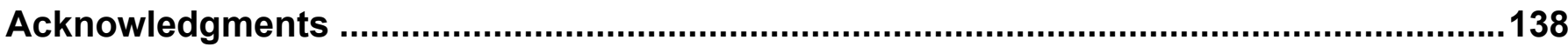

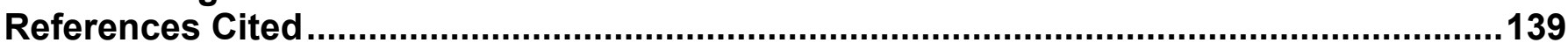

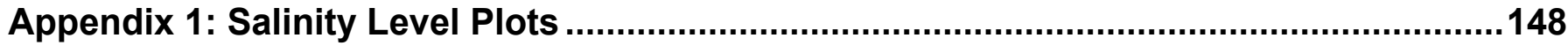

Appendix 2: FRAGSTATS Classification Criteria and Thresholds .................................184 


\section{Figures}

1. Map of the major navigation channels in coastal Louisiana ............................................

2. Location map of the Houma Navigation Canal centerline and project area boundary .............4

3. General vegetation zones for the Houma Navigation Canal study area over time..................5

4. Schematic of an estuarine system illustrating the major pathways of freshwater and coastal ocean water inputs to the system............................................................................

5. Plots of measured monthly mean salinity and predicted monthly salinity ...........................10

6. Summary of saltwater intrusion model results for the Houma Navigation Canal ...................14

7. Summary of saltwater intrusion model results for Bayou Petite Caillou ................................15

8. Map of salinity outlets, pathways along the Houma Navigation Canal, and various salinity

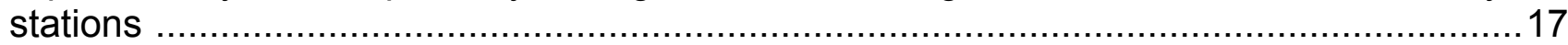

9. Chloride exceedance (days per year) from Houma water treatment plant .........................18

10. Map of salinity stations in the east Louisiana coastal marshes......................................22

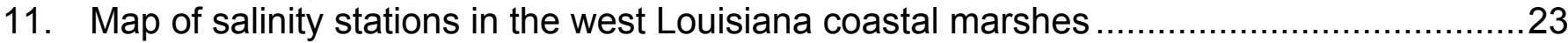

12. Plot of the relationship between salinity in grains per gallon and salinity in parts per

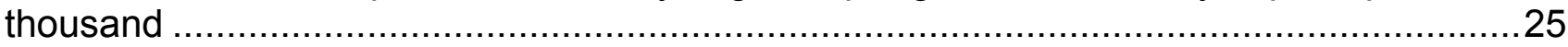

13. Plot of the relationship between salinity measured by the U.S. Army Corps of Engineers and the Louisiana Department of Wildlife and Fisheries ............................................2. 26

14. Plot of surface salinity against bottom salinity for Louisiana Department of Wildlife and

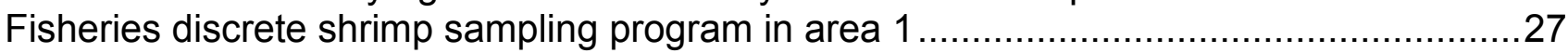

15. Distribution of data series lengths for the salinity datasets used in the final analysis .........29

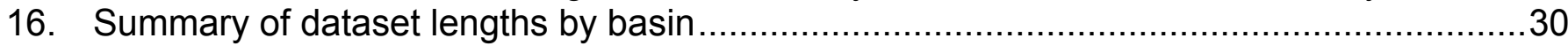

17. Time series plot of daily and 90-day running mean salinity from Grand Terre station ........32

18. Time series plot of daily and 90-day running mean salinity from Cameron station ............33

19. Time series plot of daily and 90-day running mean salinity from Bayou Grand Caillou ......34

20. Time series plot of daily and 90-day running mean salinity from Little Lake station ...........35

21. Time series plot of daily mean salinity from Houma Navigation Canal at Crozier ...............36

22. Average salinity for the period of record for the 44 stations used in the final analysis ........39

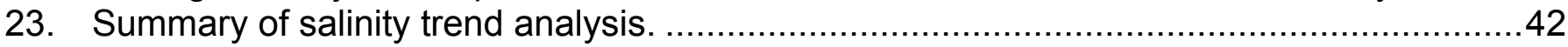

24. Summary of salinity change in parts per thousand over the period from 1975-98 …........43

25. Plot of salinity level data for Bayou Petite Caillou at Cocodrie.......................................46

26. Plot of salinity level data for Bayou Petite Caillou near Boudreaux Canal .........................47

27. Plot of salinity level data for Bayou Grand Caillou near Dulac ......................................48

28. Plot of salinity level data for Bayou Terrebonne near Bourg .......................................49

29. Plot of salinity level data for the Houma Navigation Canal near Crozier ............................50

30. Plot of salinity level data for the Gulf Intracoastal Waterway at Houma.............................51

31. Map of stations used in the salinity pulse analysis .......................................................52

32. Schematic of the three coast-inland transects in the Houma Navigation Canal..................56

33. Time series plot of hourly and 25-hour filtered salinity from Bayou Terrebonne .................57

34. Time series plot of hourly and 25-hour filtered salinity from Bayou Grand Caillou...............58

35. Time series plot of hourly and 25-hour filtered salinity from the Houma Navigation Canal.59

36. Time series plot of hourly and 25-hour water level from Bayou Terrebonne......................60

37. Time series plot of hourly and 25-hour water level from Bayou Grand Caillou ...................61

38. Time series plot of hourly and 25-hour water level from the Houma Navigation Canal ......62 


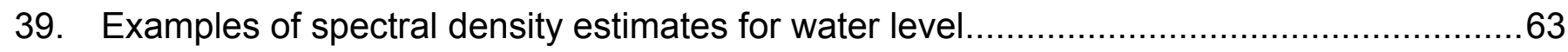

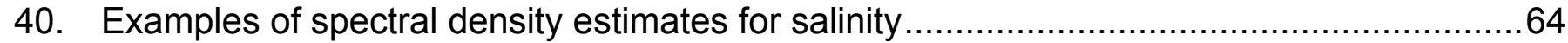

41. Time series plot of filtered discharge in Bayou Grand Caillou and the Houma Navigation

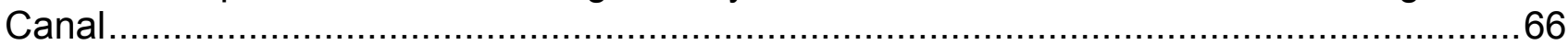

42. Mean salinity pulse magnitude for stations in the Houma Navigation Canal........................67

43. Mean salinity pulse coast-inland decrease for stations in the Houma Navigation Canal ....68

44. Mean salinity pulse duration, in days, for stations in the Houma Navigation Canal ............69

45. Plot of salinity amplitude at Falgout Canal versus discharge through the Houma Navigation

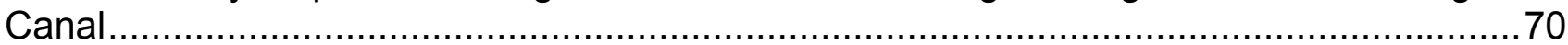

46. Summary of salinity records in the Houma Navigation Canal area .................................72

47. Examples from the Dulac quadrangle of the classification scheme …..............................

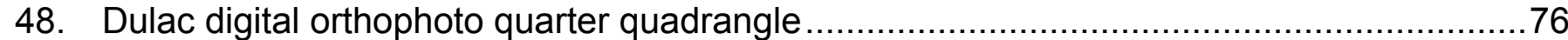

49. Preliminary FRAGSTATS marsh fragmentation and configuration classification .................81

50. Salinity monitoring station, dredge history, and river mile locations................................. 84

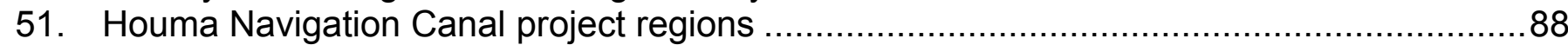

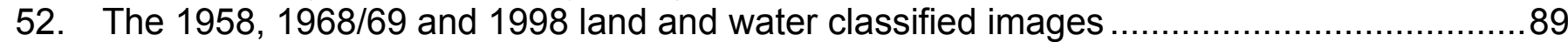

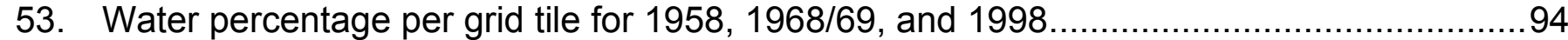

54. Largest patch index per grid tile for 1958, 1968/69, and 1998 ....................................95

55. Percentage of landscape difference per tile among 1958, 1968/69, and $1998 \ldots \ldots \ldots \ldots \ldots . . . .96$

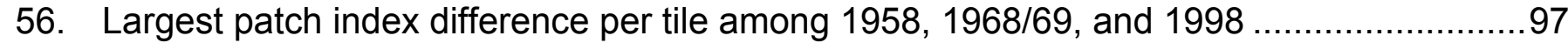

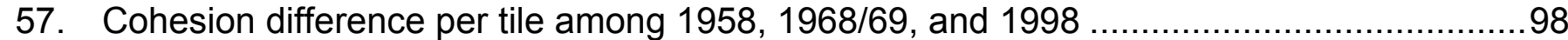

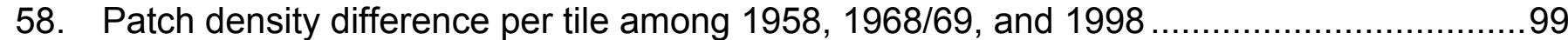

59. Landscape shape index difference per tile among 1958, 1968/69, and $1998 \ldots \ldots \ldots \ldots \ldots \ldots . . . .100$

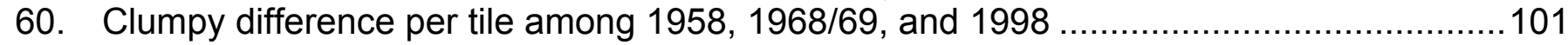

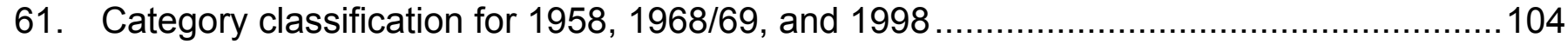

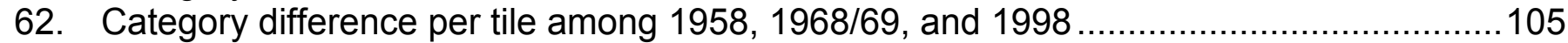

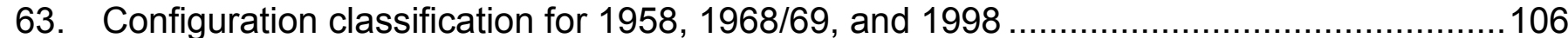

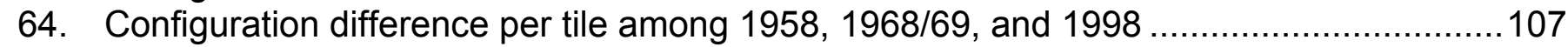

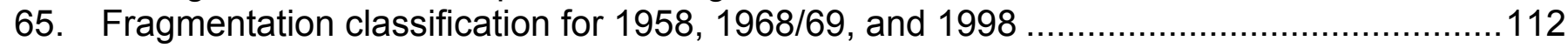

66. Marsh degradation classification for 1958, 1968/69, and 1998................................113

67. Map of buffers and vegetation zones within the Houma Navigation Canal .....................116

68. Tile summary for each buffer by year, along with totals for each buffer zone ..................117

69. Average largest patch per tile for buffers in the project area ...................................118

70. Average cohesion value per tile for buffers in the project area .................................119

71. A section of the 1998 land change image with a vegetation change layer.......................120

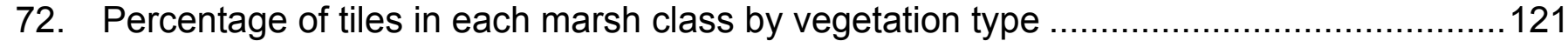

73. Average largest patch per tile for vegetation zones within the project area .....................122

74. Average cohesion index per tile and vegetation zones...........................................123

75. Marsh classification by fresh vegetation zone, buffer, and years................................. 124

76. Marsh classification by intermediate vegetation zone, buffer, and years.........................125

77. Marsh classification by brackish vegetation zone, buffer, and years. ...........................126

78. Marsh classification by salt vegetation zone, buffer, and years................................. 127

79. Map of fragmentation difference per tile between 1958 and $1998 \ldots \ldots \ldots \ldots \ldots \ldots \ldots \ldots \ldots \ldots \ldots . . .129$

\section{Tables}

1. Summary of regression results to predict salinity in the Barataria system ............................

2. Results of the Kendall-Tau test on monthly mean salinity …........................................... 12 
3. List of stations used in the final analysis.

4. Comparison of daily mean salinity versus daily 8 a.m. salinity readings

5. Summary of dataset lengths, by basin, for the 44 salinity stations used for the final analysis

6. Summary statistics for the stations used in the final analysis

7. Results of salinity trend analysis using time as the independent variable

8. Results of salinity trend analysis using time as the independent variable from 1975 to 1998

9. Data availability for the salinity "spike" analysis in the Houma Navigation Canal for year 2003

10. Correlation between filtered salinity and water level

11. Dulac sample area shift and scale analyses

12. FRAGSTATS classification system metric descriptions.

13. Status of project-wide available photography

14. Area of total project landscape and feature classes for all project land-water images.

15. Total area lost and land loss rates at various spatial and temporal scales

16. Project-scale landscape metrics

17. Summary statistics of core class metrics....

18. Summary count of category and configuration classes.

19. Marsh classes and the classification system used for interpretation of aerial photography

20. Summary of fragmentation class groupings for the three time periods. 108

21. Frequency and percentage of tiles within each region for the three project dates. 108

22. Average primary metric values by year and orientation to the Houma Navigation Canal 111

23. Change in classification from 1968 to 1998 for all 1958 class ' 1 ' tiles

24. Explanation of buffer intervals 


\section{Conversion of International System of Units (SI) used in this report to U.S. Units}

\begin{tabular}{|c|c|c|}
\hline Unit & Multiply By & To obtain \\
\hline \multicolumn{3}{|l|}{ Length } \\
\hline centimeter $(\mathrm{cm})$ & 0.3937 & inch (in.) \\
\hline meter $(\mathrm{m})$ & 3.281 & foot $(\mathrm{ft})$ \\
\hline kilometer (km) & 0.6214 & mile (mi) \\
\hline meter $(\mathrm{m})$ & 1.094 & yard (yd) \\
\hline \multicolumn{3}{|l|}{ Area } \\
\hline hectare (ha) & 2.471 & acre \\
\hline square kilometer $\left(\mathrm{km}^{2}\right)$ & 247.1 & acre \\
\hline square meter $\left(\mathrm{m}^{2}\right)$ & 10.76 & square foot $\left(\mathrm{ft}^{2}\right)$ \\
\hline hectare (ha) & 0.003861 & square mile $\left(\mathrm{mi}^{2}\right)$ \\
\hline square kilometer $\left(\mathrm{km}^{2}\right)$ & 0.3861 & square mile $\left(\mathrm{mi}^{2}\right)$ \\
\hline \multicolumn{3}{|l|}{ Volume } \\
\hline liter (L) & 33.82 & ounce, fluid (fl. oz) \\
\hline liter (L) & 0.2642 & gallon (gal) \\
\hline cubic meter $\left(\mathrm{m}^{3}\right)$ & 264.2 & gallon (gal) \\
\hline cubic decimeter $\left(\mathrm{dm}^{3}\right)$ & 0.2642 & gallon (gal) \\
\hline cubic meter $\left(\mathrm{m}^{3}\right)$ & 35.31 & cubic foot $\left(\mathrm{ft}^{3}\right)$ \\
\hline cubic meter $\left(\mathrm{m}^{3}\right)$ & 1.308 & cubic yard $\left(\mathrm{yd}^{3}\right)$ \\
\hline \multicolumn{3}{|l|}{ Flow rate } \\
\hline cubic meter per second $\left(\mathrm{m}^{3} / \mathrm{s}\right)$ & 35.31 & cubic foot per second $\left(\mathrm{ft}^{3} / \mathrm{s}\right)$ \\
\hline \multicolumn{3}{|l|}{ Land loss/gain rate } \\
\hline $\begin{array}{l}\text { Square kilometer per year } \\
\left(\mathrm{km}^{2} / \mathrm{yr}\right)\end{array}$ & 247.1 & acre per year (acre/yr) \\
\hline $\begin{array}{l}\text { Square kilometer per year } \\
\left(\mathrm{km}^{2} / \mathrm{yr}\right)\end{array}$ & 0.3861 & square mile per year $\left(\mathrm{mi}^{2} / \mathrm{yr}\right)$ \\
\hline
\end{tabular}

Temperature in degrees Celsius $\left({ }^{\circ} \mathrm{C}\right)$ may be converted to degrees Fahrenheit $\left({ }^{\circ} \mathrm{F}\right)$ as follows:

${ }^{\circ} \mathrm{F}=\left(1.8 \times{ }^{\circ} \mathrm{C}\right)+32$

Vertical coordinate information is referenced to the insert datum name (and abbreviation) here, for instance, "North American Vertical Datum of 1988 (NAVD 88)"

Concentrations of chemical constituents in water are given either in milligrams per liter $(\mathrm{mg} / \mathrm{L})$ or gram per liter $(\mathrm{g} / \mathrm{L})$

Grains per gallon may be converted to parts per thousand (ppt) as follows:

Grains per gallon=62.5×ppt 


\title{
Influence of the Houma Navigation Canal on Salinity Patterns and Landscape Configuration in Coastal Louisiana
}

\author{
By Gregory D. Steyer, Charles Sasser, Elaine Evers, Erick Swenson, Glenn Suir, and \\ Sijan Sapkota
}

\section{Introduction}

Coastal Louisiana is a dynamic and ever-changing landscape. From 1956 to 2004, over 297,000 ha of Louisiana's coastal wetlands have been lost because of a combination of natural and human-induced activities (Barras, 2006). Subsidence, sea-level rise, freshwater and sediment deprivation, saltwater intrusion, the dredging of oil and gas canals, navigation canals, shoreline erosion, and herbivory are all contributors to wetland loss in Louisiana. Separating the influences of each of these factors is extremely difficult because of the wide range of spatial and temporal scales over which they occur. Direct impacts associated with an immediate physical conversion of habitat have been well described for coastal Louisiana (Boesch, 1982; Turner and Cahoon, 1988); however, the indirect impacts that are subtle and operate over longer time horizons (such as salinity intrusion) have been difficult to discern.

The distribution of marsh vegetation is strongly affected by salinity (Fuller and others, 1995), with changes in species composition occurring in response to salinity changes (Visser and others, 2002). Vegetation distributions are commonly used as an indicator of salinity regime, when salinity data are not available. Connectivity of the landscape can greatly influence vegetation distributions, since the degree of connectivity influences movement of water from primary sources (canals, bayous, lakes, bays) to interior estuarine marshes. Saltwater intrusion into marshes can be increased by the location of straight and deep canals that connect the coast with the interior marshes (Gosselink, 1984). Thus, the extent of connectivity, percentage of water in the marsh, and the configuration of water bodies within the marsh landscape are useful indicators to evaluate marsh conditions (Sasser and others, 2002).

Ten major Federal navigation canals - up to $13.7 \mathrm{~m}$ deep and $304.8 \mathrm{~m}$ wide - have been constructed in coastal Louisiana since the mid-1800s (fig. 1; Good and others, 1995). These channels are partly responsible for the severity of coastal wetland loss that Louisiana is experiencing via direct/primary losses and by indirect/secondary losses including saltwater intrusion, hydrologic disruption, and shoreline erosion. Louisiana Department of Natural Resources (LDNR) has estimated that approximately 23,100 ha of coastal wetland habitat have been lost via shoreline erosion of the 10 major Federal navigation canals, with erosion losses ranging from 145 percent to greater than 300 percent of the original direct loss of approximately6,880 ha associated with construction (Good and others, 1995). Maintenance dredging and the deepening of existing channels to accommodate increased and larger vessel traffic also increase the movement of more saline waters farther inland (Wang, 1988), further exacerbating the problem. Because of the adverse impacts of canals (direct excavation, saltwater intrusion, hydrologic disruption), there is a need to better quantify the secondary impacts of navigation canals as well as gain a better understanding of the patterns of change and wetland loss in order to minimize future impacts. 


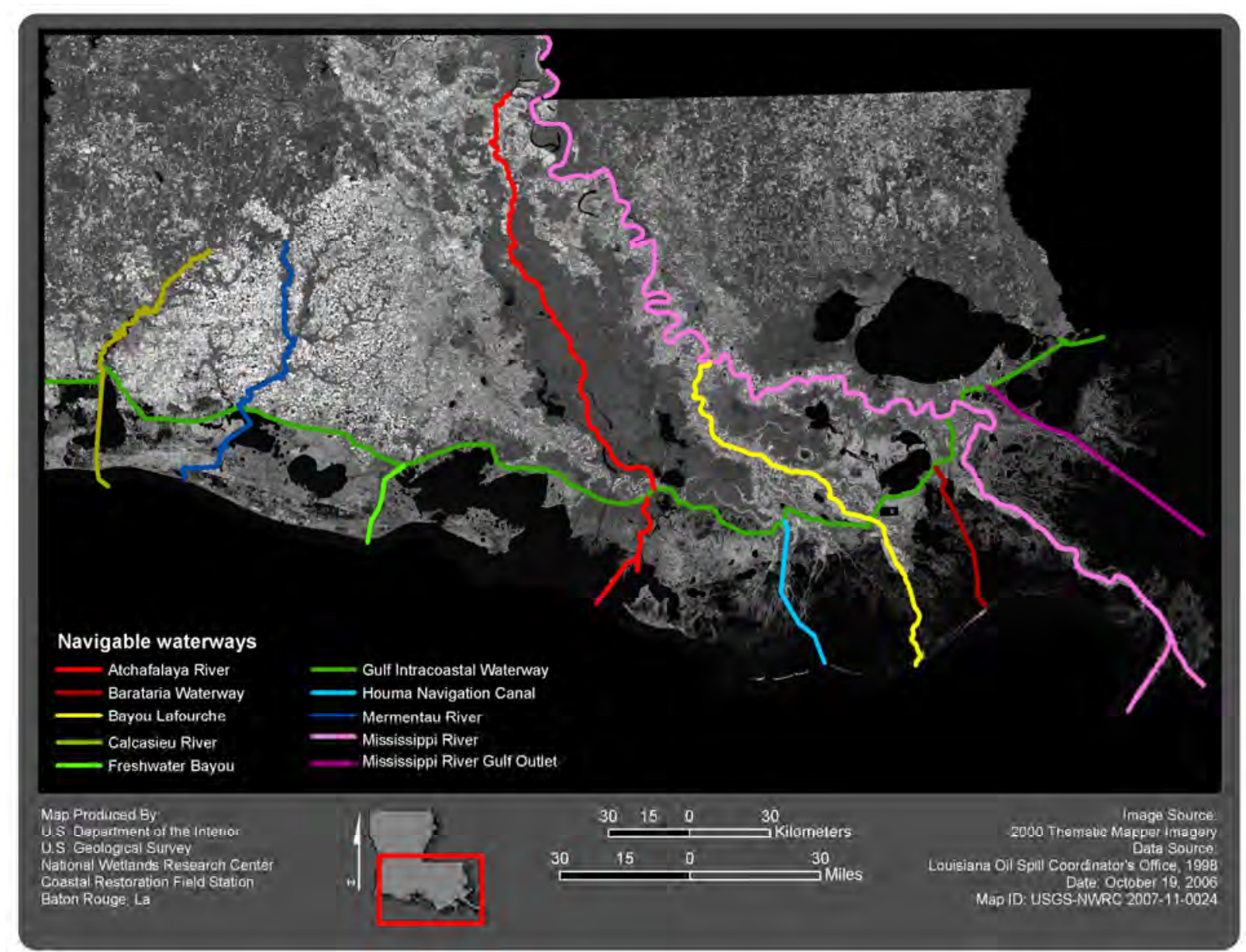

\section{Figure 1. Major navigation channels in coastal Louisiana.}

The objective of this project is to perform an evaluation of the extent that Outer Continental Shelf (OCS) waterways and navigation canals have contributed to changes in salinity and wetland landscape patterns in coastal Louisiana. Our approach includes (1) assembling and synthesizing all available salinity data, salinity management studies, and salinity models for coastal Louisiana; (2) conducting temporal and spatial analyses of available salinity data to determine changes in those variables relative to pre- and post-navigation canal construction and subsequent deepening events; and (3) relating salinity changes to hydraulic connectivity and associated habitat changes over time. The last element of our approach includes developing a marsh water configuration classification and fragmentation index to classify marsh within the study area into multiple categories based on estimates of percentages of marsh and water, configurations of water bodies within the marsh, and connectivity of water bodies with selected navigation canals related to the (OCS). This approach will help to identify breakup patterns of interior marshes over time and the relationship between fragmentation, hydrologic connectivity, and salinity intrusion via straight, deep channels. 


\section{Study Site Description}

The study site selected for analysis in this project was the Houma Navigation Canal (HNC) area (fig. 2). The canal study site is located in the Terrebonne basin bordered on the north by the Gulf Intracoastal Waterway (GIWW); the east by Bayou Terrebonne; the west by Minors Canal, Lake de Cade, and Bayou du Large; and extends south to the lower regions of the Bayou Sauveur and Lake Quitman quadrangles (USGS). Construction of the HNC began in 1958 and was completed by 1962 . The canal dimensions were originally $4.6 \mathrm{~m}$ deep by $45.7 \mathrm{~m}$ wide; however, in 1974, the lower reaches near Terrebonne Bay were enlarged to $4.5 \mathrm{~m}$ deep by $91.5 \mathrm{~m}$ wide. The entire length of the HNC is maintenance dredged approximately every 10 years and spot dredged in intervening years. The canal is used for many purposes including navigation for the oil and gas industry, commercial shipping, and commercial and recreational fishing.

The Houma Navigation Canal study site contains swamp forest and fresh, intermediate, brackish, and saline marshes. Based on historical vegetative change, this area has shown a trend of increasing salinity over time (fig. 3), much of which is attributed to the construction of the canal. The study site was chosen on the basis of the availability of adequate data (historical salinity data and photography) for analysis. Moreover, this site provides a broad spectrum of wetland habitats and physical characteristics representing the Deltaic Plain of coastal Louisiana. 


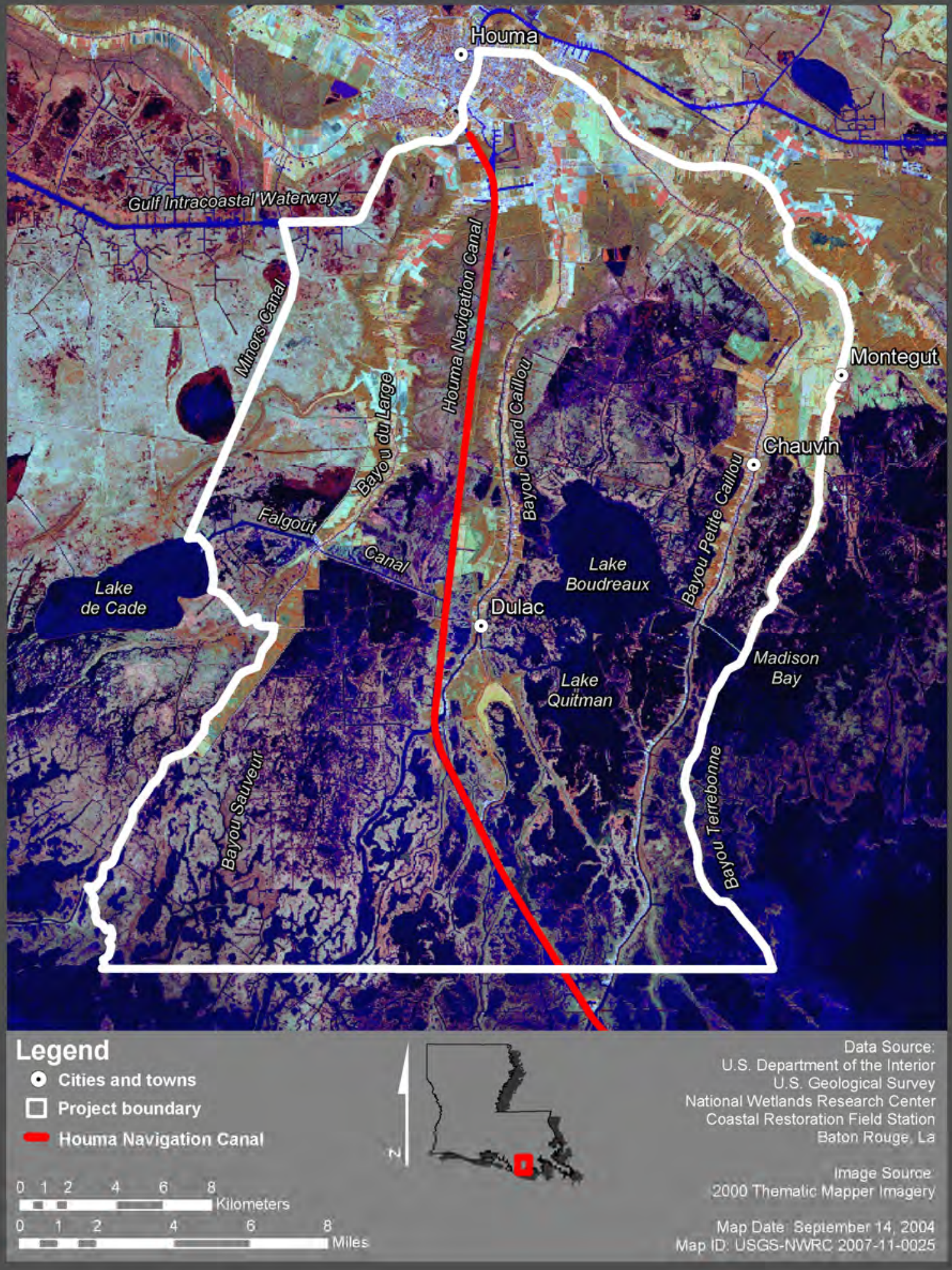

Figure 2. The Houma Navigation Canal and project area in coastal Louisiana. 


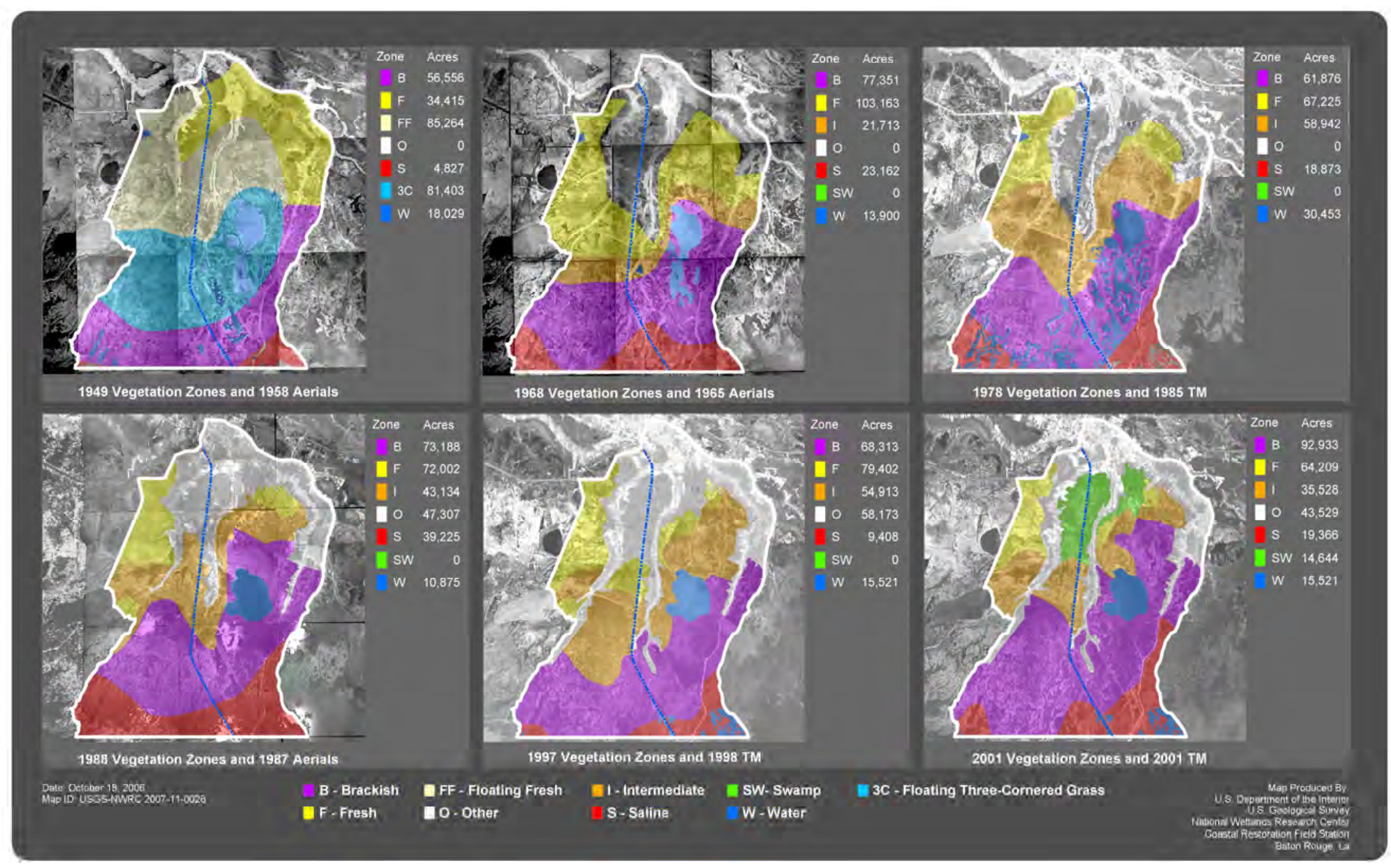

Figure 3. General vegetation zones for the Houma Navigation Canal study area in coastal Louisiana over time. Digital data provided by the U.S. Geological Survey with original data from O'Neil (1949), Chabreck and others (1968, 1978, 1988, 1997), and Linscombe and others (2001). 


\section{Salinity Assessment}

\section{Salinity Literature Review}

\section{Forcing Function Studies}

Water levels and open-water salinity in coastal estuaries are generally controlled by a balance between the freshwater input generated from precipitation and runoff and the saltwater mixing into the coastal estuaries through the coastal boundary layer. The coastal boundary is in turn influenced by exchange with the deeper shelf and Gulf of Mexico waters as well as with the freshwater plume from the Mississippi River. These exchanges are bidirectional with significant transfers of mass and momentum and also with chemical and geological constituents occurring between the shelf and the estuary (Wiseman, 1986).

Meteorological forcing in estuaries along the northern Gulf of Mexico can be considered in terms of (1) exchange between the estuarine waters and the waters in the coastal zone and (2) local forcing within the estuary proper. Baumann (1987) attributed the changes in the spatial and temporal salinity patterns in the Barataria Estuary to three basic factors: (1) the seasonal evapotranspiration and precipitation regime, (2) Mississippi River discharge, and (3) seasonal water level cycle. At shorter time scales (a few days), the along-estuary wind stress drives an estuarine-shelf exchange, whereas at longer time scales, Ekman convergence/divergence driven by the alongshore wind stress drives estuarine-shelf exchanges (Schroeder and Wiseman, 1986). Work by Kjerfve (1975) in Caminada Bay, La., demonstrated that the diurnal tidal influence, in addition to the wind forcing, can be important in controlling the internal dynamics of these systems. The most pronounced effect of wind forcing on the central northern Gulf of Mexico systems is the difference between a northerly and a southerly wind. Strong winds from the south "push" water towards the coast, forcing water into the estuaries, raising water levels about $0.3-0.5$ $\mathrm{m}$ above normal. Conversely, winds from the north force water out of the estuaries, depressing the water levels $0.3-0.5 \mathrm{~m}$ below normal. The "set up" of water usually develops as a cold front approaches the area from the west and the southerly winds pile water along the coast; after the front passes the winds shift to a more northerly direction. This situation results in a rapid drop in the estuarine water levels as described for the Chandeleur-Breton Sound (Hart and Murray, 1978) and

for Fourleague Bay (Perez and others, 2000). These events result in substantial fluxes of water into and out of estuarine systems and can have dramatic effects on the salinity distribution within the system. Thus, the salinity signal in these estuarine systems is fairly complex. A schematic detailing the major forcing functions discussed above is shown in figure 4.

Orlando and others (1993) described the factors influencing salinity in 26 estuarine systems in the northern Gulf of Mexico. The Mississippi-Atchafalaya discharge dominates the input in Louisiana and in the central portion of the gulf, while the western (Texas) and eastern (Mississippi to Florida) portions of the gulf are more heavily influenced by local river flow. In general, the Gulf of Mexico is characterized by low precipitation in Texas, higher and uniform precipitation in the central gulf, and a distinct wet-dry season in Florida. Evapotranspiration exhibits a fairly uniform pattern across the central and eastern gulf. Texas and southern Florida are characterized by high evapotranspiration. The surplus shows an overall pattern in which there is a rainfall deficit (evaporation exceeds precipitation) in the western part of the gulf (and southern Florida) and a rainfall surplus (precipitation exceeds evaporation) in the central portion of the gulf. The overall result is that some of the estuaries in the northern gulf have the highest freshwater input per unit of estuarine volume (Ward, 1980). Orlando and others (1993) concluded that high Mississippi River 
flows reduced the salinities in the lower portion of the estuaries in the central gulf because of advection of Mississippi River water into the estuaries. During times of high river flow, the local precipitation is unimportant. Conversely, at times of low Mississippi River flow, the salinities in the lower bays increase, and local precipitation becomes more important. The MississippiAtchafalaya River flow serves as a primary or secondary source of fresh water to a large proportion of the Louisiana estuaries.

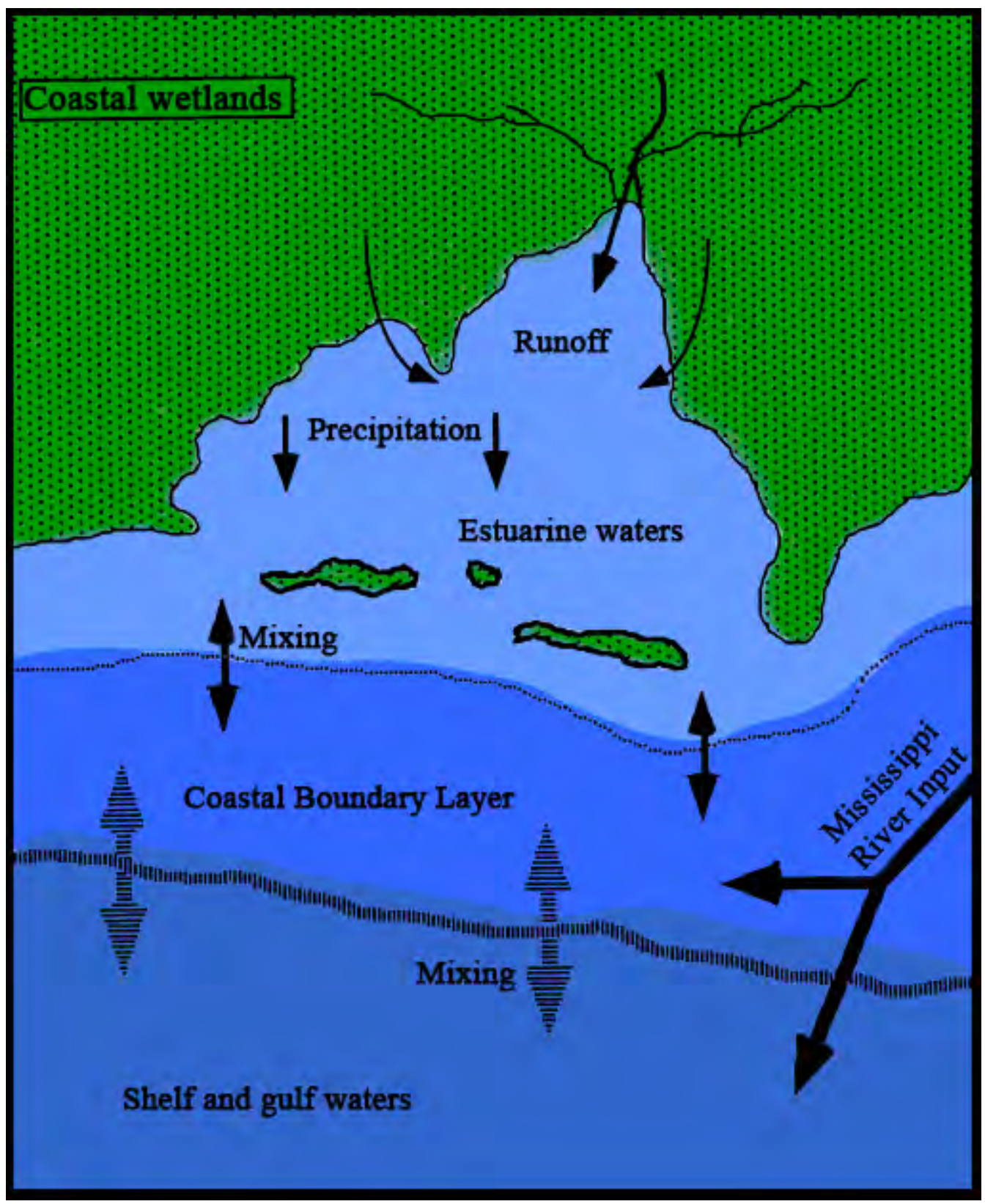

Figure 4. Schematic of an estuarine system illustrating the major pathways of freshwater and coastal ocean water inputs to the system. 
The salinity of the estuaries around the Gulf of Mexico shows a fairly large range of values as a result of the freshwater input distribution. In general, the central gulf estuaries exhibit lower salinities because of the effect of the Mississippi River discharge. The south Texas estuaries and the south Florida estuaries exhibit the highest salinities as a result of the general pattern of rainfall deficits in these locations. The data from Orlando and others (1993) were analyzed by Swenson (2003) to detect the salinity changes that occur in the Gulf of Mexico estuaries with changes in freshwater input for high and low freshwater input years. The data show a general trend of salinity decreases of 2-5 parts per thousand (ppt) for high freshwater input years and increases of 5-7 ppt for low freshwater input years. There were a few exceptions to the overall pattern, which were to be expected, since the data were limited in spatial and temporal extent.

The inverse relationship between Mississippi River discharge and Louisiana coastal salinities was first pointed out by Geyer (1950). Barrett (1971) and Gagliano and others (1973) further described this inverse relationship by using linear statistical models. Wiseman and others (1990a) used autoregressive moving average (ARMA) models to analyze the relationship between weekly discharge of the Mississippi River and Louisiana coastal salinities. The river discharge portion of the models accounted for 30-50 percent of the variance of the observed salinity data along the coast. The results were consistent with a conceptual model in which Mississippi River discharge alters coastal salinities, which in turn propagate up-estuary and westward along the coast (Wiseman and others, 1990b). Swenson and Turner (1998) developed empirical statistical models to explain the seasonal isohalines in the Barataria estuary system by using coastal water levels, Mississippi River discharge, and local (New Orleans) precipitation from 1980 through 1995. The models were able to explain approximately 50 percent of the variance of the observed data (table 1) and reproduced the observed monthly salinity pattern over the 1999-2000 drought period quite well (fig. 5).

Swenson and others (2004) investigated the role of climate drivers on salinity in the Louisiana coastal zone. They concluded that the extremely high salinities observed during the 1999-2000 drought period were the result of prolonged drought coupled with low Mississippi River discharge and low coastal water levels. The combination of these events resulted in a time period characterized by the highest salinities on record. The duration of the high salinities observed during the 1999-2000 time period for the Barataria basin was characterized by salinities greater than $30 \mathrm{ppt}$ at Grand Terre for 12 months, salinities greater than $20 \mathrm{ppt}$ at St. Marys Point for 10 months, and salinities greater than $7.5 \mathrm{ppt}$ at Little Lake for 8 months. This is a fourfold increase in the high salinity levels observed in this system. Systems throughout the Louisiana coastal zone were characterized by much higher than normal salinities during this time period, dramatically illustrating the important role of freshwater input (rainfall as well as river flow) in determining Louisiana coastal salinities. 
Table 1. Summary of regression results to predict salinity in the Barataria system using Mississippi River discharge, precipitation at Louisiana climate region 9, and detrended coastal water levels.

[LDWF, Louisiana Department of Wildlife and Fisheries]

\section{LDWF S315: Grand Terre}

Overall model, R-square $=0.72$

Linear portion, $\mathrm{R}$-square $=0.48$

Variable
Intercept

Mississippi discharge

Region 9 precipitation

Grand Isle water level

1 month previous salinity

\section{Estimate}

19.99

$-0.00029$

$-0.2761$

$-0.0329$

$+0.5466$
F-value

544.38

99.56

83.50

354.00
Probability $>$ F

0.0001

0.0001

0.0001

0.0001

\section{LDWF S317: St. Marys Point}

Overall model, R-square $=0.74$

Linear portion, $\mathrm{R}$-square $=0.41$

\section{Variable \\ Intercept}

Mississippi discharge

Region 9 precipitation

Grand Isle water level

1 month previous salinity
Estimate

9.66

$-0.00024$

$-0.3806$

$-0.0065$

$+0.6297$
F-value

277.17

88.96

22.74

330.94
Probability $>$ F

0.0001

0.0001

0.0001

0.0001

\section{LDWF S326: Little Lake}

Overall model, R-square $=0.63$

Linear portion, $\mathrm{R}$-square $=0.16$

\section{Variable \\ Intercept}

Mississippi discharge

Region 9 precipitation

Previous month salinity

2 months previous salinity

3 months previous salinity
Estimate

2.916

$-0.00007$

$-0.1522$

$+0.8728$

$-0.4220$

$+0.2511$
F-value

47.25

11.55

145.63

7.37

6.96
Probability $>$ F

0.0001

0.0009

0.0001

0.0075

0.0094 

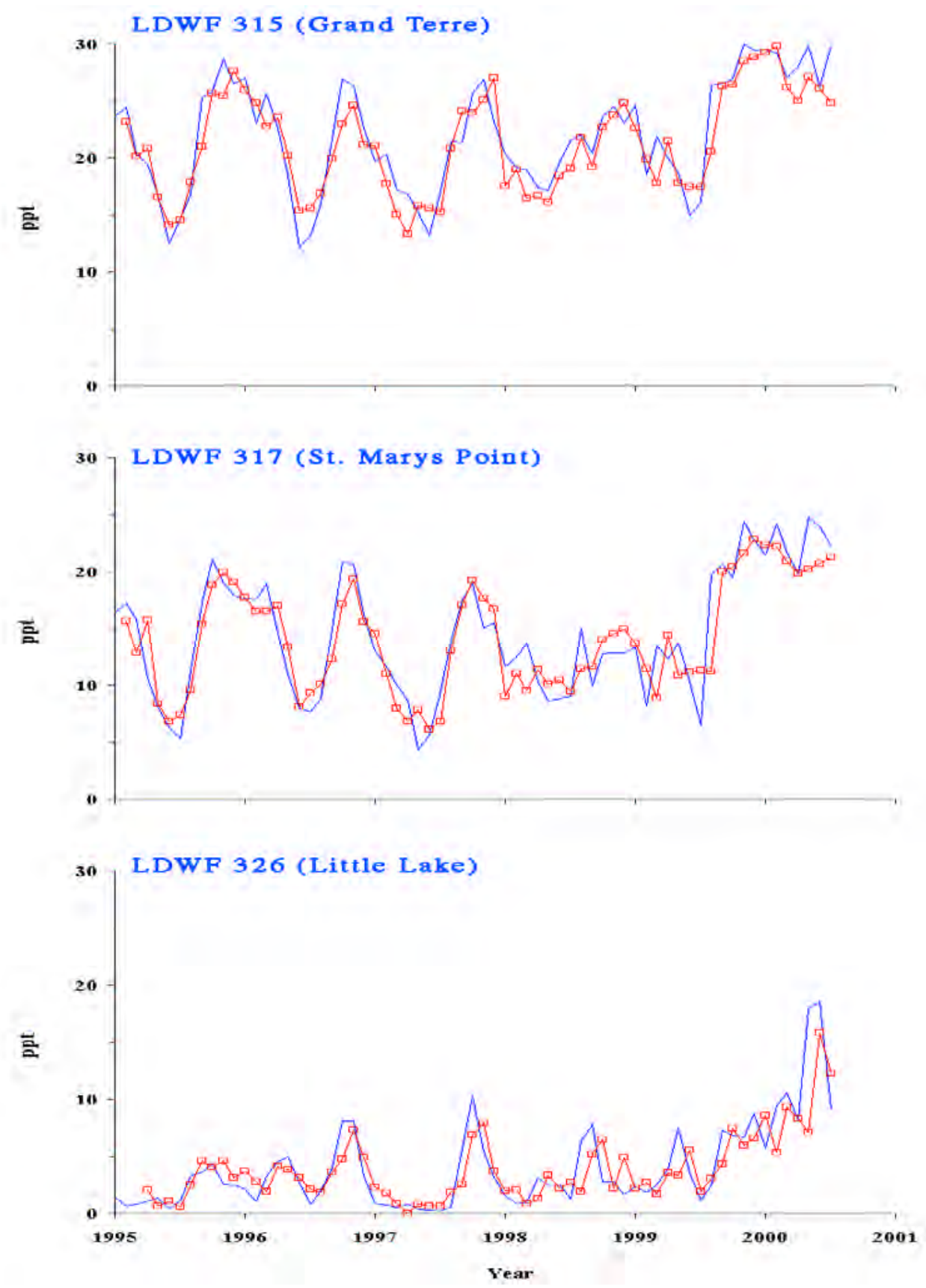

Figure 5. Plots of measured monthly mean salinity (solid blue line) and predicted monthly salinity (red line with open circles) for Louisiana Department of Wildlife and Fisheries (LDWF) station 315, LDWF station 317, and LDWF station 326 in the Barataria system. The following models were used: station 315: salinity $=19.99-0.00029 \mathrm{Q}-$ $2761 \mathrm{P}-0.0329 \mathrm{WL}-0.5466 \mathrm{~S}_{-1}$; station 317 : salinity $=9.66-0.00024 \mathrm{Q}-0.3806 \mathrm{P}-$ $0.00655 \mathrm{WL}+0.6297 \mathrm{~S}_{-1}$; and station 326 : salinity $=2.92-0.00007 \mathrm{Q}-0.1522 \mathrm{P}+$ $0.8728 \mathrm{~S}_{-1}-0.4220 \mathrm{~S}_{-2}+0.2511 \mathrm{~S}_{-3}$, where $\mathrm{Q}=$ total monthly Mississippi River discharge $\left(\mathrm{m}^{3} \mathrm{~s}^{-1}\right), \mathrm{P}=$ total monthly precipitation $(\mathrm{cm}), \mathrm{WL}=$ detrended water level at Grand Isle $(\mathrm{cm}), \mathrm{S}_{-1}=$ salinity (ppt) of previous month, $\mathrm{S}_{-2}=$ salinity $(\mathrm{ppt}) 2$ months previous, and $\mathrm{S}_{-3}=$ salinity (ppt) 3 months previous. 


\section{Coastwide Patterns}

Salinity intrusion into historically fresher wetland areas has been identified as a likely cause of large-scale coastal wetland change, deterioration, and subsequent conversion to open water. In order to determine whether salinities were increasing throughout the coast, several studies of salinity trends in Louisiana coastal marshes and estuaries have focused on broad-scale coastwide patterns and trends. Gagliano and others (1970) provided a comprehensive summary of salinity statistics of available data for coastal Louisiana from 1946 to 1968 but did not offer a comprehensive analysis of the data. Wiseman and Swenson (1988) and Wiseman and others (1990b) reported on a study with the objective of analyzing existing data throughout coastal Louisiana to determine if there were any long-term trends in estuarine salinity levels. They were specifically interested in determining changes related to natural and human-induced factors.

Hourly and daily salinity data from the U.S. Army Corps of Engineers (USACE) and Louisiana Department of Wildlife and Fisheries (LDWF) over the period 1946-85 were averaged to obtain monthly data to remove tidal aliasing in the daily values. The data were first investigated by using a linear model that used time and an annual harmonic to remove the seasonal effects.

Many of the test results had to be discarded since much of the data lacked normality. Wiseman and Swenson (1988) reanalyzed the seasonal data by using the Kendall-Tau, a nonparametric test used by Hirsch and others (1982) to assess water quality parameters. The Kendall-Tau approach (which does not require fulfilling normality or linearity assumptions) tests for the presence or absence of a trend. If a significant trend was observed, then the magnitude of the trend was estimated by using the Kendall seasonality slope estimator (Hirsch and others, 1982). Although significant trends were identified within individual estuaries, many of them showed a significant decrease in salinity; however, no consistent pattern of increasing, decreasing, or static salinity trends was noted for the overall coast (table 2). Wiseman and Swenson (1988) suggested that the lack of trend was likely due to the differences in record length and strong cyclical climate, river discharge, and relative sea level variations which may make weak trends hard to detect. Nevertheless, the authors state that "extensive coastal degradation and land loss documented over time periods of the same order of our data records. If this were caused by a trend in the salinity regime, the present analysis should have identified the trend"(Wiseman and Swenson, 1988, p. 121). Similarly, in a coastwide analysis of 17 LDWF stations originally located in brackish or saline marshes, Fuller and others (1990) found no broad-scale pattern on increasing salinity, but to the contrary, several of the individual datasets showed decreasing trends in salinity. Again, Fuller and others (1990) identify short data records (most were less than 5 years in duration) as being a major obstacle in detecting trends. They also suggest that, because the stations were in salt or brackish marshes, the areas may have already been subjected to saltwater intrusion and, additionally, that saltwater intrusion may not be a broad phenomenon but rather a more local occurrence.

\section{Local Patterns and Canal Effects}

Several studies have provided detailed analyses of spatial and temporal salinity patterns on the local level. For instance, Van Sickle and others (1976) reported an increasing salinity trend at the St. Marys Point station in the Barataria basin from 1961 to 1974; however, Fuller and others (1990) did not detect a significant trend at the same site for the time period of 1973-80 because of an increasing salinity trend during 1973-77 and a decreasing trend during 1978-80. Also for the Barataria basin, analyses by Byrne and others (1976) suggested that salinities in the basin prior to the dredging of the Barataria Waterway in 1962 were lower than post dredging activities. Using most of the same stations and longer data records, Wiseman and others (1990a) concluded that there was a negative (decreasing) trend in mean salinity at the mouth of Barataria Bay and that 
there was no trend in the upper reaches of the bay. Significant increases in salinity trends were found, however, at the lower end of Bayou Lafourche and in Lake Pontchartrain in southeast Louisiana (Wiseman and others, 1990a). Increases in salinities in Lake Pontchartrain also were described by Sikora and Kjerfve (1985), who analyzed a 36-year record (from 1946 to 1982).

Table 2. Results of the Kendall-Tau test on monthly mean salinity. The station, years of record, the significance level (alpha), the trend (estimated from the Kendall slope estimator) in parts per thousand per year, and the expected change over the period of record are listed.

[Datasets with short records are in bold since these results are questionable. Three-digit stations are those of the Louisiana Department of Wildlife and Fisheries (LDWF), and five-digit stations are those of the U.S. Army Corps of Engineers (USACE). These results are from Wiseman and Swenson (1988). ppt/yr, parts per thousand per year]

\begin{tabular}{|c|c|c|c|c|}
\hline Station & $\begin{array}{r}\text { Years of } \\
\text { record }\end{array}$ & Alpha & $\begin{array}{r}\text { Trend } \\
\text { (ppt/year) }\end{array}$ & $\begin{array}{r}\text { Change over } \\
\text { period of } \\
\text { record (ppt) }\end{array}$ \\
\hline 719 (Cameron) & 17.4 & 0.006 & -0.449 & -7.8 \\
\hline $\begin{array}{l}70675 \text { (Mermentau River) } \\
76800 \text { (Vermilion Lock W on the Gulf }\end{array}$ & 31.6 & 0.000 & -0.010 & -0.3 \\
\hline $\begin{array}{l}\text { Intracoastal Waterway) } \\
76720 \text { (Vermilion Lock E on the Gulf }\end{array}$ & 19.6 & 0.000 & -0.024 & -0.5 \\
\hline Intracoastal Waterway) & 29.1 & 0.025 & 0.039 & 1.3 \\
\hline 88850 (Cypremort Point) & 24.3 & 0.012 & -0.067 & -1.6 \\
\hline 64380 (Bayou Teche at Charenton) & 24.4 & 0.000 & -0.009 & -0.2 \\
\hline 03720 (Wax Lake Outlet) & 10.0 & 0.012 & 0.000 & 0.0 \\
\hline 64450 (Charenton Drainage Canal) & 29.0 & 0.000 & -0.008 & -0.3 \\
\hline 88600 (Eugene Island) & 8.5 & 0.068 & 0.131 & 1.2 \\
\hline $\begin{array}{l}03780 \text { (Morgan City) } \\
76343 \text { (Houma Navigation Canal at }\end{array}$ & 18.0 & 0.000 & 0.000 & 0.0 \\
\hline $\begin{array}{l}\text { Crozier) } \\
76320 \text { (Gulf Intracoastal Waterway at }\end{array}$ & 20.3 & 0.000 & -0.012 & -0.2 \\
\hline Houma) & 30.8 & 0.000 & 0.002 & 0.1 \\
\hline 76403 (Bayou Terrebonne at Bourg) & 19.1 & 0.003 & -0.009 & -0.2 \\
\hline 82203 (Larose) & 22.9 & 0.093 & -0.003 & -0.1 \\
\hline 82350 (Leeville) & 21.8 & 0.000 & 0.156 & 3.4 \\
\hline $\begin{array}{l}315 \text { (Grand Terre) } \\
85683 \text { (North Shore of Lake }\end{array}$ & 26.3 & 0.000 & -0.242 & -6.4 \\
\hline Pontchartain) & 3.8 & 0.002 & 1.992 & 7.8 \\
\hline 85650 (Little Woods) & 31.9 & 0.000 & 0.086 & 2.8 \\
\hline 221 (Bay Gardene) & 12.3 & 0.010 & -0.344 & -4.2 \\
\hline 85700 (The Rigolets pass) & 24.0 & 0.061 & 0.039 & 0.9 \\
\hline 253 (Sable Island) & 4.8 & 0.095 & 0.870 & 4.2 \\
\hline
\end{tabular}

Most of the studies described above were designed to describe and evaluate salinity patterns throughout the coast; however, only a few studies have investigated trends in historical salinity records as they relate to waterways or navigation canals and the effects they may have on salinity intrusion, wetland change, and wetland loss. It has been estimated that navigation canals, via direct and indirect actions, are responsible for 20-50 percent of total wetland loss in coastal 
Louisiana (Johnson and Gosselink, 1982; Boesch and others, 1994). Primary losses that are due to Federal navigation channel construction have been estimated approximately at 23,500 ha to 38,900 ha and secondary loss (bankline erosion, saltwater intrusion) estimated at 110,900 ha since the late 1800s (Good and others, 1995). Wang (1988) developed a two-dimensional, laterally averaged, semi-implicit hydrodynamic model coupled with a salt flux model to investigate the salinity distribution for various channel dimensions. The study was of limited scope in that it only investigated two constructed channels (the Calcasieu Ship Channel [CSC] and the Houma Navigation Canal) and one natural channel (Bayou Petite Caillou) and was based only on data collected during one season of the year (late fall to early spring) under low to moderate freshwater inflow conditions. Despite these limitations, Wang (1988) concluded that, under similar external forcings, salt water moves further inland in larger, deeper channels than in smaller, shallower channels and also that channel deepening changes the salinity distribution pattern and the degree of saltwater intrusion. For instance, model results show that, by doubling the Houma Navigation Canal's depth to $13.2 \mathrm{~m}$, the $5 \mathrm{ppt}$ isohaline moves from $45 \mathrm{~km}$ to $80 \mathrm{~km}$ inland (fig. 6), whereas with a doubling of the depth in Bayou Petite Caillou, a smaller natural channel, to $6 \mathrm{~m}$, the $5 \mathrm{ppt}$ isohaline moves only from $20 \mathrm{~km}$ to $23 \mathrm{~km}$ inland (fig. 7; Wang, 1988). 
Houma Navigation Canal salinity distribution: existing depth

$\square 0.0-4.0 \quad \square 4.0-8.0 \quad \square 8.0-12.0 \quad \square 12.0-16.0 \quad \square 16.0-20.0$

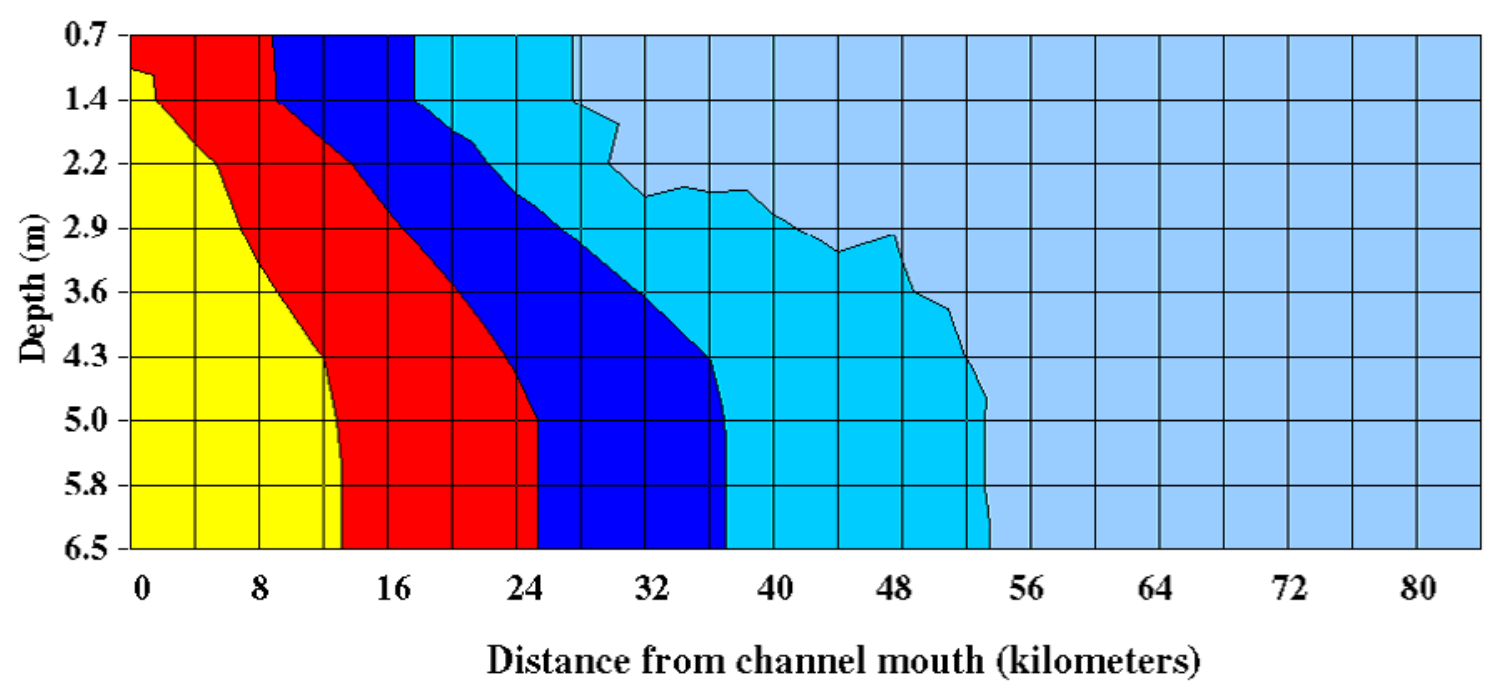

Houma Navigation Canal salinity distribution: twice existing depth $\square$ 0.0-4.0 $\square$ 4.0-8.0 $\square 8.0-12.0 \quad \square 12.0-16.0 \quad \square 16.0-20.0$

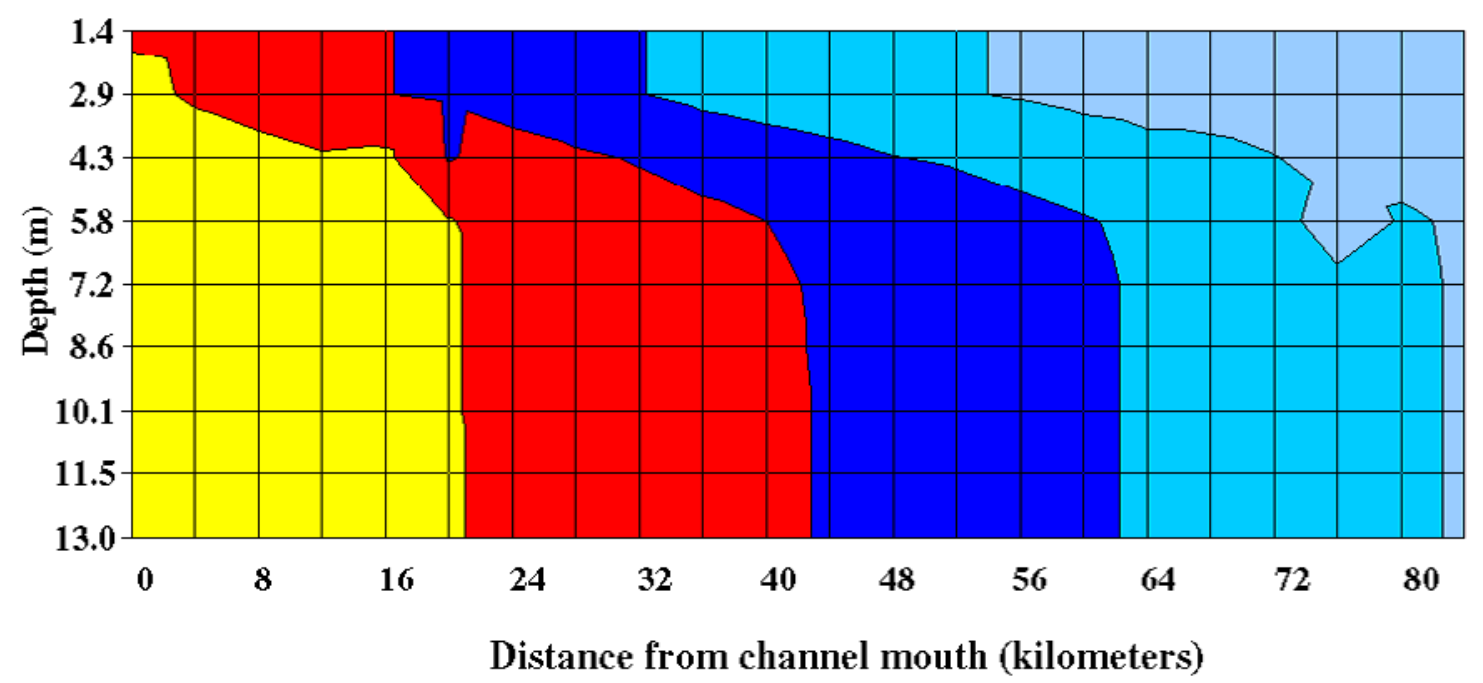

Figure 6. Summary of saltwater intrusion model results (adapted from Wang, 1988) for the Houma Navigation Canal in coastal Louisiana. The top panel shows the salinity distribution under the present conditions, and the bottom panel shows the predicted salinity distribution that would result from a doubling of the channel depth. 


\section{Petite Caillou salinity distribution: existing depth}

$\square$ 0.0-2.0 $\square 2.0-4.0 \quad \square 4.0-6.0 \quad \square 6.0-8.0 \quad \square 8.0-10.0$

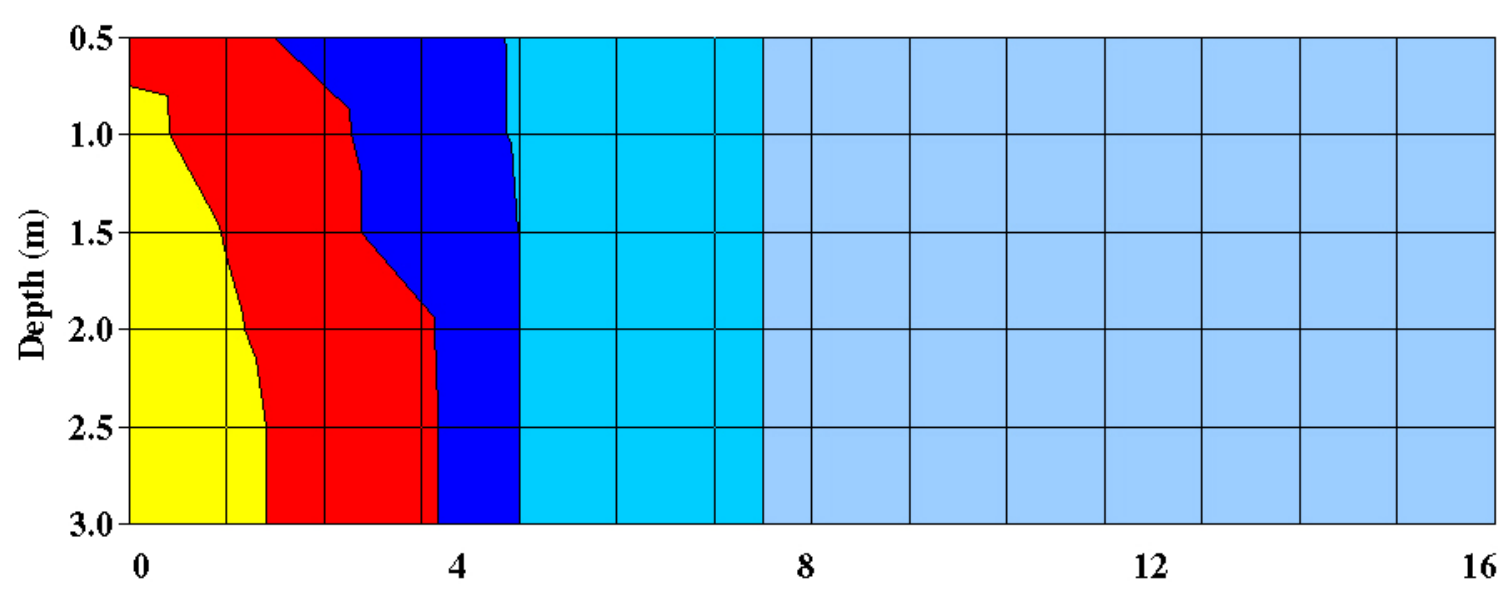

Distance from channel mouth (kilometers)

Petite Caillou salinity distribution: twice existing depth

$\square 0.0-2.0 \quad \square 2.0-4.0 \quad \square 4.0-6.0 \quad \square 6.0-8.0 \quad \square 8.0-10.0$

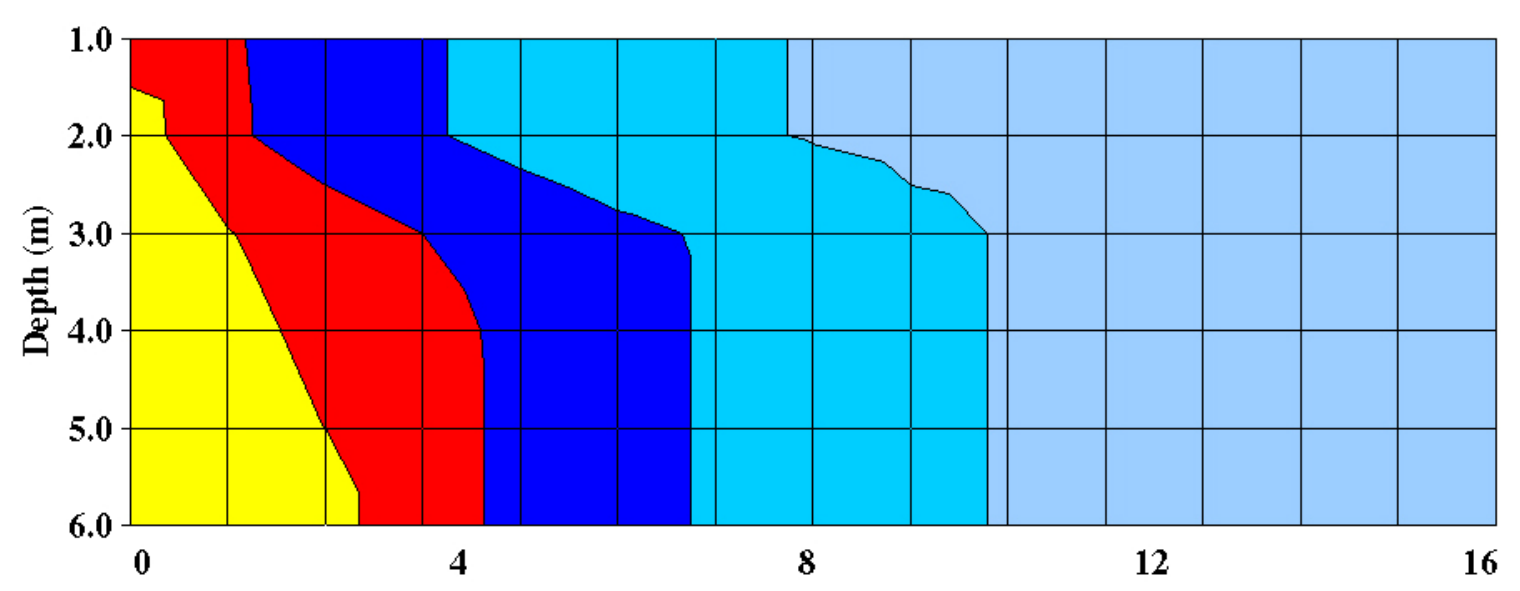

Distance from channel mouth (kilometers)

Figure 7. Summary of saltwater intrusion model results (adapted from Wang, 1988) for Bayou Petite Caillou in coastal Louisiana. The top panel shows the salinity distribution under the present conditions, and the bottom panel shows the predicted salinity distribution that would result from a doubling of the channel depth. 
Saltwater intrusion via the Houma Navigation Canal (HNC) into the fresh and brackish marshes of the Terrebonne basin and the secondary impacts associated with increased salinity are of great concern yet very difficult to quantify. Construction of the HNC contributed to the direct conversion of 744 haof wetland habitat to open water and spoil banks (Good and others, 1995; T. Baker Smith, Inc., 2002; and U.S. Army Corps of Engineers, 2003). Since construction, significant erosion has taken place within the HNC (channel widths exceeding $305 \mathrm{~m}$ in some areas). The erosion, coupled with the direct connectivity of existing natural waterways with the HNC, has provided greater opportunities for saltwater intrusion into the Terrebonne marshes and the Houma Water Treatment Plant (HWTP) (U.S. Army Corps of Engineers, 2003). Figure 8 illustrates the natural pathways through which water flowed prior to the construction of the HNC and all major outlets (blow-outs and connections to other canals) that provided direct saltwater pathways from the Gulf of Mexico via the HNC.

Long-term salinity (chloride) records have been kept at the HWTP since the 1940s with records indicating periods when chlorides exceed $250 \mathrm{mg} / \mathrm{L}$ (approximately $0.4 \mathrm{ppt}$, fig. 9). Data collected after the construction of the Houma Navigation Canal (HNC) show an increase in the number of days in which the $250 \mathrm{mg} / \mathrm{L}$ limit was exceeded, with a higher occurrence during the months of September, October, and November due to the low Atchafalaya River discharge and frontal passage events (T. Baker Smith, Inc., 2002). A study by Swarzenski (2003) of the surface water hydrology of the Gulf Intracoastal Waterway (GIWW) indicated that the GIWW is a source of fresh river water to many coastal Louisiana wetlands. Through prevailing hydraulic gradients, this navigation channel captures and distributes water from the lower Atchafalaya River to areas in coastal Louisiana 48-80 km east and west of Morgan City. The flow in the GIWW increases with increasing stage of the lower Atchafalaya River. Analysis of salinity data indicated that salinity in the HNC at Dulac and at Cypremort Point decreased as the Atchafalaya River stage in Morgan City increased, with monthly averaged values remaining below 3 ppt whenever monthly averaged river stage equaled or exceeded 1.5 meters North American Vertical Datum-1988 (NAVD88) (Swarzenski, 2003). In a salinity intrusion/channel deepening/canal lock study for the HNC related to the proposed Morganza to the gulf project, a model was created to evaluate the effects that deepening the HNC would have on salinities at the HWTP and on the operation of the proposed Houma Navigation Canal Lock near Dulac (U.S. Army Corps of Engineers, 2003). Model results showed that increasing the channel depth to $5.5 \mathrm{~m}(6.1 \mathrm{~m}$ actual depth, $)$ would increase salinities on average by $0.0024 \mathrm{ppt}$, and increasing the depth to $6.1 \mathrm{~m}$ ( $7 \mathrm{~m}$ actual depth) would increase salinities by $0.0054 \mathrm{ppt}$, both figures fairly insignificant considering the variability of salinities in the channel (U.S. Army Corps of Engineers, 2003). The depth increases would yield a mean HWTP closure rate of 47 and 48 days per year, respectively, a slight increase from a mean closure of 46 days from 1981 to 2002 (U.S. Army Corps of Engineers, 2003). 


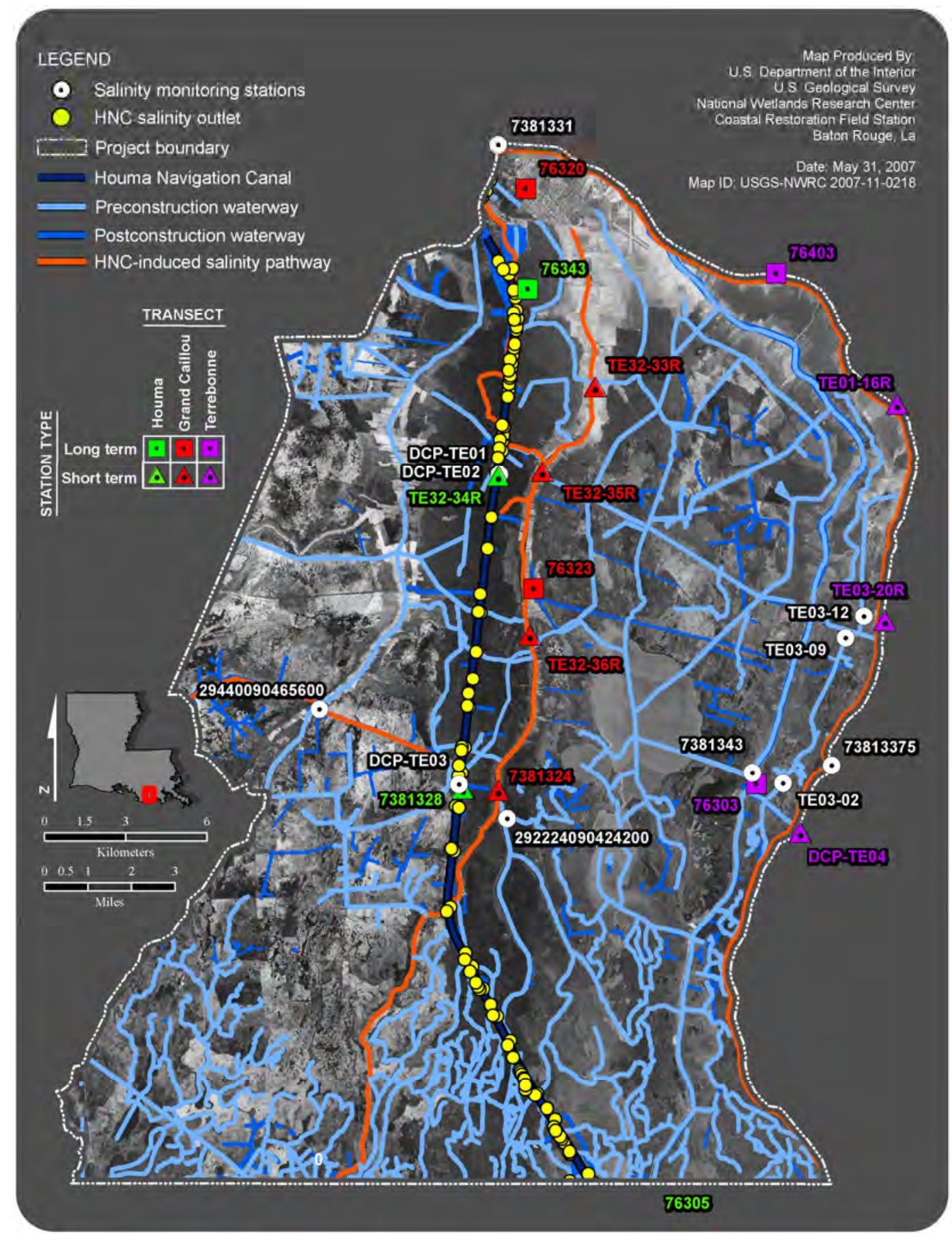

Figure 8. Map of salinity outlets, pathways along the Houma Navigation Canal (HNC), and various salinity stations within the project area in coastal Louisiana. The light blue lines represent preconstruction natural and constructed waterways, the medium blue lines represent post-construction canals, and the yellow circles represent salinity outlets along the HNC. 


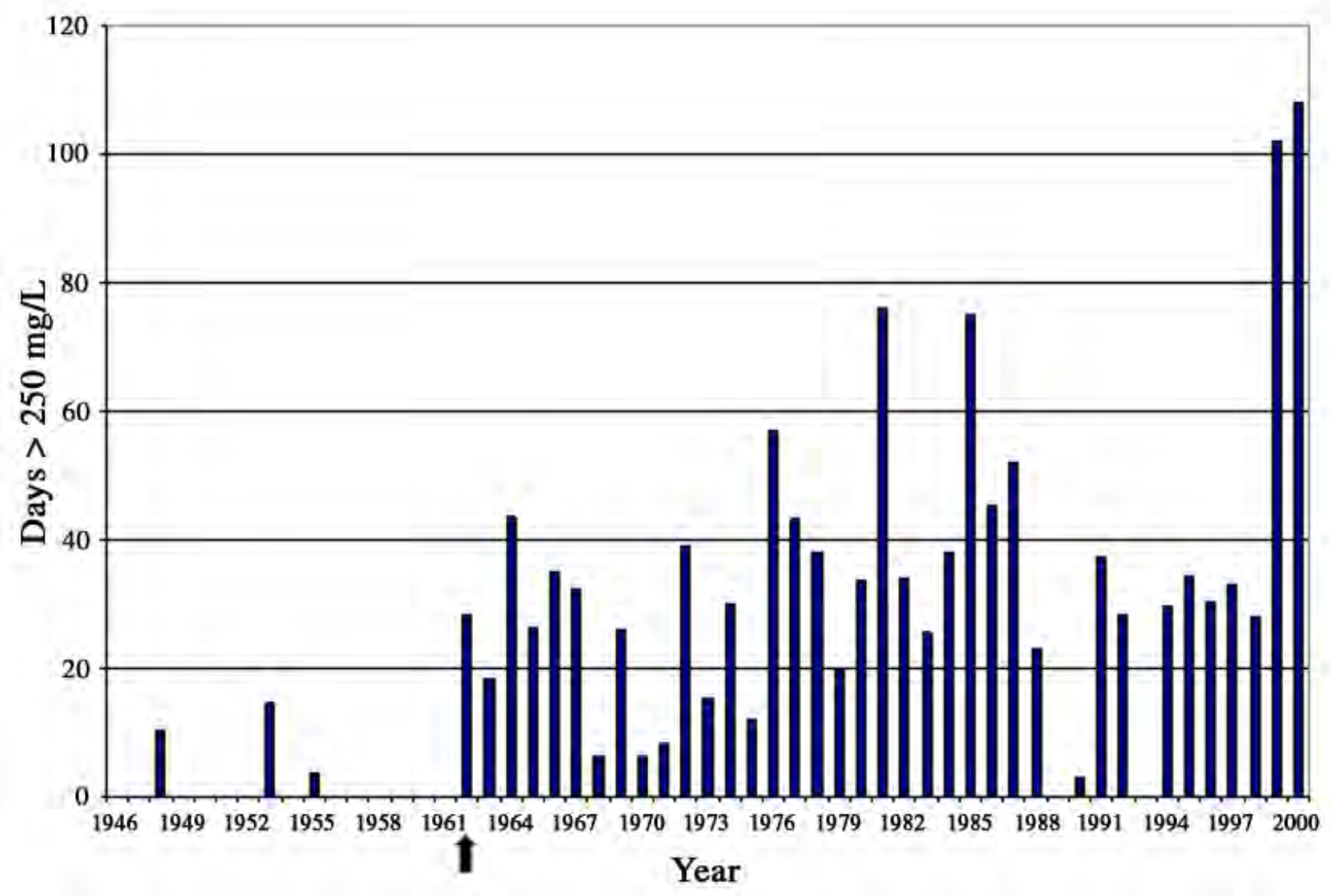

Figure 9. Days per year that chlorides measured greater than $250 \mathrm{mg} / \mathrm{L}$ at the Houma Water Treatment Plant on the Intracoastal Canal near its confluence with the Houma Navigation Canal in coastal Louisiana (T. Baker Smith, Inc., 2002). The completion date for the Houma Navigation Canal is indicated by the arrow below the x-axis.

Salinities in Lake Pontchartrain, a brackish-water estuary in southeast Louisiana, have increased in the past decades with the primary cause often cited as the construction of the Mississippi River-Gulf Outlet (MRGO), a 120-km-long deep-water channel connecting the lake to the Gulf of Mexico. In a preconstruction study, Rounsefell (1964) predicted a salinity increase in the lake of 4-5 ppt depending on the amount of freshwater flow entering the lake. Sikora and Kjerfve (1985), however, conducted a study using a three-decade salinity record in the lake to describe the salinity pattern, determine the effects of the MRGO, and determine which forcing functions controlled salinity in the lake. They found no significant trend in salinity mainly as a result of large variability in the salinity range (0-15 ppt). In the analysis, an 11-year periodicity also was found "probably caused by synoptic meteorologic/hydrologic forcing functions" (Sikora and Kjerve, 1985, p. 175) but the authors noted that the 36-year record was insufficient to make broad statements regarding these cycles with confidence. Salinities did increase in the lake after completion of the MRGO by $0.2 \mathrm{ppt}$ at Pass Manchac in the west to $2.0 \mathrm{ppt}$ at The Rigolets in the east. These increases were less than predicted, but no changes in the variation of the salinity pattern were found (Sikora and Kjerfve, 1985).

In the Chenier Plain of coastal Louisiana, there have been many alterations to the natural hydrology since the late 1800s, leading to significant losses of wetland habitat through saltwater intrusion (Louisiana Department of Natural Resources, 2002). For example, the Calcasieu Ship 
Channel (CSC), which runs from the Gulf Intracoastal Waterway (GIWW) south through Calcasieu Lake and into the Gulf of Mexico near Cameron, has been maintained for navigation since 1874. Original dimensions were $1.5 \mathrm{~m}$ deep and $24.4 \mathrm{~m}$ wide, with several enlargement events occurring in 1903, 1937, and 1968 bringing the current dimensions to $12.2 \mathrm{~m}$ deep and $122 \mathrm{~m}$ wide at the bottom (Wang, 1988; Louisiana Department of Natural Resources, 2002). Historically there was a shoal at the mouth of the Calcasieu River which retarded saltwater intrusion into the system, but after the initial dredging in 1870 and subsequent widening and deepening of the CSC there has been a shift to more saline habitats in the basin (Louisiana Department of Natural Resources, 2002). Several other channels are maintained in the Chenier Plain, including the Sabine River, Mermentau River, and Freshwater Bayou Canal.

\section{Salinity Effects on Vegetation}

Salinity is a major stressor on wetland plants that strongly influences vegetation establishment and spatial distribution. Salinity effect on wetland vegetation is a constant issue in coastal Louisiana because processes and activities including subsidence, storm events, river channelization, and canal construction can facilitate redistribution of salt water within the estuaries, changing salinity levels in established marshes. The widely different ranges of tolerance to salinity by wetland plant species are evident in the Louisiana coastal landscape by the presence of broad bands of vegetation community types more or less parallel to the coast, which is a response to the decreasing salinity gradient from the coast inland. Spartina alterniflora dominates most saline marshes in Louisiana and is found in areas with an average salinity of about $15 \mathrm{ppt}$ (Chabreck, 1972). The less saline brackish marsh is dominated by S. patens, occurring at an average salinity of $8.5 \mathrm{ppt}$ (Chabreck, 1972) but with growth inhibited at salt concentrations greater than about $5 \mathrm{ppt}$ (Pezeshki and Delaune, 1993). In freshwater marshes dominated by Panicum hemitomon or Sagittaria latifolia, salinity increases cause a species shift to more salt-tolerant plants such as Eleocharis spp., Scirpus sp., and S. patens or cause a dramatic loss to open water. Experiments under both controlled settings and field conditions confirmed that $P$. hemitomon has little tolerance of salt and grows only in a nearly salt-free environment (McKee and Mendelssohn, 1989; Flynn and others, 1995; Howard and Mendelssohn, 1999a, b); however, different genotypes of this species have shown different salinity resistance thresholds (Hester and others, 1998). In recently developing marshes in the Atchafalaya River Delta, freshwater vegetation species that have low salinity tolerance colonized new land. A study by Holm and others (2001) pointed out the potential importance of salinity in the temporal and spatial distribution of plants on delta land, concluding that periodic salinity incursions negatively impact the development of $S$. latifolia marshes in the Atchafalaya River Delta. Incursions of higher salinity water periodically affect newly colonized land and affect the composition and productivity of colonizing plant species.

\section{Historical Salinity Data Collection and Trend Analyses}

\section{Methods}

Historical salinity data in coastal Louisiana have been collected from as many long-term stations as possible in order to analyze long-term coastal salinity trends and salinity levels during pre- and postconstruction periods, as well as between dredging events, for navigation canals. Datasets were collected from several sources including the USACE, Louisiana Department of 
Natural Resources (LDNR), the U.S. Environmental Protection Agency STORET database, the brown marsh database, and personal data files. At present, during the course of this study, over 125 historical data files containing salinity information for the coast were gathered and cataloged; however, not all files contained useable data. The data obtained were in various formats and were, therefore, converted to a standard file format. Data were converted to and reported as salinity in parts per thousand, and common start and end dates were added for all datasets. The length of salinity record (in years) and daily minimum, mean, and maximum salinity values were calculated for all datasets, in addition to long-term trend analyses performed via linear regression. Salinity baseline readings for each station were identified via habitat classification overlays, and the frequency and duration of salinity spikes were calculated for all datasets.

Data were processed and inventoried from a total of 125 stations. Many of these stations contained only limited salinity data (a few observations over a period of several years) and were not used for the final analysis. The final dataset was composed of 44 stations, which covered the time period from 1948 through 2003. A list of the stations is presented in table 3, and the station distribution is shown in figures 10 and 11.

The data files were obtained in digital form either directly through the Internet or in the form of a data compact disk. These files were transferred to a desktop computer for analysis by using Statistical Analysis System software (SAS, 1990a, b, c) or Microsoft EXCEL ${ }^{\circledR}$ (Microsoft Corp., 1994). Because all of the data were in time series format (hourly, daily, weekly, or monthly), the same basic techniques were used for all sites. The levels of quality assurance/quality control (QA/QC) were variable and inconsistent among the various datasets. Therefore, the datasets were inventoried and checked for data quality and consistency when needed. Several of the datasets obtained from the brown marsh study conducted by Swenson and others (2004) had already been through QA/QC procedures and were ready for use upon receipt. 
Table 3. List of stations used in the final analysis.

[LDWF, Louisiana Department of Wildlife and Fisheries; USACE, U.S. Army Corps of Engineers]

Table 3

\begin{tabular}{|c|c|c|c|c|c|c|}
\hline Agency & Station description & $\begin{array}{l}\text { Latitude } \\
\text { (degree) }\end{array}$ & $\begin{array}{l}\text { Longitute } \\
\text { (degree) }\end{array}$ & $\begin{array}{l}\text { Start } \\
\text { year }\end{array}$ & $\begin{array}{l}\text { End } \\
\text { year }\end{array}$ & $\begin{array}{l}\text { Total } \\
\text { year }\end{array}$ \\
\hline LDWF & 315 Marine lab at Grand Terre & 29.2744 & -89.9422 & 1973 & 2005 & 32 \\
\hline LDWF & 317 St. Marys Point & 29.4231 & -89.9506 & 1961 & 2005 & 44 \\
\hline LDWF & 326 Little Lake & 29.5156 & -90.1842 & 1981 & 2005 & 24 \\
\hline LDWF & 518 Sister Lake & 29.2531 & -90.9217 & 1967 & 2005 & 38 \\
\hline LDWF & 619 Cypremort Point & 29.7136 & -91.8781 & 1974 & 2005 & 31 \\
\hline LDWF & 719 Cameron & 29.8272 & -93.3336 & 1967 & 1994 & 27 \\
\hline USACE & 1386 Mississippi River at Braithewaite & 29.2744 & -89.9422 & 1961 & 2000 & 39 \\
\hline USACE & 1420 Mississippi River at Port Sulphur & 29.4667 & -89.6833 & 1933 & 1982 & 49 \\
\hline USACE & 1480 Mississippi River at Venice & 29.2667 & -89.3500 & 1975 & 1978 & 3 \\
\hline USACE & 1575 Southwest Pass at mile 9.2 & 29.2667 & -89.3500 & 1988 & 1995 & 7 \\
\hline USACE & 1670 Southwest Pass at east jetty & 28.9000 & -89.4167 & 1971 & 1989 & 18 \\
\hline USACE & 67890 Vermilion River at Intracoastal City & 29.7833 & -92.1333 & 1971 & 1982 & 11 \\
\hline USACE & 70600 Mermentau River at Lacassine Refuge & 30.0000 & -92.7667 & 1947 & 1981 & 34 \\
\hline USACE & 70675 Mermentau River at Catfish Point Structure (North) & 29.8500 & -92.8500 & 1949 & 1982 & 33 \\
\hline USACE & 70750 Mermentau River at Catfish Point Structure (South) & 29.8500 & -92.8500 & 1951 & 1981 & 30 \\
\hline USACE & 73472 Calcasieu River saltwater barrier channel (East) & 30.2500 & -93.2167 & 1968 & 1982 & 14 \\
\hline USACE & 76060 Inner Harbor Canal near Seabrook Bridge, New Orleans & 30.0167 & -90.0167 & 1957 & 1994 & 37 \\
\hline USACE & 76303 Bayou Petit Caillou near Boudreaux Canal & 29.3833 & -90.6167 & 1948 & 1981 & 33 \\
\hline USACE & 76305 Bayou Petit Caillou at Cocodrie & 29.2333 & -90.6500 & 1970 & 1982 & 12 \\
\hline USACE & 76320 Gulf Intracoastal Waterway at Houma & 29.5833 & -90.7000 & 1946 & 1981 & 35 \\
\hline USACE & 76323 Bayou Grand Ca & 29.4500 & -90.7000 & 1948 & 2001 & 53 \\
\hline USACE & 76343 Houma Navigation Canal near Croz & 29.5500 & -90.7000 & 1961 & 1993 & 32 \\
\hline USACE & 76403 Bayou Terrebonne near Bourg & 29.5536 & -90.6052 & 1962 & 1981 & 19 \\
\hline USACE & 76480 Wax Lake East Drainage Area at Control Structure & 29.6391 & -91.3185 & 1991 & 1993 & 2 \\
\hline USACE & 76592 Freshwater Canal at Freshwater Bayou Lock (North) & 29.5500 & -92.3000 & 1975 & 1981 & 6 \\
\hline USACE & 76600 Schooner Bayou (Inland Waterway) at Control Structure (East) & 29.7500 & -92.2500 & 1947 & 1981 & 34 \\
\hline USACE & 76680 Schooner Bayou (Inland Waterway) at Control Structure (West) & 29.7500 & -92.2500 & 1947 & 1982 & 35 \\
\hline USACE & 76720 Gulf Intracoastal Waterway at Vermilion Lock (East) & 29.7833 & -92.1833 & 1949 & 1981 & 32 \\
\hline USACE & 76800 Intracoastal Waterway at Leland Bowman Lock (West) & 29.7833 & -92.1833 & 1947 & 1981 & 34 \\
\hline USACE & 76873 Intracoastal Waterway at Gibbstown & 29.9333 & -93.0833 & 1951 & 1981 & 30 \\
\hline USACE & 76880 Intracoastal Waterway at Calcasieu Lock (Ea & 30.0833 & -93.2833 & 1951 & 1981 & 30 \\
\hline USACE & 81050 Bayou Blue 1 Mile at Grand Bayou Canal & 29.5167 & -90.4000 & 1987 & 1999 & 12 \\
\hline USACE & 82203 Bayou Lafourche at Larose & 29.5667 & -90.3833 & 1949 & 1981 & 32 \\
\hline USACE & 82250 Bayou Lafourche at Golden Meadow Floodgate (North) & 29.3417 & -90.2456 & 1991 & 1996 & 5 \\
\hline USACE & 82300 Bayou Lafourche at Galliano & 29.3667 & -90.2500 & 1961 & 1985 & 24 \\
\hline USACE & 82750 Bayou Barataria at Barataria & 29.7333 & -90.1167 & 1967 & 2002 & 35 \\
\hline USACE & 82875 Bayou Barataria at Lafitte & 29.6667 & -90.1000 & 1955 & 1988 & 33 \\
\hline USACE & 85600 Lake Pontchartrain at Midlake near New Orleans, La & 30.1833 & -90.1167 & 1971 & 1981 & 10 \\
\hline USACE & 85800 Mississippi River-Gulf Outlet at Shell Beach, La & 29.8500 & -89.6833 & 1961 & 1965 & 4 \\
\hline USACE & 85850 Breton Sound near Gardner Island & 29.6883 & -89.4034 & 1987 & 1993 & 6 \\
\hline USACE & 88410 Grand Isle at Coast Guard station & 29.2476 & -89.9863 & 1992 & 1997 & 6 \\
\hline USACE & 88550 Atchafalaya Bay near Eugene Island & 29.3861 & -91.3978 & 1990 & 1997 & 8 \\
\hline
\end{tabular}




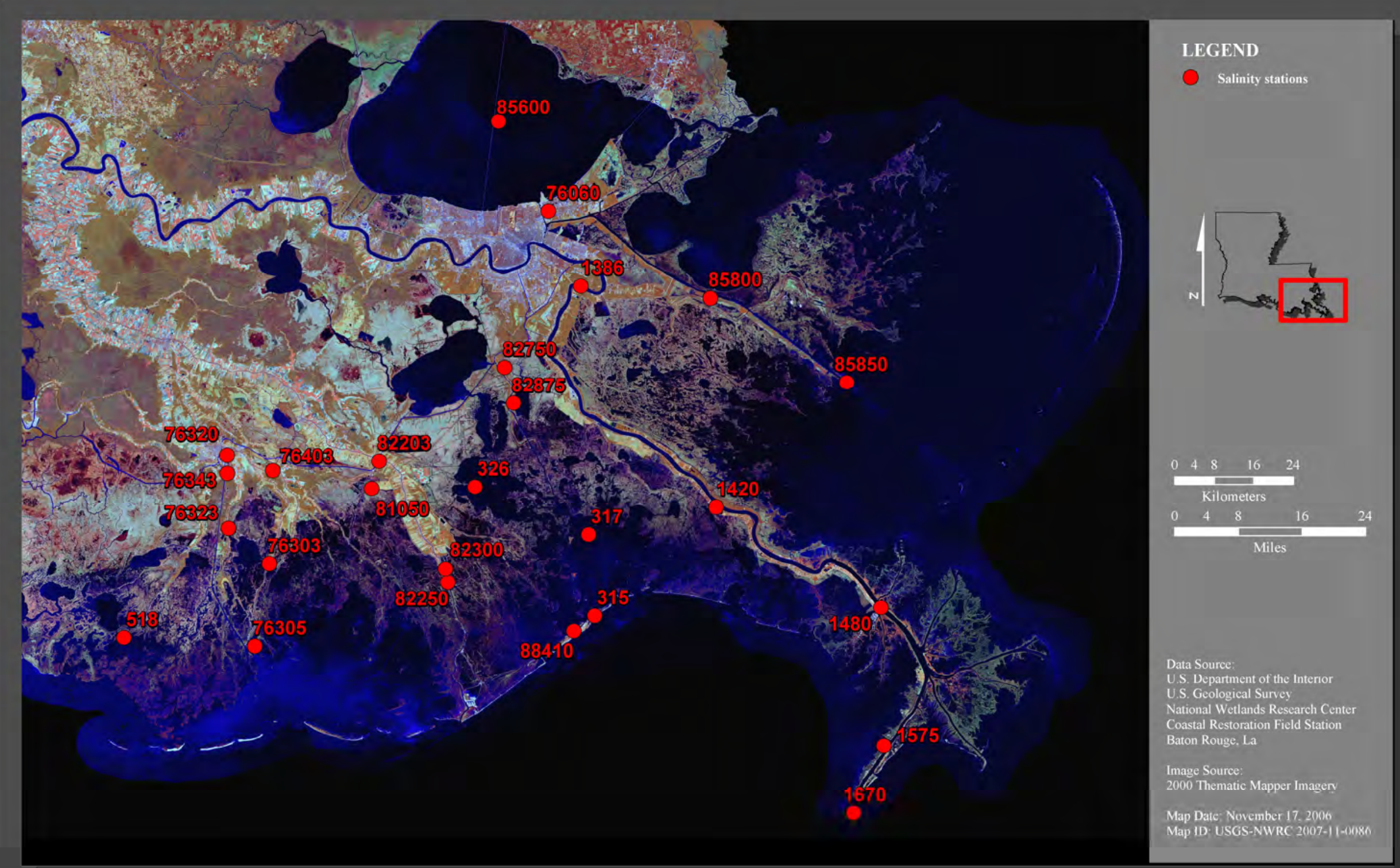

Figure 10. Map of salinity stations in the east Louisiana coastal marshes. Stations with five-digit numbers are those of the U.S. Army Corps of Engineers; stations with three-digit numbers are those of the Louisiana Department of Wildlife and Fisheries. 


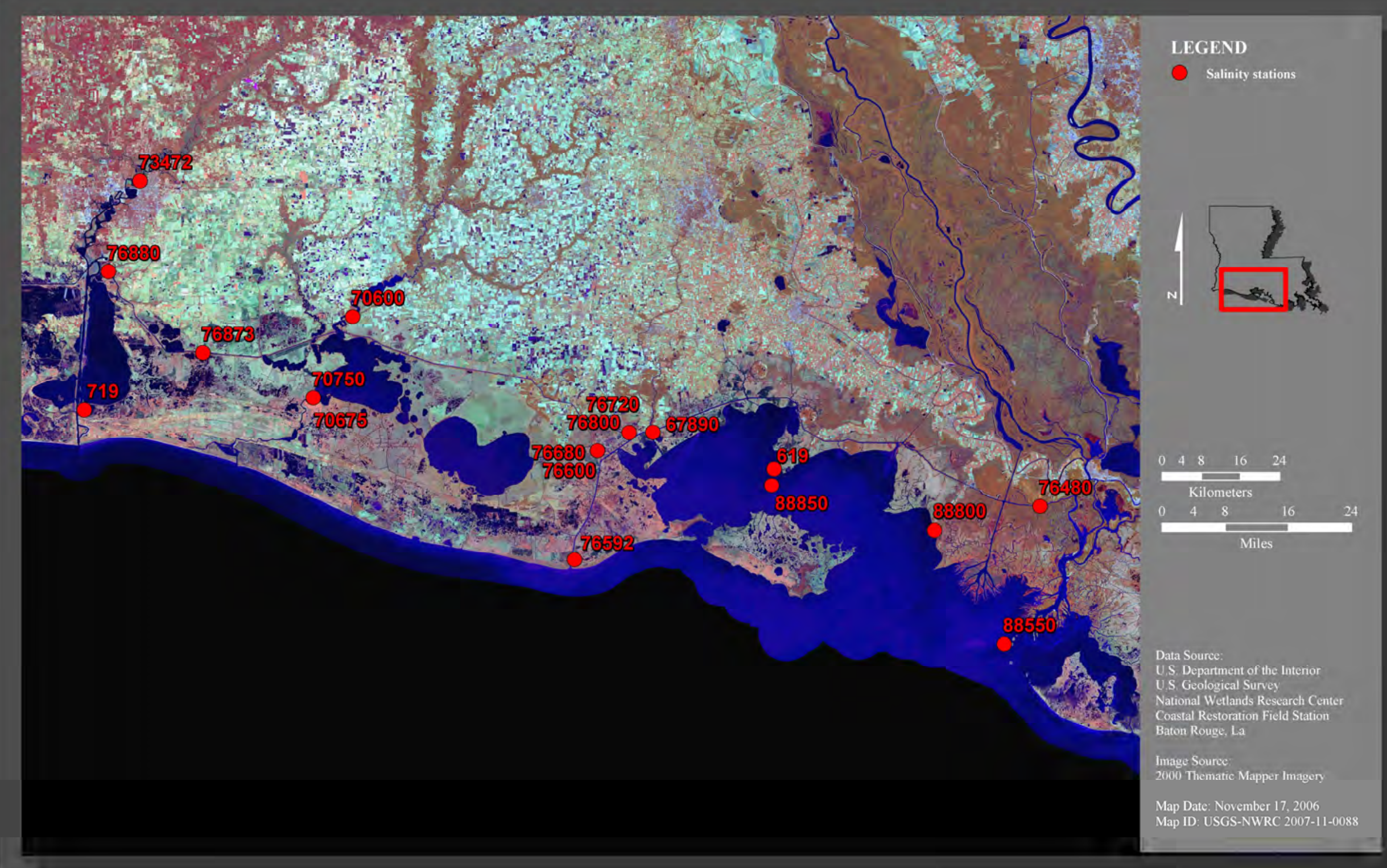

Figure 11. Map of salinity stations in the west Louisiana coastal marshes. Stations with five-digit numbers are those of the U.S. Army Corps of Engineers; stations with three-digit numbers are those of the Louisiana Department of Wildlife and Fisheries. 
The following general procedures were used in the analysis:

\section{a. Data Input}

The data from the USACE were processed in order to strip the headers from text files to create time series data files that could be used in subsequent analysis.

\section{b. Data Inventories}

The data inventory included identifying the total observations in each dataset, sampling frequency, and spatial distribution of stations.

\section{c. Data Conversion}

The following relationship (Grasshoff and others, 1999) was used to calculate salinity from chloride:

$$
\text { Salinity }(\mathrm{ppt})=1.80655 \mathrm{x} \text { chloride }(\mathrm{g} / \mathrm{L}) \text {. }
$$

The relationship between temperature, conductivity, and salinity was used to convert conductivity readings to salinity. Algorithms for the calculation are given in Grasshoff and others (1999). The authors also stated that there are differences in the salinity calculated by using various algorithms on the order of 0.02 ppt. Discrepancies of this small magnitude are considered negligible for the present study since the data were recorded from instruments that have accuracies on the order of $\pm 0.2 \mathrm{ppt}$.

The relationship between salinity expressed in grains per gallon (a unit used by the rice farmers in western Louisiana) and parts per thousand was investigated by using data downloaded from the USACE Lock Operations site. The results (fig. 12) yielded the following equation:

Salinity in ppt $=0.016 \mathrm{x}$ salinity in grains per gallon. 


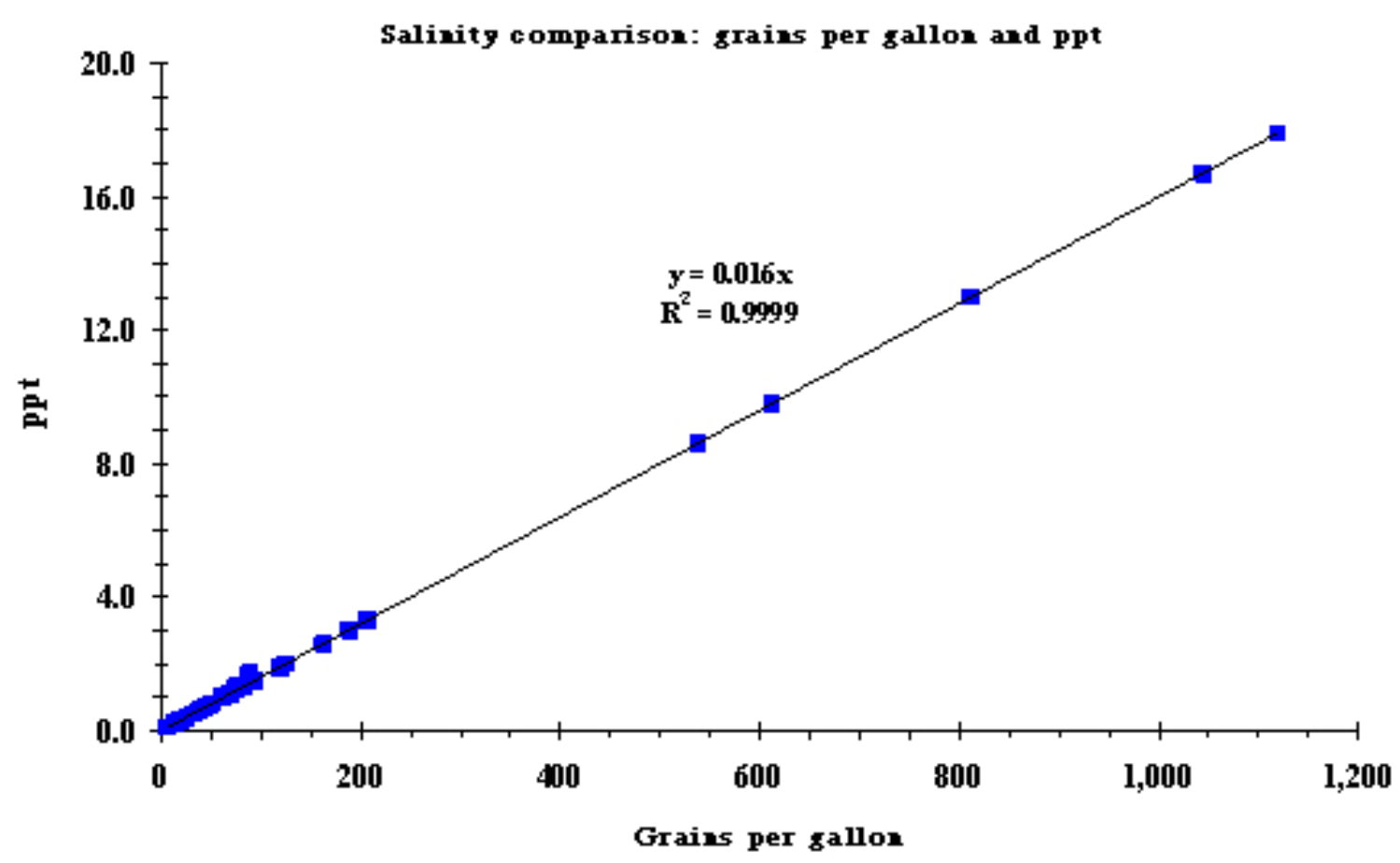

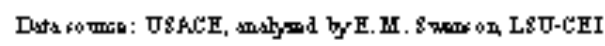

Figure 12. Plot of the relationship between salinity in grains per gallon and salinity in parts per thousand (ppt) in coastal Louisiana. The results of a regression analysis are indicated on the figure.

\section{d. QA/QC Information}

Salinity data values greater than $30 \mathrm{ppt}$ were considered to be suspect. In most cases the high salinity values (usually $>60 \mathrm{ppt}$ ) were coupled with either high $\left(50^{\circ} \mathrm{C}\right)$ or low $\left(-5^{\circ} \mathrm{C}\right)$ temperature readings, indicating an equipment malfunction. These values were set to "missing."

The salinity data from the different agencies were compared whenever possible. Swenson and Turner (1998), for example, presented data to show that the salinity from LDWF and Louisiana Department of Health and Hospitals were comparable. A comparison between USACE and LDWF data is shown in figure 13. The relationship is quite reasonable considering that, although the data were collected at the same general site on the same day, the samples were not simultaneous.

Routine salinity data collected by LDWF as part of their shrimp monitoring program were used to observe salinity stratification in the open water bodies. Figure 14 presents relationships between surface and bottom salinity for the open water in the Pontchartrain-Borgne basin and Barataria basin. These data indicate that there is very little stratification in the open-water areas. Barrett (1971) stated that stratification in the open waters was rare because of the mixing of the water column that was due to shallow depth, tidal actions, winds, and heavy boat traffic.

Stratification does occur, however, in the deeper bayous and dredged channels such as the Inner Harbor Navigation Canal in Lake Pontchartrain (Swenson, 1980), the Houma Navigation Canal (Wang, 1988), and the Calcasieu Ship Channel (Wang, 1988). 


\section{e. Computation of daily means}

Since the data were collected at different sampling frequencies (hourly, daily), they were averaged to put all observations on a common interval. All of the data could be merged on a daily basis since all sampling intervals were equal to or less than a day. There was some concern over the potential incompatibility of using daily means computed from hourly data with daily observations. Swenson and Swarzenski (1995) compared daily means computed from hourly data and daily data. The results (table 4 ) indicate that the daily 8 a.m. readings were equivalent to the daily means computed from hourly data. Byrne and others (1976) reported similar results for a comparison of daily water levels against daily mean water levels (from 3-hour data) in the Barataria system.

\section{f. Salinity Trend Analysis}

Linear regressions were run on all salinity datasets by using computed daily mean salinity values. Slopes were converted to indicate increases or decreases of salinity in parts per thousand per year. The trends were then multiplied by the period of record to obtain the total salinity change at the station.

\section{g. Merging of All Datasets by Date}

Once all of the data computations were completed, all datasets were merged by date.

\section{h. Data Filtering}

In order to identify the large-scale changes (on the order of a season), the daily data were filtered by using a 90-day running mean.

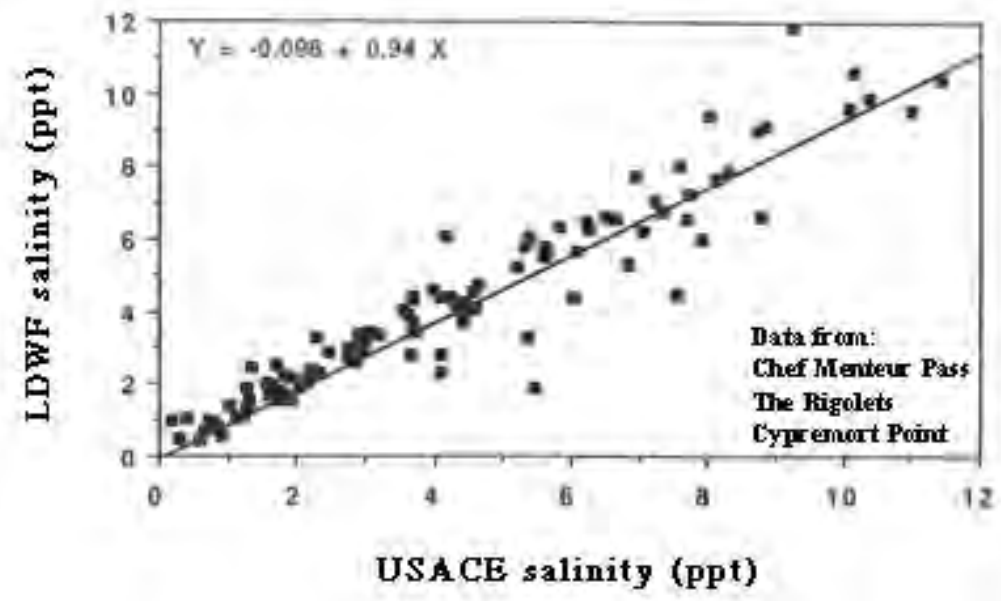

Figure 13. Plot of the relationship between salinity measured by the U.S. Army Corps of Engineers (USACE) and Louisiana Department of Wildlife and Fisheries (LDWF) for three stations in the Louisiana coastal marshes. 


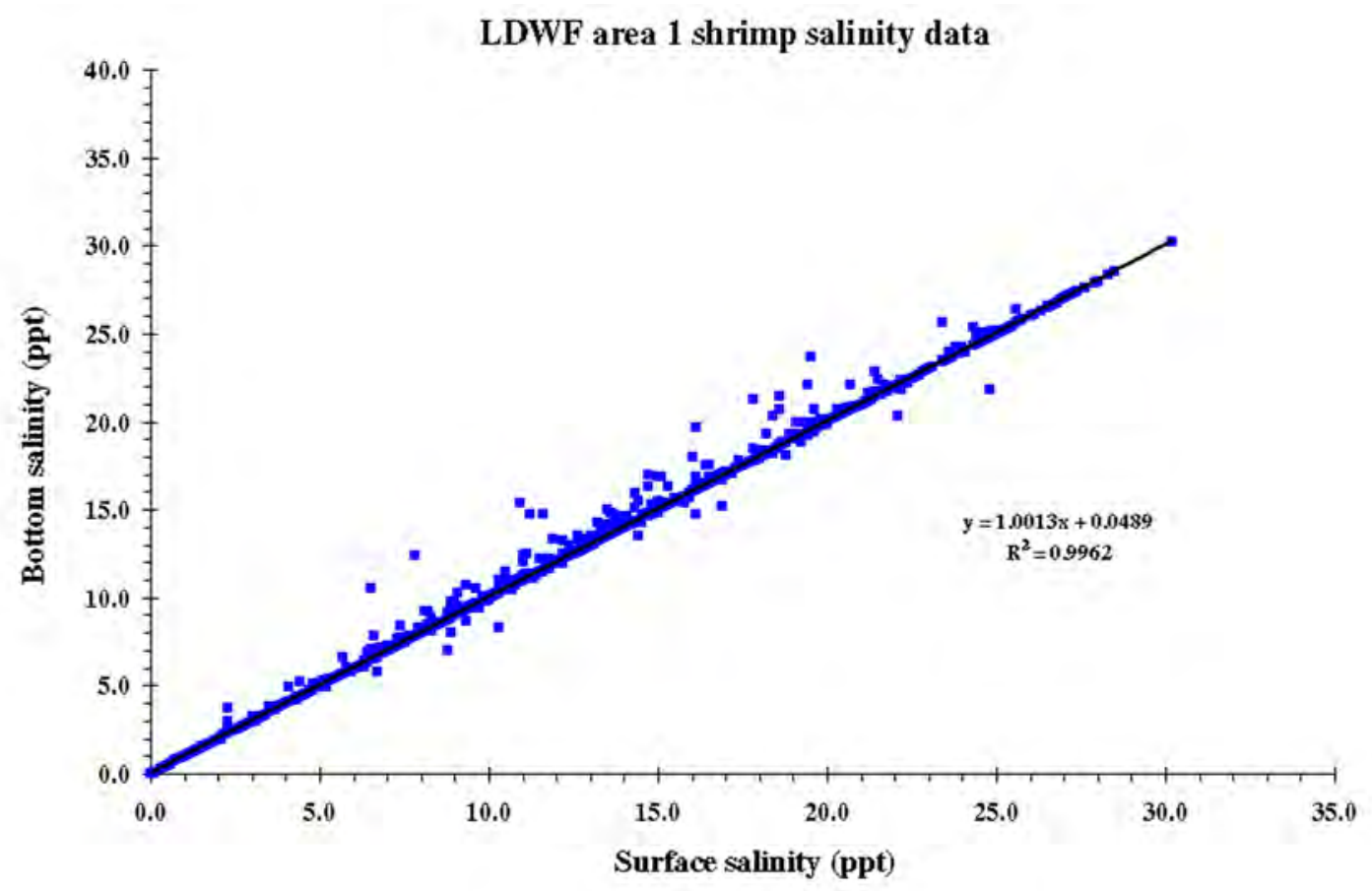

LDWF area 3 shrimp salinity data

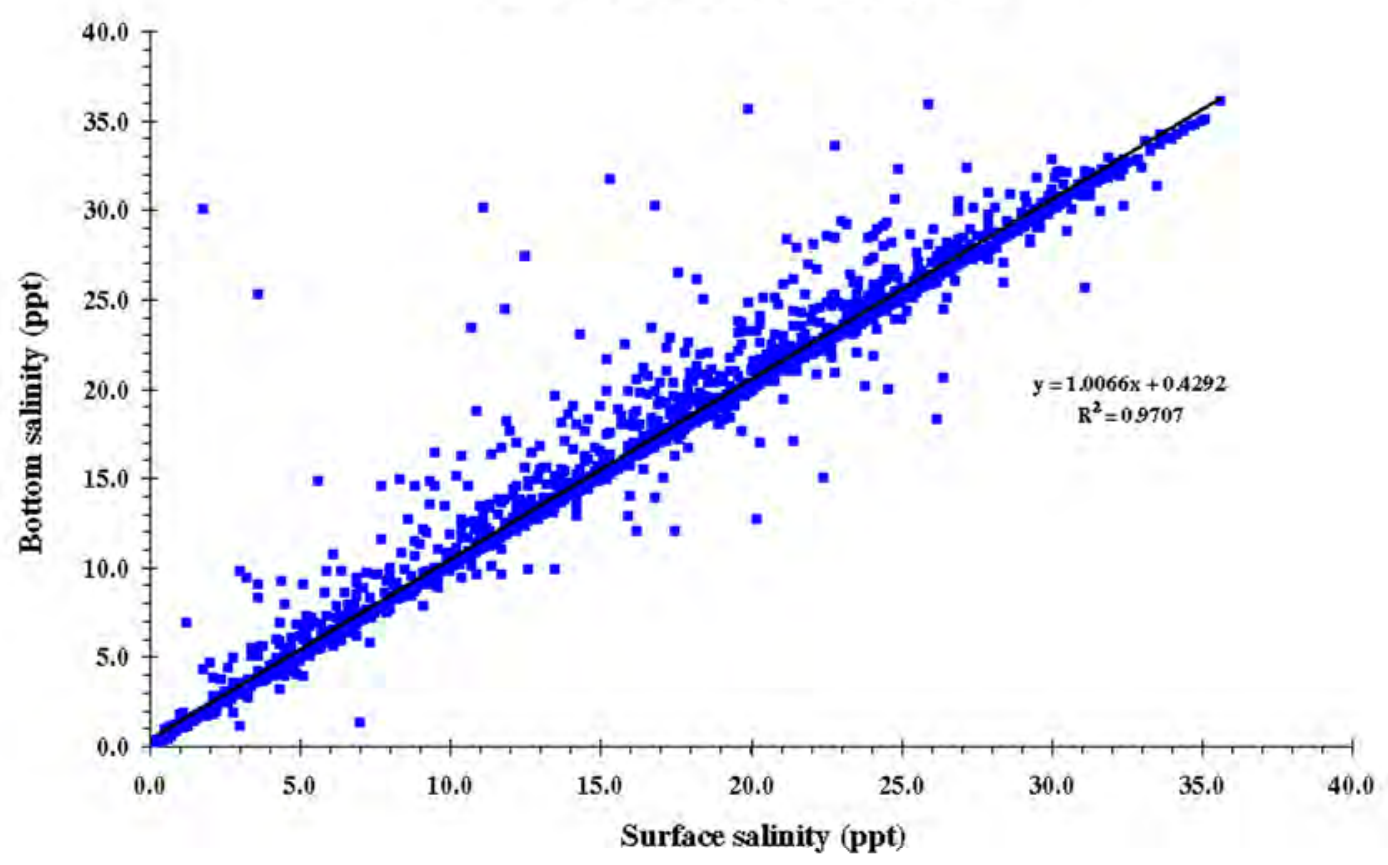

Figure 14. Plot of surface salinity against bottom salinity for Louisiana Department of Wildlife and Fisheries (LDWF) discrete shrimp sampling program in area 1 (Lakes Pontchartrain and Borgne) and area 3 (Barataria basin). The results of a regression analysis are indicated on each plot. 
Table 4. Regression analysis of daily mean salinity (calculated from hourly values) versus daily 8 a.m. salinity readings in coastal Louisiana.

[Adapted from Swenson and Swarzenski (1995); daily 8 a.m. reading and daily mean from hourly data; LDWF, Louisiana Department of Wildlife and Fisheries]

\begin{tabular}{lrrrrr}
\hline Agency & Station & $\mathbf{n}$ & Intercept & Slope & R-square \\
\hline LDWF & 315 & 5,800 & -0.16 & 1.00 & 0.95 \\
LDWF & 317 & 5,460 & -0.21 & 1.01 & 0.95 \\
LDWF & 323 & 1,271 & -0.21 & 1.01 & 0.97 \\
LDWF & 325 & 3,004 & -0.01 & 0.99 & 0.98 \\
LDWF & 326 & 1,874 & -0.08 & 1.05 & 0.97 \\
LDWF & 416 & 2,065 & 0.00 & 1.00 & 0.96 \\
LDWF & 518 & 2,180 & -0.16 & 1.00 & 0.95 \\
\hline
\end{tabular}

\section{Results}

A summary of the distribution of dataset lengths in years and the percent of the data records in each basin is shown in figure 15 and table 5. The main interest in this study was the availability of long-term data records to compare with the landscape changes. A summary of the percent of all data records within a basin by length of record is shown in figure 16. With the exception of the Atchafalaya and Mississippi River basins (which are not being considered in this study), all basins considered have datasets with lengths of at least 25 years for at least 20 percent of their data records. The basins with a large portion of their data records being 30 years or more are Terrebonne, Vermilion, and Calcasieu. Thus, there are sufficient data in all of the basins of interest to investigate the long-term changes. 

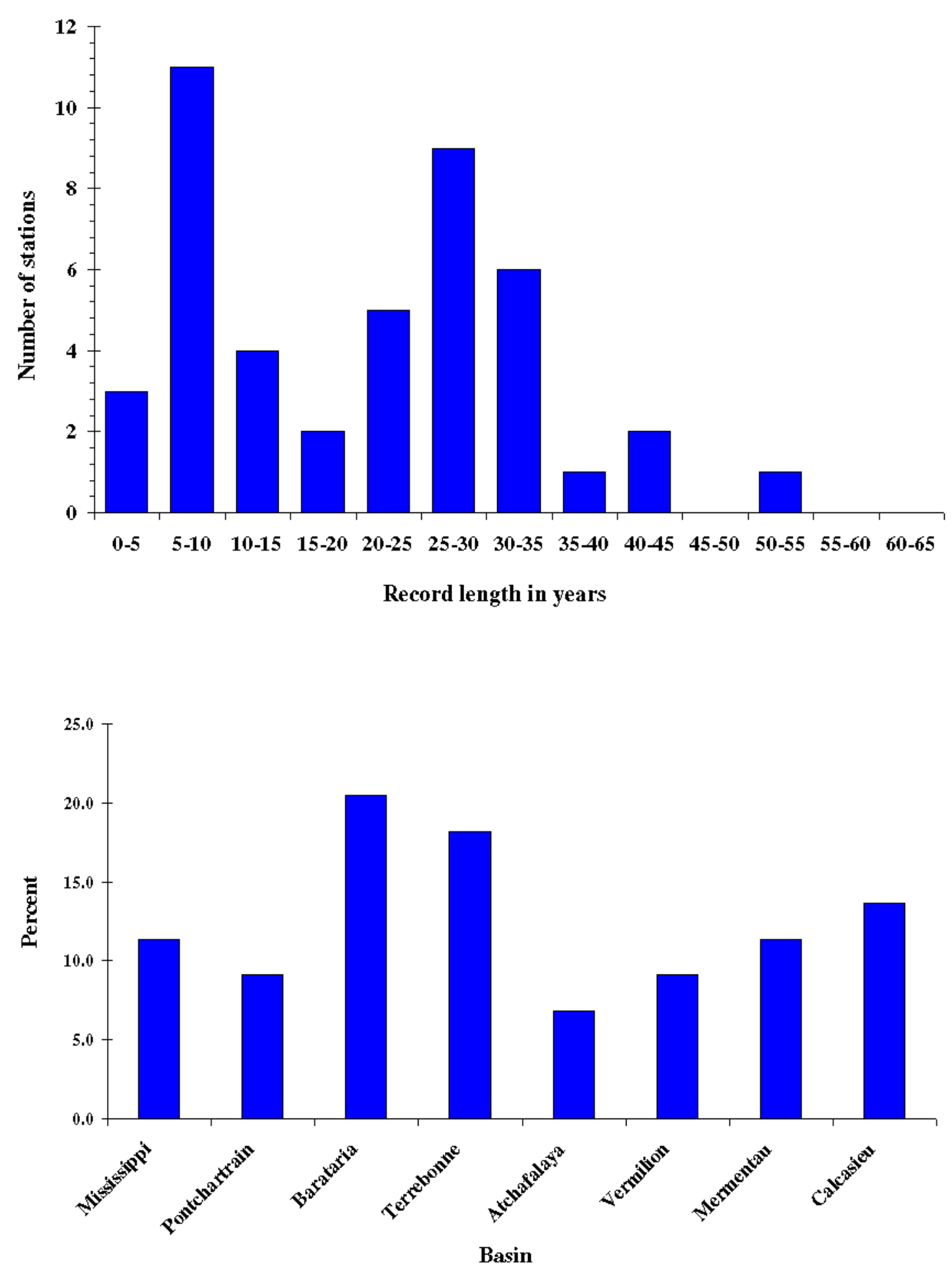

Figure 15. Distribution of data series lengths for the salinity datasets from the 44 stations in coastal Louisiana used in the final analysis. The top panel shows the distribution of all datasets as a function of dataset length. The bottom panel shows the distribution of all of the datasets by basin. 
Table 5. Summary of dataset lengths, by basin, for 44 salinity stations in coastal Louisiana. The number of stations of a given length and the total number of stations and percent of total stations within each basin also are indicated.

\begin{tabular}{|c|c|c|c|c|c|c|c|c|}
\hline \multirow{2}{*}{$\begin{array}{l}\text { Record } \\
\text { length } \\
\text { year }\end{array}$} & \multicolumn{8}{|c|}{ Basin } \\
\hline & $\begin{array}{r}\text { Mississippi } \\
\text { River }\end{array}$ & $\begin{array}{r}\text { Pontchartain } \\
\text { and Borgne }\end{array}$ & Barataria & Terrebonne & Atchafalaya & Vermilion & Mermentau & Calcasieu \\
\hline 00-05 & 0 & 0 & 1 & 1 & 1 & 0 & 0 & 0 \\
\hline 05-10 & 4 & 2 & 0 & 0 & 2 & 1 & 1 & 1 \\
\hline $10-15$ & 0 & 0 & 1 & 1 & 0 & 1 & 0 & 1 \\
\hline $15-20$ & 0 & 0 & 1 & 1 & 0 & 0 & 0 & 0 \\
\hline $20-25$ & 1 & 1 & 1 & 0 & 0 & 0 & 0 & 1 \\
\hline $25-30$ & 0 & 0 & 1 & 1 & 0 & 2 & 4 & 3 \\
\hline $30-35$ & 0 & 0 & 3 & 2 & 0 & 0 & 0 & 0 \\
\hline $35-40$ & 0 & 0 & 1 & 0 & 0 & 0 & 0 & 0 \\
\hline $40-45$ & 0 & 1 & 0 & 0 & 0 & 0 & 0 & 0 \\
\hline $45-50$ & 0 & 0 & 0 & 0 & 0 & 0 & 0 & 0 \\
\hline $50-55$ & 0 & 0 & 0 & 1 & 0 & 0 & 0 & 0 \\
\hline Total & 5 & 4 & 9 & 8 & 3 & 4 & 5 & 6 \\
\hline $\begin{array}{l}\text { Percent } \\
\text { of total }\end{array}$ & 11.4 & 9.1 & 20.5 & 18.2 & 6.8 & 9.1 & 11.4 & 13.6 \\
\hline
\end{tabular}

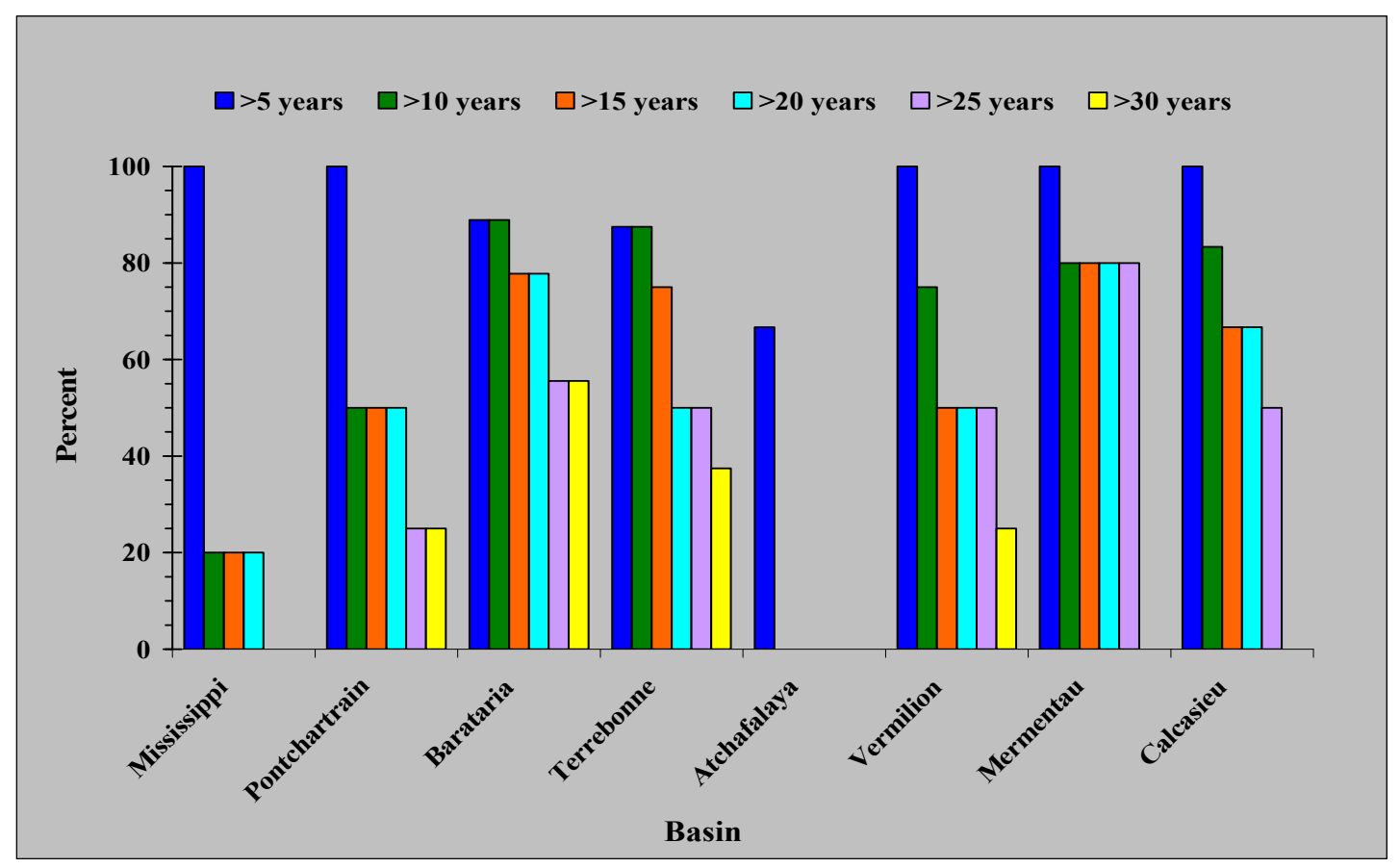

Figure 16. Summary of dataset lengths by basin in coastal Louisiana. The percentage of the total number of data records with a given basin by data record length is indicated. 
Examples of long-term daily mean coastal salinity from Grand Terre (Barataria basin) and Cameron (Calcasieu basin) are presented in figures 17 and 18. The overall patterns at both sites are similar, exhibiting seasonal fluctuations as well as large-scale fluctuations (usually from frontal passage influence). Daily salinity plots from Bayou Grand Caillou and Little Lake are shown in figures 19 and 20. The patterns at these locations are typical of a more inland location and are characterized by a more pronounced seasonal change from low salinities ( $0-2 \mathrm{ppt})$ to moderate salinities (5-10 ppt). The presence of short duration pulses or "spikes" up to 15-20 ppt also are apparent. These spikes are the result of meteorological forcing (strong frontal passages). The greater frequency of salinity spikes after 1976 at Bayou Grand Caillou is coincident with a change in vegetation communities from fresh to intermediate. The high salinities associated with the large scale drought during 1999-2000 are also quite evident on the filtered plots from Grand Terre, Bayou Grand Caillou, and Little Lake.

Figure 21 shows data from the Houma Navigation Canal at Crozier. The pattern in this figure is typical of an inland station on a large channel and is characterized by low salinities $(0-1$ ppt) most of the time with short duration, high salinity (approximately $15 \mathrm{ppt}$ ) spikes from meteorological forcing (strong frontal passages). The comparison of these salinity spikes between navigation channels and natural channels and the potential impact on the surrounding marshes are also of interest in this study and will be examined further in the next section. 

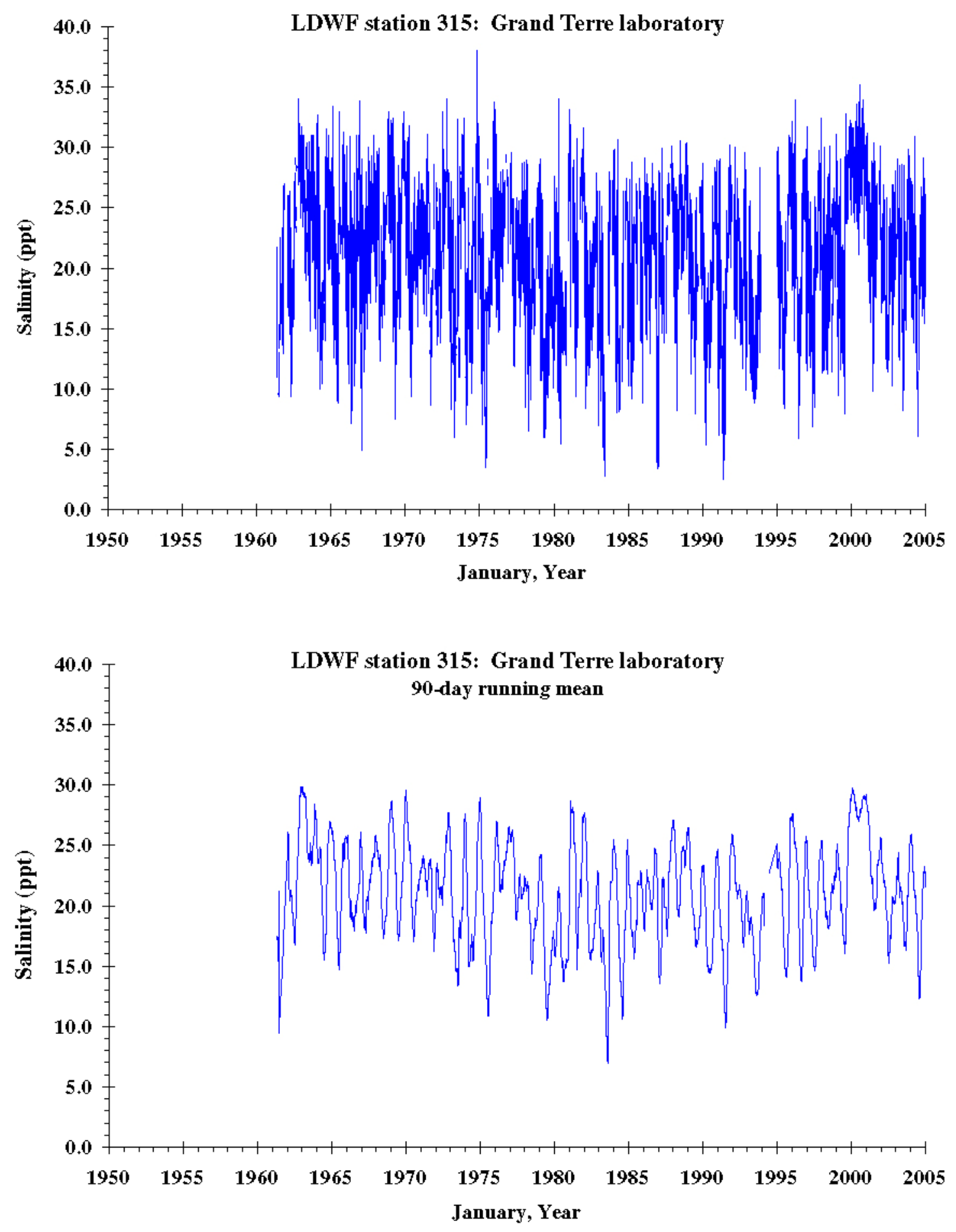

Figure 17. Time series plot of daily mean salinity (top panel) and 90-day running mean filtered data (bottom panel) from the Louisiana Department of Wildlife and Fisheries (LDWF) continuous monitoring station at Grand Terre, La. (station 315). Hourly data were used in this analysis. 

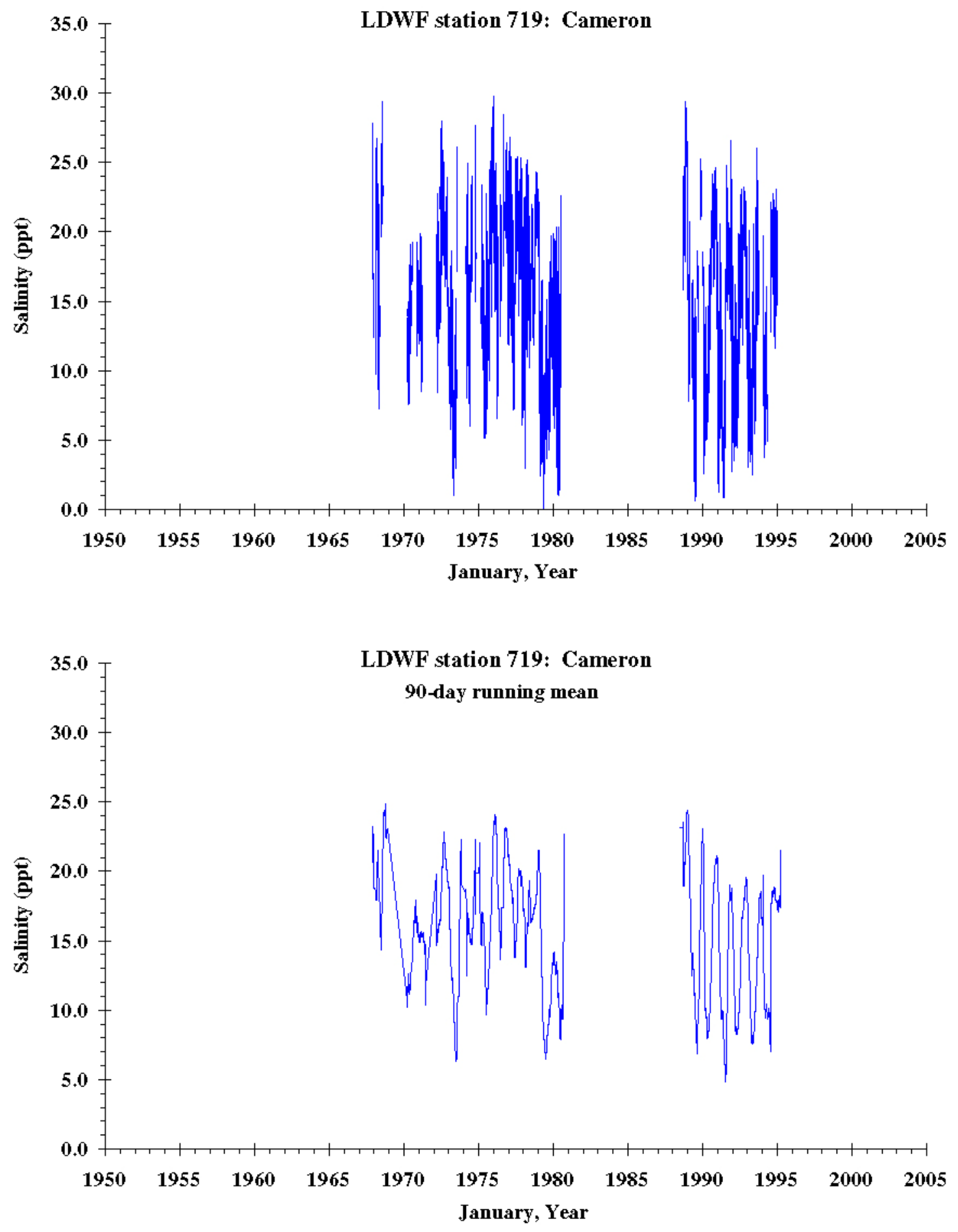

Figure 18. Time series plot of daily mean salinity (top panel) and 90-day running mean filtered data (bottom panel) from the Louisiana Department of Wildlife and Fisheries (LDWF) continuous monitoring station at Cameron, La. (station 719). Hourly data were used in this analysis. 

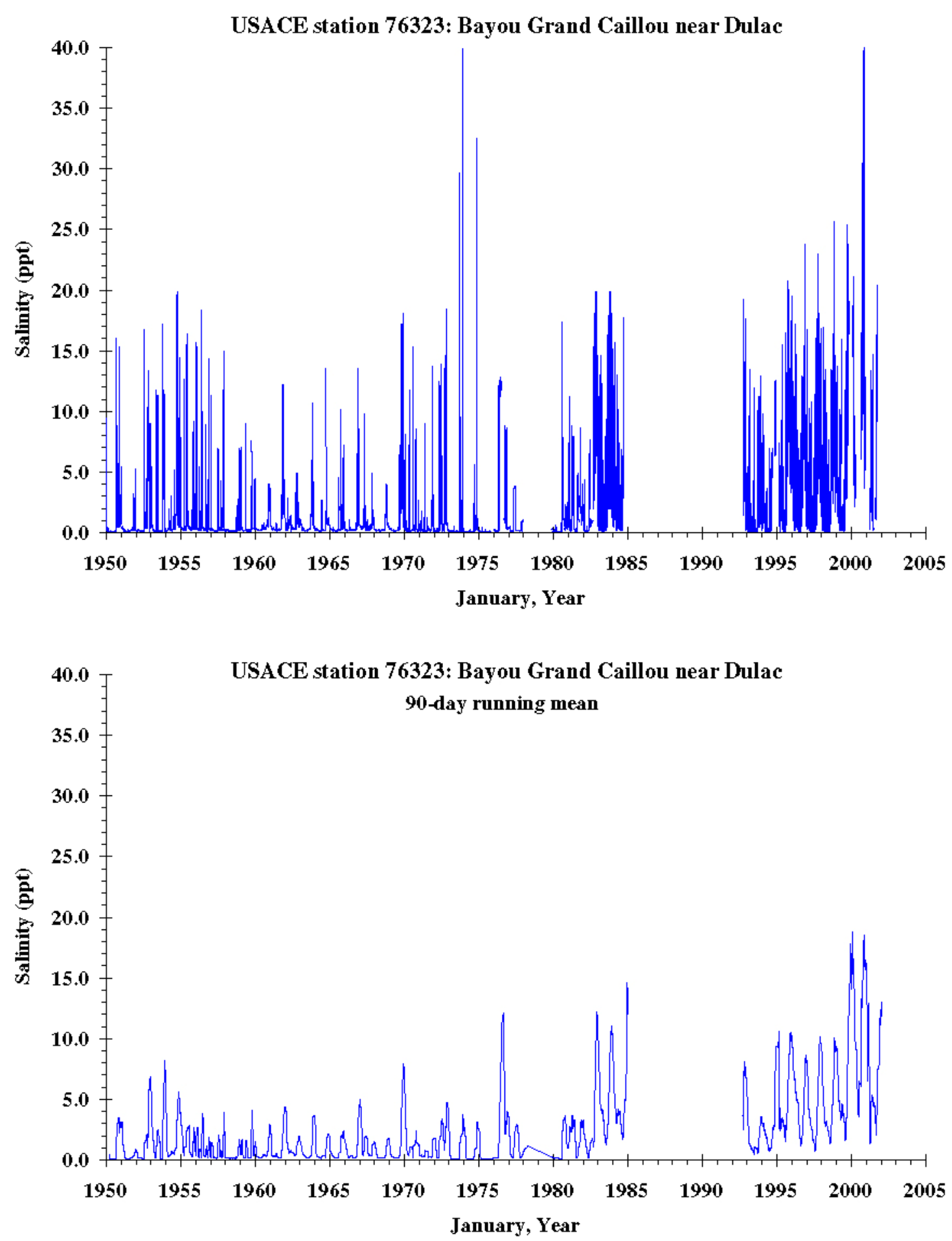

Figure 19. Time series plot of daily mean salinity (top panel) and 90-day running mean filtered data (bottom panel) from the U.S. Army Corps of Engineers (USACE) monitoring station in Bayou Grand Caillou, La. (station 76323). Daily data were used in this analysis. 

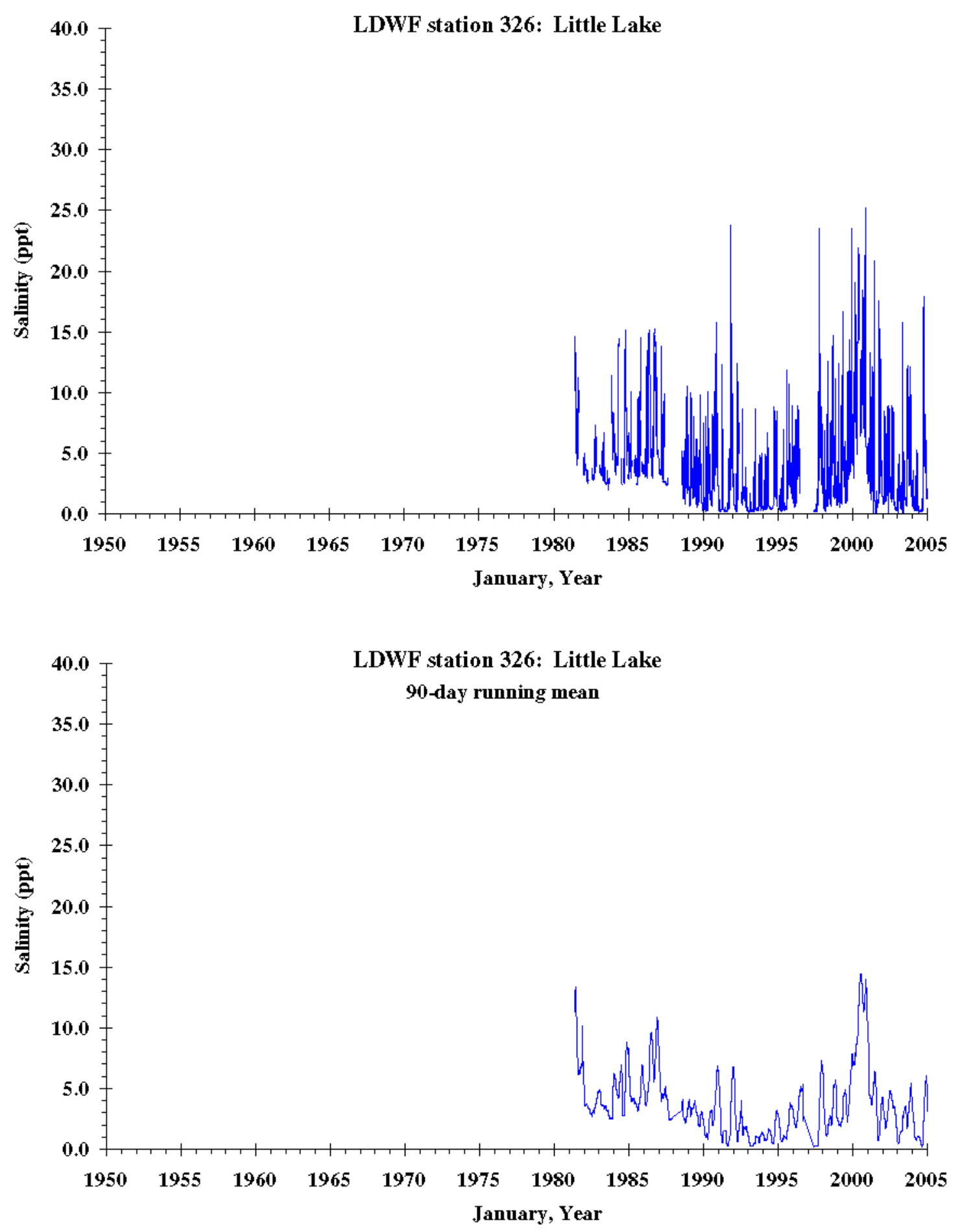

Figure 20. Time series plot of daily mean salinity (top panel) and 90-day running mean filtered data (bottom panel) from the Louisiana Department of Wildlife and Fisheries (LDWF) continuous monitoring station in Little Lake, La. (station 326). Hourly data were used in this analysis. 

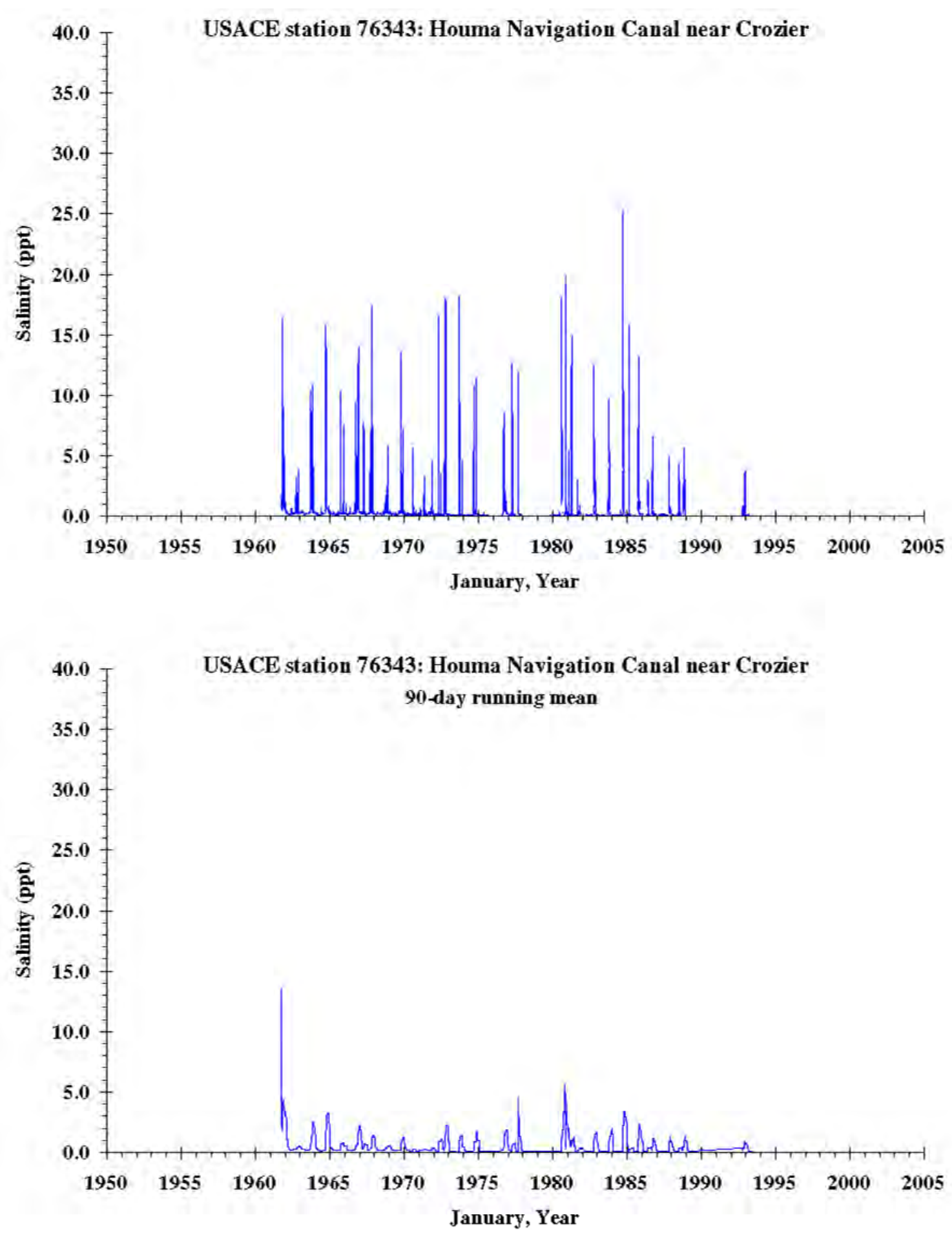

Figure 21. Time series plot of daily mean salinity from the U.S. Army Corps of Engineers (USACE) monitoring station in the Houma Navigation Canal at Crozier, La. (station 76343). Daily data were used in this analysis. 
The basic statistics for each of the stations are presented in table 6, and the station means are plotted in figure 22. The coastal waters have a mean salinity of 15-20 ppt, which decreases fairly rapidly as you move inland. The inland water bodies in the eastern part of the State tend to have higher salinity than do the inland water bodies in the western part of the State. The estuaries in the western part have limited exchange with the coastal waters compared to the estuaries in the eastern part of the State. In addition, a large portion of the western part of the State (e.g., Grand Lake and White Lake basins) is managed (by a series of locks and water control structures) with the goal of maintaining fresh water for agriculture (Gammill and others, 2001). 
Table 6. Summary statistics for coastal Louisiana stations used to analyze salinity, 1951-2005. [ppt, parts per thousand]

\begin{tabular}{|c|c|c|c|c|c|c|c|c|c|}
\hline \multirow[b]{2}{*}{$\begin{array}{l}\text { Station } \\
\text { number }\end{array}$} & \multirow[b]{2}{*}{$\begin{array}{l}\text { Latitude } \\
\text { decimal }\end{array}$} & \multirow[b]{2}{*}{$\begin{array}{r}\text { Longitude } \\
\text { decimal }\end{array}$} & \multirow[b]{2}{*}{$\begin{array}{l}\text { Start } \\
\text { year }\end{array}$} & \multirow[b]{2}{*}{$\begin{array}{l}\text { End } \\
\text { year }\end{array}$} & \multirow[b]{2}{*}{$\begin{array}{r}\text { Bapsed" } \\
\text { years }\end{array}$} & \multicolumn{4}{|c|}{ Salinity (ppt) } \\
\hline & & & & & & Mean & $\begin{array}{l}\text { Standard } \\
\text { deviation }\end{array}$ & Minimum & Maximum \\
\hline 315 & 29.27444 & -89.94222 & 1961 & 2005 & 44 & 20.9 & 5.7 & 2.5 & 38.0 \\
\hline 317 & 29.42306 & -89.95056 & 1973 & 2005 & 32 & 13.8 & 6.3 & 0.3 & 31.4 \\
\hline 326 & 29.51556 & -90.18417 & 1981 & 2005 & 24 & 3.6 & 3.7 & 0.0 & 25.2 \\
\hline 518 & 29.25306 & -90.92167 & 1967 & 2005 & 38 & 11.0 & 5.6 & 0.0 & 31.6 \\
\hline 619 & 29.71361 & -91.87806 & 1974 & 2005 & 31 & 4.0 & 3.3 & 0.0 & 18.7 \\
\hline 719 & 29.82722 & -93.33361 & 1967 & 1994 & 27 & 15.1 & 6.1 & 0.1 & 29.8 \\
\hline 1386 & 29.87829 & -89.95331 & 1988 & 1996 & 8 & 0.2 & 0.1 & 0.1 & 1.0 \\
\hline 1420 & 29.46667 & -89.68333 & 1975 & 1997 & 22 & 0.1 & 0.2 & 0.0 & 2.1 \\
\hline 1480 & 29.26667 & -89.35000 & 1991 & 1998 & 7 & 0.4 & 0.5 & 0.0 & 2.9 \\
\hline 1575 & 29.04360 & -89.31780 & 1988 & 1995 & 7 & 0.7 & 0.7 & 0.0 & 4.9 \\
\hline 1670 & 28.90000 & -89.41667 & 1990 & 1999 & 9 & 3.9 & 3.7 & 0.0 & 17.8 \\
\hline 67890 & 29.78333 & -92.13333 & 1987 & 1999 & 12 & 3.4 & 6.8 & 0.0 & 43.0 \\
\hline 70600 & 30.00000 & -92.76667 & 1975 & 1997 & 22 & 0.2 & 0.1 & 0.0 & 0.6 \\
\hline 70675 & 29.85000 & -92.85000 & 1973 & 2002 & 29 & 2.0 & 4.3 & 0.0 & 33.5 \\
\hline 70750 & 29.85000 & -92.85000 & 1975 & 1982 & 7 & 3.8 & 5.5 & 0.0 & 23.5 \\
\hline 73472 & 30.25000 & -93.21667 & 1975 & 2002 & 27 & 2.0 & 3.1 & 0.0 & 21.7 \\
\hline 76060 & 30.01667 & -90.01667 & 1957 & 2001 & 44 & 5.3 & 2.9 & 0.0 & 22.2 \\
\hline 76303 & 29.38333 & -90.61667 & 1975 & 2002 & 27 & 4.8 & 3.9 & 0.0 & 24.8 \\
\hline 76305 & 29.23333 & -90.65000 & 1987 & 2002 & 15 & 7.7 & 5.1 & 0.1 & 26.1 \\
\hline 76320 & 29.58333 & -90.70000 & 1975 & 1993 & 18 & 0.4 & 1.2 & 0.0 & 18.4 \\
\hline 76323 & 29.45000 & -90.70000 & 1948 & 2001 & 53 & 2.1 & 3.9 & 0.0 & 41.8 \\
\hline 76343 & 29.55000 & -90.70000 & 1961 & 1993 & 32 & 0.5 & 1.7 & 0.0 & 25.3 \\
\hline 76403 & 29.58333 & -90.50000 & 1975 & 1993 & 18 & 0.6 & 1.8 & 0.0 & 36.1 \\
\hline 76480 & 29.63908 & -91.31845 & 1991 & 1993 & 2 & 0.6 & 0.1 & 0.3 & 0.8 \\
\hline 76592 & 29.55000 & -92.30000 & 1975 & 2002 & 27 & 8.6 & 4.9 & 0.0 & 37.9 \\
\hline 76600 & 29.75000 & -92.25000 & 1975 & 1982 & 7 & 2.0 & 2.5 & 0.0 & 15.2 \\
\hline 76680 & 29.75000 & -92.25000 & 1975 & 2001 & 26 & 0.9 & 1.2 & 0.0 & 11.4 \\
\hline 76720 & 29.78333 & -92.18333 & 1975 & 1982 & 7 & 2.1 & 2.5 & 0.0 & 13.9 \\
\hline 76800 & 29.78333 & -92.18333 & 1975 & 2002 & 27 & 1.3 & 1.9 & 0.0 & 14.8 \\
\hline 76873 & 29.93333 & -93.08333 & 1951 & 1981 & 30 & 0.4 & 0.8 & 0.0 & 14.9 \\
\hline 76880 & 30.08333 & -93.28333 & 1987 & 2000 & 13 & 5.7 & 5.9 & 0.0 & 30.9 \\
\hline 81050 & 29.51667 & -90.40000 & 1987 & 1999 & 12 & 0.2 & 0.4 & 0.0 & 5.5 \\
\hline 82203 & 29.56667 & -90.38333 & 1949 & 1981 & 32 & 0.6 & 1.2 & 0.0 & 19.9 \\
\hline 82250 & 29.34165 & -90.24561 & 1991 & 1996 & 5 & 4.2 & 3.1 & 0.5 & 17.5 \\
\hline 82300 & 29.36667 & -90.25000 & 1961 & 1984 & 23 & 1.9 & 3.5 & 0.0 & 25.4 \\
\hline 82750 & 29.73333 & -90.11667 & 1967 & 2002 & 35 & 5.7 & 3.1 & 0.1 & 18.5 \\
\hline 82875 & 29.66667 & -90.10000 & 1955 & 1988 & 33 & 2.2 & 2.4 & 0.0 & 24.6 \\
\hline 85600 & 30.18333 & -90.11667 & 1973 & 1996 & 23 & 3.0 & 1.2 & 0.0 & 6.6 \\
\hline 85800 & 29.85000 & -89.68333 & 1988 & 1996 & 8 & 9.8 & 4.0 & 0.0 & 21.2 \\
\hline 85850 & 29.68834 & -89.40338 & 1987 & 1993 & 6 & 15.7 & 5.9 & 0.0 & 28.3 \\
\hline 88410 & 29.24764 & -89.98630 & 1992 & 1997 & 5 & 17.3 & 5.8 & 0.7 & 30.1 \\
\hline 88550 & 29.38609 & -91.39783 & 1990 & 1997 & 7 & 0.7 & 1.1 & 0.0 & 10.2 \\
\hline 88800 & 29.59786 & -91.54145 & 1992 & 1999 & 7 & 0.0 & 1.2 & 0.0 & 19.5 \\
\hline 88850 & 29.68333 & -91.88333 & 1973 & 2001 & 28 & 4.1 & 3.5 & 0.0 & 21.3 \\
\hline
\end{tabular}




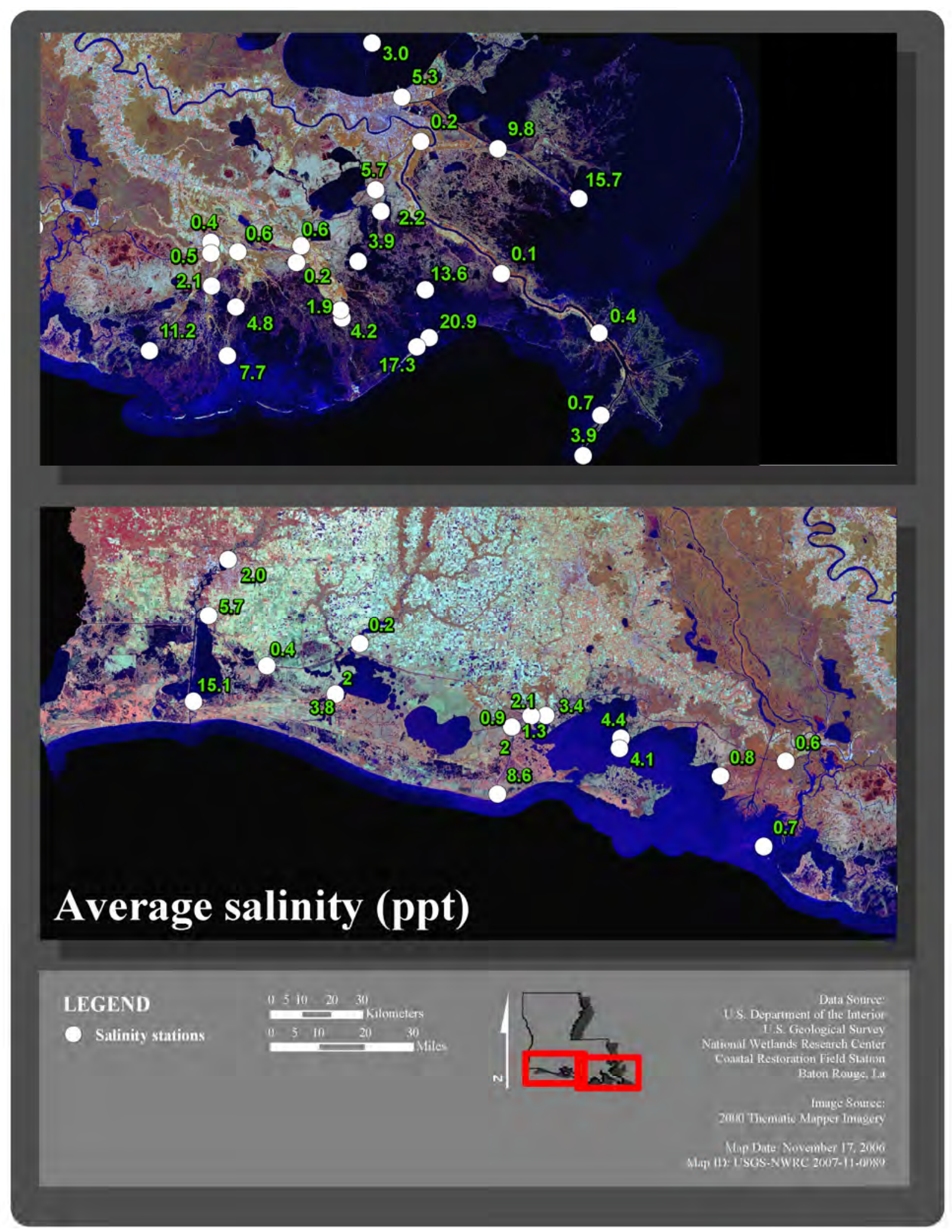

Figure 22. Average salinity for 44 stations used to analyze salinity in coastal Louisiana, 1951-2005. 
The results of the trend analysis (linear regression), which used daily salinity as the dependent variable and time as the independent variable, are presented in table 7 . This table presents, for each station, the data start year, the data end year, the total number of years, the intercept of the linear fit, the slope (parts per thousand per year) of the linear fit, the model rsquare, the F value for the overall linear model, the probability, and the salinity change (parts per thousand) over the period of record. The spatial distribution of the trends is presented in figure 23 . The linear fit was significant at 42 of the 44 stations. Salinity increases occurred at 27 (64 percent) of the stations, and salinity decreases occurred at 15 (36 percent) of the stations. The changes in salinity were small, with 74 percent being increases or decreases of less than 2 ppt over the period of record. The long-term trends explained less than 10 percent $(r$-square $<0.1)$ of the variance at most ( 72 percent) of the stations. The lower r-square was also noted by Wiseman and others (1990a), who stated that the statistically significant but weak trends are hidden by the high natural variability in the Mississippi River discharge and local climatology.

The coastal salinities in Louisiana exhibit interannual variability, which is inversely related to Mississippi River discharge (Wiseman and others, 1990b). The trends presented in figure 23 contain data from many stations with short records, as well as data from different time periods. Wiseman and others (1990a) pointed out that there are longer term (years to decades) climatic variations that affect the estuary. To address this point, a subset of stations which had data over the same 23-year period (1975-98) was used. There were a total of 15 stations with data over this time period; 12 (80 percent) of these had statistically significant trends. Salinity increases occurred at 6 (50 percent) of the 12 stations, and salinity decreases occurred at 6 (50 percent) of these stations. The spatial distribution of the 1975-88 trends is presented in figure 24, and the trend analysis results are presented in table 8 . In general, most of the changes over the time period were fairly small; 67 percent of the increases and 50 percent of the decreases were 2 ppt or less. As was the case when using all data (table 7), the trend explained a small amount of the observed salinity signal (5 ppt or less at 75 percent of the stations). Although there is no coherent coastwide trend of increasing or decreasing salinity, there is a consistent salinity increase for the internal basins of the Chenier Plain. There is also an indication of salinity increase in the Houma Navigation Canal as opposed to the stations on either side, which both show decreases. 
Table 7. Results of a trend analysis (linear regression) in coastal Louisiana that uses time as the independent variable and salinity as the dependent variable.

[ppt, parts per thousand; ppt/yr, parts per thousand per year; >, greater than; POR, period of record; <, less than]

\begin{tabular}{|c|c|c|c|c|c|c|c|c|c|}
\hline $\begin{array}{l}\text { Station } \\
\text { number }\end{array}$ & $\begin{array}{l}\text { Start } \\
\text { year }\end{array}$ & $\begin{array}{l}\text { End } \\
\text { year }\end{array}$ & $\begin{array}{c}\text { Bapsed } \\
\text { years }\end{array}$ & $\begin{array}{c}\text { Intercept } \\
\text { (ppt) }\end{array}$ & $\begin{array}{l}\text { Slope } \\
\text { (ppt/yr) }\end{array}$ & R-square & $\begin{array}{l}\text { Overall } \\
\text { model F }\end{array}$ & $\begin{array}{c}\text { Overall } \\
\text { model Pr>F }\end{array}$ & $\begin{array}{l}\text { PORsalinity } \\
\text { change (ppt) }\end{array}$ \\
\hline 315 & 1961 & 2005 & 44 & 21.3 & -0.0178 & 0.002 & 24.21 & $<0.0001$ & -0.78 \\
\hline 317 & 1973 & 2005 & 32 & 11.7 & 0.0690 & 0.010 & 93.70 & $<0.0001$ & 2.21 \\
\hline 326 & 1981 & 2005 & 24 & 5.4 & -0.0511 & 0.010 & 72.70 & 0.0871 & -1.23 \\
\hline 518 & 1967 & 2005 & 38 & 10.7 & 0.0088 & 0.000 & 2.43 & 0.1188 & 0.33 \\
\hline 619 & 1974 & 2005 & 31 & 3.5 & 0.0146 & 0.003 & 12.75 & 0.0004 & 0.45 \\
\hline 719 & 1967 & 1994 & 27 & 18.2 & -0.1376 & 0.037 & 178.90 & 0.0001 & -3.72 \\
\hline 1386 & 1988 & 1996 & 8 & 0.5 & -0.0107 & 0.130 & 148.63 & $<0.0001$ & -0.09 \\
\hline 1420 & 1975 & 1997 & 22 & -0.1 & 0.0114 & 0.255 & 1762.02 & $<0.0001$ & 0.25 \\
\hline 1480 & 1991 & 1998 & 7 & 4.2 & -0.1095 & 0.154 & 218.21 & $<0.0001$ & -0.77 \\
\hline 1575 & 1988 & 1995 & 7 & 5.3 & -0.1502 & 0.288 & 271.03 & $<0.0001$ & -1.05 \\
\hline 1670 & 1990 & 1999 & 9 & 0.1 & 0.1139 & 0.006 & 11.57 & 0.0007 & 1.03 \\
\hline 67890 & 1987 & 1999 & 12 & -0.8 & 0.1278 & 0.005 & 16.13 & $<0.0001$ & 1.53 \\
\hline 70600 & 1975 & 1997 & 22 & -0.1 & 0.0099 & 0.313 & 957.62 & $<0.0001$ & 0.22 \\
\hline 70675 & 1973 & 2002 & 29 & 0.3 & 0.0588 & 0.012 & 77.08 & $<0.0001$ & 1.71 \\
\hline 70750 & 1975 & 1982 & 7 & -0.3 & 0.2232 & 0.008 & 16.79 & $<0.0001$ & 1.56 \\
\hline 73472 & 1975 & 2002 & 27 & 0.6 & 0.0502 & 0.017 & 112.06 & $<0.0001$ & 1.35 \\
\hline 76060 & 1957 & 2001 & 44 & 6.5 & -0.0417 & 0.027 & 121.63 & $<0.0001$ & -1.83 \\
\hline 76303 & 1975 & 2002 & 27 & 2.1 & 0.0949 & 0.052 & 328.62 & $<0.0001$ & 2.66 \\
\hline 76305 & 1987 & 2002 & 15 & -4.6 & 0.3642 & 0.090 & 384.70 & $<0.0001$ & 5.46 \\
\hline 76320 & 1975 & 1993 & 18 & 0.0 & 0.0185 & 0.005 & 19.26 & $<0.0001$ & 0.33 \\
\hline 76323 & 1948 & 2001 & 53 & 1.0 & 0.0949 & 0.136 & 2321.96 & $<0.0001$ & 5.03 \\
\hline 76343 & 1961 & 1993 & 32 & 0.6 & -0.0086 & 0.002 & 14.13 & 0.0002 & -0.28 \\
\hline 76403 & 1975 & 1993 & 18 & 0.1 & 0.0195 & 0.002 & 9.46 & 0.0021 & 0.35 \\
\hline 76480 & 1991 & 1993 & 2 & -3.6 & 0.1277 & 0.591 & 862.22 & $<0.0001$ & 0.26 \\
\hline 76592 & 1975 & 2002 & 27 & 16.6 & -0.2802 & 0.205 & 1720.01 & $<0.0001$ & -7.57 \\
\hline 76600 & 1975 & 1982 & 7 & -1.4 & 0.1797 & 0.031 & 75.07 & $<0.0001$ & 1.26 \\
\hline 76680 & 1975 & 2001 & 26 & 1.5 & -0.0231 & 0.020 & 114.80 & $<0.0001$ & -0.60 \\
\hline 76720 & 1975 & 1982 & 7 & -2.2 & 0.2295 & 0.047 & 113.47 & $<0.0001$ & 1.61 \\
\hline 76800 & 1975 & 2002 & 27 & 3.2 & -0.0670 & 0.078 & 1097.52 & $<0.0001$ & -1.81 \\
\hline 76873 & 1951 & 1981 & 30 & 0.4 & 0.0059 & 0.002 & 18.85 & $<0.0001$ & 0.18 \\
\hline 76880 & 1987 & 2000 & 13 & -17.4 & 0.7191 & 0.169 & 512.72 & $<0.0001$ & 9.35 \\
\hline 81050 & 1987 & 1999 & 12 & 0.8 & -0.0167 & 0.018 & 46.18 & $<0.0001$ & -0.20 \\
\hline 82203 & 1949 & 1981 & 32 & 0.5 & 0.0071 & 0.003 & 22.90 & $<0.0001$ & 0.23 \\
\hline 82250 & 1991 & 1996 & 5 & 26.3 & -0.6502 & 0.105 & 99.71 & $<0.0001$ & -3.25 \\
\hline 82300 & 1961 & 1984 & 23 & 3.6 & 0.0772 & 0.584 & 329.65 & $<0.0001$ & 1.77 \\
\hline 82750 & 1967 & 2002 & 35 & 1.2 & 0.0590 & 0.013 & 100.53 & $<0.0001$ & 2.07 \\
\hline 82875 & 1955 & 1988 & 33 & 1.6 & 0.0754 & 0.097 & 1623.23 & $<0.0001$ & 2.49 \\
\hline 85600 & 1973 & 1996 & 23 & 1.2 & 0.0206 & 0.003 & 8.45 & 0.0039 & 0.47 \\
\hline 85800 & 1988 & 1996 & 8 & 3.9 & -0.1504 & 0.010 & 26.91 & $<0.0001$ & -1.20 \\
\hline 85850 & 1987 & 1993 & 6 & 29.8 & -0.4611 & 0.020 & 26.91 & $<0.0001$ & -2.77 \\
\hline 88410 & 1992 & 1997 & 5 & 6.2 & 0.3170 & 0.007 & 7.92 & 0.0050 & 1.59 \\
\hline 88550 & 1990 & 1997 & 7 & -6.1 & 0.1961 & 0.176 & 416.77 & $<0.0001$ & 1.37 \\
\hline 88800 & 1992 & 1999 & 7 & -6.1 & 0.1895 & 0.009 & 15.58 & $<0.0001$ & 1.33 \\
\hline 88850 & 1973 & 2001 & 28 & 3.5 & -0.0135 & 0.001 & 4.80 & 0.0285 & -0.38 \\
\hline
\end{tabular}




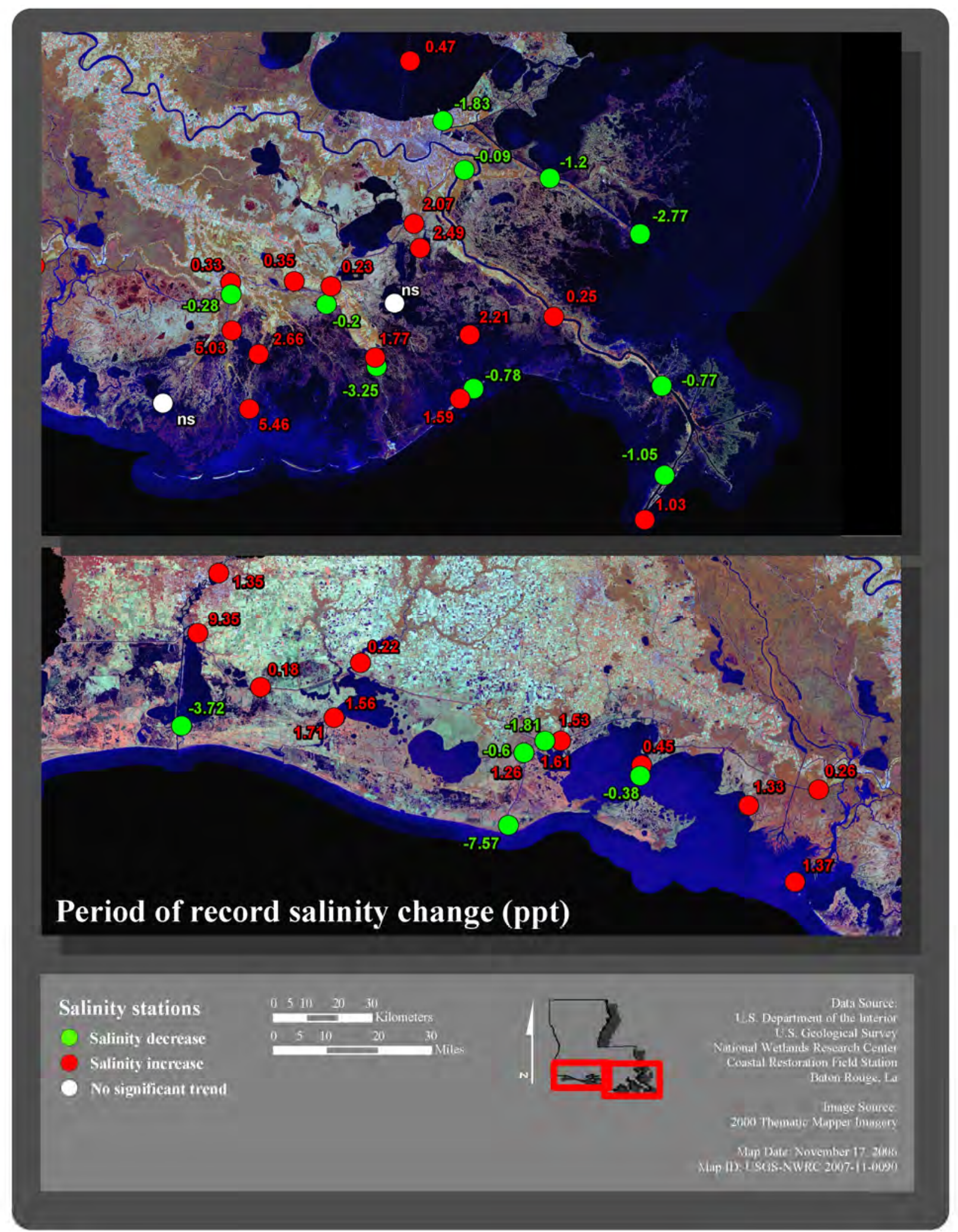

Figure 23. Summary of salinity trend analysis in coastal Louisiana. The salinity change in parts per thousand (ppt) over the period of record is shown. 


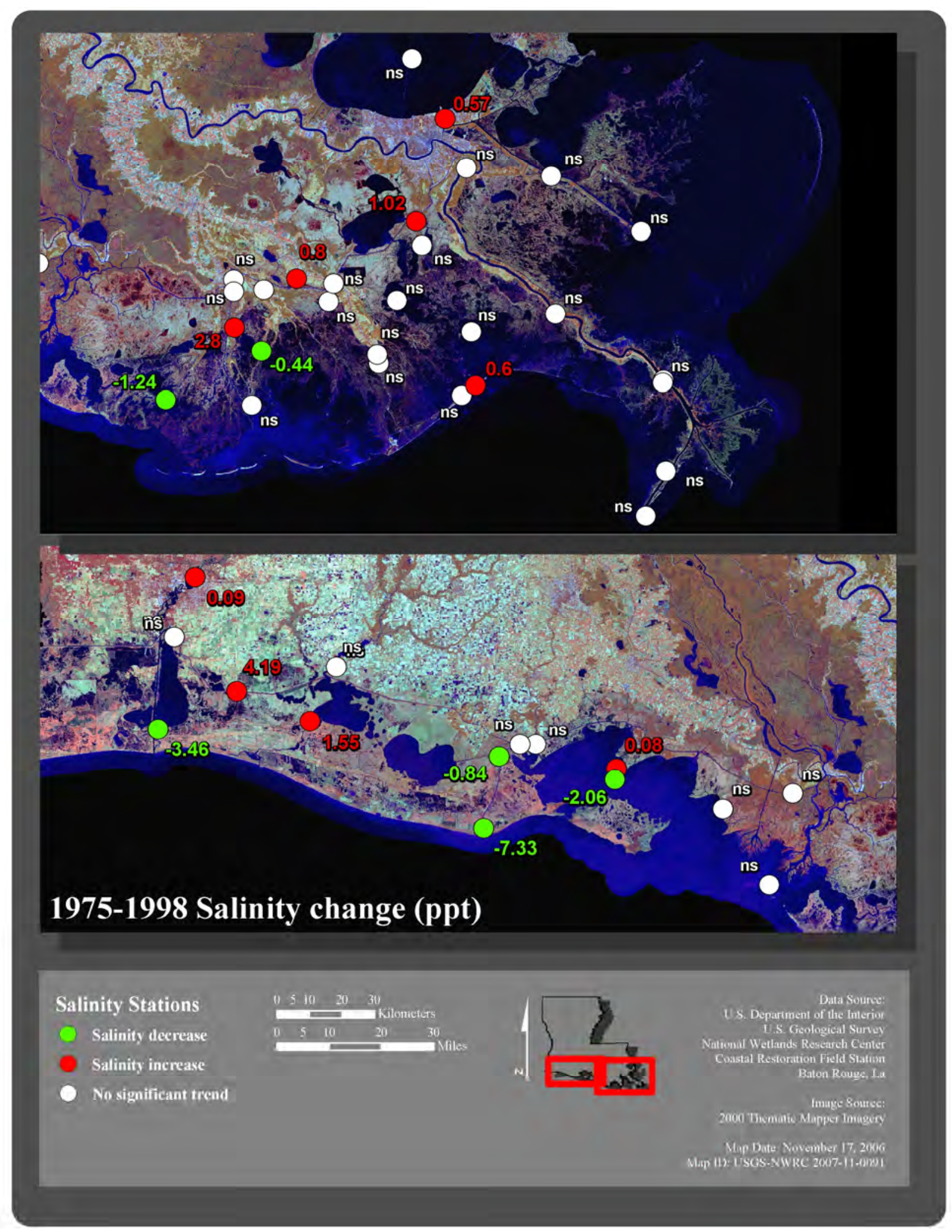

Figure 24. Summary of salinity change in parts per thousand (ppt) over the period from 1975 through 1998 in coastal Louisiana. 
Table 8. Results of a trend analysis (linear regression) using time as the independent variable and salinity as the dependent variable. Only stations in Louisiana with data over the time period from 1975 through 1998 were used in this analysis.

[ppt, parts per thousand; ppt/day, parts per thousand per day; ppt/yr, parts per thousand per year; >, greater than; POR, period of record; <, less than]

\begin{tabular}{rcccccccrr}
$\begin{array}{c}\text { Station } \\
\text { number }\end{array}$ & $\begin{array}{c}\text { Decimal } \\
\text { latitude }\end{array}$ & $\begin{array}{c}\text { Decimal } \\
\text { longitude }\end{array}$ & $\begin{array}{c}\text { Mean } \\
\text { salinity }\end{array}$ & $\begin{array}{c}\text { Intercept } \\
\text { (ppt) }\end{array}$ & $\begin{array}{c}\text { Slope } \\
\text { (ppt/day) }\end{array}$ & $\begin{array}{c}\text { Slope } \\
\text { (ppt/yr) }\end{array}$ & R-square & $\begin{array}{c}\text { Overall } \\
\text { model F }\end{array}$ & $\begin{array}{c}\text { Overall } \\
\text { model Pr>F }\end{array}$ \\
\hline 315 & 29.27444 & -89.94222 & 19.8 & 19.1 & 0.00007 & 0.026 & 0.001 & 7.96 & 0.0048 \\
518 & 29.25306 & -90.92167 & 10.5 & 11.8 & -0.00015 & -0.054 & 0.009 & 26.46 & $<0.0001$ \\
619 & 29.71361 & -91.87806 & 3.8 & 3.7 & 0.00001 & 0.003 & 0.000 & 0.34 & 0.5598 \\
719 & 29.82722 & -93.33361 & 14.8 & 18.6 & -0.00041 & -0.150 & 0.030 & 116.81 & $<0.0001$ \\
70675 & 29.85000 & -92.85000 & 2.0 & 0.1 & 0.00019 & 0.068 & 0.014 & 80.87 & $<0.0001$ \\
73472 & 30.25000 & -93.21667 & 1.7 & 1.6 & 0.00001 & 0.004 & 0.000 & 0.54 & 0.4625 \\
76060 & 30.01667 & -90.01667 & 4.6 & 5.5 & 0.00007 & 0.025 & 0.001 & 3.49 & 0.0617 \\
76303 & 29.38333 & -90.61667 & 4.1 & 4.6 & -0.00005 & -0.019 & 0.002 & 11.13 & 0.0009 \\
76323 & 29.45000 & -90.70000 & 3.4 & 0.0 & 0.00033 & 0.122 & 0.052 & 254.40 & $<0.0001$ \\
76403 & 29.58333 & -90.50000 & 0.6 & 0.1 & 0.00010 & 0.035 & 0.002 & 9.46 & 0.0021 \\
76592 & 29.55000 & -92.30000 & 8.7 & 17.5 & -0.00087 & -0.319 & 0.220 & 1713.70 & $<0.0001$ \\
76680 & 29.75000 & -92.25000 & 0.9 & 1.8 & -0.00010 & -0.036 & 0.047 & 265.73 & $<0.0001$ \\
76873 & 29.93333 & -93.08333 & 0.6 & -2.8 & 0.00050 & 0.182 & 0.162 & 346.05 & $<0.0001$ \\
82750 & 29.73333 & -90.11667 & 5.2 & 4.0 & 0.00012 & 0.044 & 0.021 & 95.86 & $<0.0001$ \\
88850 & 29.68333 & -91.88333 & 3.7 & 6.3 & -0.00025 & -0.090 & 0.055 & 242.36 & $<0.0001$ \\
\hline
\end{tabular}

\section{Salinity Pulse Analysis}

\section{Long-Term Data Records}

The daily datasets were summarized to calculate the percent of time, on an annual basis, that the salinity at each station exceeded values of 2.5, 5.0, 10.0, 15.0, 20.0, and $25.0 \mathrm{ppt}$. The results for all stations are presented in appendix 1. Although there appears to be no coherent coastwide pattern, the effects of the drought of 1999-2000 is evident on many of the plots (appendix 1). Of primary interest to this study is salinity behavior across the stations in and near the Houma Navigation Canal (HNC). The stations used for the pulse analysis are shown in figure 8 along with canals that existed during the pre- and post-construction periods of the HNC. The annual salinity level data for six long-term stations near the HNC are presented in figures 25 through 30. These figures indicate the percent of time during the year that the salinity exceeded a given level. The completion date for the HNC is indicated on each figure.

In general, salinity levels exceeded 10-15 ppt less than 10 percent of the time at all of the stations, although there were time periods when these levels occurred at greater frequency (up to 60 percent of the time). The effect of the 1999-2000 droughts (higher percentage of values greater than $10.0 \mathrm{ppt}$ ) is an example of this and can be seen in the data from Bayou Petite Caillou at Cocodrie (fig. 25), Bayou Petite Caillou near Boudreaux Canal (fig. 26), and Bayou Grand Caillou at Dulac (fig. 27). With the exception of the 1999-2000 drought, there does not appear to be any obvious pattern in increasing salinity levels closely following the completion of the HNC, except for the immediate increase in salinity spikes during completion of construction in 1961 (fig. 29). 
The data from Bayou Grand Caillou at Dulac (fig. 27) do show a longer term trend of increasing salinity levels. Salinity values were greater than 5 ppt about 10 percent of the time in 1950; this frequency of occurrence increased substantially in 1978 and rose to a level of 50-60 percent by 2001. This pattern is similar to the pattern observed at the HWTP (fig. 9). A potential explanation for these patterns is based on the dredging history of the HNC. The HNC was completed in 1962 but required maintenance dredging on a large extent of it in 1964-65 (2.73 million $\left.\mathrm{m}^{3}\right)$. Spot dredging $\left(<0.1\right.$ million $\left.\mathrm{m}^{3}\right)$ was done in the main channel between each full dredging event $(6.30$ million $\mathrm{m}^{3}$ between 1972 and 1974 and 6.38 million $\mathrm{m}^{3}$ between 1980 and 1983; U.S. Army Corps of Engineers, 1975, 1984). These events opened a deeper route from the HNC to Crozier and into Grand Bayou Caillou. Although the available salinity data are insufficient to conduct statistical correlations, the salinity exceedance values shown in figures 27 and 29 correspond fairly closely to the timing of the dredging events. The increase also may be a reflection of the general breakup of the marsh in the area, which led to increased exchange with the HNC as spoil banks deteriorated.

A comparison of data from Bayou Terrebonne at Bourg (fig. 28) and the HNC at Crozier (fig. 29) indicates that the magnitude and frequency of the salinity spikes (especially those greater than $10.0 \mathrm{ppt}$ ) are greater at the HNC station, even though it is almost $6 \mathrm{~km}$ further inland. This observation agrees with the Wang (1988) study discussed previously.

\section{Short-Term Data Records}

To investigate the salinity characteristics of the Houma Navigation Canal and adjacent natural bayous in greater detail, hourly salinity, water level, and discharge data from 2003 were obtained from stations in the area. The purpose of the study was to characterize the nature of the salinity spikes discussed previously. Data came from the LDNR, the USGS, and the Louisiana Universities Marine Consortium (LUMCON). The data availability is shown in table 9, and the station distribution is shown in figure 31. The stations used for this analysis are also shown in figure 8 along with canals that existed during the pre- and postconstruction phases of the HNC. Data from these stations defined three coastal-inland transects (fig. 32):

1. Bayou Terrebonne transect: from Terrebonne Bay northward to Montegut (stations 102, TE03-20R, TE01-16R)

2. Bayou Grand Caillou transect: from the Houma Navigation Canal northward to Ashland (stations 07381324, TE32-36R, TE32-35R, TE32-33R).

3. The Houma Navigation Canal transect: from Terrebonne Bay northward to Theriot (stations 102, TE03-20R, TE01-16R)

Datasets were obtained either from Web servers, in the case of the LDNR and LUMCON data, or from files supplied by the agency (USGS). There were few corrections that needed to be made to the datasets since the agencies collecting the data had already performed QA/QC checks before making the data available. The data obtained were in various formats and had to be converted to a standard file format for each station. The data from all stations were then merged, by hour, into a final dataset for analysis. The data were filtered by using a 25 -hour running mean to remove the tidal fluctuations. The salinity and water level patterns were analyzed further by using signal analysis techniques, specifically spectral density analysis to compute the variance spectrum. The variance spectrum partitions the variance in the observed data signal into a number of intervals, or frequency bands, with the quantity shown being the spectral density (Haan, 1977). 
The spectral density is the amount of variance per interval of frequency (Haan, 1977). The results are presented with frequency (cycles per hour) or period (hours) on the horizontal axis, and the spectral density is presented on the vertical axis.

Available information on the historical dredging activities of navigation canals within the selected study site was obtained from the USACE. These datasets and supporting attribute information (for example, river mile locations and center lines) were processed and digitized into a georectified vector layer. This information was combined with salinity data to perform an assessment to analyze the relationship between salinity changes and specific dredging events.

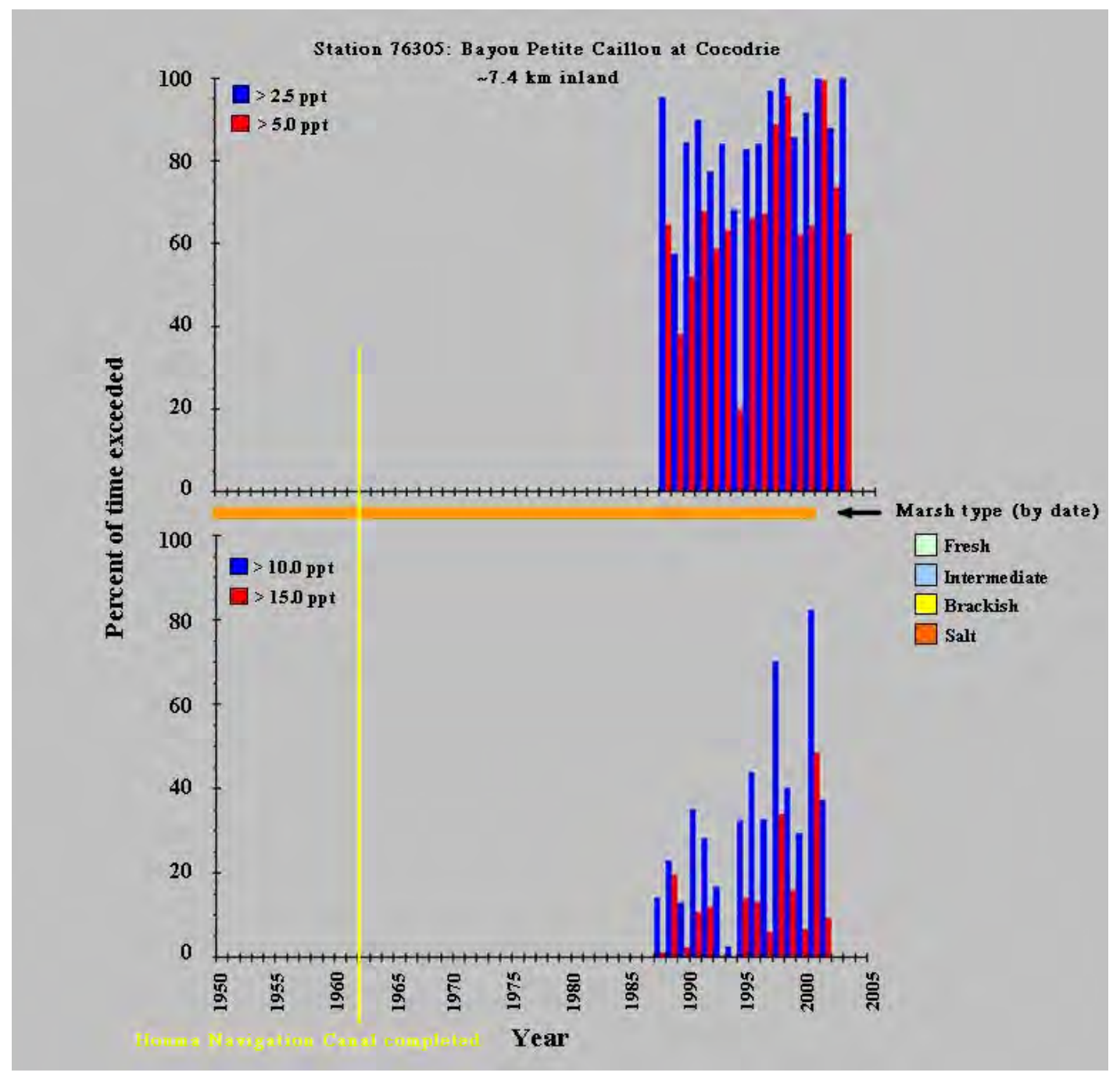

Figure 25. Plot of salinity level data for Bayou Petite Caillou at Cocodrie in coastal Louisiana (U.S. Army Corps of Engineers station 76305). The percent of time per year that salinity values exceeded the given threshold values is indicated. The distance inland (from Terrebonne Bay) is also indicated on the plot. The top panel indicates the percent of time that the salinity exceeded 2.5 parts per thousand (ppt) and $5.0 \mathrm{ppt}$, and the bottom panel indicates the percent of time that the salinity exceeded $10.0 \mathrm{ppt}$ and $15.0 \mathrm{ppt}$. The colored horizontal bar between the two panels indicates the marsh type in the vicinity of the station for a given time period. 


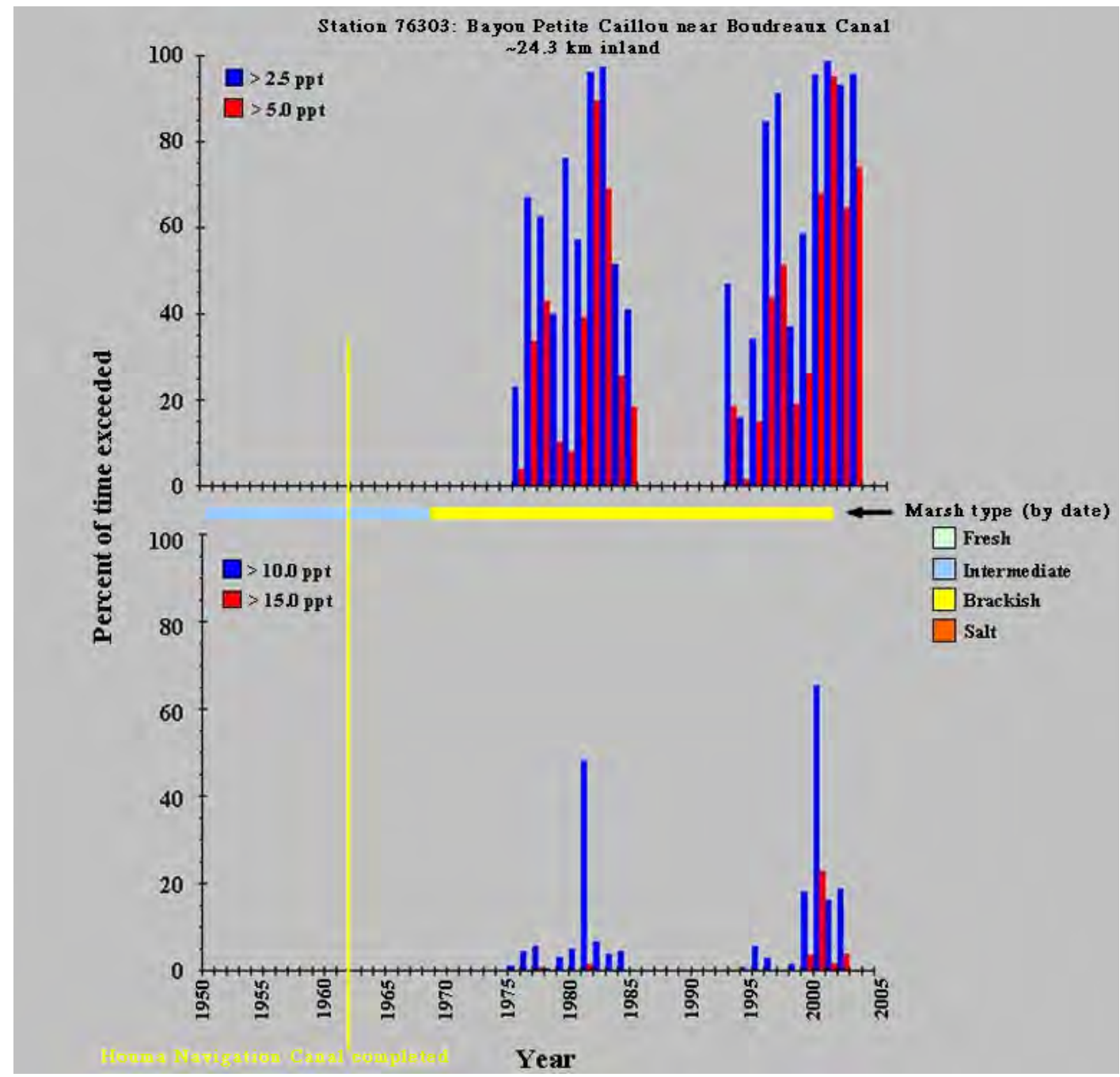

Figure 26. Plot of salinity level data for Bayou Petite Caillou near Boudreaux Canal in coastal Louisiana (U.S. Army Corps of Engineers station 76303). The percent of time per year that salinity values exceeded the given threshold values is indicated. The distance inland (from Terrebonne Bay) is also indicated on the plot. The top panel indicates the percent of time that the salinity exceeded 2.5 parts per thousand (ppt) and $5.0 \mathrm{ppt}$, and the bottom panel indicates the percent of time that the salinity exceeded $10.0 \mathrm{ppt}$ and 15.0 ppt. The colored horizontal bar between the two panels indicates the marsh type in the vicinity of the station for a given time period. 


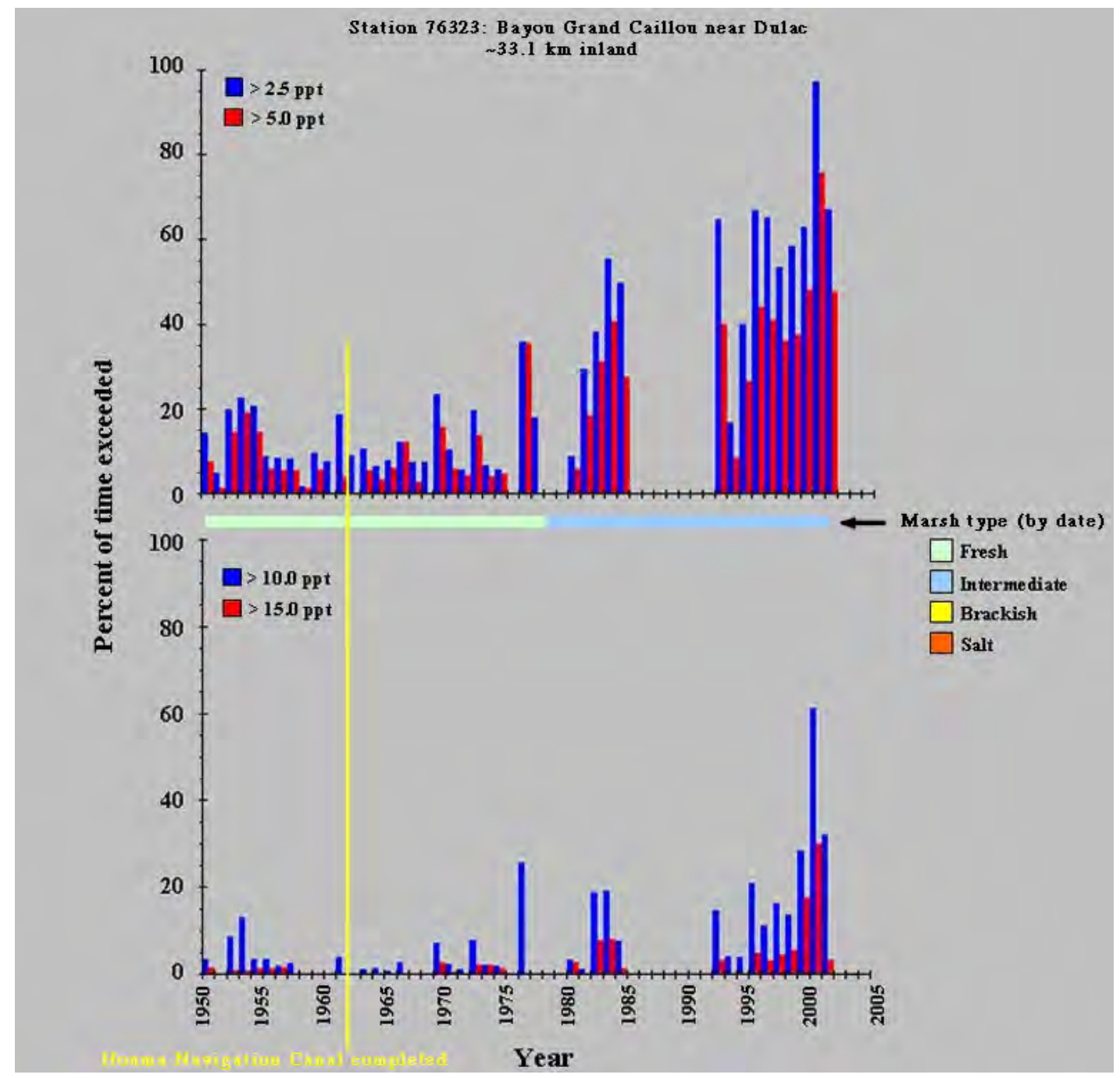

Figure 27. Plot of salinity level data for Bayou Grand Caillou near Dulac in coastal Louisiana (U.S. Army Corps of Engineers station 76323). The percent of time per year that salinity values exceeded the given threshold values is indicated. The distance inland (from Terrebonne Bay) is also indicated on the plot. The top panel indicates the percent of time that the salinity exceeded 2.5 parts per thousand (ppt) and $5.0 \mathrm{ppt}$, and the bottom panel indicates the percent of time that the salinity exceeded $10.0 \mathrm{ppt}$ and $15.0 \mathrm{ppt}$. The colored horizontal bar between the two panels indicates the marsh type in the vicinity of the station for a given time period. 


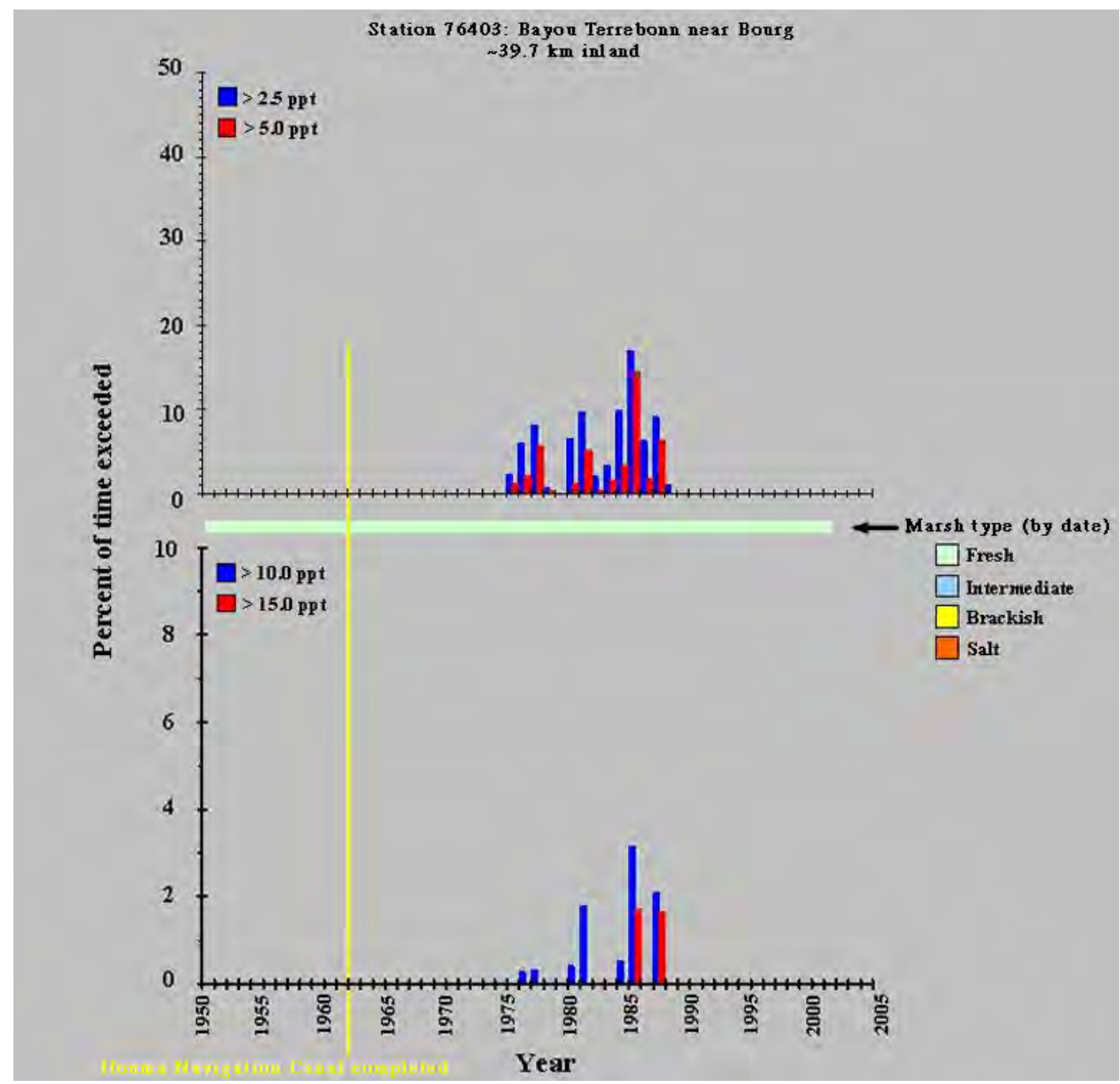

Figure 28. Plot of salinity level data for Bayou Terrebonne near Bourg in coastal Louisiana (U.S. Army Corps of Engineers station 76403). The percent of time per year that salinity values exceeded the given threshold values is indicated. The distance inland (from Terrebonne Bay) is also indicated on the plot. The top panel indicates the percent of time that the salinity exceeded 2.5 parts per thousand (ppt) and $5.0 \mathrm{ppt}$, and the bottom panel indicates the percent of time that the salinity exceeded $10.0 \mathrm{ppt}$ and $15.0 \mathrm{ppt}$. The colored horizontal bar between the two panels indicates the marsh type in the vicinity of the station for a given time period. 


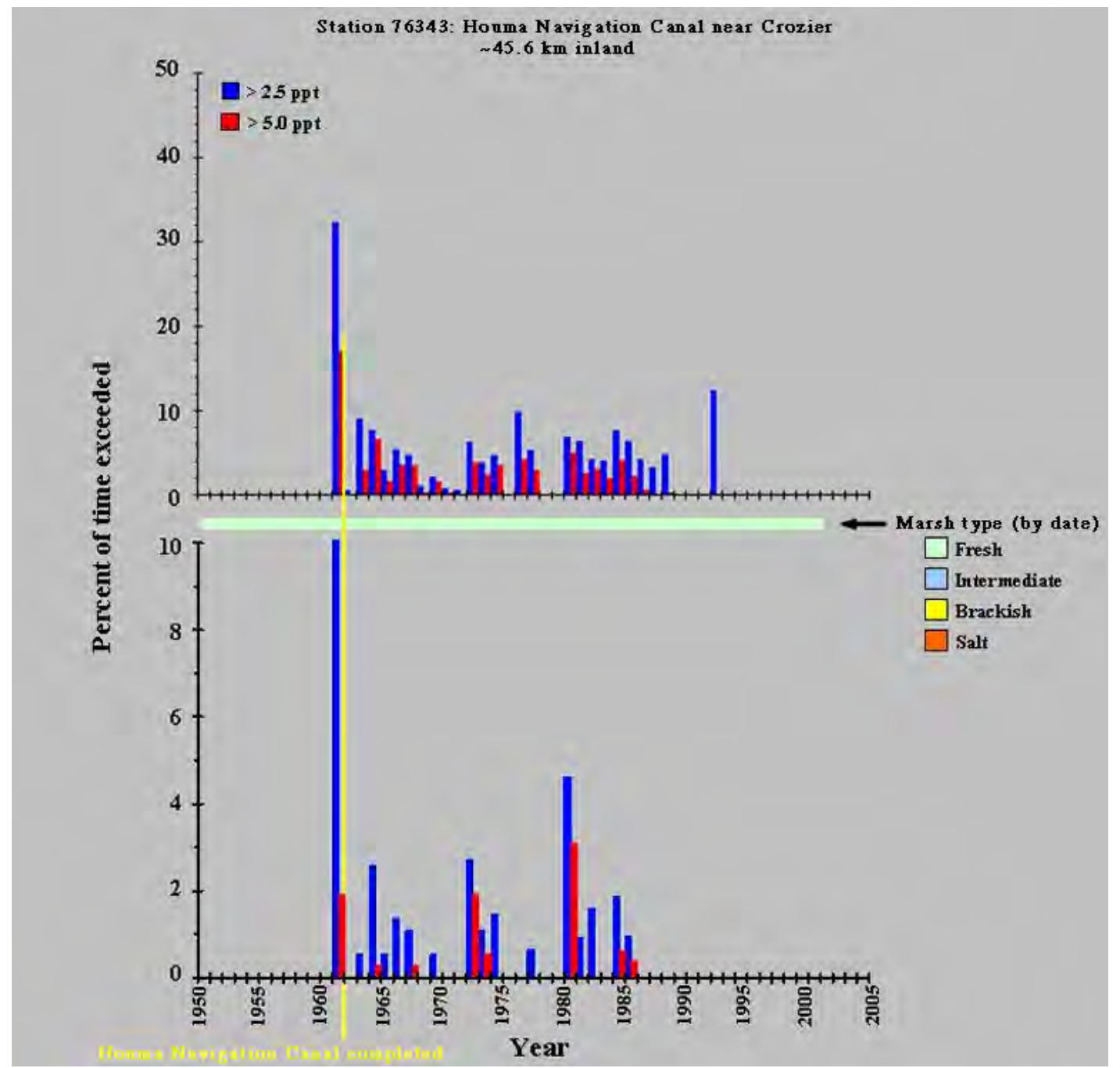

Figure 29. Plot of salinity level data for the Houma Navigation Canal near Crozier in coastal Louisiana (U.S. Army Corps of Engineers station 76343). The percent of time per year that salinity values exceeded the given threshold values is indicated. The distance inland (from Terrebonne Bay) is also indicated on the plot. The top panel indicates the percent of time that the salinity exceeded 2.5 parts per thousand (ppt) and $5.0 \mathrm{ppt}$, and the bottom panel indicates the percent of time that the salinity exceeded $10.0 \mathrm{ppt}$ and 15.0 ppt. The colored horizontal bar between the two panels indicates the marsh type in the vicinity of the station for a given time period. 


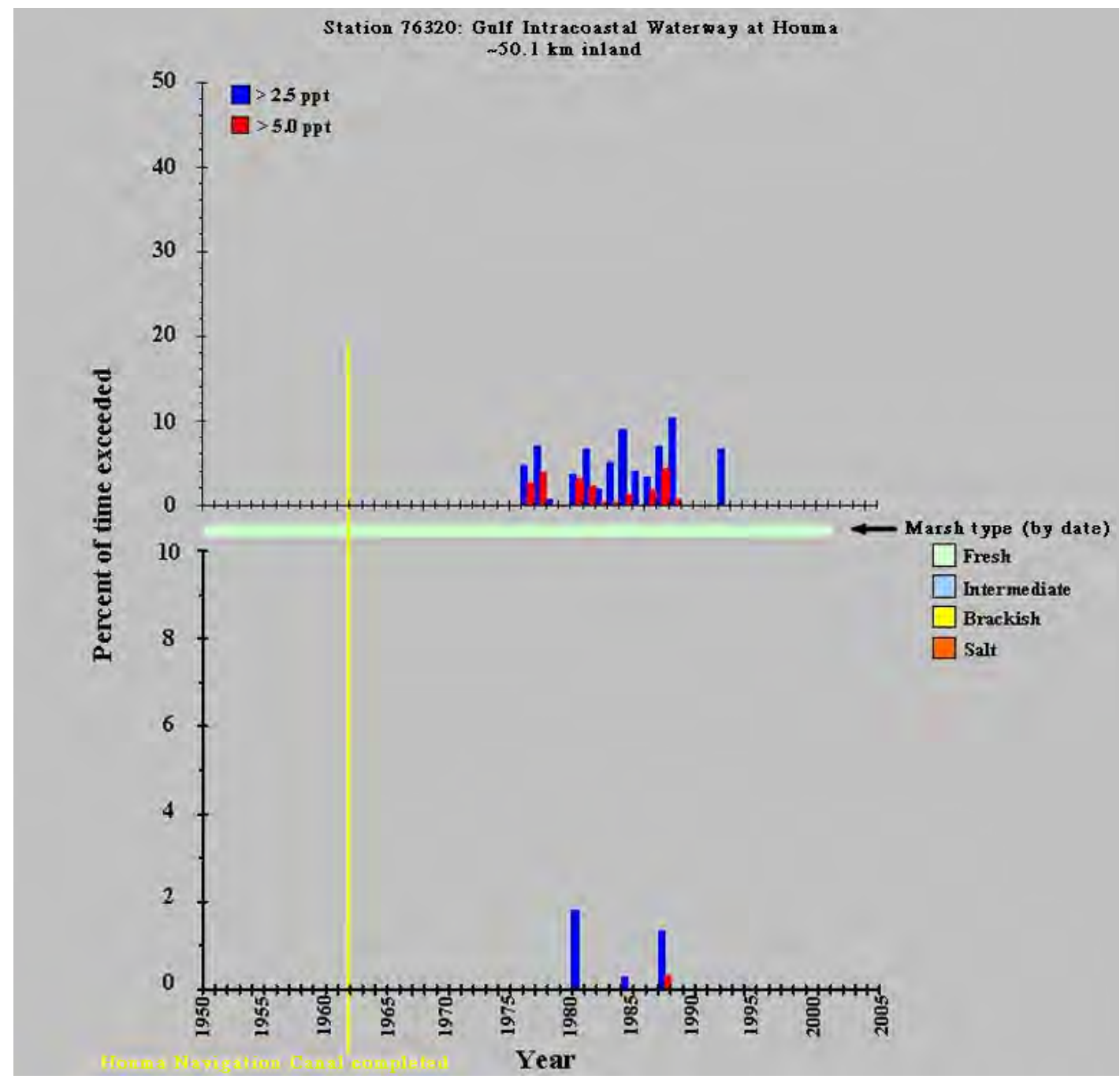

Figure 30. Plot of salinity level data for the Gulf Intracoastal Waterway at Houma in coastal Louisiana (U.S. Army Corps of Engineers station 76320). The percent of time per year that salinity values exceeded the given threshold values is indicated. The completion date for the Houma Navigation Canal is indicated by the vertical yellow line. The distance inland (from Terrebonne Bay) is also indicated on the plot. The top panel indicates the percent of time that the salinity exceeded $2.5 \mathrm{ppt}$ and $5.0 \mathrm{ppt}$, and the bottom panel indicates the percent of time that the salinity exceeded $10.0 \mathrm{ppt}$ and $15.0 \mathrm{ppt}$. The colored horizontal bar between the two panels indicates the marsh type in the vicinity of the station for a given time period. 


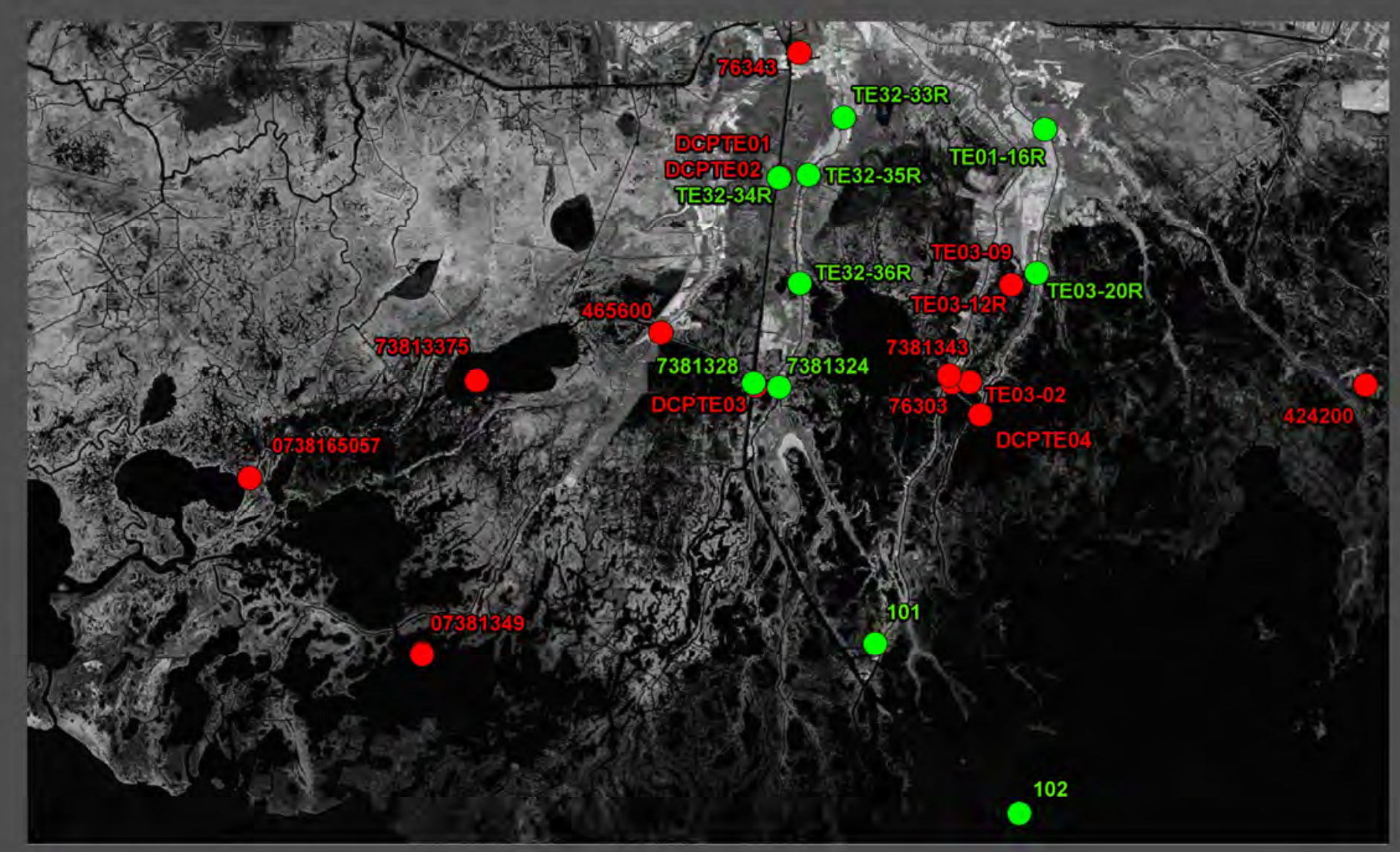

SALINITY STATIONS

Final analysis stations

Salinity stations
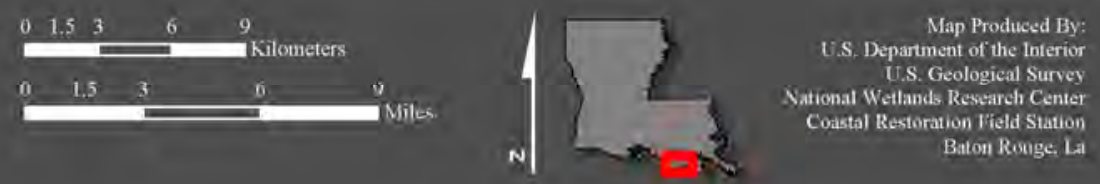

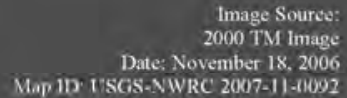
Batom Ronge: La

Figure 31. Stations used in salinity pulse analysis in coastal Louisiana. The green stations denote the stations that were used in the final analysis. 
Table 9. Data availability for salinity "spike" analysis in the Houma Navigation Canal area in coastal Louisiana, by month, for the year 2003.

[An X indicates that data were available at a station for the indicated month. Data types: L, water level; S, salinity; Q, discharge. LDNR, Louisiana Department of Natural Resources; LUMCON, Louisiana Universities Marine Consortium; USGS, U.S. Geological Survey]

\begin{tabular}{|c|c|c|c|c|c|c|c|c|c|c|c|c|c|c|}
\hline Agency & Station & Types & Jan. & Feb. & Mar. & Apr. & May & June & July & Aug. & Sept. & Oct. & Nov. & Dec. \\
\hline LDNR & TE01-16R & L, S & & $x$ & $x$ & $x$ & $x$ & $x$ & $x$ & $x$ & $x$ & $\mathrm{x}$ & $\mathrm{x}$ & $x$ \\
\hline LDNR & TE03-02 & L, S & $x$ & $x$ & $x$ & $x$ & $x$ & $x$ & $x$ & $x$ & $x$ & $x$ & $x$ & $x$ \\
\hline LDNR & TE03-09 & L, S & $\mathrm{x}$ & $x$ & $x$ & $x$ & $x$ & $x$ & $x$ & $x$ & $x$ & $x$ & $x$ & $x$ \\
\hline LDNR & TE03-20R & L, S & $x$ & $x$ & $x$ & $x$ & $x$ & $x$ & $x$ & $x$ & $\mathrm{X}$ & $x$ & $x$ & $x$ \\
\hline LDNR & TE32-33R & L, S & & & & & & & & $x$ & $\mathrm{x}$ & $x$ & & \\
\hline LDNR & TE32-34R & L, S & & & & & & & & $x$ & $\mathrm{x}$ & $x$ & & \\
\hline LDNR & TE32-35R & L, S & & & & & & & & $x$ & $\mathrm{x}$ & $x$ & & \\
\hline LDNR & TE32-36R & L, S & & & & & & & & $\mathrm{x}$ & $x$ & $x$ & & \\
\hline LDNR & DCP-TE03 & L, S & $x$ & $x$ & $\mathrm{x}$ & $x$ & $x$ & $x$ & $x$ & $x$ & $\mathrm{X}$ & $x$ & $x$ & $x$ \\
\hline LDNR & DCP-TE04 & L, S & & & & & & & & & & & & \\
\hline LUMCON & 101 & L, S & $\mathrm{x}$ & $x$ & $X$ & $x$ & $x$ & $\mathrm{X}$ & $x$ & $x$ & $x$ & $x$ & $x$ & $\mathrm{X}$ \\
\hline LUMCON & 102 & L, S & $\mathrm{x}$ & $x$ & $\mathrm{x}$ & $x$ & $x$ & $\mathrm{x}$ & $\mathrm{x}$ & $x$ & $\mathrm{x}$ & $x$ & $x$ & $x$ \\
\hline USGS & 07381324 & L, S, Q & $x$ & $x$ & $x$ & $x$ & $x$ & $x$ & $x$ & $x$ & $\mathrm{X}$ & $x$ & $x$ & $x$ \\
\hline USGS & 07381328 & L, S, Q & $\mathrm{x}$ & $x$ & $\mathrm{x}$ & $x$ & $x$ & $x$ & $\mathrm{x}$ & $x$ & $x$ & $x$ & $x$ & $x$ \\
\hline USGS & 07381343 & L, S & $X$ & $\mathrm{X}$ & $\mathrm{X}$ & $x$ & $x$ & $x$ & $\mathrm{x}$ & $\mathrm{X}$ & $\mathrm{x}$ & $x$ & $x$ & $\mathrm{x}$ \\
\hline USGS & 07381349 & L, S & $x$ & $x$ & $x$ & $x$ & $x$ & $x$ & $x$ & $x$ & $x$ & $x$ & $x$ & $x$ \\
\hline USGS & 073813375 & L, S & $x$ & $x$ & $\mathrm{x}$ & $x$ & $\mathrm{x}$ & $x$ & $\mathrm{x}$ & $x$ & $\mathrm{x}$ & $\mathrm{x}$ & $x$ & $x$ \\
\hline USGS & 0738165057 & L, S & $x$ & $x$ & $x$ & $x$ & $x$ & $x$ & $\mathrm{x}$ & $x$ & $\mathrm{x}$ & $x$ & $x$ & $x$ \\
\hline USGS & 424200 & L, S, Q & $x$ & $x$ & $x$ & $x$ & $x$ & $x$ & $\mathrm{x}$ & $x$ & $x$ & $x$ & $x$ & $x$ \\
\hline USGS & 465600 & L, S, Q & $x$ & $x$ & $\mathrm{x}$ & $x$ & $x$ & $x$ & $\mathrm{x}$ & $x$ & $x$ & $x$ & $x$ & $x$ \\
\hline
\end{tabular}

Time series plots of data from the Terrebonne transect, the Bayou Grand Caillou transect, and the Houma Navigation Canal (HNC) transect are shown in figures 33, 34, and 35, respectively. Water level data from Bayou Terrebonne transect, the Bayou Grand Caillou transect, and the HNC transect are shown in figures 36,37 , and 38 , respectively. The plots present the hourly and the 25hour filtered data. The water level patterns are typical for the Louisiana coastal marshes, with a tidal signal superimposed on other larger scale events (Byrne and others, 1976; Adams and Baumann, 1980; Chuang and Swenson, 1981; Swenson and Turner 1987; Sasser and others, 1994). The salinity pattern is very similar to the water level patterns, although the tidal fluctuations are not as strong. Several salinity events (spikes) can be seen in the data plots.

Spectral density estimates for salinity and water level for Terrebonne Bay and the northernmost stations from each transect are shown in figures 39 and 40, respectively. The diurnal tidal signal (approximately 25 hours) is quite strong for the water levels at all stations but is only noticeable in the salinity at the Terrebonne Bay station.

Correlations between filtered salinity and water level in Terrebonne Bay and filtered salinity and water level at each of the transect stations are presented in table 10. Water levels have a fairly high correlation ( $>0.7$ at 7 of 10 stations), indicating that the water level patterns in this area are mostly driven by the coastal water levels. The salinity levels show much lower correlations ( $<0.5$ at 7 of 10 stations), indicating that the salinity of the Terrebonne Bay waters is not the entire driving force for the more interior locations. Although high coastal water levels result 
in high water levels throughout the system, high salinity at the coast does not always result in high salinity at the inland stations. Figure 41 presents the filtered discharge data from Bayou Grand Caillou and the HNC. It can be seen that time periods characterized by flow reversals, or inflow events, tend to correspond with higher salinity events. Swarzenski (2003) pointed out that, during tropical storm events when normal hydraulic gradients are reversed, saline waters move inland into the Gulf Intracoastal Waterway (GIWW) along north-south trending ship channels, such as the HNC. Although the GIWW normally moves fresh water into and towards the coast, under these conditions it also can serve as a conduit for saltwater movement, resulting in pulses of saline water moving laterally via the GIWW into areas which contain marsh plants with a low tolerance for salt (Swarzenski, 2003).

The characteristics of the salinity pulses that occurred during the time period of August 2003 through September 2003 were summarized for each transect (figs. 8 and 32), and the means were compared using Duncan's Multiple Range test (SAS, 1990c). The pulse magnitude (fig. 42) ranged from values of about $2.0 \mathrm{ppt}$ to about $14 \mathrm{ppt}$ depending on station location. The salinity at the southern station in the HNC (26.2 km from Terrebonne Bay) was $13.3 \mathrm{ppt}$, and the salinity at the southern station in Bayou Grand Caillou (24.7 km from Terrebonne Bay) was $10.3 \mathrm{ppt}$; these values are not statistically different. The mean salinity at the middle station in Bayou Terrebonne (21.2 km from Terrebonne Bay) was $6.1 \mathrm{ppt}$, which is significantly different. The mean salinity at the middle station in the HNC (41.5 km from Terrebonne Bay) was $5.5 \mathrm{ppt}$, which is significantly higher than the salinity of $1.8 \mathrm{ppt}$ at the middle station in Bayou Grand Caillou (42.3 km from Terrebonne Bay). The mean salinity at Bayou Terrebonne north (31.8 km from Terrebonne Bay) station was $3.3 \mathrm{ppt}$, which is not significantly different from either the middle HNC station or the middle Bayou Grand Caillou station. This similarity in mean salinity levels at Bayou Terrebonne north and the middle HNC station or the middle Bayou Grand Caillou station is most likely because of the closeness of the Bayou Terrebonne north station (about $10 \mathrm{~km}$ closer) to Terrebonne Bay.

The coast-inland decrease in salinity, calculated as parts per thousand per kilometer, is presented in figure 43. The decreases at all stations in Bayou Grand Caillou and the north station in the Bayou Terrebonne transect were about $0.6 \mathrm{ppt} \mathrm{km}^{-1}$ and are not statistically different from each other or from the Houma Navigation Canal transect. The middle station on the Bayou Terrebonne transect exhibited the largest decrease, about $0.8 \mathrm{ppt} \mathrm{km}^{-1}$, which is statistically significant compared to all the other stations. The HNC stations exhibited the smallest decreases, about $0.4 \mathrm{ppt} \mathrm{km}$, and are significantly different from all of the other stations.

The duration, in days, of each pulse was also calculated. The results are presented in figure 44. The data indicate that the shortest salinity pulse duration, about 1.5 days, occurred in the middle and north stations in Bayou Grand Caillou. These two stations are statistically different from all of the other stations. The longest salinity pulse duration, about 5 days, which is statistically different from that of all the other stations, occurred at the middle station in Bayou Terrebonne. The shortest pulse durations, about 1.5 days, which are statistically different from all of the other stations, occurred in the Houma Navigation Canal. The remainder of the stations are statistically all the same, with a duration of 3-4 days.

The southern stations (Houma Navigation Canal at Falgout Canal [station 07381328] and Bayou Grand Caillou at Dulac [station 07381324]) on the HNC and Bayou Grand Caillou salinity transects (figs. 8 and 32) had data for the entire year of 2003. Their salinity pulse characteristics were compared by using a paired t-test (SAS, 1990c). The results indicated salinity pulse magnitudes of $10.5 \mathrm{ppt}$ for the Houma Navigation Canal at Falgout Canal station and $11.0 \mathrm{ppt}$ for the Bayou Grand Caillou at Dulac station. These values are not statistically different. Analysis of the salinity pulse duration indicated a duration of 4.8 days at the HNC station, which is statistically different from the value of 7.3 days at the Bayou Grand Caillou station. This difference indicates 
that the higher salinity waters associated with the pulses tend to remain longer in the Bayou Grand Caillou system. The longer duration of higher salinity in the Bayou Grand Caillou system may be a reflection of the flushing that also can occur in the HNC, which also is directly connected to the Gulf Intracoastal Waterway, which can serve as a conduit of fresh water (Swarzenski, 2003).

The salinity pulse data were compared with discharge data for the HNC to investigate the influence of freshwater head on the observed pulses. The relationship between discharge and the magnitude of the salinity pulses is presented in figure 45 . Regression analysis indicates that discharge explains almost 50 percent of the observed salinity pulses in the HNC. This result supports the study of saltwater intrusion in the Houma Navigation Canal area by Wang (1988), who stated that the freshwater head was one of the major driving forces influencing the intrusion of salt water in the channels. 


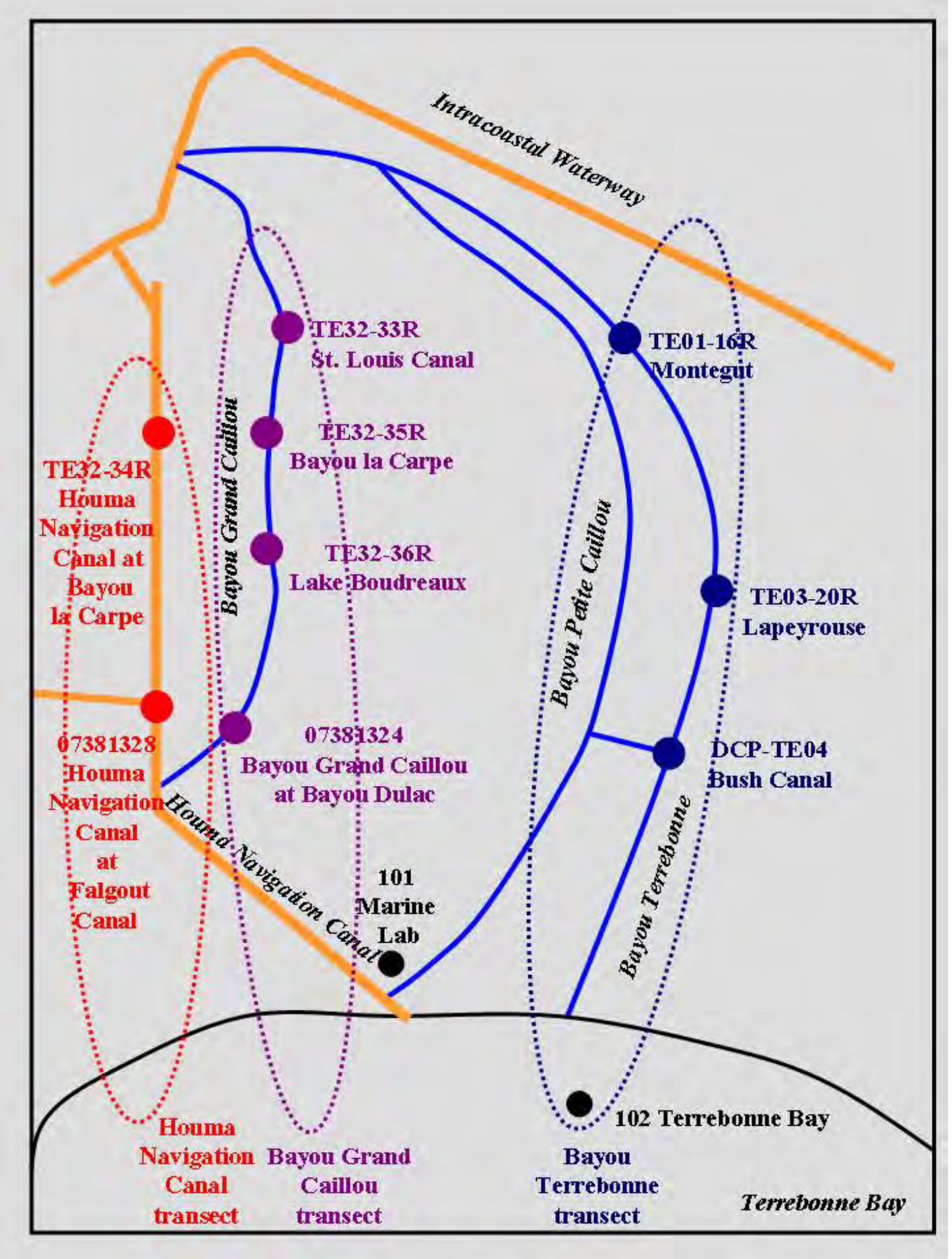

Figure 32. Schematic of the three coast-inland transects in the Houma Navigation Canal area in Louisiana. The station numbers are indicated next to each station. Eight-digit numbers indicate U.S. Geological Survey (USGS) stations, three-digit numbers indicate Louisiana Universities Marine Consortium (LUMCON) stations, and the numbers starting with TE (Terrebonne) indicate Louisiana Department of Natural Resources stations. 

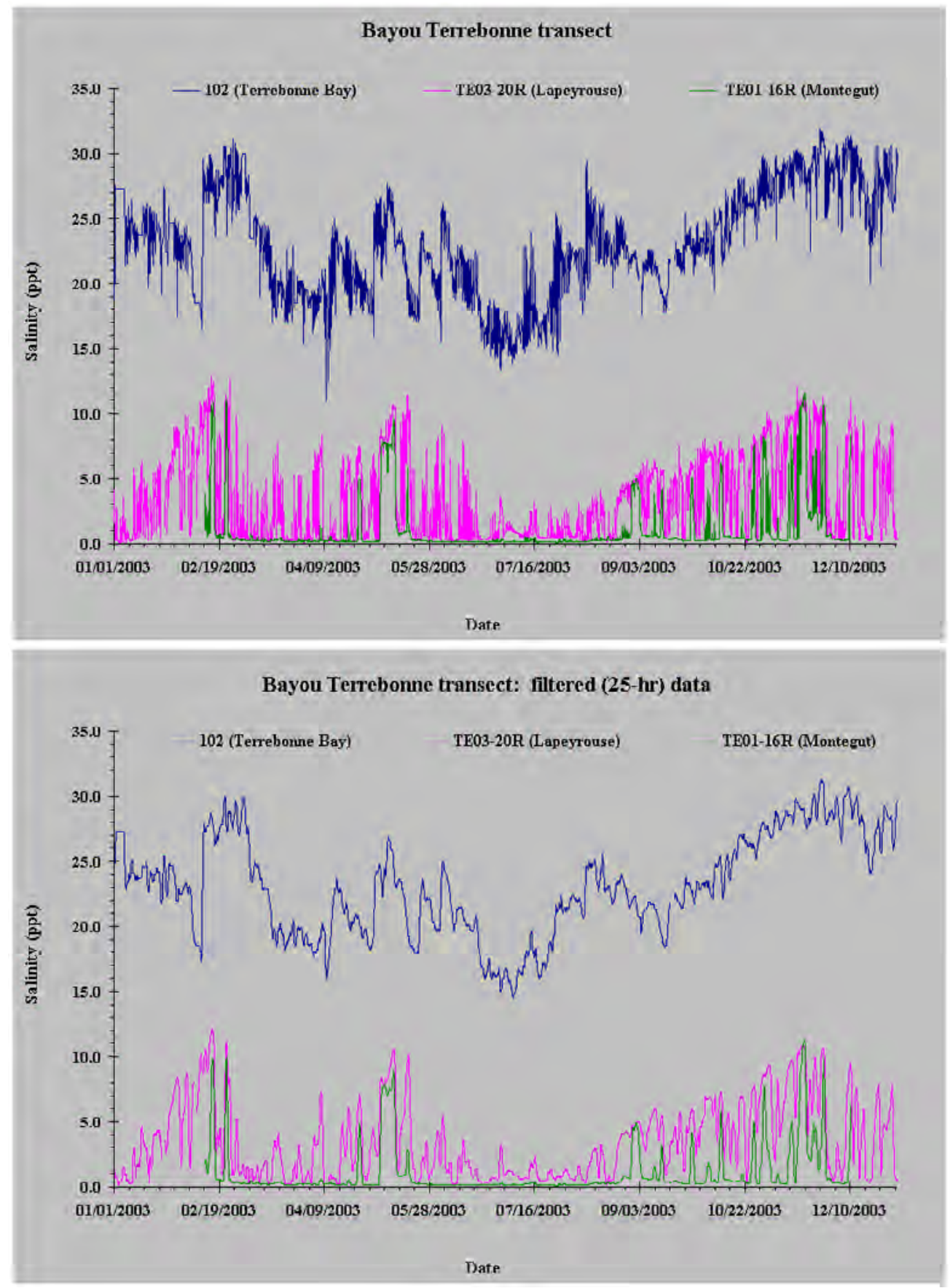

Figure 33. Time series plot of hourly salinity and 25-hour filtered salinity from the Bayou Terrebonne transect in coastal Louisiana. Station locations are shown in figure 31. 

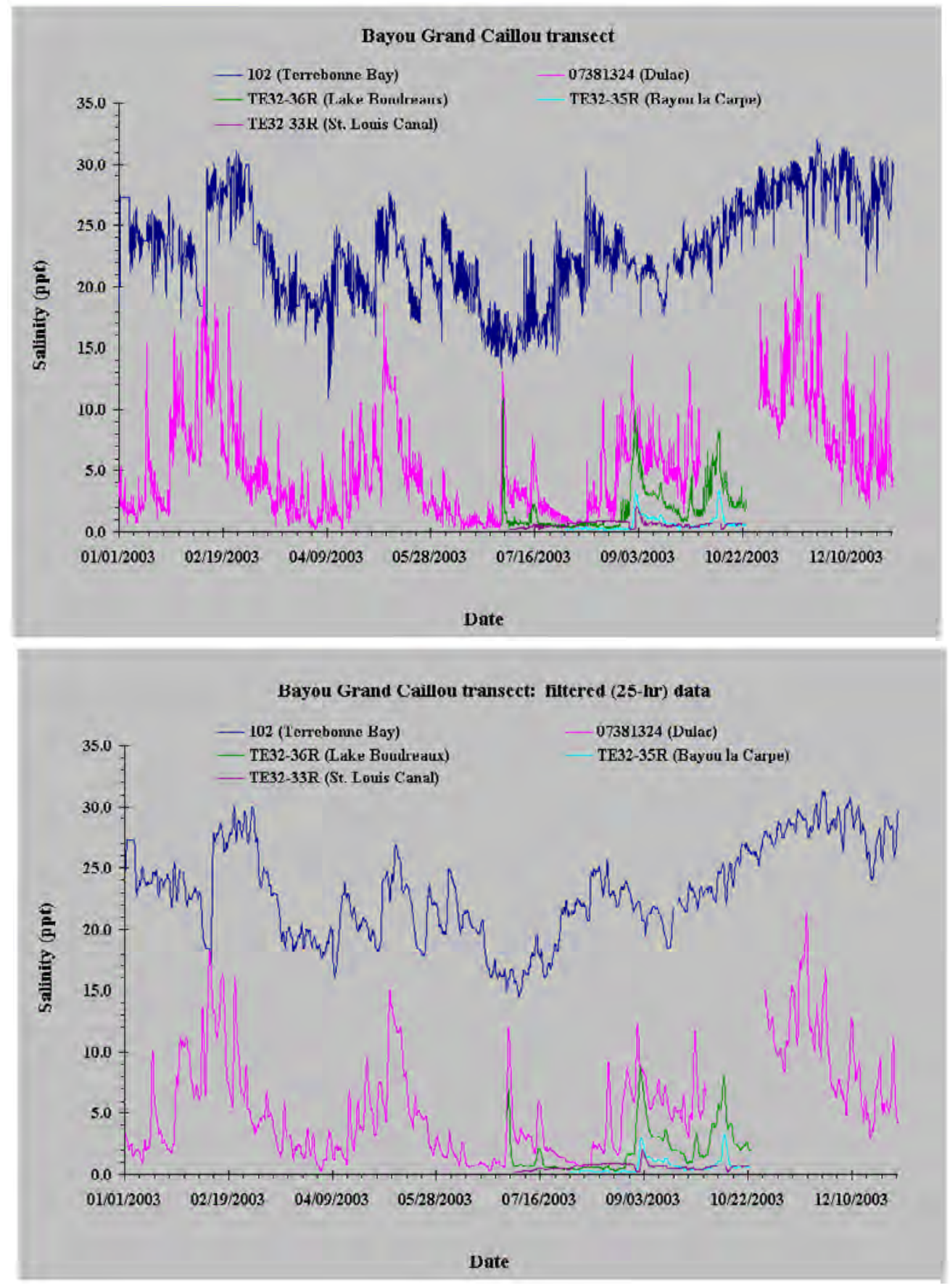

Figure 34. Time series plot of hourly salinity and 25-hour filtered salinity from the Bayou Grand Caillou transect in coastal Louisiana. Station locations are shown in figure 31. 

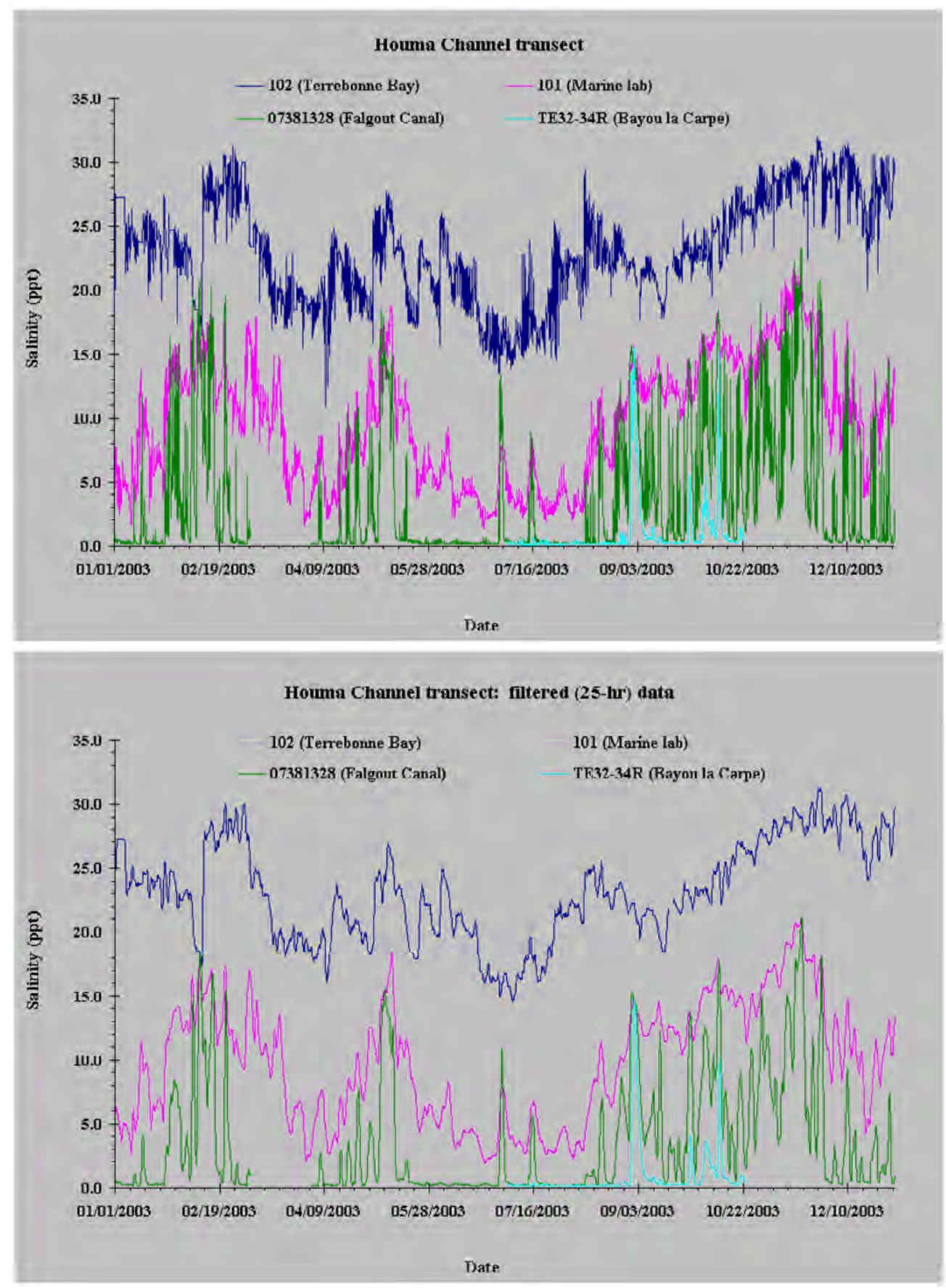

Figure 35. Time series plot of hourly salinity and 25-hour filtered salinity from the Houma Navigation Canal transect in coastal Louisiana. Station locations are shown in figure 31. 

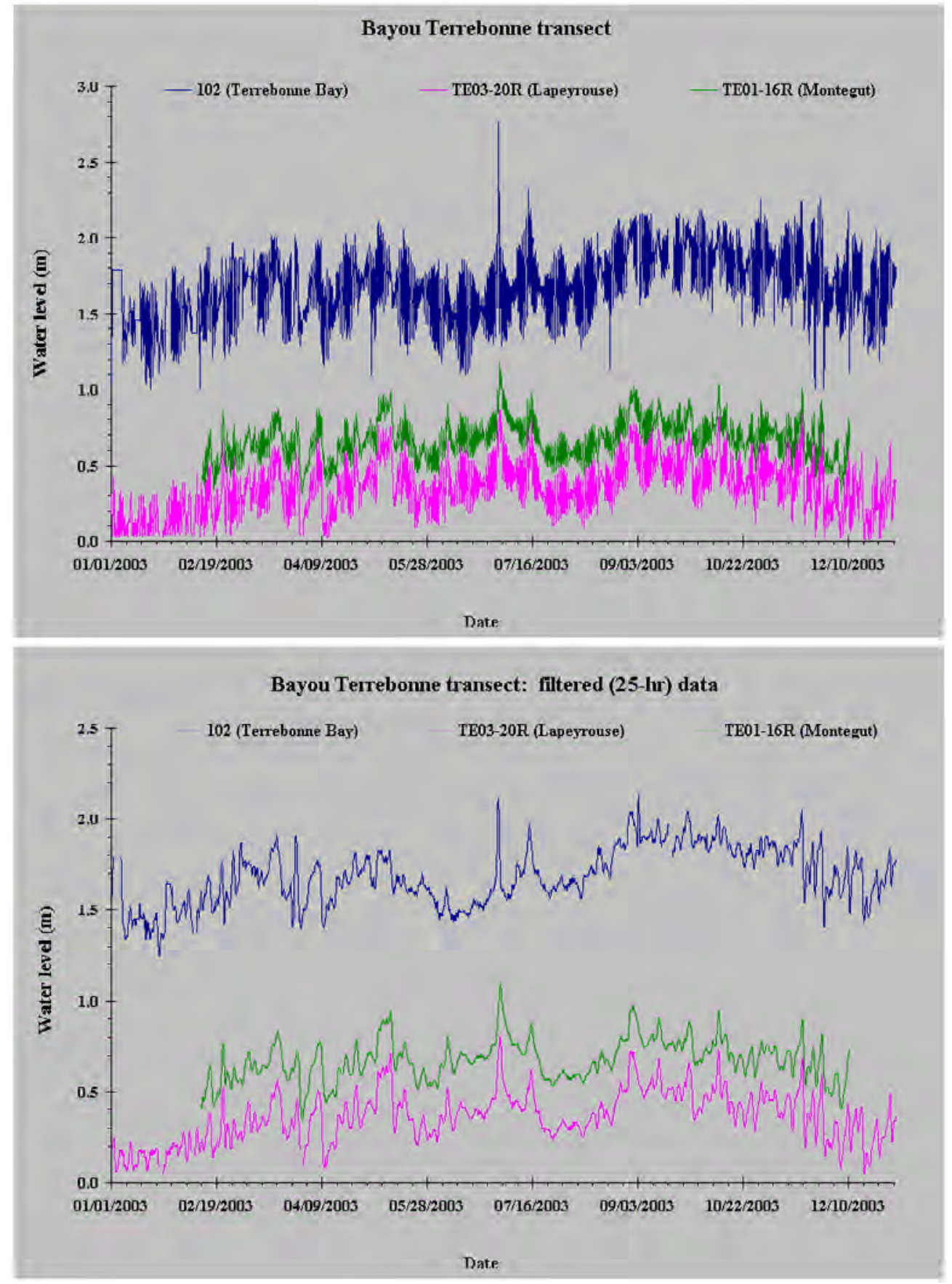

Figure 36. Time series plot of hourly water level and 25-hour filtered water level from the Bayou Terrebonne transect in coastal Louisiana. Station locations are shown in figure 31. 

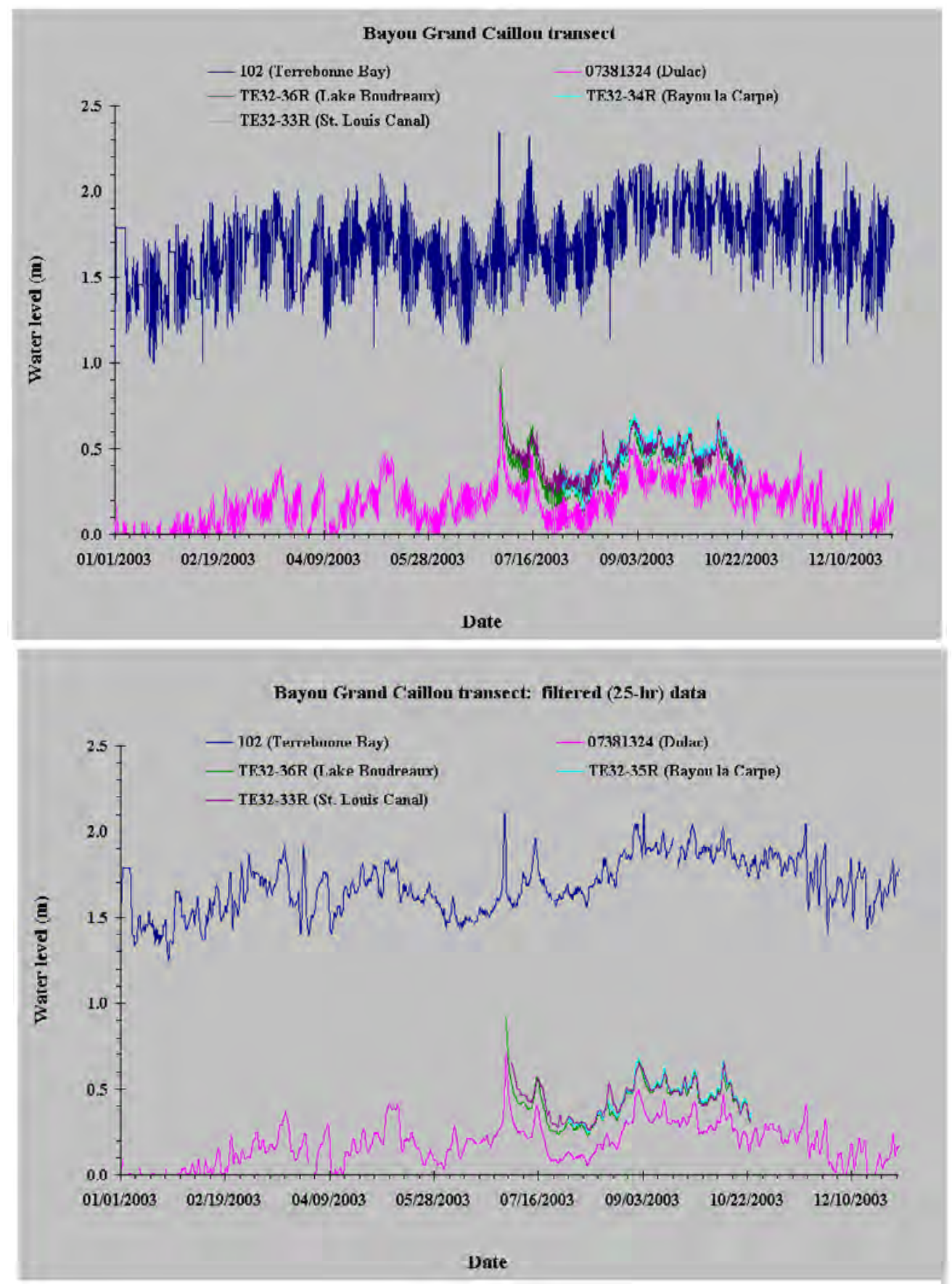

Figure 37. Time series plot of hourly water level and 25-hour filtered water level from the Bayou Grand Caillou transect in coastal Louisiana. Station locations are shown in figure 31. 

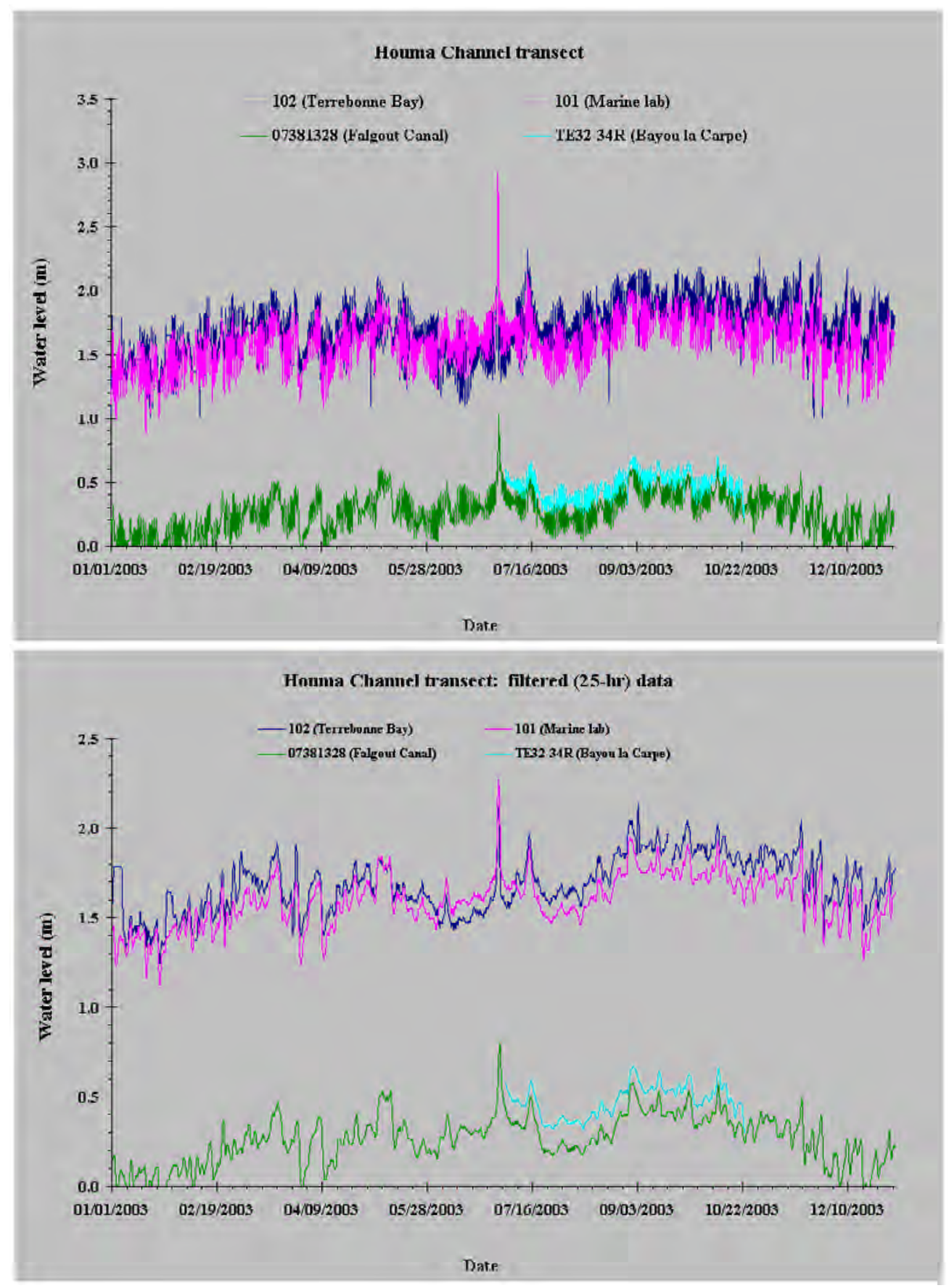

Figure 38. Time series plot of hourly water level and 25-hour filtered water level from the Houma Navigation Canal transect in coastal Louisiana. Station locations are shown in figure 31 . 


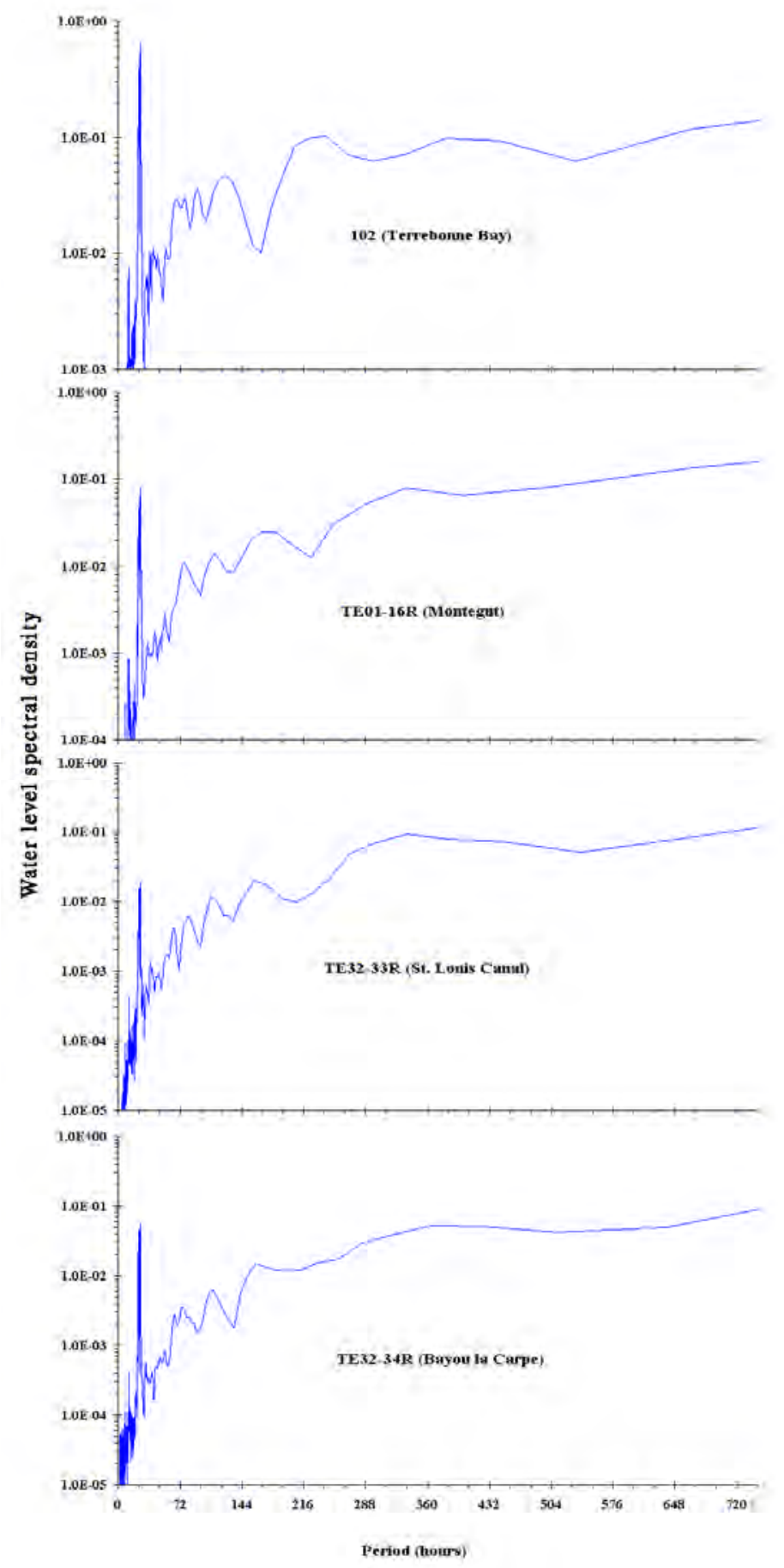

Figure 39. Examples of spectral density estimates for water level in Terrebonne Bay (102), Montegut (TE01-16R), the northern portion of Bayou Grand Caillou (TE32-33R), and the northern portion of the Houma Navigation Canal (TE32-34R). Station locations are indicated in figure 31. 


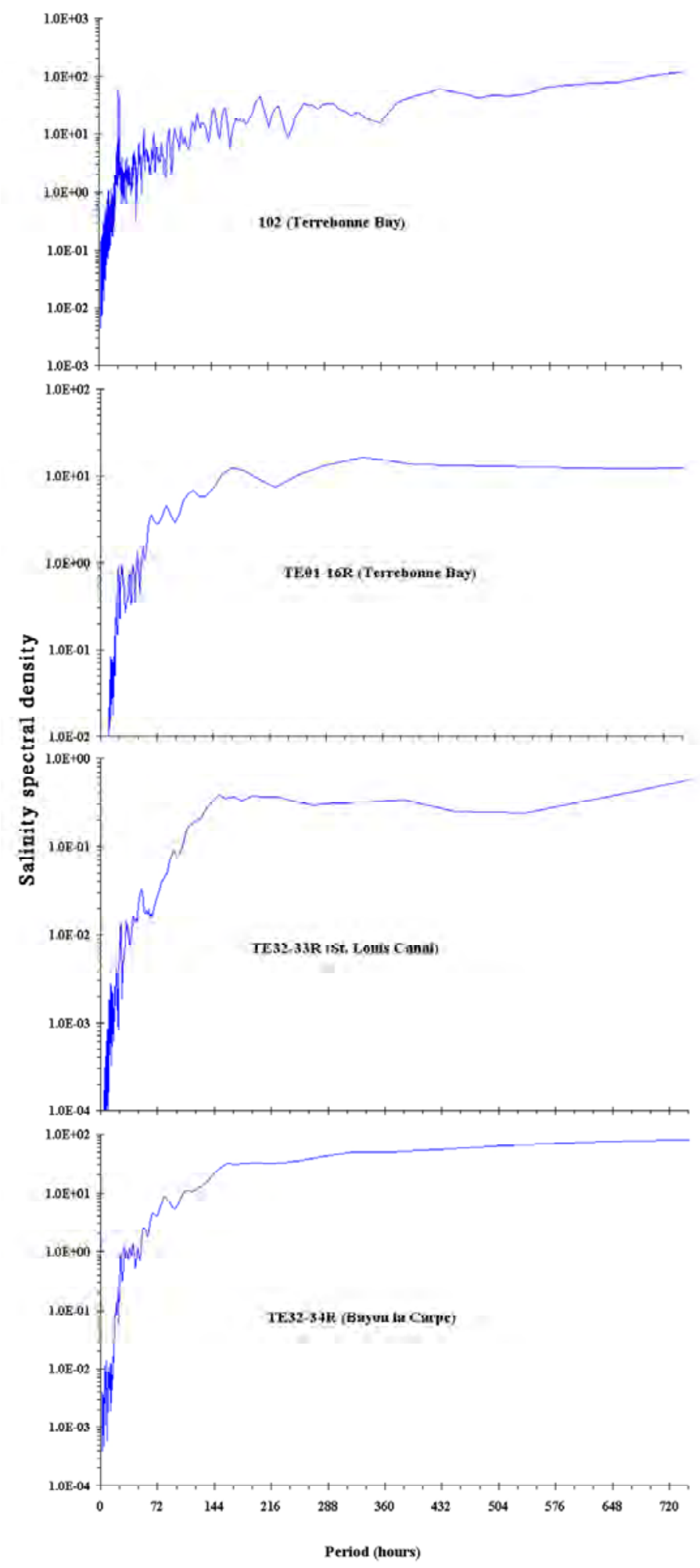

Figure 40. Examples of spectral density estimates for salinity in Terrebonne Bay (102), Montegut (TE01-16R), the northern portion of Bayou Grand Caillou (TE32-33R), and the northern portion of the Houma Navigation Canal (TE32-34R). Station locations are indicated in figure 31. 
Table 10. Correlation between filtered (25-hour mean) salinity and water level in Terrebonne Bay (station 102) and filtered (25-hour mean) water level and salinity in the Bayou Terrebonne, Bayou Grand Caillou, and Houma Navigation Canal coastal-inland transects in coastal Louisiana. Indicated are the Pearson correlation coefficients. Station locations are indicated in figure 31. $[<$, less than $]$

\begin{tabular}{|c|c|c|c|c|c|}
\hline \multirow{2}{*}{ Transect } & \multirow[b]{2}{*}{ Station } & \multicolumn{2}{|c|}{ Salinity } & \multicolumn{2}{|c|}{ Water level } \\
\hline & & $\begin{array}{c}\text { Correlation } \\
\text { coefficient }\end{array}$ & Probability & $\begin{array}{c}\text { Correlation } \\
\text { coefficient }\end{array}$ & Probability \\
\hline Bayou Terrebonne & TE03-20R & 0.388 & $<0.0001$ & 0.704 & $<0.0001$ \\
\hline Bayou Terrebonne & TE01-16T & 0.403 & $<0.0001$ & 0.592 & $<0.0001$ \\
\hline $\begin{array}{r}\text { Bayou Grand } \\
\text { Caillou } \\
\text { Bayou Grand }\end{array}$ & 101 & 0.562 & $<0.0001$ & 0.75 & $<0.0001$ \\
\hline $\begin{array}{r}\text { Caillou } \\
\text { Bayou Grand }\end{array}$ & 7381324 & 0.439 & $<0.0001$ & 0.738 & $<0.0001$ \\
\hline $\begin{array}{r}\text { Caillou } \\
\text { Bayou Grand }\end{array}$ & TE32-36R & 0.227 & $<0.0001$ & 0.685 & $<0.0000$ \\
\hline $\begin{array}{r}\text { Caillou } \\
\text { Bayou Grand }\end{array}$ & TE32-35R & -0.141 & $<0.0001$ & 0.891 & $<0.0001$ \\
\hline $\begin{array}{l}\text { Caillou } \\
\text { Houma Navigation }\end{array}$ & TE32-33R & 0.523 & $<0.0001$ & 0.705 & $<0.0001$ \\
\hline $\begin{array}{r}\text { Canal } \\
\text { Houma Navigation }\end{array}$ & 7381328 & 0.238 & $<0.0001$ & 0.72 & $<0.0001$ \\
\hline Canal & TE32-34R & 0.124 & $<0.0001$ & 0.822 & $<0.0001$ \\
\hline
\end{tabular}



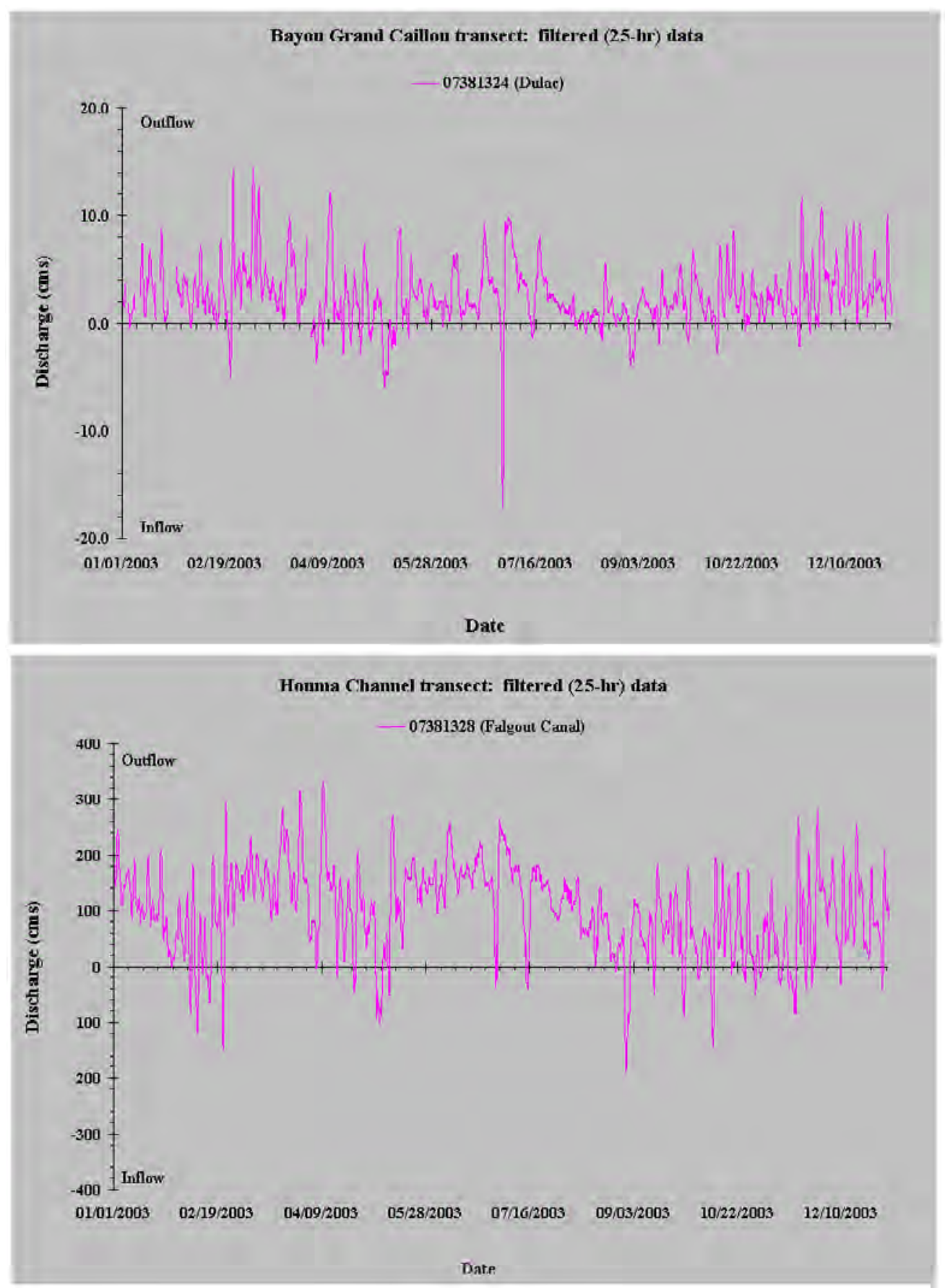

Figure 41. Time series plot of filtered (25-hour running mean) discharge in Bayou Grand Caillou and the Houma Navigation Canal in coastal Louisiana. Positive values indicate downstream flow. Station locations are indicated in figure 31. 


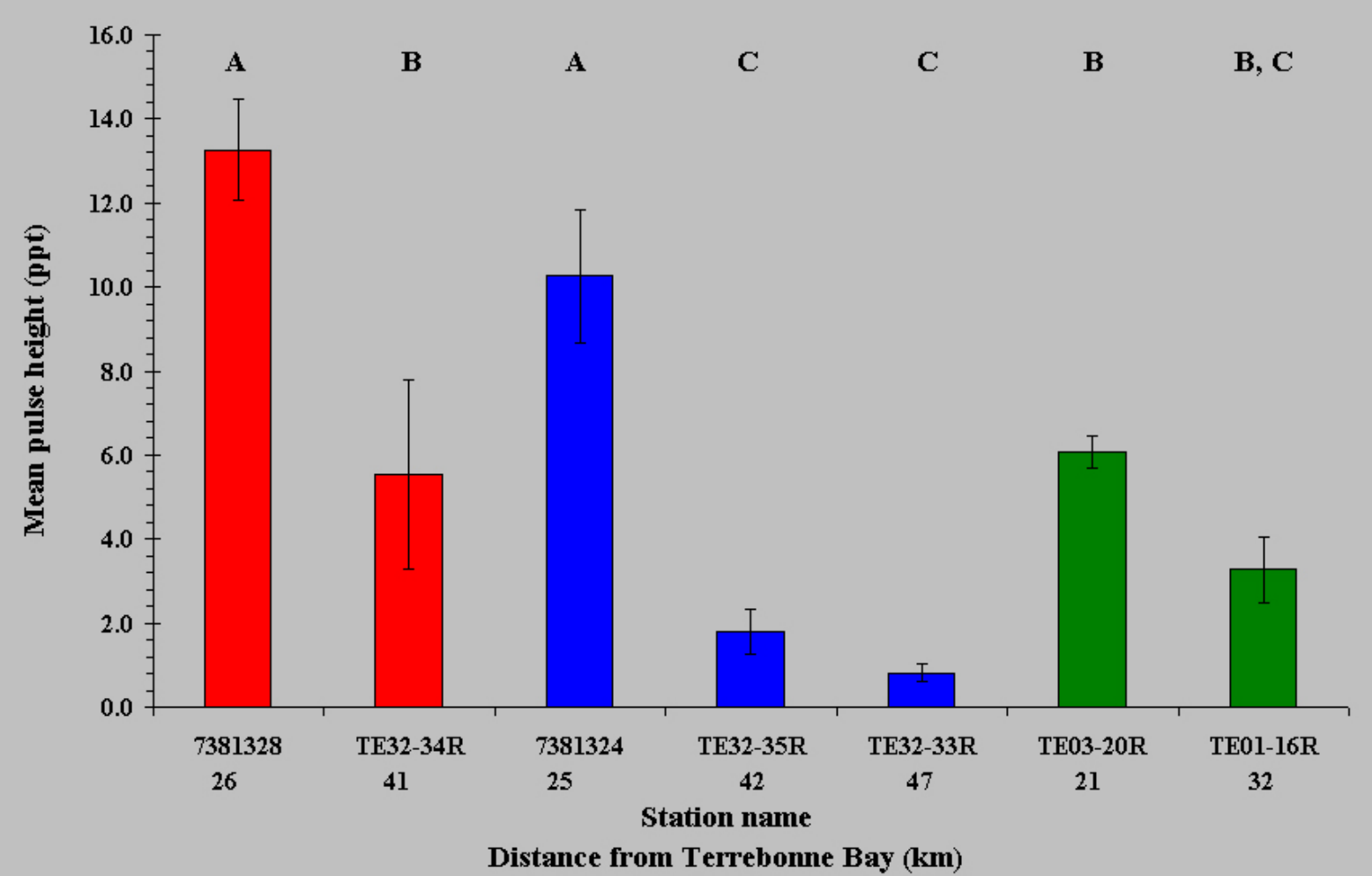

Houma Navigation Canal transect

Bayou Grand Caillou transect

Bayou Terrebonne transect

Figure 42. Mean salinity pulse magnitude, in parts per thousand (ppt), for stations in the Houma Navigation Canal area in coastal Louisiana for August through September 2003. The station name and distance from Terrebonne Bay (in kilometers) are indicated. Bars with the same letter above them are not significantly different, as determined by using Duncan's multiple range test. Station locations are indicated in figure 31 . 


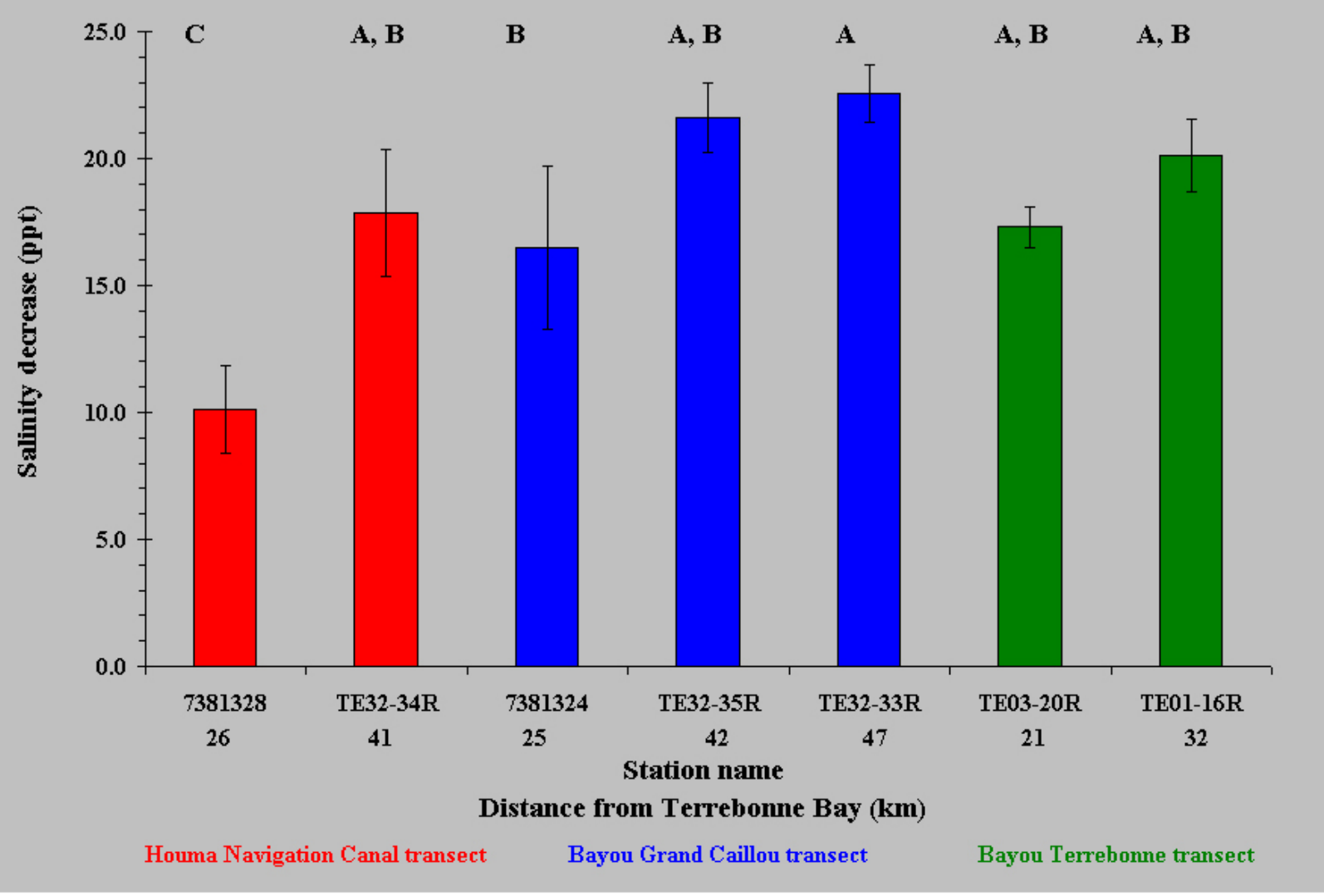

Figure 43. Mean salinity pulse coast-inland decrease, in parts per thousand per kilometer $(\mathrm{ppt} / \mathrm{km})$, for stations in the Houma Navigation Canal area in coastal Louisiana for August through September 2003. The station name and distance from Terrebonne Bay (in kilometers) are indicated. Bars with the same letter above them are not significantly different, as determined by using Duncan's multiple range test. Station locations are indicated in figure 31. 


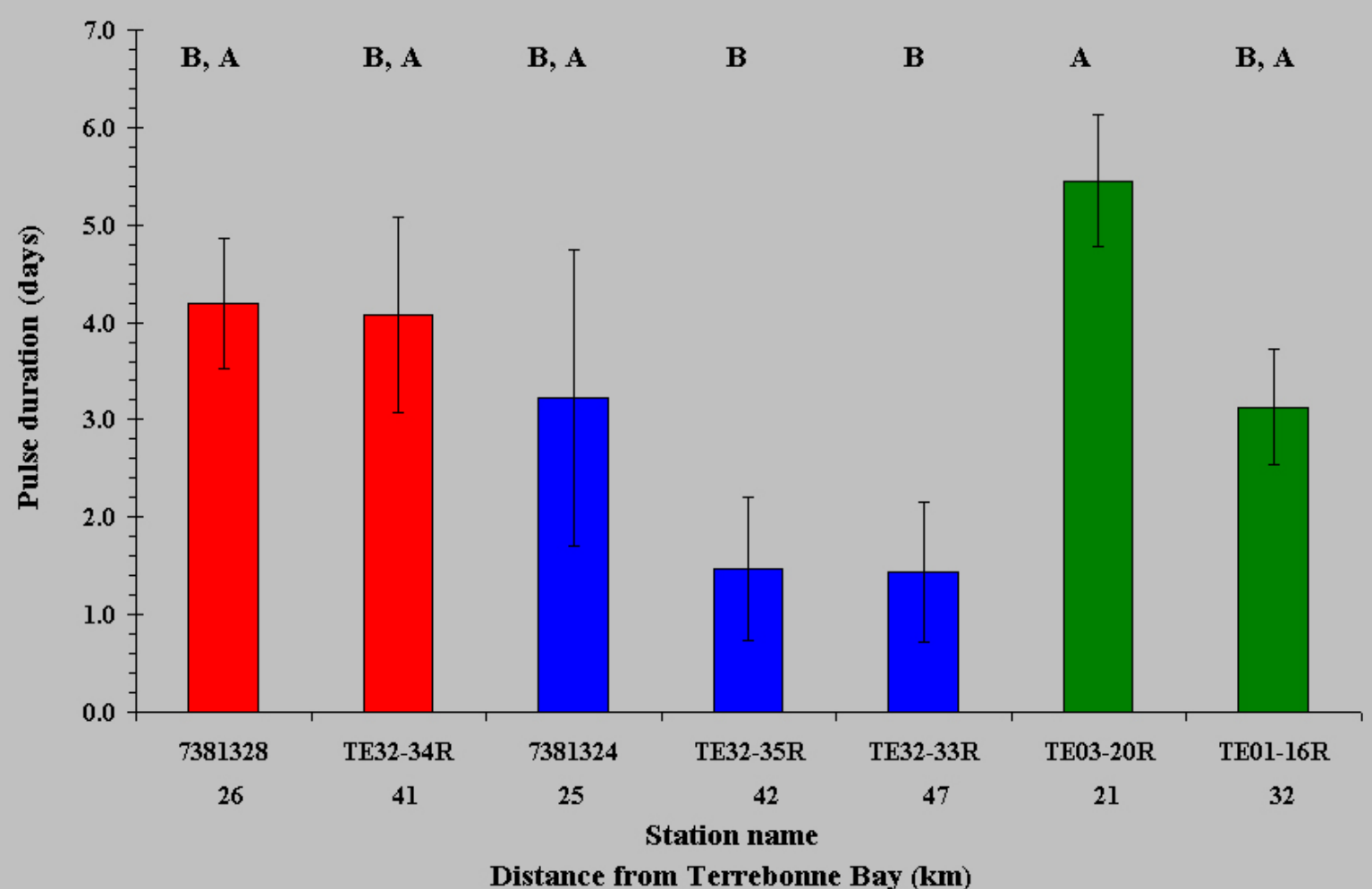

Figure 44. Mean salinity pulse duration, in days, for stations in the Houma Navigation Canal area in coastal Louisiana for August through September 2003. The station name and distance from Terrebonne Bay (in kilometers) are indicated. Bars with the same letter above them are not significantly different, as determined by using Duncan's multiple range test. Station locations are indicated in figure 31. 


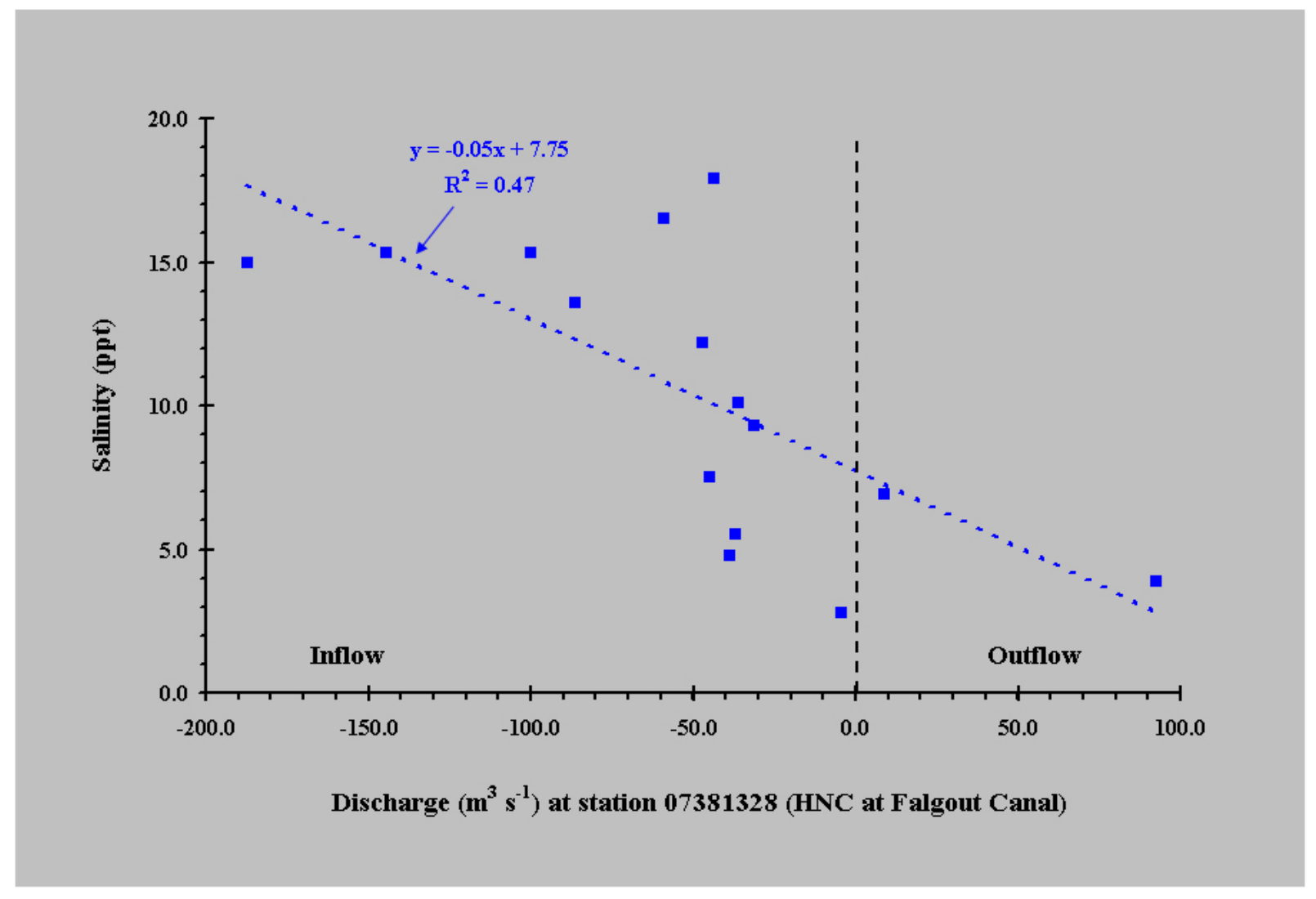

Figure 45. Plot of salinity event (or pulse) amplitude, in parts per thousand (ppt), in the Houma Navigation Canal at Falgout Canal in coastal Louisiana against discharge through the Houma Navigation Canal, in cubic meters per second. Positive discharge values indicate outflow, and negative discharge values indicate inflow. The result of a regression analysis is indicated on the plot. The data cover the time period from January through December 2003. Station locations are indicated in figure 31.

\section{Salinity Summary}

Figure 46 summarizes the salinity and marsh types for the long-term stations in the Houma Navigation Canal (HNC) vicinity by time periods based on dates of vegetation data as well as on photography from before and after construction of the canal. Salinity data from the Bayou Grand Caillou station at Dulac show that a major shift to higher salinity levels occurred by 1978; this shift actually occurred around 1975 (there was a slight increase post-construction). This time period coincides with the first full dredging of the full length of the HNC $\left(6.30\right.$ million $\left.\mathrm{m}^{3}\right)$ that occurred between April 1972 and August 1974 (U.S. Army Corps of Engineers, 1975). The upper portion of the canal never had been fully dredged until 1964. The marshes in this area (east of the HNC) also show a shift from fresh marsh prior to construction of the HNC (completed in approximately 1962) to intermediate marsh by 1978. This vegetation shift may be a result of the general breakup of the marshes east of the HNC, which was quite extensive by 1978, as opposed to a direct impact of the channel. 
The salinities at Bayou Grand Caillou were high enough prior to construction of the HNC to impact the fresh floating marshes in the areas west of the canal; however, the connections between the marshes west of the canal and the Bayou Grand Caillou station at Dulac were mainly smaller, sinuous channels, which limited water exchange. Once the HNC was constructed and after maintenance dredging, the connections between the canal and Bayou Grand Caillou were found to be efficient (U.S. Army Corps of Engineers, 1975). The construction of the canal resulted in increases to the connections between the marshes west of the canal and the lower portion of Bayou Grand Caillou (south of Dulac), which was essentially replaced by the lower portion of the canal. These connections may have allowed higher salinity waters to reach the marshes west of the canal, particularly those areas just north and south of Falgout Canal. These areas also became impounded by numerous canal spoil banks, which may have exacerbated any salinity intrusion events since water would be held in these impounded areas for greater lengths of time (Swenson and Turner, 1987). 


\begin{tabular}{|c|c|c|c|c|c|c|c|}
\hline & Salinity station: & $\begin{array}{c}\text { 76305: Petite } \\
\text { Caillou at Cocodrie }\end{array}$ & $\begin{array}{c}\text { 76303: Petite } \\
\text { Caillou at } \\
\text { Boudreaux Canal }\end{array}$ & $\begin{array}{c}\text { 76323: Bayou } \\
\text { Grand Caillou at } \\
\text { Dulac }\end{array}$ & $\begin{array}{l}\text { 76403: Bayou } \\
\text { Terrebonne at } \\
\text { Bourg }\end{array}$ & $\begin{array}{c}\text { 76343: Houma } \\
\text { Navigation Canal } \\
\text { at Crozier }\end{array}$ & $\begin{array}{c}76320: \text { Gulf } \\
\text { Intracoastal } \\
\text { Waterway at } \\
\text { Houma } \\
\end{array}$ \\
\hline & Distance inland (km): & 7.4 & 24.3 & 33.1 & 39.7 & 45.6 & 50.1 \\
\hline \multirow{6}{*}{ 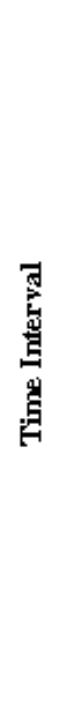 } & 1958.1962 & & & $0.7 / 0.9$ & & & \\
\hline & $1963-1968$ & & & $0.9 / 1.3$ & & $0.6 / 0.9$ & \\
\hline & $1969-1978$ & & $3.3 / 4.8$ & $1.4 / 4.0$ & $04 . / 0.7$ & $0.4 / 0.9$ & $0.2 / 0.4$ \\
\hline & 1979.1988 & $6.1 / 6.1$ & $5.0 / 9.2$ & $2.8 / 5.2$ & $0.6 / 1.2$ & $0.4 / 0.9$ & $0.4 / 0.8$ \\
\hline & $1989-1997$ & $7.7 / 12.8$ & $3.5 / 5.4$ & $4.2 / 5.8$ & $0.2 / 0.2$ & $0.4 / 0.7$ & $0.2 / 0.4$ \\
\hline & $1998-2001$ & $9.5 / 14.4$ & $7.4 / 11.9$ & $7.4 / 13.0$ & & & \\
\hline & & & & & & Salinity (ppt & er interval \\
\hline & Fresh & Intermediate & Brackish & Salt & & Average & ximum \\
\hline
\end{tabular}

Figure 46. Summary of salinity records in the Houma Navigation Canal area in coastal Louisiana. The distance inland (in kilometers), the average and maximum salinity in parts per thousand (ppt) over the listed time interval, and the marsh type for the marshes in the vicinity of the station are shown for each station. 


\section{Landscape Metrics}

\section{Fragmentation Introduction}

With their ability to sustain wildlife, reduce erosion, filter out pollutants, and act as a buffer against storms and flooding, Louisiana's coastal marshes are among the Nation's most fragile and valuable wetlands (Williams, 1995). Therefore, understanding how those marshes respond to natural and anthropogenic forcing events (for example, increases in salinity and canal construction) has become vital to both the maintenance and the restoration of Louisiana's coastline. Methods for establishing percentage of water, along with configuration and connectivity of that water within the marsh landscape, have been developed for evaluating the effects of navigation canals related to the Outer Continental Shelf (OCS) and of salinity on wetland landscape patterns. A water body configuration and fragmentation index was used to classify study area marshes into multiple landscape categories. The initial step in the development of this methodology was a search of habitat fragmentation and patch connectivity literature. The review helped to uncover numerous studies that successfully utilized fragmentation and patch analysis software to describe and predict habitat patterns and change. Though this review provided project feasibility, as well as standard procedures and software for a "typical" fragmentation study, it did not produce any literature regarding fragmentation analysis methods that used a marsh landscape. Therefore, a purpose of this project was to establish, evaluate, and improve methods of analyzing and classifying marsh fragmentation and configuration. Three test methods were proposed for this study: (1) a holistic manual interpretation method, (2) a holistic computer interpretation method, envisioned as a "moving window"-class boundary delineation, and (3) a FRAGSTATS landscape statistical gridbased method.

The preferred method for determining marsh configurations is the holistic approach.

Previous studies have used a manual method to analyze areas of interest to determine wetland loss rates with a classification system based upon percentages of water and their configurations within the marsh (Dozier, 1983; Sasser and others, 1986; Evers and others, 1992), but this method can be subjective, lacks accurate reproducibility, and is not adequate for potential development into a packaged management tool. A holistic computer interpretation method was investigated, but the limitations and restrictions (for example, there are infinitely many polygons corresponding to each water class) that are associated with this method proved to be insurmountable.

Because of the shortcomings of both holistic approaches, a grid-based method of determining water percentage and configurations that used the FRAGSTATS computer software was developed. Though this grid-based approach is not suitable for class-scale determinations on the landscape as a whole, it can provide class-level metrics and classification through individual nonrelated grid tiles and separate landscape-level metrics and analyses. Ultimately, this method provides the greatest likelihood of product reproducibility and the highest potential as a packaged management tool.

FRAGSTATS was designed to compute a wide variety of landscape metrics for categorical map patterns (McGarigal and others, 2002). Historically, FRAGSTATS has been used for habitat suitability, change, and connectivity dynamics for forested ecosystems. Though no literature on the study of marsh fragmentation and classification that used FRAGSTATS was found, personal communications with coastal GIS specialists suggest that FRAGSTATS is well suited for research of this nature. 


\section{FRAGSTATS Method Development}

The FRAGSTATS grid method developed as part of this project utilizes a land-water classified image and a two-part classification system. The two levels used in this system are (1) category: ratio of water to land and (2) configuration: marsh water density, shape, and connectivity. This classification system (modified from Dozier, 1983) assigns values 1-7 to represent percentages of water as follows: category 1, $0-<5$ percent water within marsh; category $2,5-<10$ percent water; category $3,10-<25$ percent water; category $4,25-<40$ percent water; category $5,40-<60$ percent water; category $6,60-<80$ percent water; and category $7, \geq 80$ percent water. The system subclasses are designated by the configuration of water bodies in the marsh. Subclass A includes configurations that are typically large water (in relation to percent water class) and have connected water patches with linear edge. Subclass B includes configurations that are typically small (as related to associated percent water class) disconnected patches with a more random distribution and fewer instances of connection. Subclass $\mathrm{C}$ includes configurations that are a combination of both subclass A and subclass B (with discernible regions of both). Figure 47 illustrates the classification system by using example grid tiles from the Dulac digital orthophoto quarter quadrangle (DOQQ) (Louisiana Oil Spill Coordinator's Office, 1999) (see test site information below) to represent category and configuration combinations.

The Lake Boudreaux area was chosen as the test site for establishing and evaluating the FRAGSTATS grid-based method. Selection of this test site was multipurposed: (1) a previous manual marsh classification project was performed using the 1998 Dulac DOQQ (allowing for comparison of results), and (2) it was located within the proposed Houma Navigation Canal study area. Prior to FRAGSTATS processing and evaluation, Erdas Imagine was used to perform a landto-water unsupervised classification analysis on the Dulac DOQQ. This land-water classification process was used to designate image pixels as either "water" or "land" or "other" classes based on individual pixel signature (fig. 48). All nonwater and nonmarsh features were initially recoded into the "other" category. This category — which consisted of fastlands and forested, agricultural, and developed lands-was ultimately appended with large bayous and channelized canals to ensure their exclusion from all statistical analyses and classification.

The initial phase of the FRAGSTATS system development was to determine the appropriate grid scale required for maximizing accuracy of classification. To compensate for extensive computer processing and to determine appropriate grid scale, the entire classified Dulac image was subset down to $62,500-\mathrm{m}^{2}\left(1 / 16-\mathrm{km}^{2}\right), 15,625-\mathrm{m}^{2}\left(1 / 64-\mathrm{km}^{2}\right)$, and $3,906-\mathrm{m}^{2}\left(1 / 256-\mathrm{km}^{2}\right)$ raster grids. Each extracted raster grid, or "tile," was then processed using FRAGSTAT and analyzed at the class metric level (statistics computed for every patch type or class in the landscape) and at each designated grid scale. Tiles were sorted by adjusted water percentages (recalculated category class, excluding "other" class) and by preliminary configuration thresholds (established to assess suitable metrics and metric combinations). Countless arrangements of metrics and metric combinations were selected and tested against configuration definitions. Ultimately, category and configuration class outputs were assessed to evaluate results of various metric, threshold, and scale combinations. 


\section{Configuration}

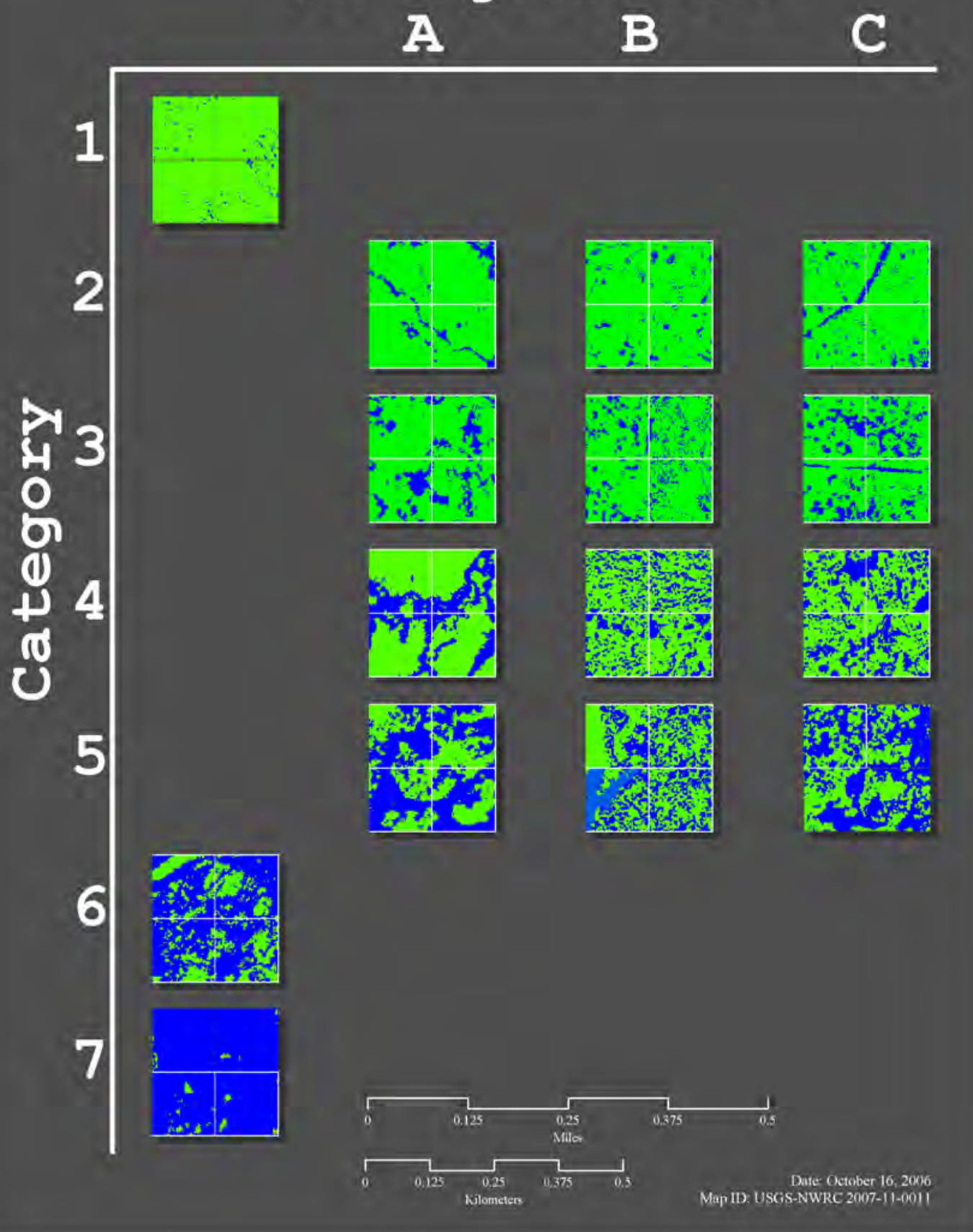

Figure 47. Examples of the classification scheme from the Dulac, La., quadrangle, with the percentages of water (modified from Dozier, 1983) used for interpretation of aerial photographs. The numbers 1-7 represent percentages of water as category 1 , $0-<5$ percent water within marsh; category $2,5-<10$ percent water; category $3,10-$ $<25$ percent water; category $4,25-<40$ percent water; category $5,40-<60$ percent water; category $6,60-<80$ percent water; and category $7, \geq 80$ percent water. Letters $\mathrm{A}, \mathrm{B}$, and $\mathrm{C}$ are subclasses determined by configuration of water bodies in the marsh. 


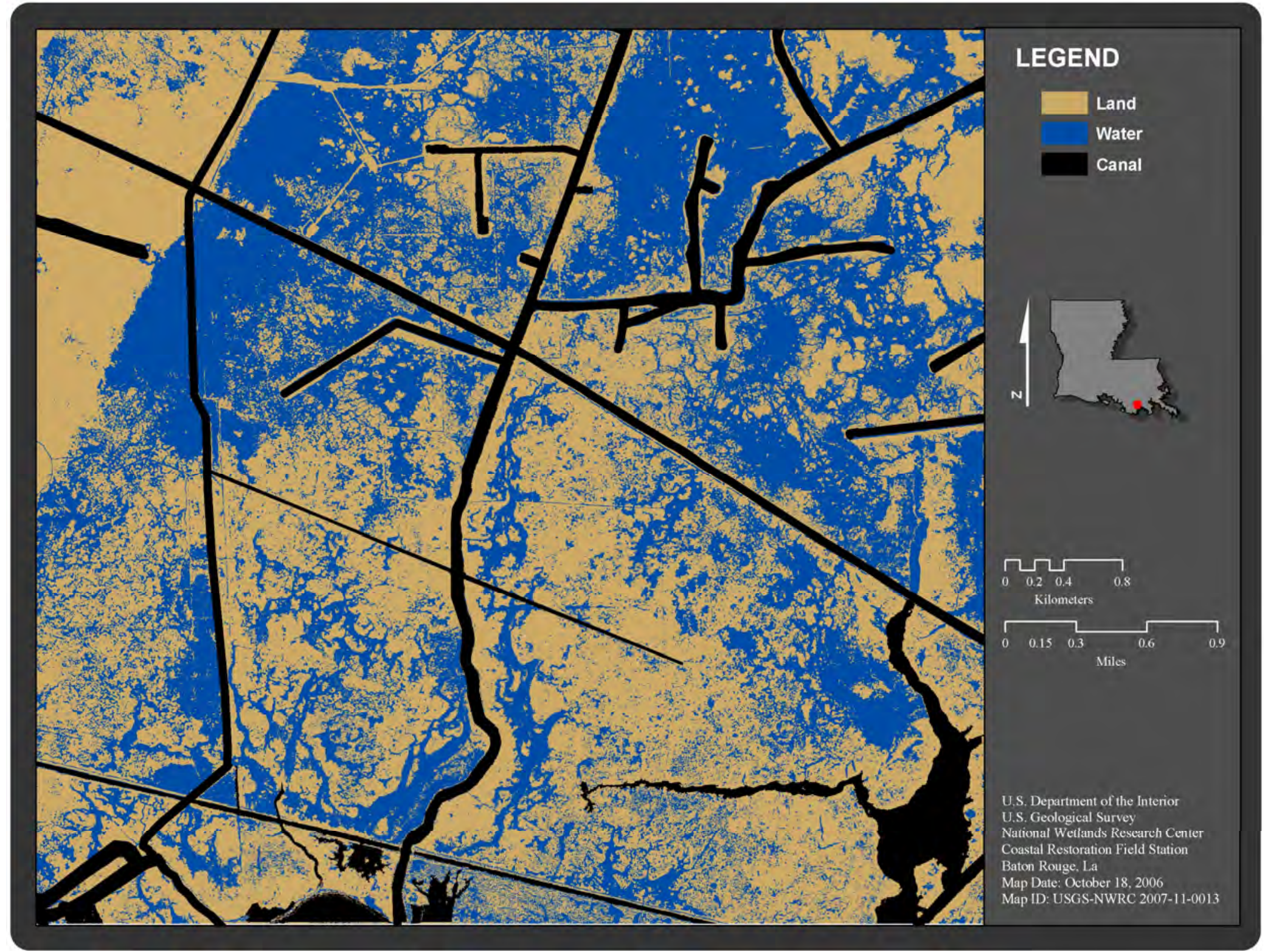

Figure 48. Dulac, La., digital orthophoto quarter quadrangle (DOQQ) (Louisiana Oil Spill Coordinator's Office, 1999) classified via the FRAGSTATS system. 
Scale emerged as a major factor in metric output and classification accuracy. Ideally, each individual grid tile would contain a landscape with only one category/configuration class. Visual assessments determined that, at the $1 / 16-\mathrm{km}^{2}$ scale, tiles regularly contained three or more configuration classes. Conversely, the $1 / 256-\mathrm{km}^{2}$ scale tiles resulted in areas that were too small to accurately classify the landscape and, therefore, repeatedly over classified water features. The $1 / 64-\mathrm{km}^{2}$ scale tiles provided the most accurate results and seemed to best satisfy the one category/configuration class per grid-tile criteria.

A shift error was observed in which a change in classification resulted from a one-half pixel ( $0.5 \mathrm{~m}$ east and north) shift in the vector grid boundary origin (northing and easting). A shift analysis was performed on the Dulac land-water image for all three scales (table 11). The total percent change for the $1 / 16-\mathrm{km}^{2}, 1 / 64-\mathrm{km}^{2}$, and $1 / 256-\mathrm{km}^{2}$ tiles were $70.33,58.02$, and 54.74 percent, respectively. Though the shift analysis of the $1 / 64-\mathrm{km}^{2}$ grid produced more change in overall classification than did the $1 / 256-\mathrm{km}^{2}$ grid, the difference was not significant. Through this shift analysis and the aforementioned scale classification assessment, it was concluded that the $1 / 64-\mathrm{km}^{2}$ grid provides the most accurate and suitable scale for this study. To standardize the tiling origin and alleviate potential shift error, the project vector grid origin was based on an established grid system developed by Twilley and Barras (2004) for the Louisiana Coastal Area Ecosystem Restoration Study.

Table 11. Dulac, La., sample area shift and scale analyses $\left(1 / 16 \mathrm{~km}^{2}, 1 / 64 \mathrm{~km}^{2}, 1 / 256 \mathrm{~km}^{2}\right)$. $\left[\mathrm{km}^{2}\right.$, square kilometer; ha, hectare; \%, percent]

\begin{tabular}{|c|c|c|c|c|c|c|c|c|}
\hline \multicolumn{3}{|c|}{ 1/16-km ${ }^{2}$ scale } & \multicolumn{3}{|c|}{ 1/64-km ${ }^{2}$ scale } & \multicolumn{3}{|c|}{$1 / 256-\mathrm{km}^{2}$ scale } \\
\hline Class & Change (ha) & Change (\%) & Class & Change (ha) & Change (\%) & Class & Change (ha) & Change (\%) \\
\hline 1 & 729.9 & 74.0 & 1 & 252.3 & 44.9 & 1 & 386.7 & 52.0 \\
\hline $2 \mathrm{~A}$ & 59.4 & 90.3 & $2 A$ & 86.1 & 92.9 & $2 A$ & 74.0 & 90.6 \\
\hline $2 B$ & 97.3 & 81.7 & $2 B$ & 105.6 & 82.6 & $2 B$ & 137.9 & 82.0 \\
\hline $2 \mathrm{C}$ & 60.8 & 88.4 & $2 \mathrm{C}$ & 106.5 & 88.9 & $2 \mathrm{C}$ & 95.5 & 90.6 \\
\hline $3 A$ & 194.7 & 84.5 & $3 A$ & 367.5 & 79.1 & $3 A$ & 160.6 & 88.3 \\
\hline $3 B$ & 199.3 & 63.0 & $3 B$ & 182.0 & 81.5 & $3 B$ & 268.8 & 76.5 \\
\hline $3 C$ & 255.3 & 86.9 & $3 C$ & 208.2 & 82.3 & $3 C$ & 198.4 & 83.8 \\
\hline $4 \mathrm{~A}$ & 219.5 & 90.9 & $4 \mathrm{~A}$ & 180.9 & 90.2 & $4 \mathrm{~A}$ & 223.9 & 88.0 \\
\hline $4 \mathrm{~B}$ & 263.1 & 69.5 & $4 \mathrm{~B}$ & 295.3 & 74.9 & $4 \mathrm{~B}$ & 170.0 & 81.9 \\
\hline $4 \mathrm{C}$ & 267.2 & 89.1 & $4 C$ & 129.1 & 84.8 & $4 \mathrm{C}$ & 134.0 & 88.0 \\
\hline $5 \mathrm{~A}$ & 289.3 & 88.1 & $5 \mathrm{~A}$ & 401.9 & 78.8 & $5 \mathrm{~A}$ & 209.2 & 87.8 \\
\hline $5 B$ & 299.9 & 84.6 & $5 B$ & 97.1 & 92.6 & $5 B$ & 269.0 & 84.6 \\
\hline $5 \mathrm{C}$ & 280.1 & 84.5 & $5 C$ & 151.5 & 82.7 & $5 \mathrm{C}$ & 90.5 & 86.0 \\
\hline 6 & 492.9 & 66.7 & 6 & 443.0 & 61.7 & 6 & 388.3 & 66.8 \\
\hline 7 & 239.9 & 40.4 & 7 & 250.6 & 30.8 & 7 & 266.0 & 25.0 \\
\hline Total & 3948.8 & 70.3 & Total & 3257.6 & 58.0 & Total & 3072.7 & 54.7 \\
\hline
\end{tabular}

Of the approximately 100 FRAGSTATS class and landscape metrics that were assessed, eight emerged as responsive control metrics within the fragmentation classification process (table 12) (McGarigal and Marks, 1995). Of those eight, three primary metrics demonstrated the greatest and most accurate control over class designation. These metrics were largest patch index, patch cohesion index, and clumpy index. As the name implies, largest patch index 
quantifies the percentage of total landscape area composing the largest patch. This index is a simple measure of dominance, with percentage calculated by the equation:

$$
L P I=\frac{\max _{j=1}^{b}\left(a_{i j}\right)}{A}(100),
$$

where $a_{i j}$ is the area (in square meters) of patch $i j$, and $A$ is the total landscape area (in square meters).

Table 12. Description of metrics selected as part of FRAGSTATS fragmentation and classification system.

\begin{tabular}{ll}
\hline Metric & Description \\
\hline Largest patch index (LPI) & Percentage of total landscape area composing the largest patch \\
Clumpiness index (clumpy) & Frequency with which different classes appear side by side in the landscape \\
Patch cohesion index (cohesion) & Physical connectedness of the corresponding patches \\
Total class area (TCA) & Sum of the areas of all patches of the corresponding class \\
Percentage of landscape (PLAND) & Percentage that the landscape composed of the corresponding class \\
Number of patches (NP) & Number of patches of the corresponding class \\
Patch density (PD) & Number of patches of the corresponding class divided by total landscape area \\
Landscape shape index (LSI) & Class perimeter length divided by min perimeter needed for max aggregation \\
\hline
\end{tabular}

Patch cohesion index measures the physical connectedness of the corresponding patch type. Patch cohesion increases as the patch type becomes more clumped or aggregated in its distribution and therefore becomes more physically connected. This percentage is calculated by the equation: $\quad C O H E S I O N=\left[1-\frac{\sum_{j=1}^{n} P_{i j}}{\sum_{j=1}^{n} P_{i j} \sqrt{a_{i j}}}\right]\left[1-\frac{1}{\sqrt{A}}\right]^{-1}(100)$, where $P_{i j}$ is the perimeter of patch $i j$ in terms of number of cell surfaces, $a_{i j}$ is the area of patch $i j$ in terms of number of cells, and $A$ is the total number of cells in the landscape. Patch cohesion index ranges from 0 to 100 and equals 0 if the landscape consists of a single nonbackground cell.

The clumpiness index shows the frequency with which different pairs of patch types (including like adjacencies between the same patch types) appear side by side on the map, varying from -1 (totally disaggregated class) to 1 (maximally clumped). This unitless value is calculated by the equation:

$$
\begin{gathered}
C L U M P Y=\left[\frac{G_{i}-P_{i}}{P_{i}}\right] \text { for } G_{i}<P_{i} \& P_{i}<.5, \text { else }\left[\frac{G_{i}-P_{i}}{1-P_{i}}\right], \\
\left.{\text { Given } G_{i}=}^{\sum_{k=1}^{m} g_{i k}-\left(\min -e_{i}\right)}\right),
\end{gathered}
$$


where $g_{i i}$ is the number of like adjacencies (joins) between pixels of patch type (class) $i$ based on the double-count method, $g_{i k}$ is the number of adjacencies (joins) between pixels of patch types (classes) $i$ and $k$ based on the double-count method, min- $e_{i}$ is the minimum perimeter (in number of cell surfaces) of patch type (class) $i$ for a maximally clumped class, and $P_{i}$ is the proportion of the landscape occupied by patch type (class) $i$.

In addition to these primary FRAGSTATS metrics, secondary metrics (and their combinations) were evaluated to determine sensitivity to change in configuration class. Few combinations significantly increased the precision of the classification, while most decreased the accuracy and were therefore discarded. The set of secondary metrics that added marked precision to the classification scheme included adjusted patch density, ratio of number of patches to clumpiness index, and landscape shape index. Adjusted patch density calculates the number of patches of the corresponding patch type, divided by total grid-tile landscape area, excluding all "other" patches. This value — number per 100 ha —is calculated with the equation:

$$
A P D=\frac{n_{i}}{A}(10,000)(100)
$$

where $n i$ is the number of patches in the landscape of patch type (class) $i$, and $A$ is the total landscape area (in square meter).

The ratio of number of patches to clumpiness index is a metric combination that provides a quasi density-by-shape value that separates configurations $\mathrm{A}$ and $\mathrm{C}$ that are approaching the class threshold. This index is calculated by using the equation:

$$
\frac{N P}{C L U M P Y}=\frac{n_{i}}{\left[\frac{G_{i}-P_{i}}{P_{i}}\right] \text { for } G_{i}<P_{i} \& P_{i}<.5, \text { else }\left[\frac{G_{i}-P_{i}}{1-P_{i}}\right]},
$$

where $n_{i}$ is the number of patches in the landscape of patch type (class) $i$.

Finally, the landscape shape index is the total length of edge involving the corresponding class, given in number of cell surfaces, divided by the minimum length of class edge possible for a maximally aggregated class. Simply, this unitless statistic is the number of cell surfaces divided by the minimum length of class edge as calculated by the equation:

$$
L S I=0.25 \sum_{k=1}^{m} e^{\prime \prime}{ }_{\mathrm{ik}}
$$

where $e_{i}$ is the total length of edge of class $i$ in terms of number of cell surfaces, including all landscape boundary and background edge segments involving class $\mathrm{i}$, and $\min e_{i}$ is the minimum total length of edge of class $i$ in terms of number of cell surfaces. The minimum value for $L S I$ is 1 , with the value increasing as the patch type becomes more disaggregated.

Visual classification of sample site tiles was used to assess accuracy of the computergenerated classification. This method was used to evaluate all potential metric and metric combinations, as well as to fit value thresholds to visually derived classes (see classification criteria/thresholds, appendix 2). Final arrangement of metric and threshold combinations was established by assessing approximately 25 percent of all category 2 and category 3 sample tiles and 12.5 percent of category 4 and category 5 sample tiles. Of those randomly selected tiles, approximately one-third of categories 2 and 3 and one-half of categories 4 and 5 contained a 
metric that was in close proximity to the threshold value. Sampled tiles were used to perform final threshold value adjustments, producing a metric and threshold design with $>90$ percent classification accuracy. Figure 49 illustrates the preliminary grid-based classification image for the Dulac DOQQ. 


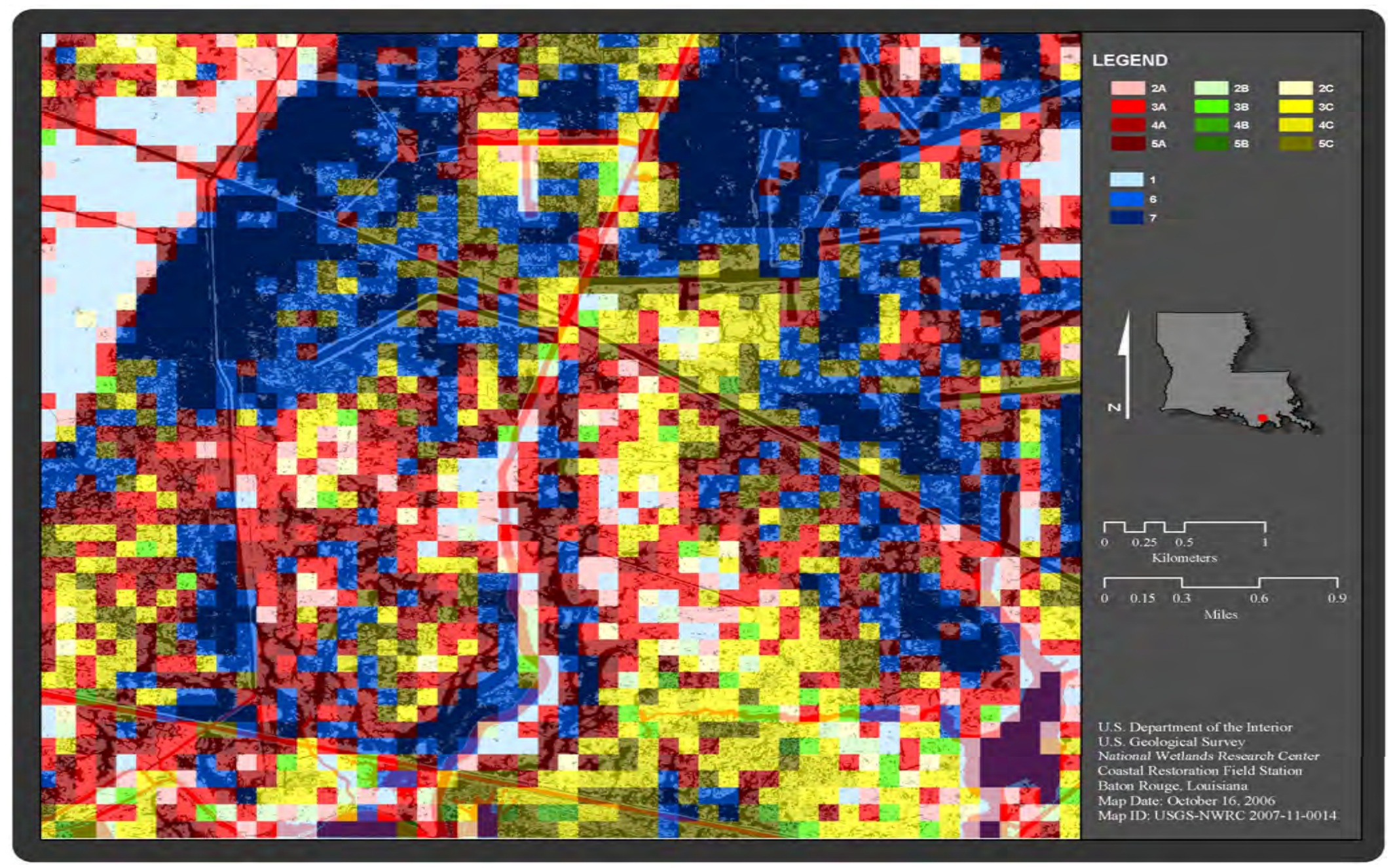

Figure 49. Preliminary FRAGSTATS marsh fragmentation and water configuration classification performed on the 1998 Dulac, La., digital orthophoto quarter quadrangle (DOQQ) (Louisiana Oil Spill Coordinator's Office, 1999) land and water classified image. 


\title{
Marsh Fragmentation Classification System
}

\section{Study Site Spatial Data}

\author{
Geospatial Datasets
}

Multiple unique geospatial datasets were acquired or constructed for this study. These datasets consist of the project area boundary, developed areas, location canals (canals that are primarily dredged within marsh landscapes to provide greater accessibility for oil and gas extraction [personal communication, Richard M. Jones]), waterway centerlines and mile markers, 3-km buffer array, vegetation zone and buffer intersection, tiling vector grid, canal dredge locations, salinity station locations, vegetation zones, forested areas, and relevant attribute data. The study area boundary was digitized by using Landsat Thematic Mapper (TM) imagery as a base map, taking into account the estimated distance of influence from the Houma Navigation Canal (HNC) and utilizing neighboring waterways as boundaries. The boundarywhich consists of Minors Canal, Lake de Cade, and Bayou du Large to the west and Bayou Terrebonne to the east and extends south from the Gulf Intracoastal Waterway (GIWW) towards the southern portions of the Bayou Sauveur and Lake Quitman quadrangles-encompasses approximately $805 \mathrm{~km}^{2}$ of various landscapes. There are two primary water features of interest within the study area: the channelized (HNC) and Bayou Terrebonne (reference bayou). The USACE survey and dredge reference digital plates for the HNC were acquired. These plates were used to extract and merge waterway centerlines and mile marker data into unique layers. These extracted data, in conjunction with the USACE dredge history data, were used to create a dredge location data layer with supporting attribute data (fig. 50). Additionally, a point theme was constructed by using salinity monitoring station data from the USACE, LDNR, and USGS, and the coastal marsh vegetation type data (USGS and LDWF) and a subset using the project boundary were acquired. Forested and shrub/scrub areas from the raster Gap Analysis Program (U.S. Geological Survey, 1998) dataset were converted to vector format and intersected with the study area boundary. In addition, multiple vector grids (differing scale) were constructed for batch grid tiling and class statistics processing.

\section{Photography Acquisition and Processing}

Photography was used to evaluate land change and wetland landscape patterns as influenced by Outer Continental Shelf waterways, specifically the Houma Navigation Canal. Aerial photography selected for analysis consisted of dates that (1) encompassed canal construction and major dredging activity (widening or deepening), (2) closely coincided with dates of supporting data (e.g., vegetation zones), and (3) exhibited best available quality, coverage, and scale and offered greatest ease of rectification.

Table 13 lists all available photography and status by canal construction phase. Three temporal data points-preconstruction, postconstruction, and end-date phase-were proposed for this study. Datasets considered for this project included three preconstruction phase (1953, 1955/56, and 1958), two postconstruction (1965 and 1968/69), and three end-date (1998, 2001, and 2004) datasets. 
Assessments of all available photography were performed for each canal construction phase. Each date of photography was evaluated to determine format (hardcopy or digital), rectification status, and completeness of coverage and to ensure appropriate scale and quality for image georectification (if needed) and classification. Preliminary assessments showed that the majority of the historical panchromatic photography (and some color photography frames) were inconsistent and problematic. These frames were either dark or contained significant cloud cover, haze, sun glint, or burned marsh. Possessing one, or a combination, of these features can greatly compromise land-water interpretation and classification.

Due to the status of coverage, scale, format, rectification, and proximity to canal construction, the 1958 panchromatic photography (Tobin, obtained from T. Baker Smith \& Son, Inc., and LDNR) was the preconstruction photography selected for this study. Though the 1955/56 and 1958 photographs were similar in most characteristics, the 1958 photography contained fewer instances of atmospheric contamination. The 1968/69 panchromatic photography (U.S. Army Corps of Engineers, 1:20000 scale) was selected as the postconstruction dataset. This photography satisfied all selection criteria, while the comparable 1965 imagery lacked adequate coverage. The 1998 DOQQs (LOSCO) were selected as the endpoint dataset; this dataset satisfied all selection criteria (the 2001 photography exhibited poor quality, and the 2004 photographs lacked complete project coverage [at the time of assessment]).

Table 13. Status of available photography for the preconstruction, postconstruction, and end-point dates, related to the salinity study in coastal Louisiana.

[LSU, Louisiana State University; USGS, U.S. Geological Survey; USACE, U.S. Army Corps of Engineers; H, hardcopy prints; D, imagery is digital; G, imagery is rectified; Q, old type orthophoto quadrangle on paper; X, problems with the imagery, not useful for this project; N/A, not applicable.]

\begin{tabular}{|c|c|c|c|c|c|}
\hline Phase & Year & Source & Coverage & Scale & Status \\
\hline \multicolumn{6}{|c|}{ Preconstruction: } \\
\hline & 1953 & LSU & Partial & $N / A$ & $\mathrm{H}$ \\
\hline & $1955 / 56$ & Amman $^{1}$ & Partial & $1: 24000$ & $\mathrm{Q}$ \\
\hline & 1958 & Tobin $^{2}$ & Full & $1: 24000$ & $D, G$ \\
\hline \multicolumn{6}{|c|}{ Postconstruction: } \\
\hline & 1965 & Tobin & Partial & 1:20000 & $\mathrm{D}, \mathrm{X}$ \\
\hline & $1968 / 69$ & USACE & Full & $1: 20000$ & $H, D, G$ \\
\hline \multicolumn{6}{|c|}{ Endpoint: } \\
\hline & 1998 & USGS & Full & 1:24000 & $D, G$ \\
\hline & 2001 & USGS & Full & $1: 24000$ & $D, G, X$ \\
\hline & 2004 & USGS & Partial & $1: 24000$ & $\mathrm{D}, \mathrm{G}$ \\
\hline
\end{tabular}

${ }^{1}$ Amman = National Aerial Resources. 12 Arrowhead Lane, Cohoes, NY 12047.

${ }^{2}$ Tobin $=$ Tobin International, Ltd. 1626 Broadway, Suite 500, Denver, CO 80202. 


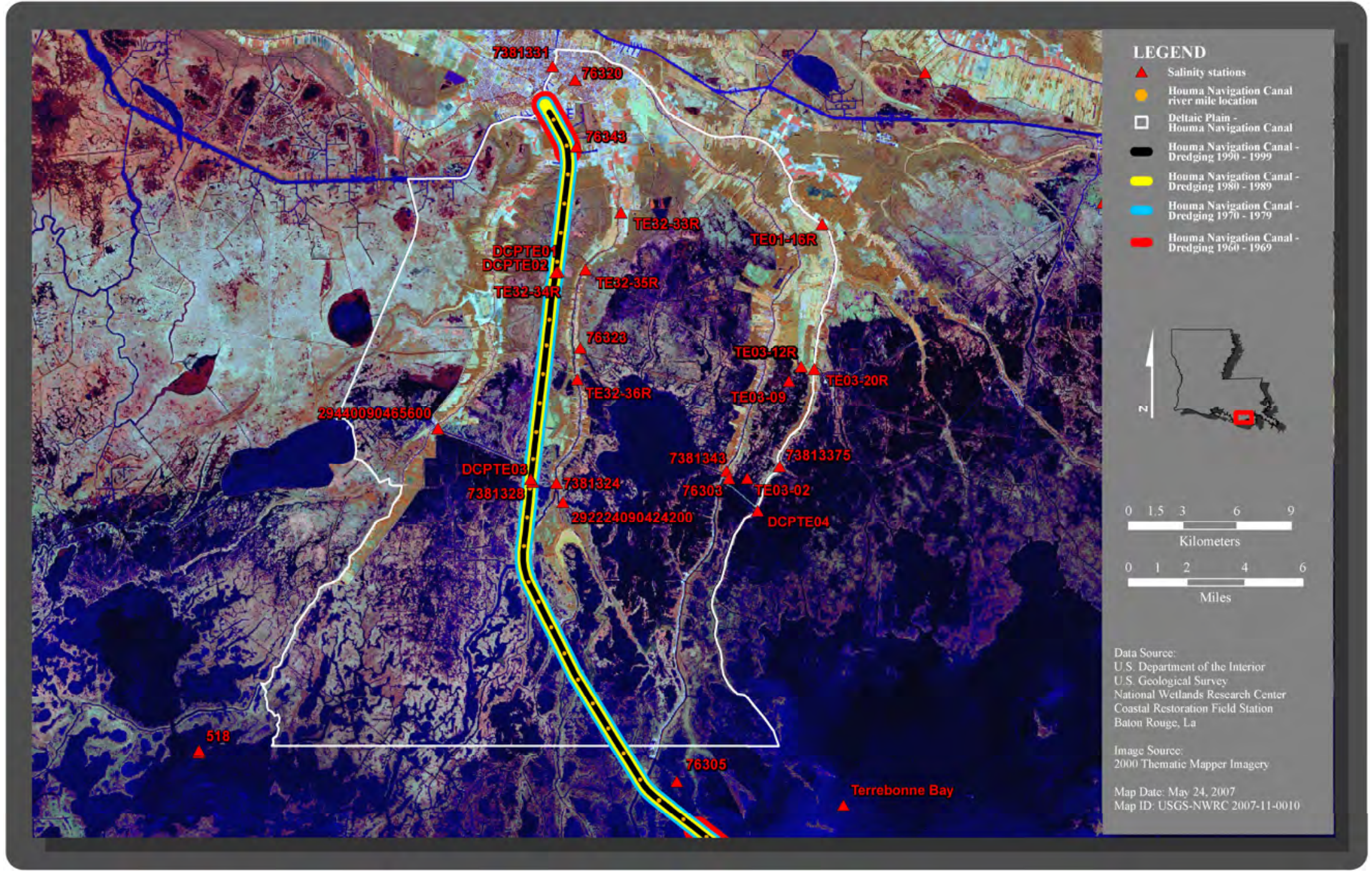

Figure 50. Salinity monitoring station, dredge history, and river mile locations within the Houma Navigation Canal study area in coastal Louisiana. 


\section{Data Processing}

Photography obtained for this project was received in either hardcopy or digital form. Hardcopy photography was scanned at 300 dots per inch (dpi) and converted to Tagged Image File Format (TIFF). All photography was then converted into an Erdas Imagine format, georectified by using the 1998 DOQQs as a control, indexed, and mosaicked. Georectification of the acquired photography was performed by the USGS (1958 and 1998 photography) and Science Applications International Corporation (SAIC, 1968 photography). The photography was then subset by project boundary and divided into smaller overlapping regions for ease of processing.

A land-water analysis was performed on each of the preconstruction, postconstruction, and enddate photography sets. An unsupervised classification within ERDAS Imagine $8.7^{\odot}$ software was performed with a 50-class assignment, 0.990 convergence threshold, and a maximum of 30 iterations on all subset photography. The intermediate cluster image was then analyzed by using the original photography, interpreted by using ancillary photography, and manually recoded to improve accuracy of classification. The original 50 classes were collapsed into three final classes: "land," "water," and an "other" class. The "other" class_-which consists of all major canals, drilling canals, and fastlands as well as agriculture and developed land-was used to exclude all features that were not either marsh or marsh water from class and landscape statistics. Though the canals were excluded from the initial landscape fragmentation analysis and classification, they were of primary interest to the overall landscape evaluation and were later utilized in the salinity pathway assessments. All vegetation, such as marsh, burned marsh, scrub/shrub, forested wetlands, emergent vegetation, and circular vegetation within water bodies received a "land" classification. Open water, floating aquatics, nonvegetated mudflats, and structures positioned over water were classified as "water." In order to minimize incorrectly classified habitat types, a photointerpreter was consulted as needed. After classification was complete, an accuracy assessment was performed by other project members to ensure proper classification. This $\mathrm{QA} / \mathrm{QC}$ provided a peer review process by which all edits and suggestions were considered and amended where appropriate.

The final 1958, 1968/69, and 1998 land-water images were remosaicked, resampled (1-m horizontal resolution), and shifted to ensure alignment of raster pixel edge to origin of the project vector grid. This vector grid was then used to subset each image into individual $1 / 64-\mathrm{km}^{2}$ tiles. Given the substantial number of project tiles (approximately 100,000) and the required processing time (on the order of weeks), extraction of individual tiles proved laborious and problematic. A geoprocessing routine was developed to expedite the preparation and extraction of raster datasets by using ArcGIS 9.1 software and Visual Basic for Applications (VBA). This routine automated the process of subsetting the project-wide raster dataset into $1 / 64-\mathrm{km}^{2}$ ASCII rasters, thereby reducing the processing time to approximately 24 hours. The ASCII format was utilized in order to circumnavigate multiple Microsoft Windows and FRAGSTATS limitations (for example, a limit of 10,000 ArcGIS Grid INFO files per Microsoft Explorer window). Since FRAGSTATS processing requires headerless input data, a second automated routine was developed to efficiently remove header information from large volume of ASCII files.

The FRAGSTATS software package has an integrated batch function for rapid processing of multiple raster files. This feature, which utilizes a batch file, specifies raster name and location, cell size, background value, file type, and number of columns and rows per ASCII tile. This batch file was used in conjunction with user-defined settings - patch neighbors, output statistics, and analysis typeto compute statistics of desired metrics for the 1958, 1968/69, and 1998 ASCII tiles. For the FRAGSTATS grid-based class statistics, the following metrics were required for calculating and 
assigning category and configuration classes: class area, percentage of landscape, number of patches, patch density, largest patch index, landscape shape index, connectivity index, and clumpiness index. These statistics were calculated at the class level for each unique ASCII tile, and the output was compiled and exported as a single output file.

Transforming the raw FRAGSTATS data into final category and configuration classes requires a two-part system. The first part comprises the definition and equation components, which are the criteria and thresholds by which the raw statistical data are classified. These rules are used to parse unneeded data, calculate secondary values, assign category classes, and apply conditional configuration criteria (appendix 2). The second part, which is a transforming routine that applies criteria equations and performs sorting routines, is known as the FRAGSTATS transformer.

Specifically, the transformer uses a multirelated table database as the target for importing and parsing raw FRAGSTATS output. The application uses a data transformation workflow to convert data types, perform configuration equation calculations, and channel data through approximately 25 conditional assessments (many of which contain multiple nested conditions). The application provides both data preview and export interface which allow data to be exported to numerous file types. Class statistics from the 1958, 1968/69, and 1998 FRAGSTATS processes were transformed and exported as unique comma-separated value (csv) files.

A project region layer was created to aid in the determination of areas that exhibit significant landscape change and influence. This "regions" dataset was developed by using the LDEQ Office of Water Resources' watershed basin subsegment management units (Louisiana Department of Environmental Quality, 1998). These units are subwatersheds that were delineated on the basis of regional topography, drainage boundaries, and principal waterways. There are 13 project regions that fall within the project boundary. They are Duplantis, Hache, West/Central/East Falgout, Rambio, Sale, Petite Caillou, La Cache, Pelton, North and South Boudreaux, and Klondyke (fig. 51).

In addition to the standard grid-based classification analysis, landscape statistics and zonal analyses were computed for all three temporal data points. The landscape statistics incorporate metrics that measure the aggregate properties of an entire patch mosaic. They were used to describe the change in marsh density, shape, and connectivity at the project scale.

\section{Land-Water Analysis}

The principal component of a landscape fragmentation and configuration study is the landwater classification analysis. Three project-scale land-water analyses were performed (1958, 1968/69, and 1998; fig. 52), producing 805-km² landscapes consisting of "land," "water," and "other" feature classes. Table 14 shows the area of each landscape feature, categorized by image date. Changes in feature class area were measured as decreases in "land" of $26.5,150.1$, and $176.6 \mathrm{~km}^{2}$ and increases in "water" of 23.5, 143.4, and $166.8 \mathrm{~km}^{2}$ for time period A (TA, 1958-68/69), time period B (TB, 1968/69-98), and the overall time period (OA, 1958-98), respectively. The "other" landscape was classified by using the fixed area developed mask (generated by using the 1998 photography), allowing for the area of location canals to be derived for each date. An increase in the amount of project area consisting of location canals was observed. These areas increased by $3.0,6.8$, and $9.8 \mathrm{~km}^{2}$ over the TA, TB, and OA time periods, respectively.

Table 15 shows land lost, rate of loss, and percentages of loss at various scales (temporal and spatial) within the Louisiana coastal zone. This table compares the land loss trends calculated for the TA, TB, and OA periods of the Houma Navigation Canal (HNC) project area, with estimates at the basin and coastwide scale for 48-year (Barras, 2006) and 68-year (Barras and others, 2003) trends, 
respectively. The land loss rate estimates are 72.4 and $62.0 \mathrm{~km}^{2} / y e a r$ for the $1932-2000$ and $1956-$ 2004 periods for the coastal areas, respectively; $17.3 \mathrm{~km}^{2} /$ year for the Terrebonne basin (1956-2004); and $4.4,5.0$, and $2.7 \mathrm{~km}^{2} /$ year for the project area $\mathrm{OA}, \mathrm{TB}$, and TA time periods, respectively. To normalize these rates, the percent land loss per year for land class area and total area were calculated. The 1932-2000 and 1956-2004 period studies, which produced coastal loss rates of 0.2 percent (percent loss per year of total area), were approximately 1.6 times slower than the rates of the TA period for the HNC area and the 48-year period for the Terrebonne basin. These increases in rate indicate that, compared to the coastal zone, the Terrebonne basin was a region of more extreme degradation and loss. Furthermore, the TB and OA periods within the HNC area experienced percentages of loss at twice the rate of both the TA and Terrebonne basin (1956-2004) periods. These results suggest that the HNC study area was losing land at a significantly faster rate than both the marshes of coastal Louisiana and the other highly degraded neighboring marshes within the Terrebonne basin.

Table 14. Area of total project landscape and feature classes for the 1958, 1968/69, and 1998 land-water images in coastal Louisiana.

\begin{tabular}{rrrrrr}
\hline & \multicolumn{5}{c}{ Area $\left.\mathbf{( k m}^{2}\right)$} \\
\cline { 2 - 6 } Date & $\begin{array}{r}\text { Total } \\
\text { area }\end{array}$ & Land & Water & $\begin{array}{r}\text { Location } \\
\text { canals }\end{array}$ & Other \\
\hline 1958 & 805.24 & 474.86 & 131.98 & 7.46 & 190.94 \\
$1968 / 69$ & 805.24 & 448.4 & 155.44 & 10.46 & 190.94 \\
1998 & 805.24 & 298.3 & 298.79 & 17.21 & 190.94 \\
\hline
\end{tabular}

Table 15. Total area lost and land loss rates within coastal Louisiana at various spatial and temporal scales. Land class areas are all landscapes within the coastal zone that have been classified as land-here the land loss rates are provided both as a percentage based on total area within the coastal zone and as a percentage based on the area of the land class at the start of each time period.

["Canal" refers to the Houma Navigation Canal]

\begin{tabular}{|c|c|c|c|c|c|c|}
\hline \multirow[b]{2}{*}{ Boundary } & \multirow[b]{2}{*}{ Period } & \multicolumn{5}{|c|}{ Land loss } \\
\hline & & $\begin{array}{c}\text { Square } \\
\text { kilometer }\end{array}$ & $\begin{array}{c}\text { Percent } \\
\text { of total } \\
\text { land } \\
\text { class } \\
\text { area } \\
\end{array}$ & $\begin{array}{l}\text { Square } \\
\text { kilometer } \\
\text { per year }\end{array}$ & $\begin{array}{c}\text { Percent } \\
\text { loss per } \\
\text { year } \\
\text { (land } \\
\text { class } \\
\text { area) } \\
\end{array}$ & $\begin{array}{c}\text { Percent } \\
\text { loss per } \\
\text { year } \\
\text { (total } \\
\text { area) } \\
\end{array}$ \\
\hline Canal & $1958-68$ & 26.5 & 5.6 & 2.7 & 0.6 & 0.3 \\
\hline Canal & 1968-98 & 150.1 & 33.5 & 5.0 & 1.1 & 0.6 \\
\hline Canal & 1958-98 & 176.6 & 37.2 & 4.4 & 0.9 & 0.6 \\
\hline Terrebonne $^{1}$ & 1956-2004 & 831.4 & 27.6 & 17.3 & 0.6 & 0.4 \\
\hline Coastal $^{1}$ & 1956-2004 & 2975.9 & 19.6 & 62.0 & 0.4 & 0.2 \\
\hline Coastal $^{2}$ & $1932-2000$ & 4921.0 & & 72.4 & & 0.2 \\
\hline
\end{tabular}

${ }^{1 .}$ Data derived from Barras (2006).

${ }^{2 .}$ Data derived from Barras and others (2003). 
Houma Navigation Canal
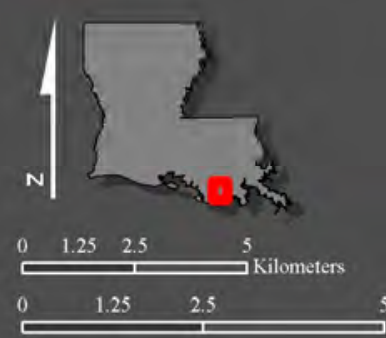


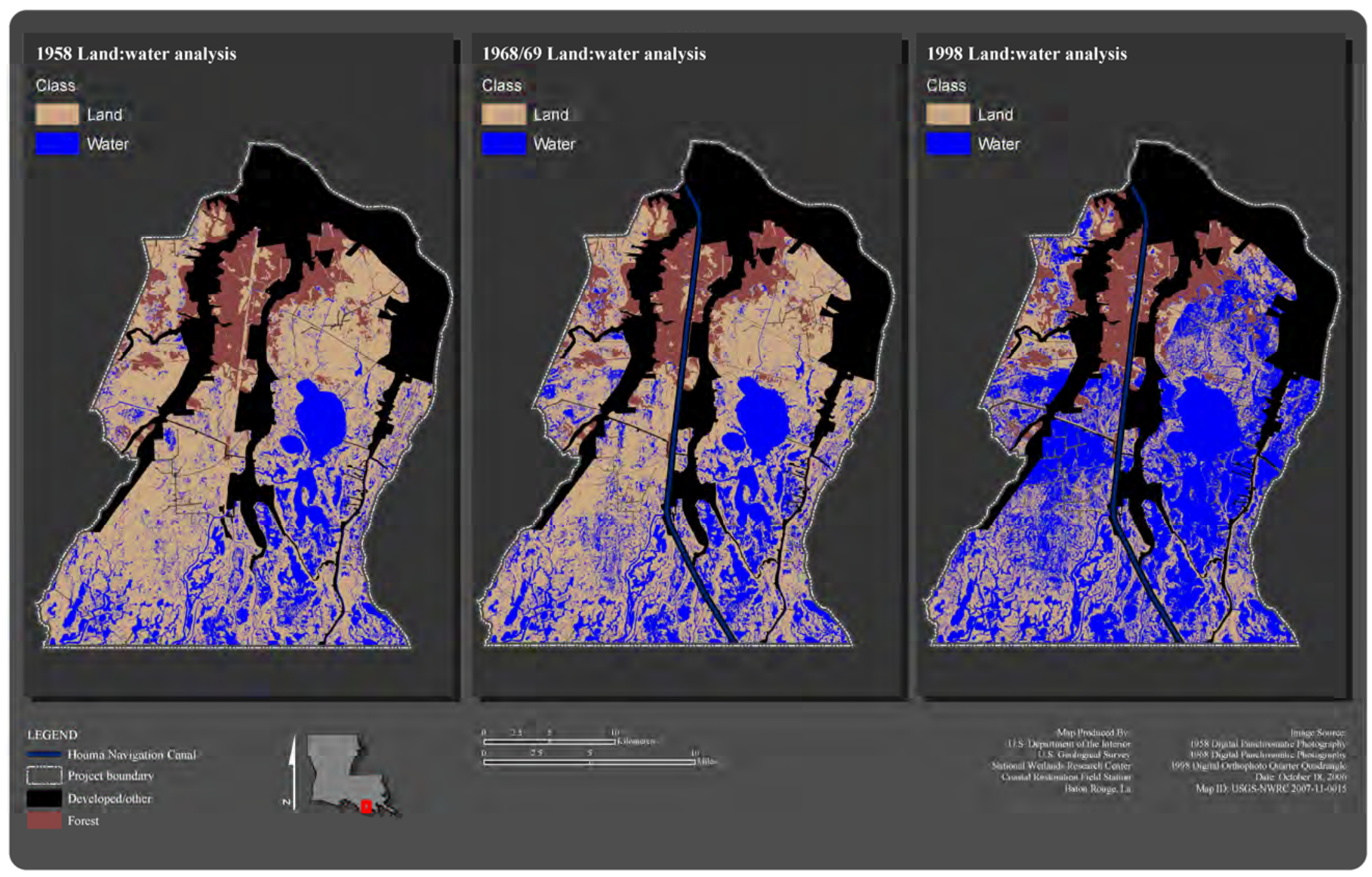

Figure 52. Three-panel map of the 1958, 1968/69, and 1998 land and water classified images in coastal Louisiana. 
The landscape-level marsh density, shape, and connectivity metrics also were computed for all three dates (table 16). This table shows that values for landscape shape index (LSI) increased and that values for largest patch index (LPI) decreased across all TA, TB, and OA time periods. The changes in patch density (PD) and patch cohesion index (cohesion) values were less typical. The PD values showed decrease at the TA period and increases for both TB and OA periods. The cohesion value changes where similar to PD, except there was a decrease in value over the OA period. In general, these shifts in landscape configuration and connectivity metric values are indicative of a marsh that transitioned from a solid and less complex landscape with high levels of marsh connectivity to a highly complex and degraded landscape with increased water connectivity.

Table 16. Project-scale landscape metrics for the 1958, 1968/69, and 1998 land-water images in coastal Louisiana.

\begin{tabular}{lrrr}
\hline Metric (weighted average) & $\mathbf{1 9 5 8}$ & $\mathbf{1 9 6 8 / 6 9}$ & $\mathbf{1 9 9 8}$ \\
\hline Patch density & 433.1 & 301.1 & 637.2 \\
Largest patch index & 40.8 & 34.3 & 31.8 \\
Landscape shape index & 19.3 & 20.6 & 34.2 \\
Cohesion & 99.9 & 99.4 & 99.5 \\
\hline
\end{tabular}

\section{Marsh Classification}

A total of 52,146 individual project tiles $\left(1\right.$ tile $\left.=15,625 \mathrm{~m}^{2}\right)$ were used to generate classlevel metric statistics. To determine changes in the marsh, the developed and forested areas were removed, lowering the number of tiles used in the rest of the calculations to 35,344. Class-level statistics were used independently to assess change of landscape characteristics over time and in combination to classify marsh category and configuration. For independent metric evaluations of marsh condition over time, the derived metric values of a former year were deducted from a latter year to develop a scale of comparison. These comparisons were used in conjunction with the category and configuration classification to determine areas of significant degradation.

Table 17 shows summary statistics for each class-level metric by date. Raw metric values were used in all cases, except where tile landscapes contained no water and were then assigned values of 0.0 for all class-level metric. Consistent with the project-scale water change, the tilebased water metric statistics show an increase in mean percentage of water to land (PLAND) of 4.5, 25.2, and 29.7 percent and LPI of 4.5, 22.1, and 26.9 percent for the TA, TB, and OA time periods, respectively. These increases indicate an average water gain (land loss), and an increase in the average size of largest water patch per tile, between the three project dates. Specifically, the percentage of total project area that was composed of tiles containing less than 5 percent water was 49 and 42 percent for pre- and postconstruction dates, respectively. Of those tiles, 12 and 13 percent, respectively, were located in areas classified as forested/shrub/scrub (Gap Analysis Program, U.S. Geological Survey, 1998). By 1998, 18 percent of the total project area contained tiles with $<5$ percent water, while 25 percent of those tiles were classified as forest/shrub/scrub. Conversely, the tiles containing $>60$ percent water covered 14 and 17 percent of the study area in 
1958 and 1968/69, respectively. The number of "water" tiles more than doubled by 1998 , encompassing 39 percent of the study area.

Core PLAND metric statistics, LPI metric statistics, PLAND difference analysis, and LPI difference analysis are shown in figures 53, 54, 55, and 56, respectively. These figures illustrate the location and magnitude of water changes within the project area. The largest increases in percentage of water occurred primarily in the Rambio, Hache, West Falgout, and eastern portions of South Boudreaux regions for the TA time period. The increases in PLAND and LPI values observed for this time period and within these regions appear to be related to shoreline and bank erosion in the southern portion of the study area, or they occurred in northern regions near major canals or pathways with direct connectivity to the Houma Navigation Canal (HNC). While all regions-except Petite Caillou-underwent significant increase in PLAND and LPI values for the TB period, the more extreme increases were observed in the Central and East Falgout, North and South Boudreaux, Pelton, Klondyke, and various portions of the Rambio, West Falgout, and La Cache regions (figs. 55 and 56). Similar to increases during the TA period, these increases appear to be related to shoreline erosion in the southern regions-which were more prominent for the TB time period-or were near the HNC, Bayou Terrebonne, or one of their connecting pathway canals. These increases, or amount of land loss, are indicative of the natural shoreline erosion that is typical in the southern brackish and saline marshes and of the interior marsh degradation caused by hydrology and salinity shifts in the northern fresh and intermediate zones. Figures 55 and 56 illustrate that the majority of the interior marsh loss occurred near the fresh-intermediate-brackish vegetation zone boundaries (see fig. 3).

Summary statistics for water patch density, shape, and connectivity metrics are shown in table 17. The connectivity metric shows a steady increase in mean cohesion value from the pre- to postconstruction periods and from the postconstruction to end-point dates. These increases indicate a progression from lesser connectivity of water in the preconstruction tiles to significantly greater connectivity within the end-point tiles. The PLAND (water/land ratio) and category class values also indicated a noticeable increase in water over time. The category class values increased from a preconstruction average of 2.6 (5-10 percent water) to a postconstruction average of 3.0 (10-25 percent water) and an end-point value of 4.8 (25-40 percent water). Relative increases were observed between the preconstruction and end-point tiles for all density and shape metrics. The overall (1958-98) mean metric values increased by 3.8, 0.3, and 0.02 for PD, LSI, and clumpy, respectively. These decreases indicate a landscape that progressed from stable marsh (less aggregated water) through the degraded marsh stages (highly aggregated) and into the water stage (more connected, less aggregated water). Figures 57, 58, 59, and 60 show the difference values for cohesion, PD, LSI, and clumpy metrics, respectively, while the distribution of those core statistical values are shown in appendix 2. The project regions that exhibited the highest increase in cohesion value for the OA period were Duplantis; Hache; North Boudreaux; West, Central, and East Falgout; and the northern portion of Rambio. The shape and density metrics showed the greatest increases in North Boudreaux, Hache, West and East Falgout, and eastern Rambio regions for PD and LSI, while Duplantis, Hache, North Boudreaux, West/East Falgout, and northern Rambio regions show marked increases in clumpy values. In this context, shape and density value increases are indicative of marsh that experienced relatively rapid degradation and/or conversion to water. Decreases in the patch density metric value were also observed between 1958 and 1968 in the project area. Both increases (change in marsh configuration) and decreases (spoil bank creation) would be expected because of the direct and indirect effects of oil and gas canal construction and subsequent shifts in hydrology (Penland and others, 2000).

Comparisons of the 1958 statistics to the 1968/69 statistics show that, while the landscape remained solid, there were large positive changes in clumpy values. In 1958 most regions were 
solid marsh, with little to no clumpiness, yet by 1968/69 the North Boudreaux and Falgout regions began experiencing ponding, with a concurrent increase in clumpiness. Similar to clumpy values, the North Boudreaux and Falgout regions experienced increasing cohesion values. The majority of the change in cohesion occurred in the transition from the 1958 solid marsh to 5-25 percent water by 1968/69. Some decreases in cohesion values for the TA period were observed. These changes appear to be the effects of altered hydrology on marsh and spoil bank creation within the North Boudreaux, Rambio, and Falgout regions and of interior marsh degradation caused by hydrology and salinity shifts in the northern fresh and intermediate vegetation zones.

Table 17. Summary statistics of core class metrics for 1958, 1968/69, and 1998 dates for coastal Louisiana study. [StdDev, standard deviation; PLAND, percentage of landscape; LPI, largest patch index; PD, patch density; LSI, landscape shape index;
Cohesion, cohesion of patch index; Clumpy, clumpiness index; Category, water category class]

\begin{tabular}{lrrrrr} 
& Min & Max & Sum & Mean & StdDev \\
\hline 1958 & & & & & \\
\hline PLAND & 0 & 100 & 850,539 & 24.1 & 32.0 \\
LPI & 0 & 100 & 777,400 & 22.0 & 31.7 \\
PD & 0 & 434.783 & 154,929 & 4.4 & 8.4 \\
LSI & 0 & 16.942 & 82,062 & 2.3 & 2.1 \\
Cohesion & 0 & 100 & $2,585,713$ & 73.2 & 40.5 \\
Clumpy & $0^{*}$ & 1 & 25,092 & 0.7 & 0.4 \\
Category & 0 & 7 & 93,447 & 2.6 & 2.3 \\
1968 & & & & & \\
PLAND & 0 & 100 & $1,009,538$ & 28.6 & 33.4 \\
LPI & 0 & 100 & 937,283 & 26.5 & 33.4 \\
PD & 0 & 119.04 & 117,702 & 3.3 & 7.1 \\
LSI & 0 & 16.671 & 86,705 & 2.5 & 2.0 \\
Cohesion & 0 & 100 & $2,856,831$ & 80.8 & 35.4 \\
Clumpy & $0^{*}$ & 1 & 27,555 & 0.8 & 0.3 \\
Category & 0 & 7 & 107,299 & 3.0 & 2.3 \\
1998 & & & & & \\
\hline PLAND & 0 & 100 & $1,901,014$ & 53.8 & 35.7 \\
LPI & 0 & 100 & $1,728,883$ & 48.9 & 37.5 \\
PD & 0 & 5000 & 278,884 & 7.9 & 60.2 \\
LSI & 0 & 17.072 & 110,153 & 3.1 & 2.4 \\
Cohesion & 0 & 100 & $3,296,549$ & 93.3 & 20.8 \\
Clumpy & $0 *$ & 1 & 31,197 & 0.9 & 0.2 \\
Category & 0 & 7 & 168,796 & 4.8 & 2.1 \\
\hline
\end{tabular}

* Because very few values were below 0 , values less than 0 were rounded to 0 .

In general, the northernmost solid areas that showed no change in shape or density metric values during the TA period underwent significant changes by 1998 . By this end date, the majority of the North Boudreaux, Hache, Duplantis, and all Falgout regions experienced significant increases in clumpy values. Similarly, these same regions showed a strong trend towards cohesion of water patches between the TB and OA periods. Figures 55 and 56 show that by 1998 the northern two-thirds of the study area experienced significant increases in PLAND and LPI. Table 17 and figure 56 show that most of the areas containing solid marsh had degraded to 25-60 percent water, increased in water patch connectivity, and underwent discernable shoreline degradation by 
1998. Although some changes in percentage of water per tile occurred in the southernmost portion of the study area, the majority of change in these regions was less severe. One noticeable area of decreasing percentage of water during the TB and OA periods was along the southern section of the Houma Navigation Canal. This observed decrease was due to the building of spoil banks along that portion of the canal. 
1958 - PLAND - Percentage of water

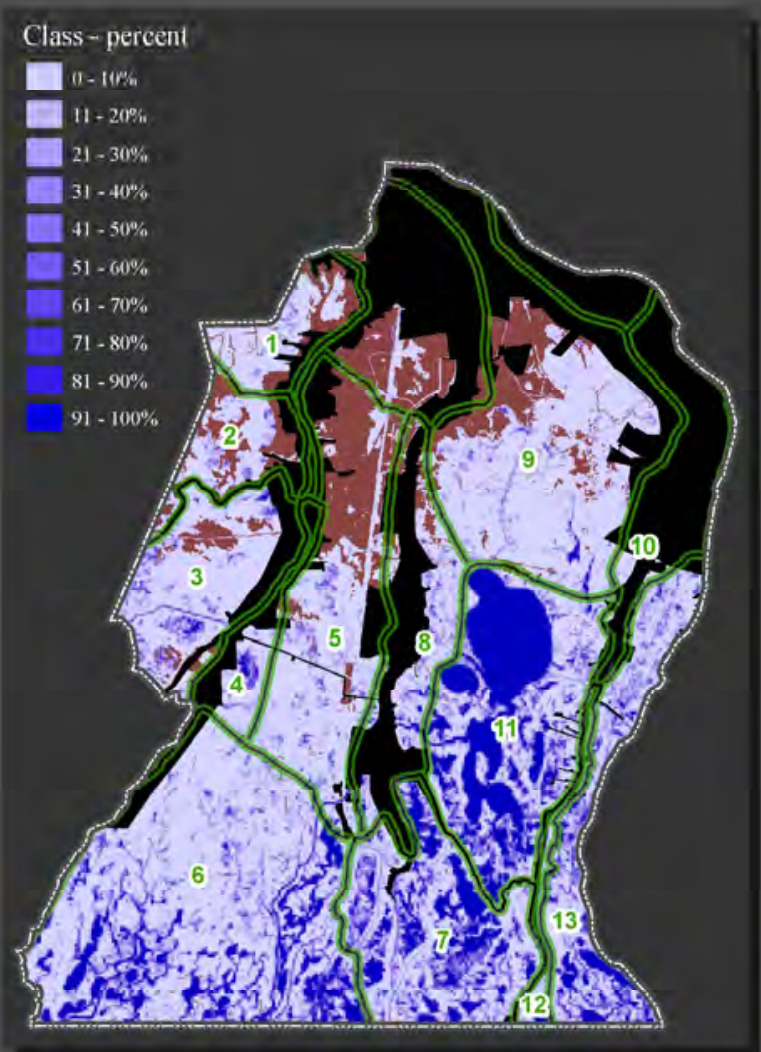

IEGEND

Houma Navigation Canal

Project boundan

Project regions

Developed/other

Forst:

$$
\begin{aligned}
& \text { PROJECT REGIONS } \\
& \text { 1. Duplantis } \\
& \text { 2. Hache } \\
& \text { 3. West Falgout } \\
& \text { 4. Central Falgout } \\
& \text { B. Esiffilgou! }
\end{aligned}
$$

6. Rambio

76 Sale

8. Pelton

Q3 North Boudreany

2 Nont Baratax
1968/69 - PLAND - Percentage of water

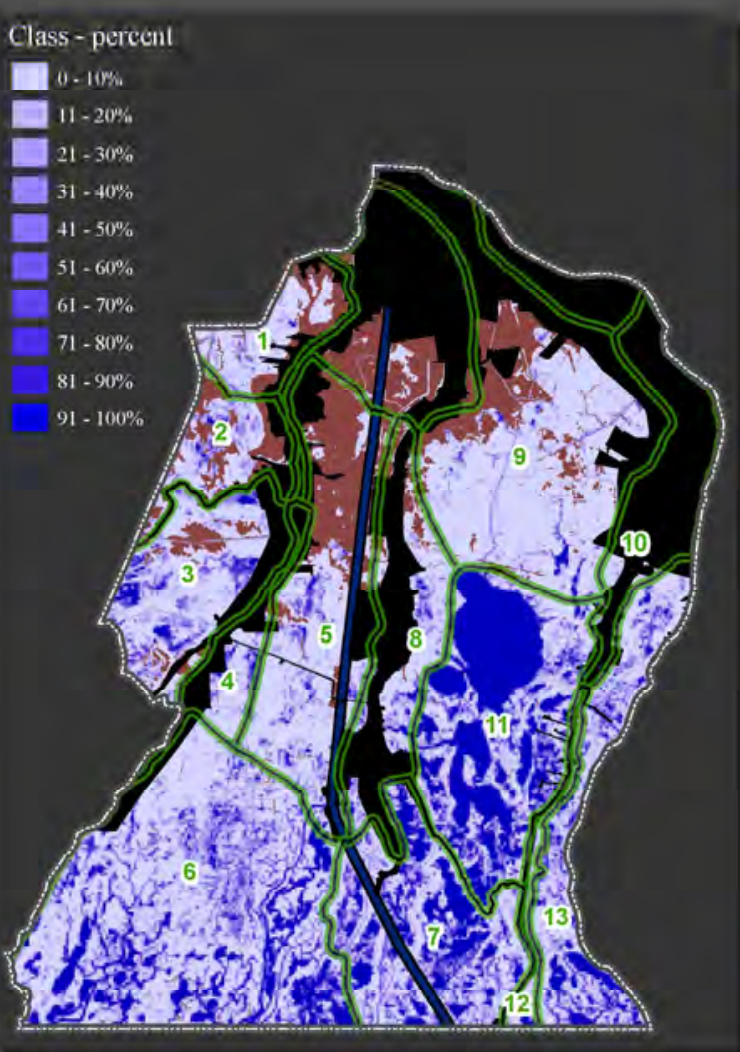

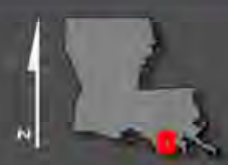

12. Petite Callou

13. LaCache
1998 - PLAND - Percentage of water

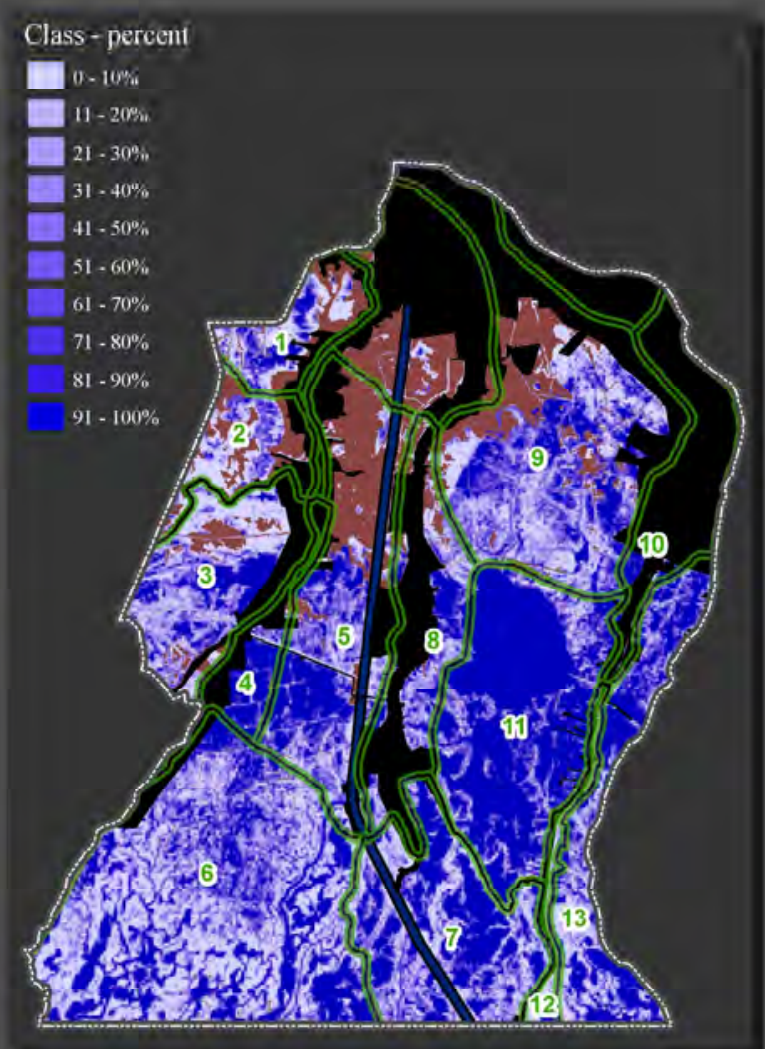

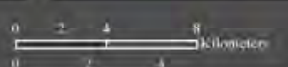
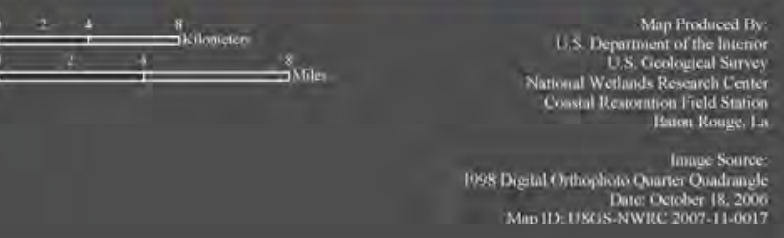

Figure 53. Map of percentage of landscape (PLAND) for 1958, 1968/69, and 1998. The PLAND (percentage of tile landscape that is composed of the corresponding water class), quantified by using the FRAGSTATS analysis tool, is shown in conjunction with project regions in coastal Louisiana. 


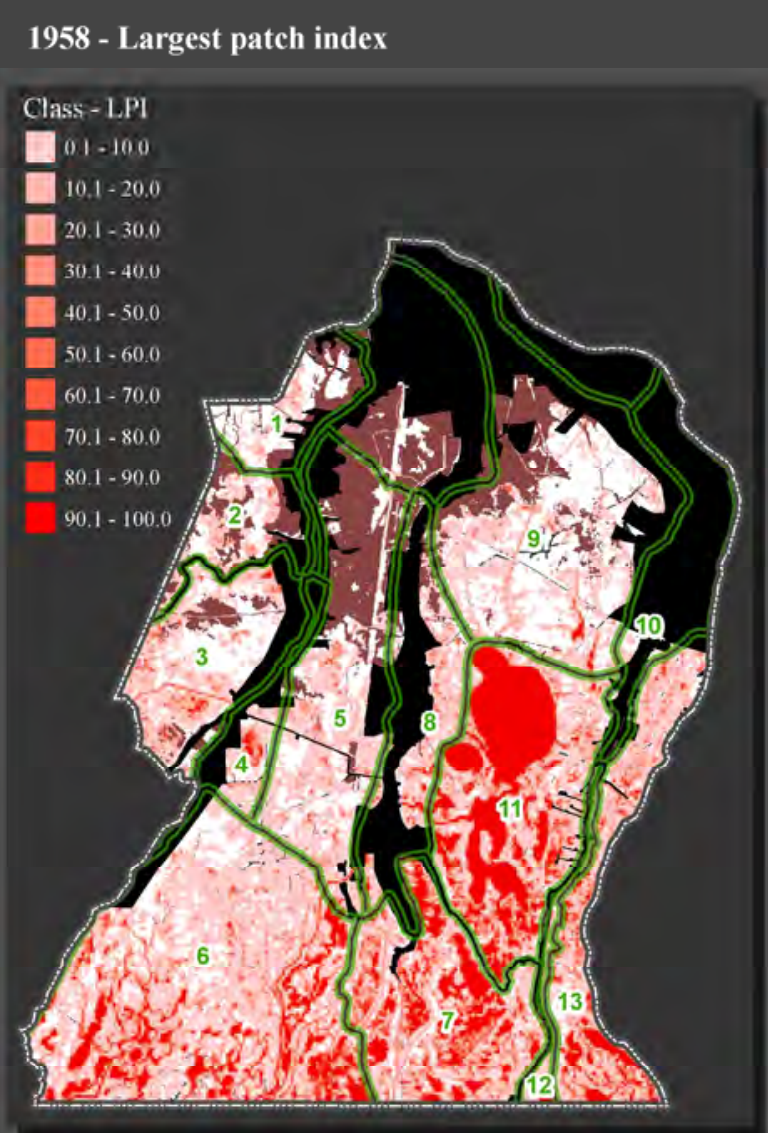

1968/69 - Largest patch index

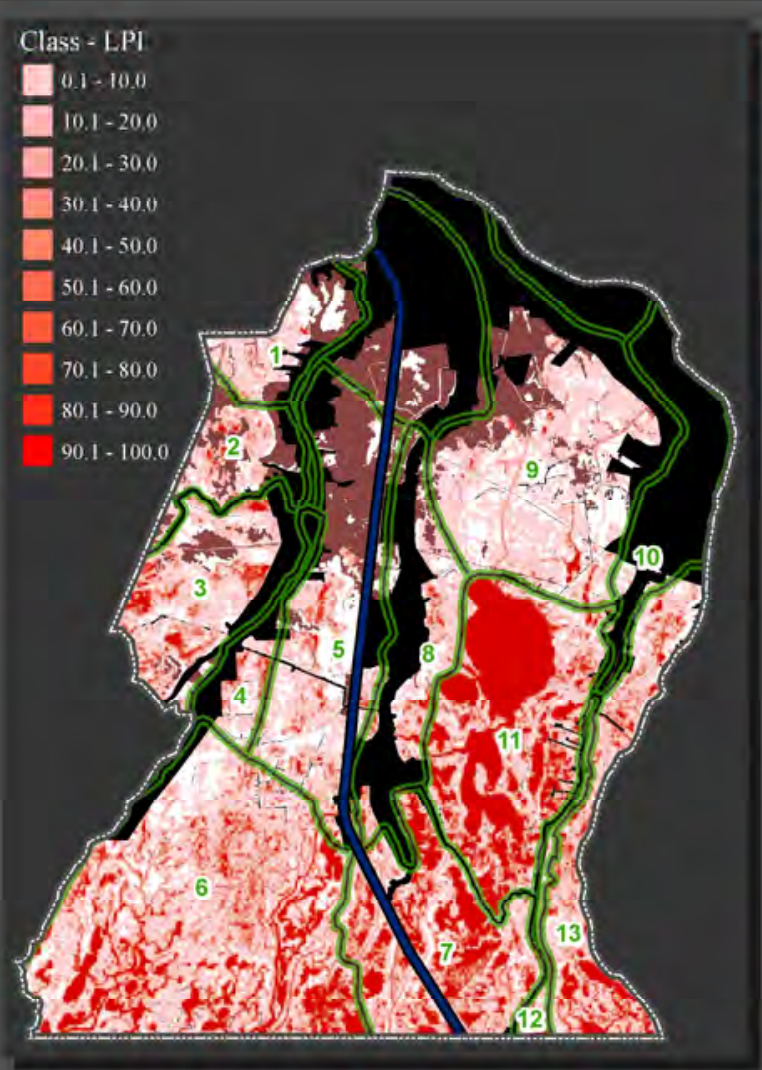

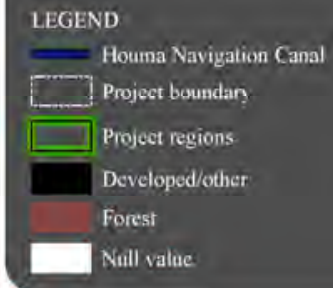

\begin{tabular}{|c|c|c|}
\hline 16. Duplantis & 6. Rambio & 10. Klondyke \\
\hline 2. Hache & 76 Sale & 1186 South Bondreaux \\
\hline 3. West Falgout & 8 Pelton & 12. Petite Caillou \\
\hline 4. Centril Falgout & 28 Norih Bondreanx & 13. La Cache \\
\hline
\end{tabular}

5. East Falgout

$$
4 \text { t }
$$

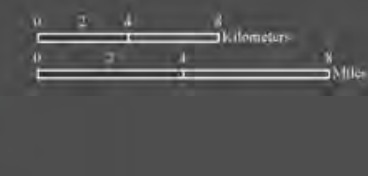

1998 - Largest patch index
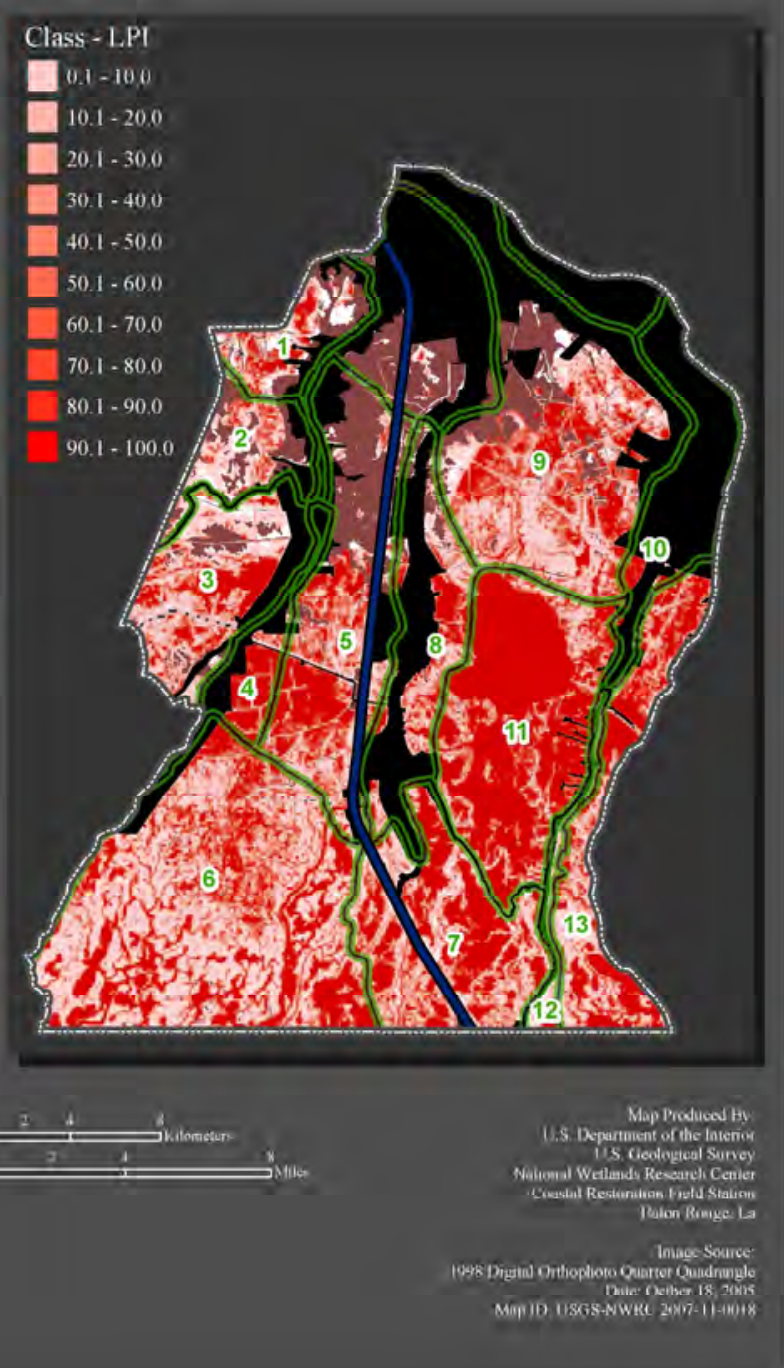

Figure 54. Map of largest patch index (LPI) for 1958, 1968/69, and 1998. The LPI (percentage of total tile landscape area that is composed of the largest water patch), quantified by using the FRAGSTATS analysis tool, is shown in conjunction with project regions in coastal Louisiana. 
1958-68/69 - Percentage of water difference

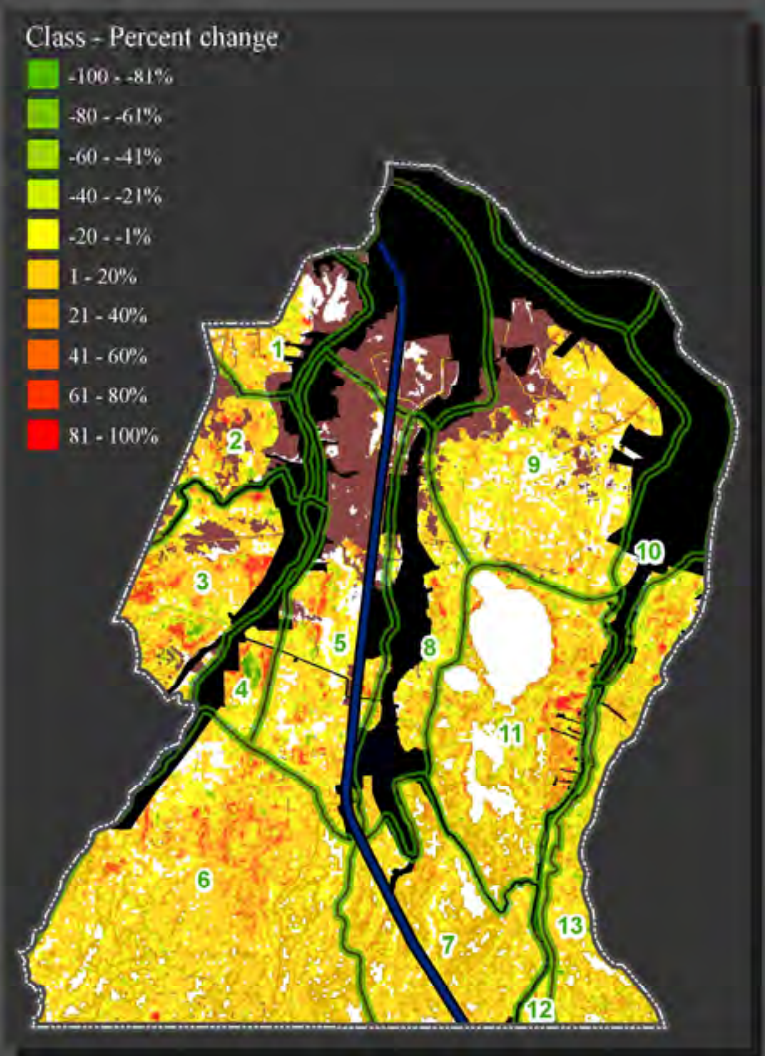

LEGEND

- Houma Navigation Caral

Project boundar

Project regions:

Developed/other

Forest

Nochang:

PROJECT REGIONS 1b. Duplantis

2. Hache

3. West Falgout

4. Central Falgout

5. East Falgout
1968/69-98 - Percentage of water difference

Class - Percent change

$.100-.81 \%$

$-80--61 \%$

$-60--41 \%$
$-40--21 \%$

$-20 \cdots 1 \%$

$1.20 \%$

$21.40 \%$

$41-60 \%$

$61-80 \%$

$81 \cdot 100 \%$

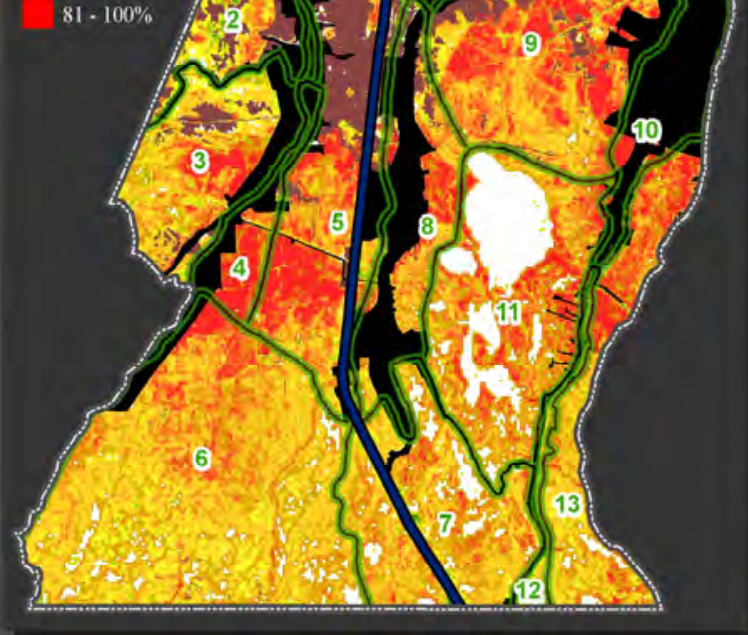

6. Rambio

76 Salo

8. Pelton

Q8 North Boudreaux

\begin{abstract}
103 Klondyke
116 South Boudreaus

12. Petite Caillou

13. La Cache
\end{abstract}
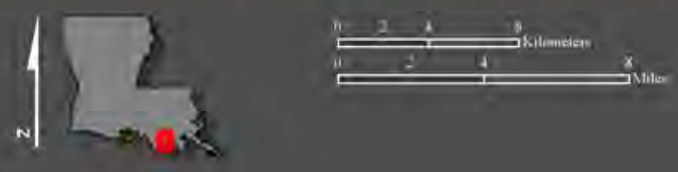

1958-98 - Percentage of water difference

Class - Percent change

$-100=-81 \%$

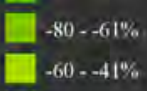

$-40-21 \%$

D. $20 \cdots 1 \%$

口. $20 \%$

$21.40 \%$

$41-60 \%$

$61-80 \%$

$81-100 \%$

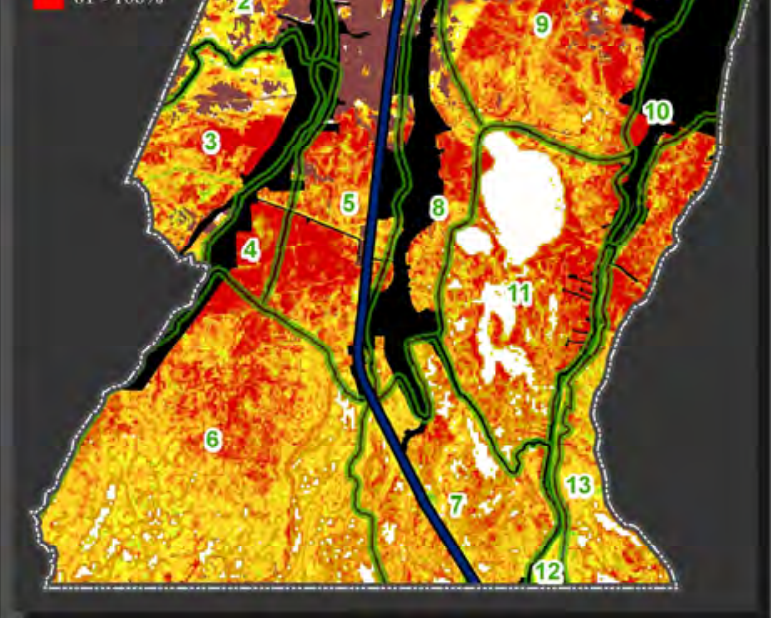

\section{.}

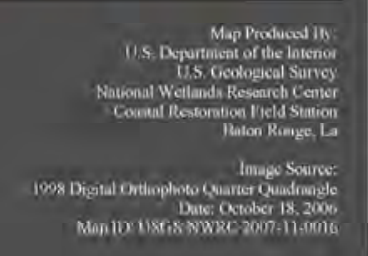

Figure 55. Map of percentage of landscape (PLAND) difference per tile among 1958, 1968/69, and 1998. The PLAND (percentage of tile landscape that is composed of the corresponding water class) values were used to calculate the difference per tile by subtracting values of a previous date from a latter date. Those difference values are shown in conjunction with project regions in coastal Louisiana. 
1958-68/69 - Largest patch index difference

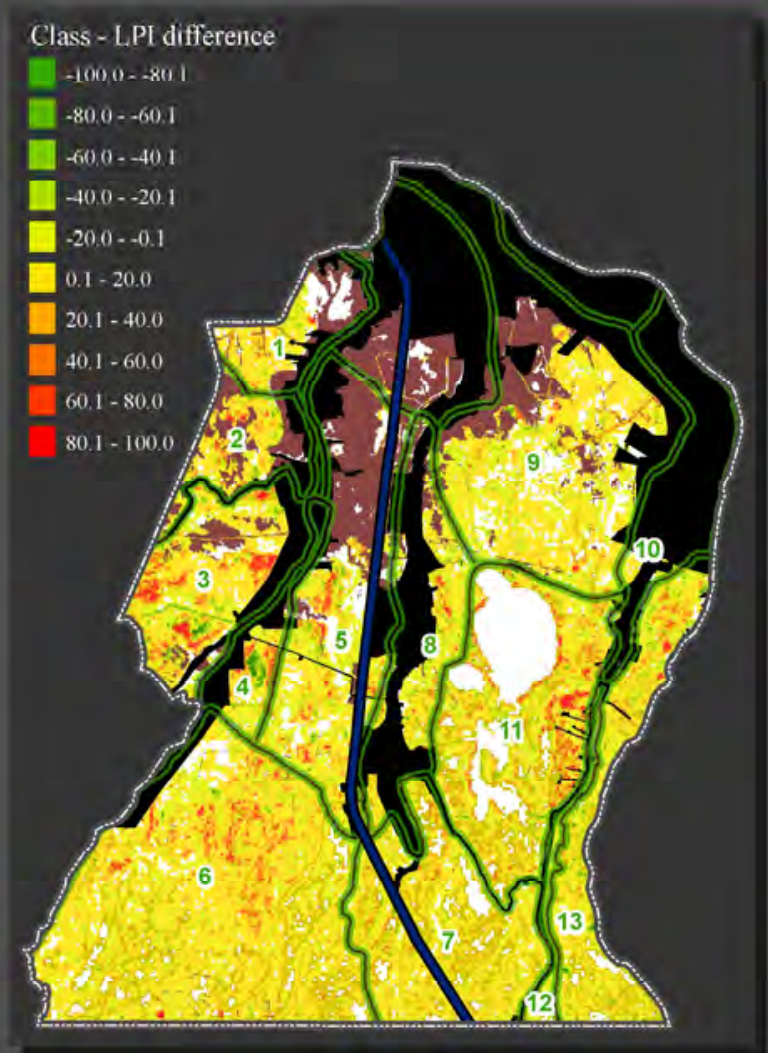

LEGEND

ב.... Houma Navigation Canal

P....... Project boundary

Project regions

Developed/other

Fonct

No chang:

PROJECT REGIONS 16. Duplantis

2. Hache

3. West Falgout

4. Central Falgout

5. East Falgoit
1968/69-98 - Largest patch index difference

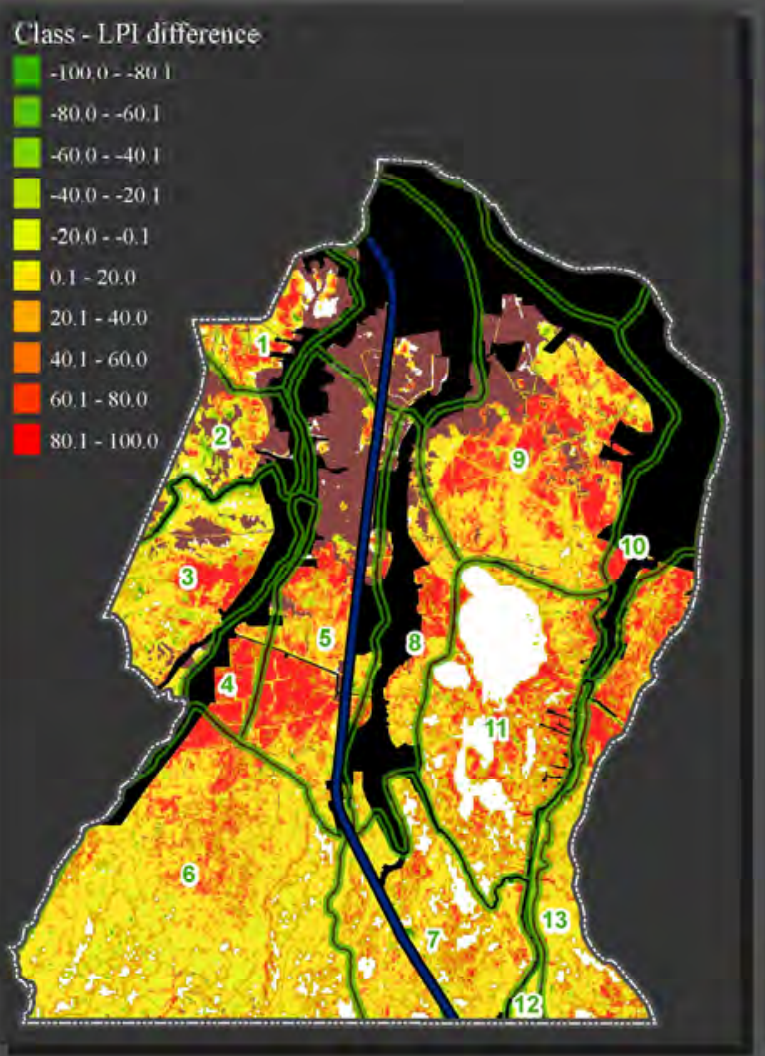

6. Rambio

7. Sale

8. Pelton

2. Nather
Q. North Boudreaux

\begin{abstract}
106 Klondyke
1116 South Boudreaix

12. Petite Caillou

133 La Cache
\end{abstract}

1958-98 - Largest patch index difference

\section{Class - LPI difference}

$-1000=-80.1$
$-80.0--60.1$

C] $\begin{array}{r}-80.0--60.1 \\ -60.0--401\end{array}$

$=-40.0--20.1$

$-20.0--0.1$

$0.1-20.0$

$20.1-40.0$

$40.1-60.0$
$60.1-800$
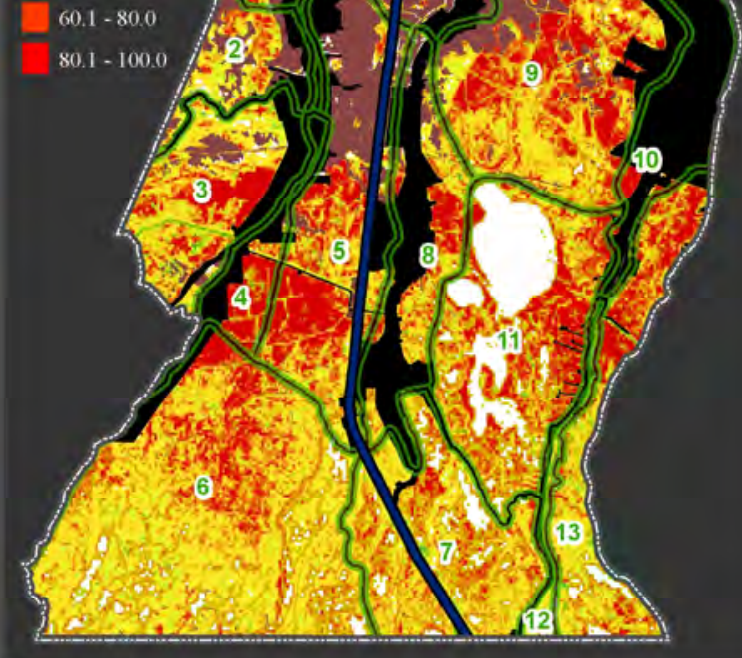

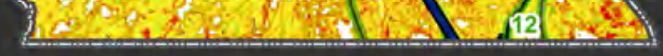
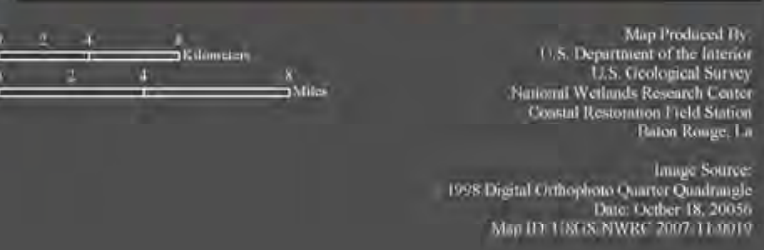

Figure 56. Map of largest patch index (LPI) difference per tile among 1958, 1968/69, and 1998. The LPI (percentage of total tile landscape area that is composed of the largest water patch) values were used to calculate the difference per tile by subtracting values of a previous date from a latter date. Those difference values are shown in conjunction with project regions in coastal Louisiana. 

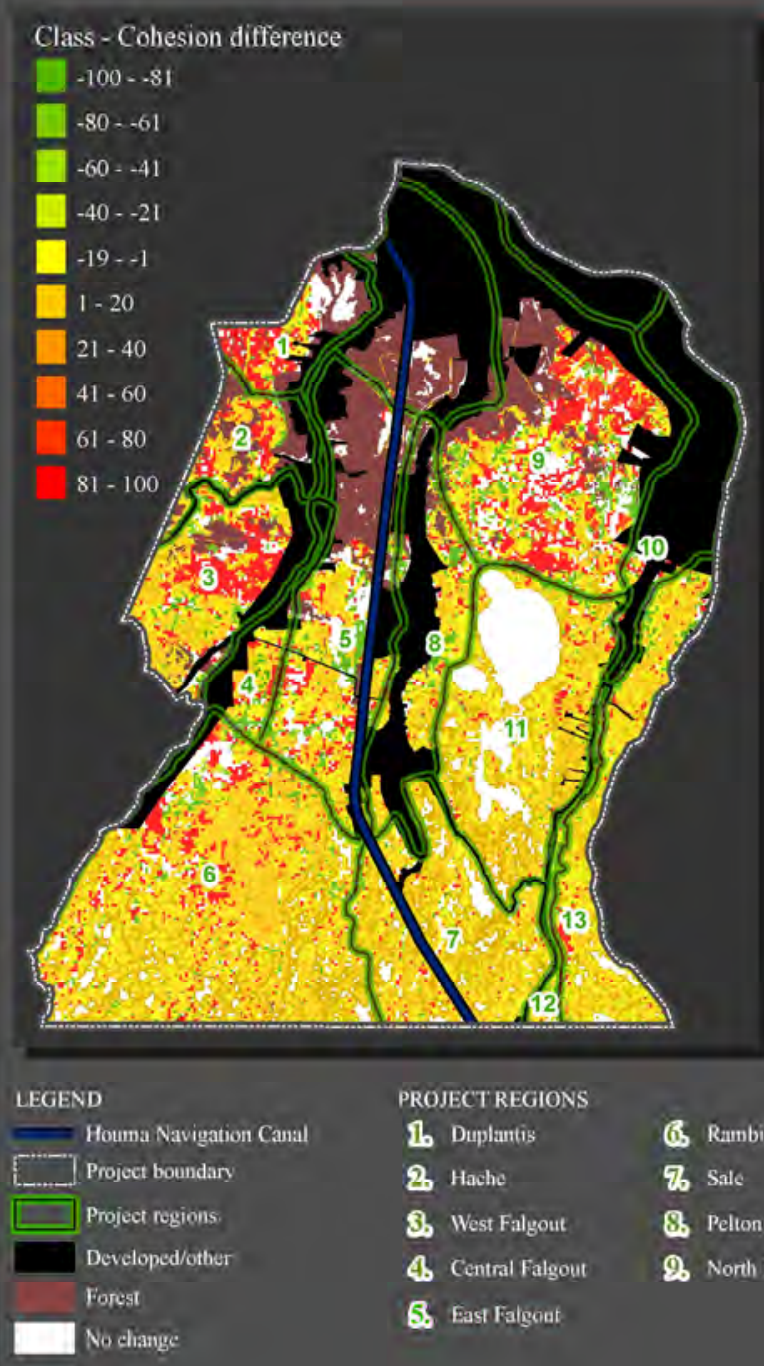

PROJECT REGIONS

16 Duplantis

2b. Hache

3. West Falgout

4. Central Falgout

5. East Falgont
Class - Cohesion difference

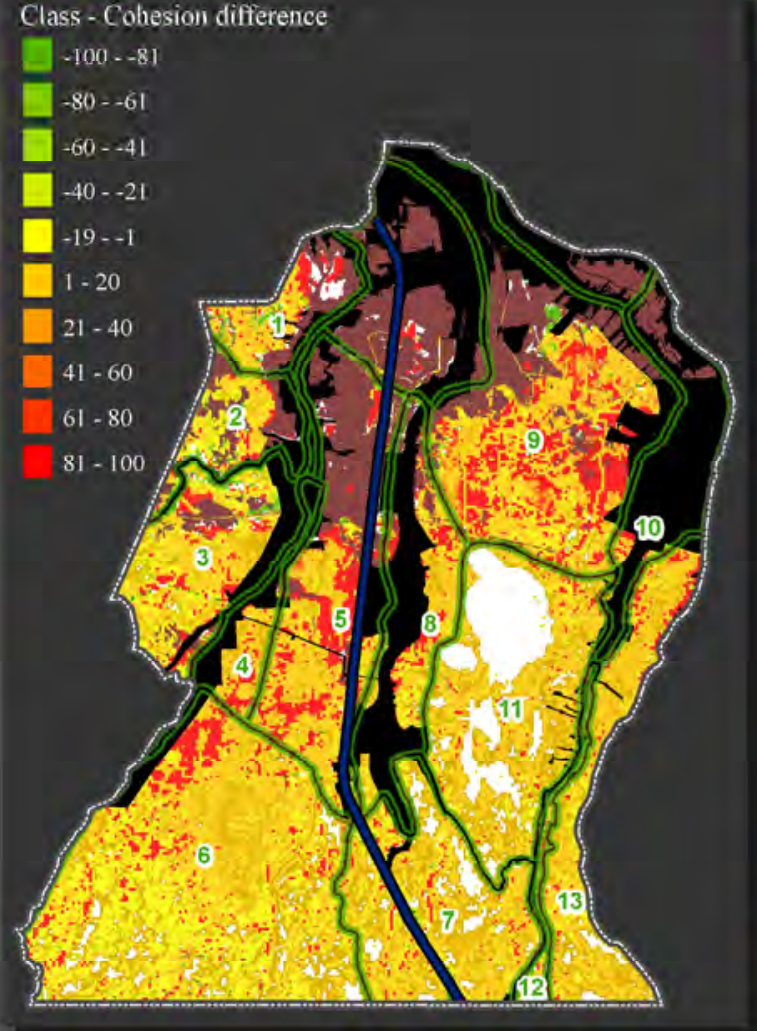

6. Rambio

76 Sale

8. Pelion

28 Norh Boudrcaux

111. South Boudruaux

12. Petitc Caillou

13 La Cache
1958-98 - Cohesion difference

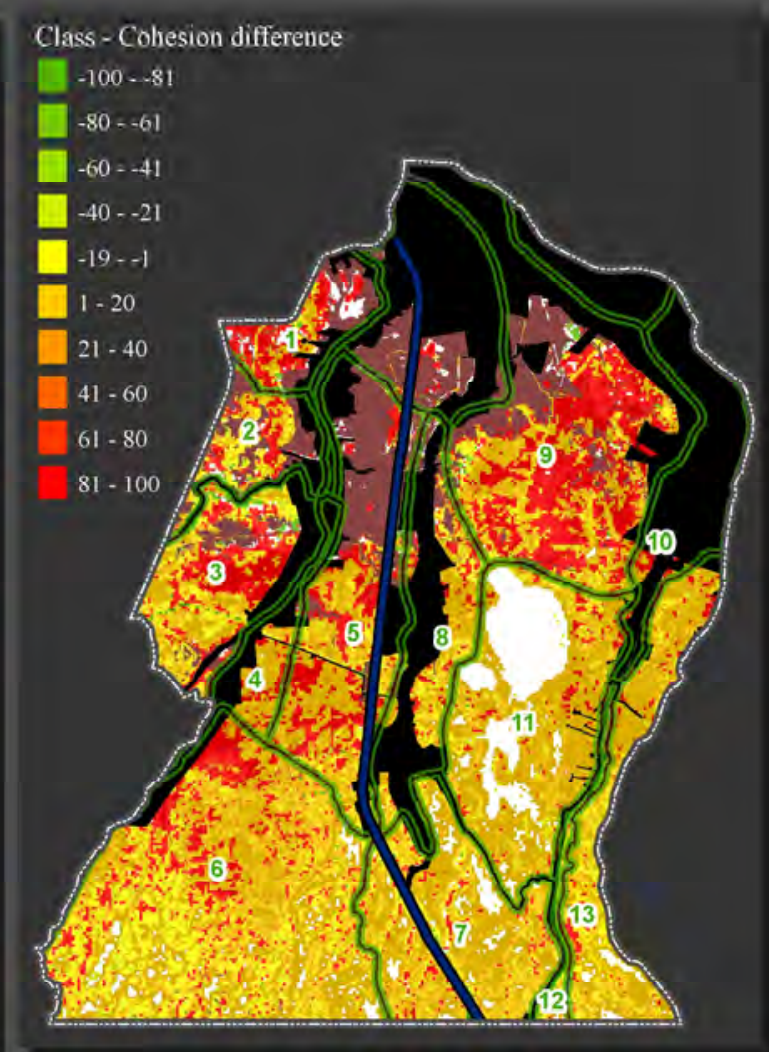

\section{2.}
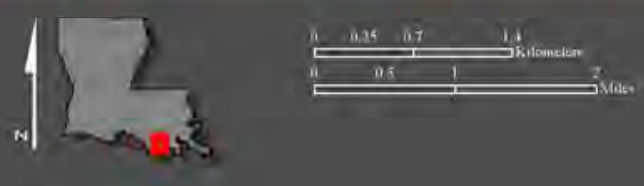

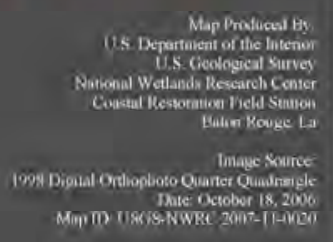

Figure 57. Map of cohesion difference per tile among 1958, 1968/69, and 1998. The cohesion (an index that measures the physical connectedness of the corresponding water patches) values were used to calculate the difference per tile by subtracting values of a previous date from a latter date. Those difference values are shown in conjunction with project regions in coastal Louisiana. 


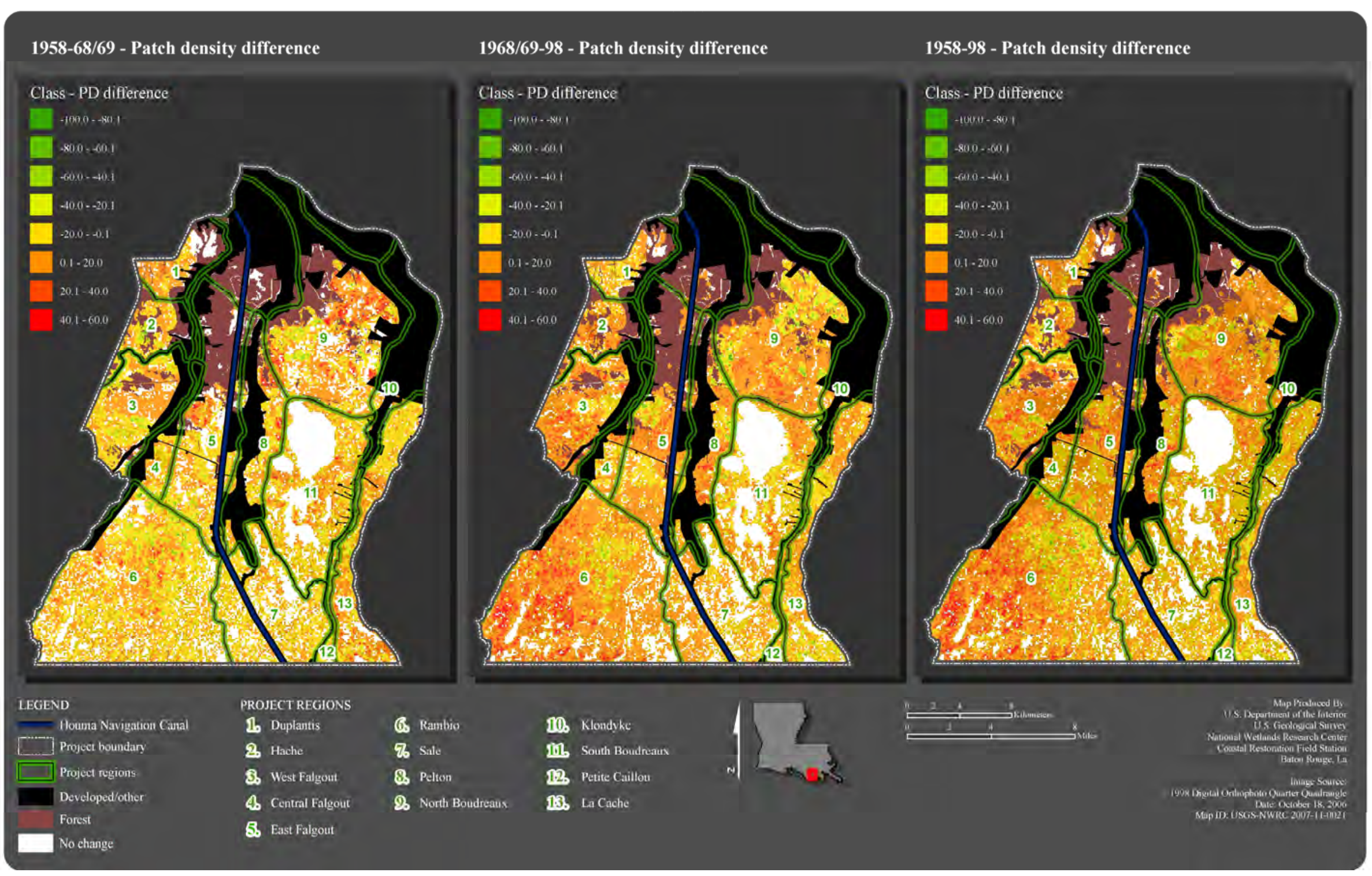

Figure 58. Map of patch density (PD) difference per tile among 1958, 1968/69, and 1998. The PD (number of patches of the corresponding water class divided by total landscape area) values were used to calculate the difference per tile by subtracting values of a previous date from a latter date. Those difference values are shown in conjunction with project regions in coastal Louisiana. 
1958-68/69 - Landscape shape index difference

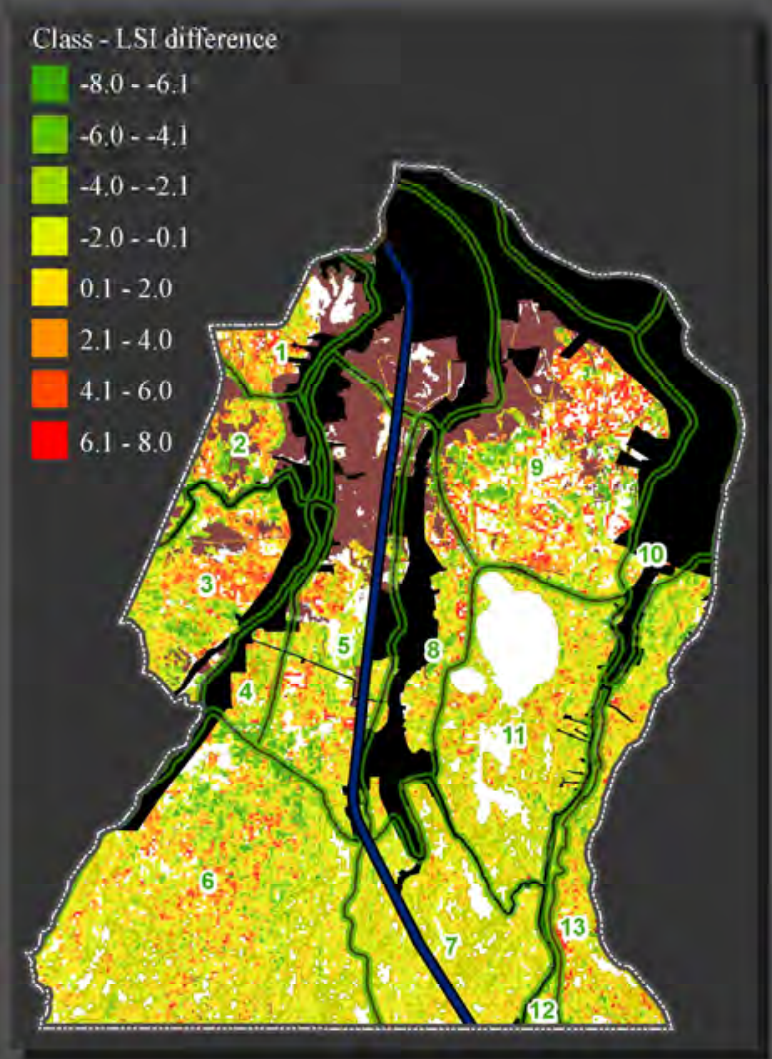

LEGEND

Houna Navigation Canal

P...... Project boundary

Project regions

Dereloped/other

Forest

No change

PROIECT REGIONS

$$
\text { 16. Duplantis }
$$

2. Hache

3. West Falgout

4. Central Falgout

5. East Fulgout
1968/69-98 - Landscape shape index difference

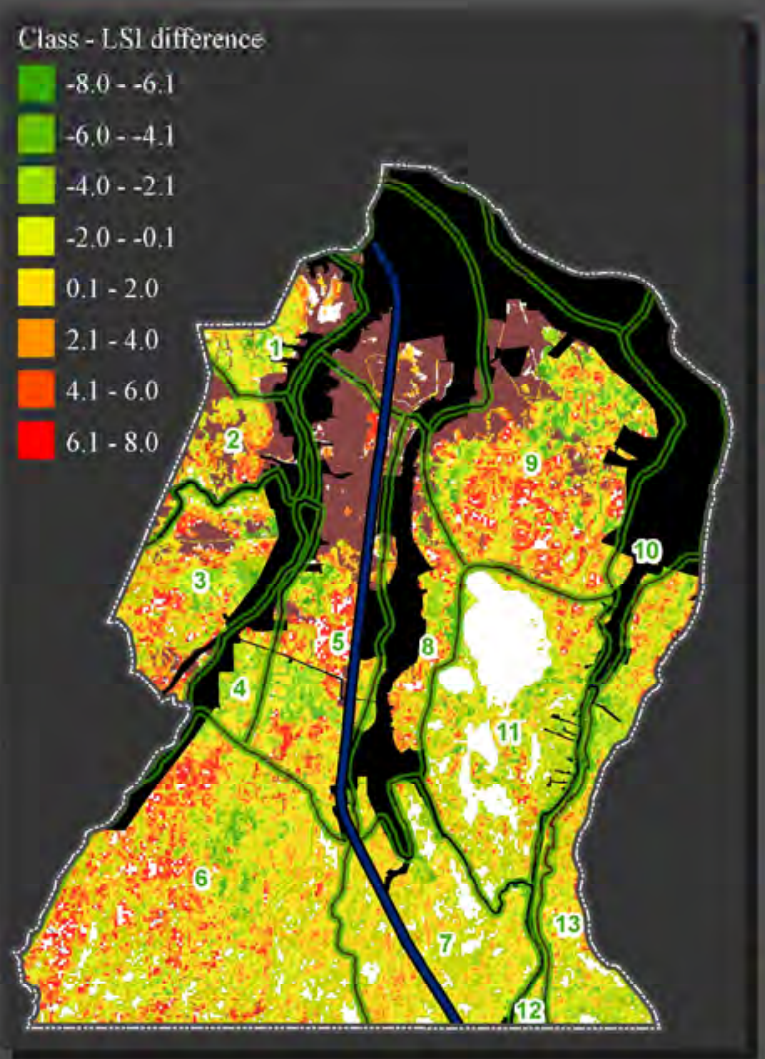

6. Rambio

76 Sale.

8. Petton

Q3 North Boudreaux

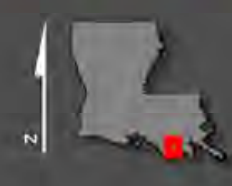

tite Caillo

13. La Cache
1958-98 - Landscape shape index difference

\section{Class - LSI difference}

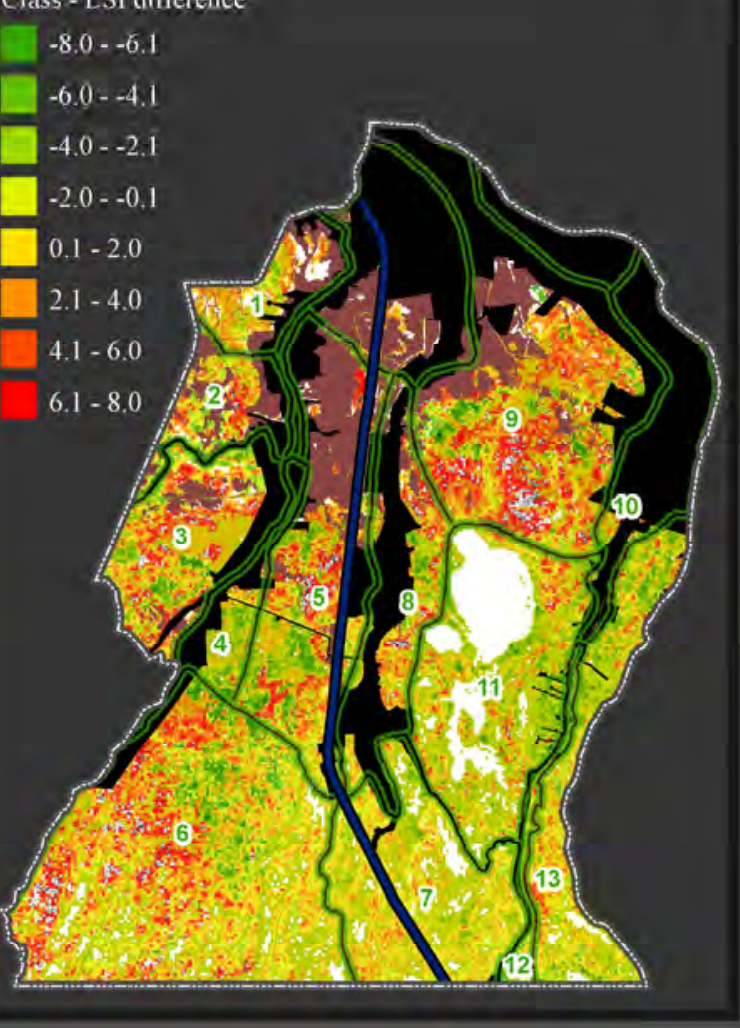

Figure 59. Map of landscape shape index (LSI) difference per tile among 1958, 1968/69, and 1998. The LSI (index of class perimeter length divided by minimum perimeter length required for maximum aggregation) values were used to calculate the difference per tile by subtracting values of a previous date from a latter date. Those difference values are shown in conjunction with project regions in coastal Louisiana. 
1958-68/69 - Clumpy difference

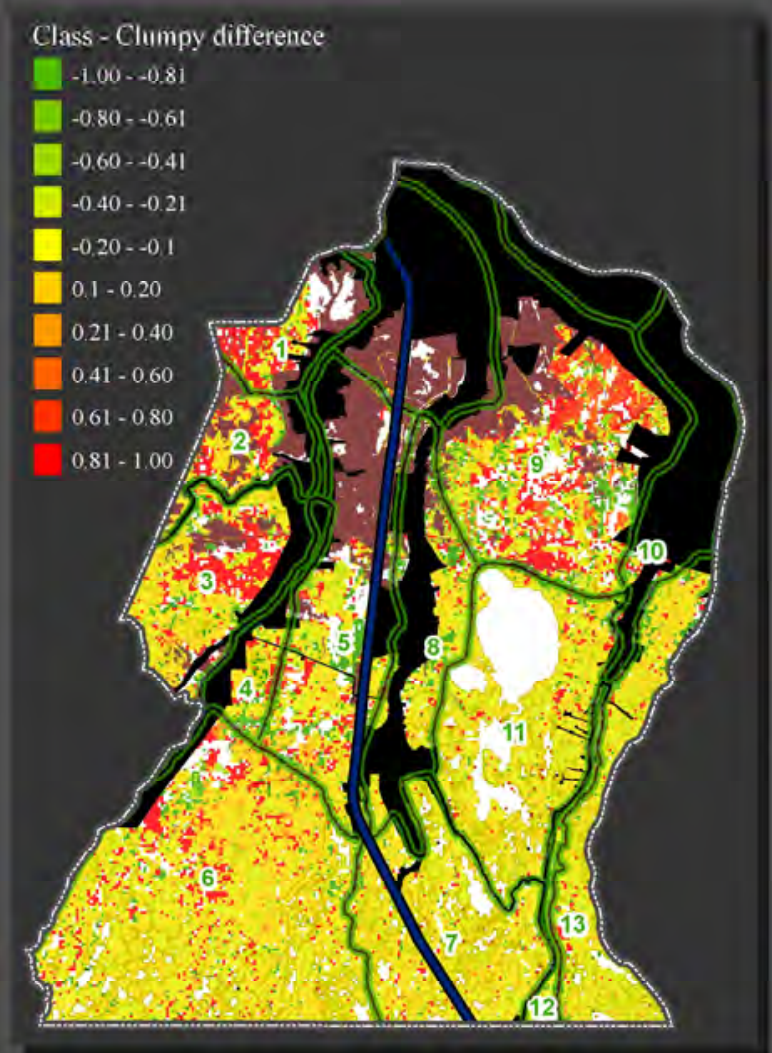

LEGEND

= Houma Navigation Canal

[....] Projcet boundary

Project regions

Developed/other

Forest

No clange:

PROJECT REGIONS 16 Duplantis

2. Hache

4. Central Falgout

5. East Failgout
1968/69-98 - Clumpy difference

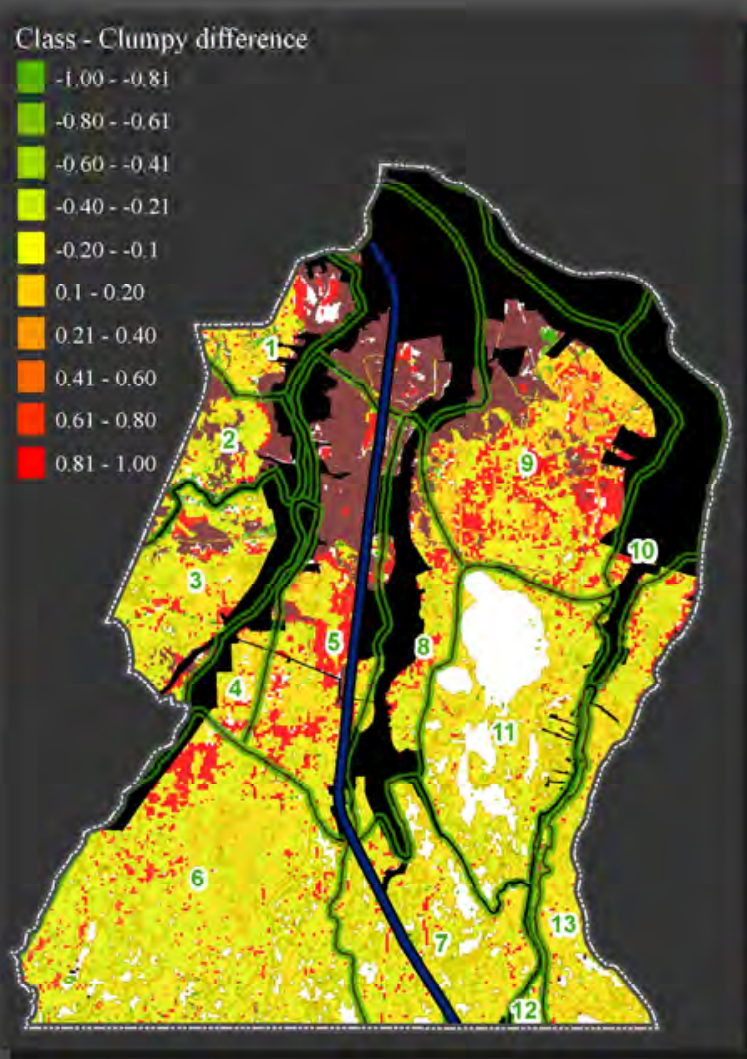

3. West Falgout a. Rambio

76. Sale

8. Pelton

Q. North Boudreaux
103 Klondyke

1016 South Boudreaux

12. Petite Caillou

13. La Cache
1958-98 - Clumpy difference

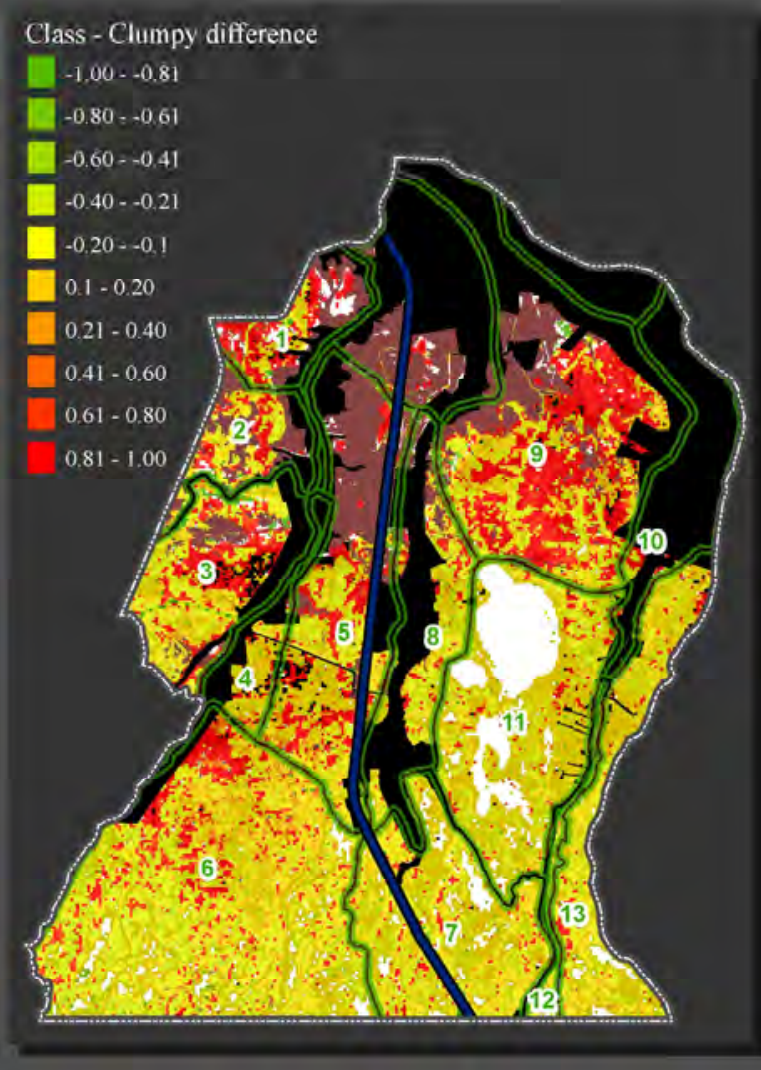

Figure 60. Map of clumpy difference per tile among 1958, 1968/69, and 1998. The clumpy (frequency with which different classes appear side by side in the landscape) values were used to calculate the difference per tile by subtracting values of a previous date from a latter date. Those difference values are shown in conjunction with project regions in coastal Louisiana. 
The category classification process utilizes the percentage of water to land to assign class value to each tile. Figure 61 shows the distribution of classified tiles throughout the project area for all three dates. The project area went from a predominantly solid marsh landscape in the north, with water classes extending south from Lake Boudreaux in 1958, to a similar landscape with minor increases in water in the northern portion of the Rambio region in 1968, to an overall water dominated landscape by 1998 . Table 18 shows the class-level category results for each of the three study dates. The number of tiles making up category classes 2 and 3 remained relatively constant over the TA time period (slight increase for class 3 ) but underwent significant decreases during the TB time period. Category classes 4 and 5 showed greater increases during the TA time period than did category classes 2 and 3, but those increases were inversely proportional to the decrease in number of category class 2 and 3 tiles during the TB period. The greatest change between all dates occurred in category classes 1 (stable marsh) and 7 (open water). Changes in these "indicator" category classes are significant since they represent extremes within the marsh degradation spectrum. The number of category class 1 tiles went from 15,164, to 12,675 , to 3,692, while the number of category class 7 tiles went from 4,065, to 4,863, to 11,574 for the 1958, 1968/69, and 1998 dates, respectively. Figure 62 shows the change in category class values between all project dates. The largest changes in category values are observed in the Duplantis, Hache, all three Falgout, North and South Boudreaux, Klondyke, and the northern portions of both the Rambio and La Cache regions.

In general, the mean category class value went from 2.6 in 1958 , to 3.0 in $1968 / 69$, to 4.8 in 1998. Table 18 and figure 62 show that since the number of category class 6 and 7 tiles remained relatively constant in the TA period, and since the areas of significant loss were isolated in the fresh and intermediate zones, the majority of change occurred as stable category class 1 tiles shifted to degraded category classes 4 and 5. The change in average category class value increased by 1998 and was due to the collapse of solid fresher marshes in the northern regions to highly degraded marsh or a conversion to open water. Extensive changes in category class values were not observed in the southern regions because the majority of tiles in these areas were classified as degraded or water in the preconstruction image and because the degradation patterns are indicative of the less severe shoreline and bank erosion.

The configuration classification was performed for all three project dates by using metric statistic thresholds to classify marsh pattern. Figures 63 and 64 show the distributions and changes in configuration classes for all three dates. Figure 63 shows that the majority of the landscape in 1958 was classified as configuration class A, which is indicative of a stable marsh with prominent and linear water patches. The majority of the configuration class $\mathrm{C}$ tiles that make up the 1958 landscape are in the East Falgout and northern Rambio regions and are scattered throughout the North/South Boudreaux and La Cache regions. The number of configuration class A tiles remained relatively constant, showing an increase in 1968/69 and then a decrease in 1998. By 1998, there was approximately a fourfold increase in the number of configuration class B tiles and threefold increase in the number of configuration class $C$ tiles within the project area. These tiles appear in the West and East Falgout, North Boudreaux, Pelton, and Rambio regions and are scattered throughout the South Boudreaux region. Figure 64 (Marsh Configuration Difference [MCD]) uses the configuration classes $\mathrm{A}, \mathrm{B}$, and $\mathrm{C}$, along with category classes 1,6 , and 7 , to assign configuration value to each tile. Values are assigned to each class as follows: category class $1=0$, configuration class $A=1$, configuration class $B=2$, configuration class $C=3$, and category classes 6 and $7=4$. To calculate the difference per tile, configuration values for a previous date were subtracted from a later date. For example, marsh configuration difference values of 4 represent areas that went from solid marsh (value $=0$ ) in 1958 to category 7 , or open water (value $=4$ ), in 1968 or 1998. The marsh configuration difference figure shows extreme change in class values in 
the Duplantis; Hache; West, Central and East Falgout; Pelton; North and South Boudreaux; and northern portions of Rambio and La Cache regions for the OA period. The configuration section of table 18 shows that, though there were sizable changes in the number of configuration $\mathrm{B}$ and $\mathrm{C}$ classified tiles, the majority of the OA change was in the land (category class 1 ) and water (category classes 6 and 7) classes.

Table 18. Summary count of category and configuration classes for the 1958, 1968/69, and 1998 dates.

\begin{tabular}{crrr}
\hline Category & $\mathbf{1 9 5 8}$ & $\mathbf{1 9 6 8 / 6 9}$ & $\mathbf{1 9 9 8}$ \\
\hline $\mathbf{1}$ & 15,164 & 12,675 & 3,692 \\
$\mathbf{2}$ & 3,399 & 3,285 & 1,776 \\
$\mathbf{3}$ & 5,726 & 5,859 & 4,801 \\
$\mathbf{4}$ & 2,939 & 3,548 & 4,211 \\
$\mathbf{5}$ & 2,436 & 3,086 & 4,870 \\
$\mathbf{6}$ & 1,615 & 2,028 & 4,420 \\
$\mathbf{7}$ & 4,065 & 4,863 & 11,574 \\
\hline Total & 35,344 & 35,344 & 35,344 \\
\hline Configuration & $\mathbf{1 9 5 8}$ & $\mathbf{1 9 6 8 / 6 9}$ & $\mathbf{1 9 9 8}$ \\
\hline Land & 15,164 & 12,675 & 3,692 \\
$\mathbf{A}$ & 13,711 & 15,120 & 13,360 \\
$\mathbf{B}$ & 100 & 84 & 417 \\
$\mathbf{C}$ & 689 & 574 & 1,881 \\
Water & 5,680 & 6,891 & 15,994 \\
\hline Total & 35,344 & 35,344 & 35,344 \\
\hline
\end{tabular}

The category and configuration classifications were combined to create the two-tier marsh fragmentation classification system. These classes combine the percentage of water (category) with the landscape pattern (configuration) to give a more complete representation of marsh fragmentation. Figure 65 shows the distribution of fragmentation classes for each date. In 1958 the majority of the landscape was composed of classes 1 and $2 \mathrm{~A}$ in the north, classes $3 \mathrm{~A}, 4 \mathrm{~A}$, and $5 \mathrm{~A}$ in the southern marshes, and classes $2 \mathrm{~B}$ and $2 \mathrm{C}$ scattered throughout the North Boudreaux; West, Central, and East Falgout; La Cache; and northern portions of Rambio regions. The 1968/69 landscape was similar to the 1958 landscape, with the addition of the 3B, 3C, 4B, 4C, 5B, and 5C classes in the North and South Boudreaux, southern La Cache, and Rambio regions. By 1998 there were fewer of the solid marsh tiles, and those remaining were isolated to the southwest portion of Rambio, areas north of Lake Boudreaux, and along the northern edge of the West Falgout region.

The fragmentation classes were also used to evaluate general marsh condition by grouping tiles based on the degree of marsh degradation (table 19). There are three levels of marsh condition: solid marsh, degraded marsh, and water. These marsh conditions are classified by using several marsh water-to-shape criteria. Solid marshes are landscapes that contain less than 10 percent water and contain the relatively less degraded configuration subclasses $2 \mathrm{~A}$ and $2 \mathrm{~B}$. Degraded marshes are landscapes that are classified as degraded configuration subclass $2 \mathrm{C}$ or contain between 10 and 60 percent water. And finally, the "water" class is any tile that contains more than 60 percent water. 


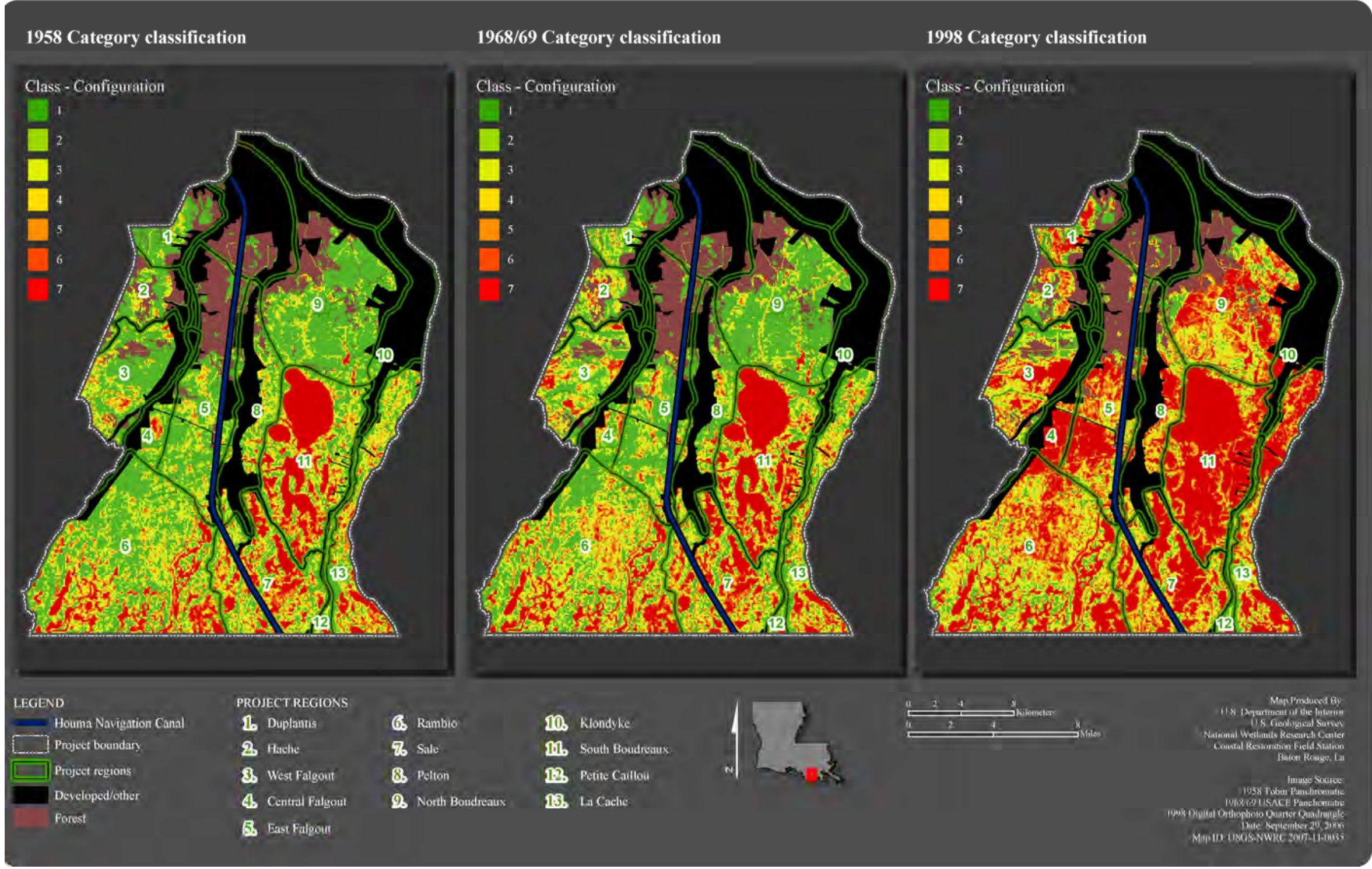

Figure 61. Map of category classification (per tile) for 1958, 1968/69, and 1998. Category classes (which represent percentages of water as category $1,0-<5$ percent water within marsh; category $2,5-<10$ percent water; category $3,10-<25$ percent water; category 4, 25-<40 percent water; category $5,40-<60$ percent water; category $6,60-<80$ percent water; and category $7, \geq 80$ percent water) are shown in conjunction with project regions in coastal Louisiana. 


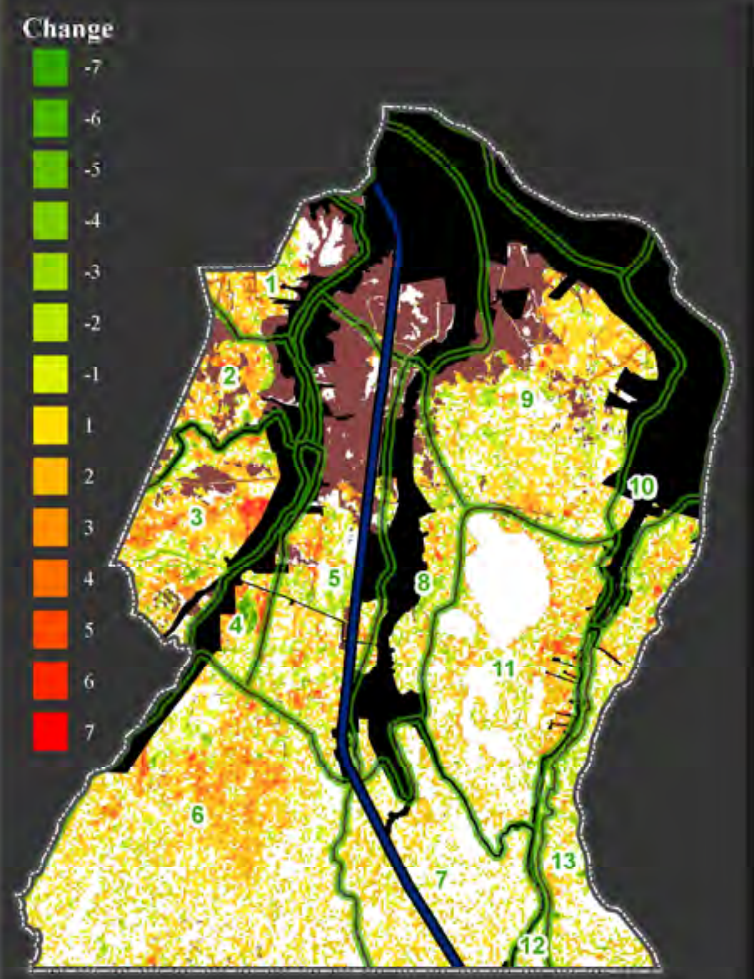

LEGEND

= Houma Navigation Canal

D..... Project boundan

Project regions

Developed/other

Fortst

No change 16. Duplantis 2. Hache

3. West Falgout

4. Central Falgout

5. East Falgout
1968/69-98 Category change

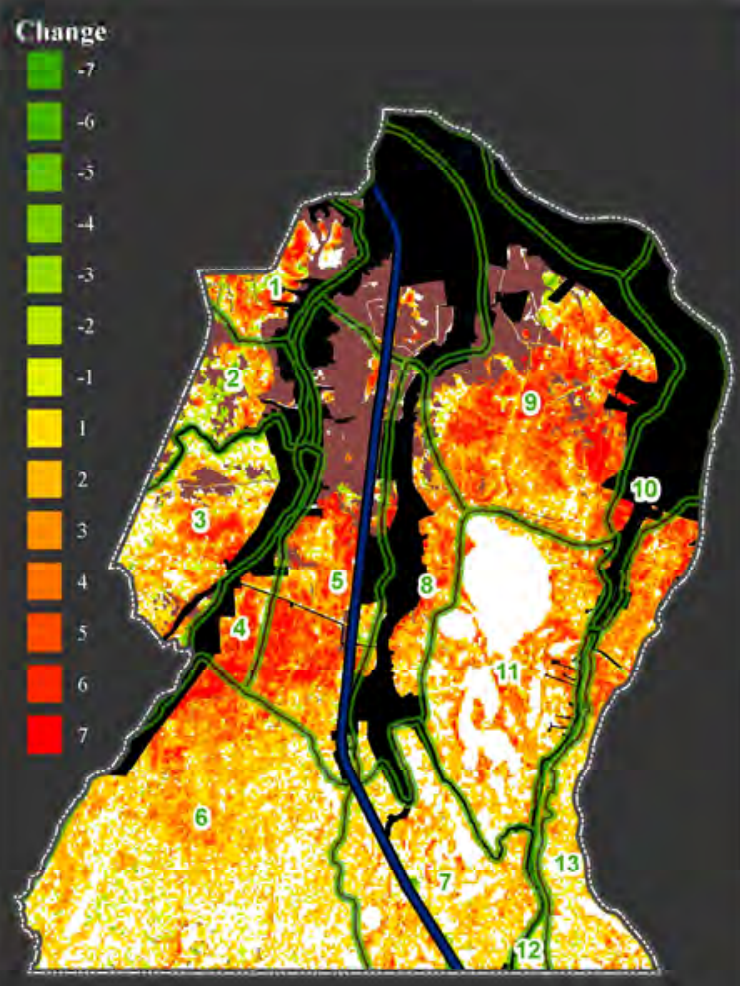

PROJECT REGIONS
6. Rambio

8 Sale

8. Pelton

28 North Boudreaux

116. South Boudreaux

12. Petite Caillow

13. La Cache
1958-98 Category change
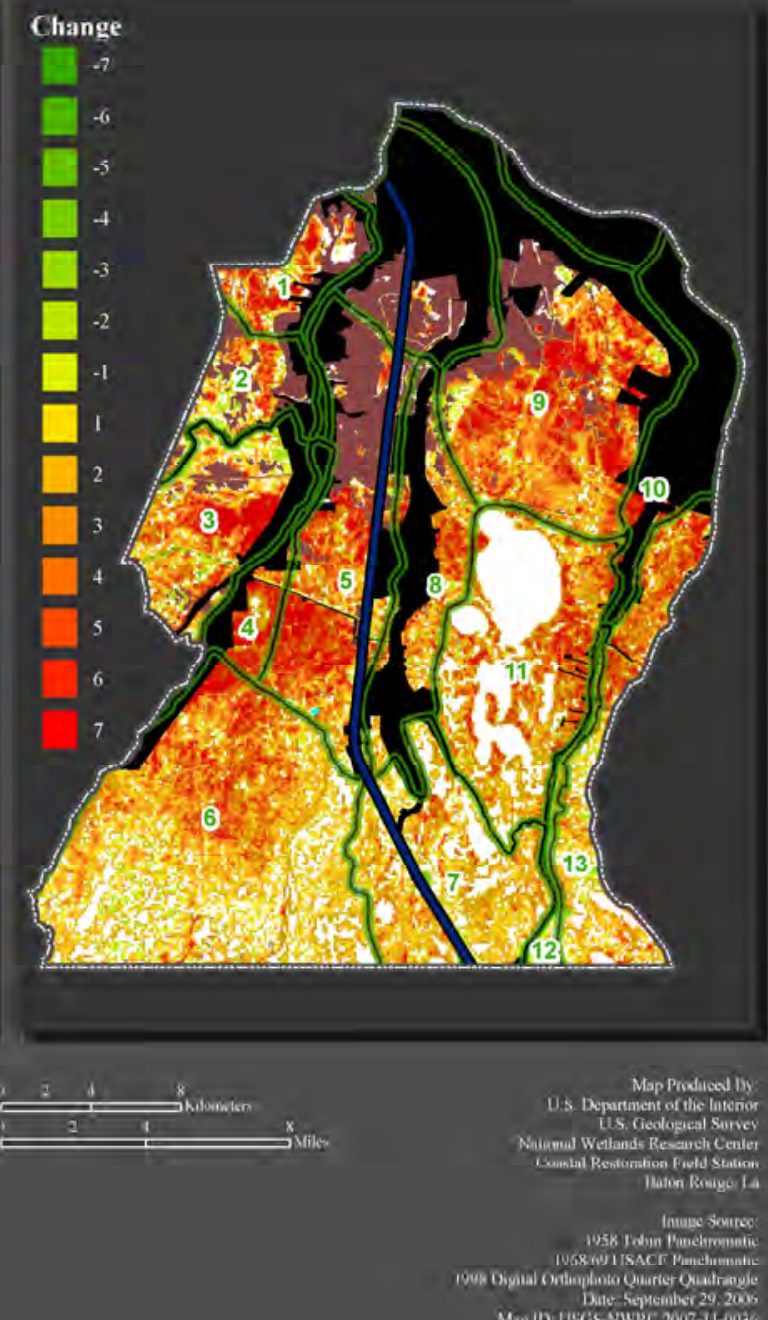

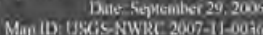

Figure 62. Map of category difference per tile among 1958, 1968/69, and 1998. Category classes were used to calculate the difference per tile by subtracting classes of a previous date from a latter date. Those difference values are shown in conjunction with project regions in coastal Louisiana. 
1958 Configuration classification

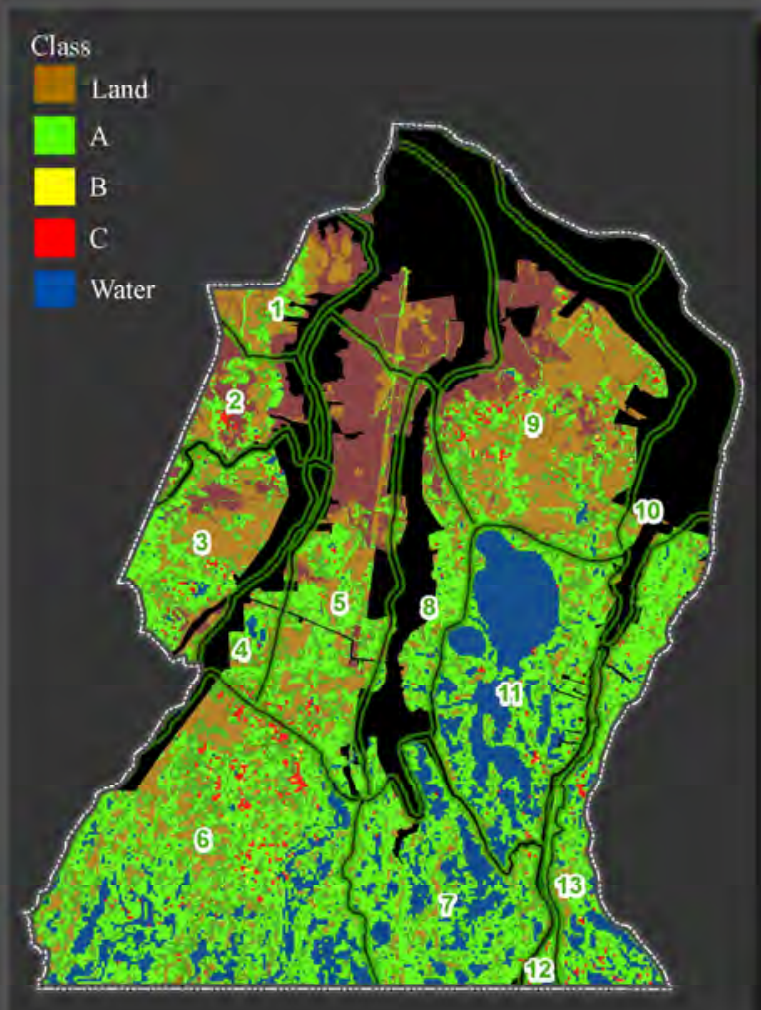

LEGEND

= Houma Navigation Canal

-.-.-1 Project boundar

Project regions

Developed/other

Forest
PROJECTREGIONS

1. Duplantis

6. Rambio

2. Hache

3. West Falgout

4. Central Falgout

5. East falgout
1968/69 Configuration classification

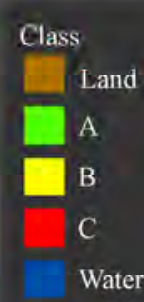

Class
Land
A
B
C
Water

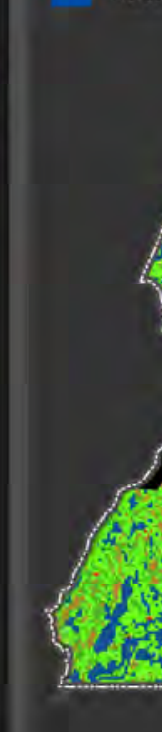

西
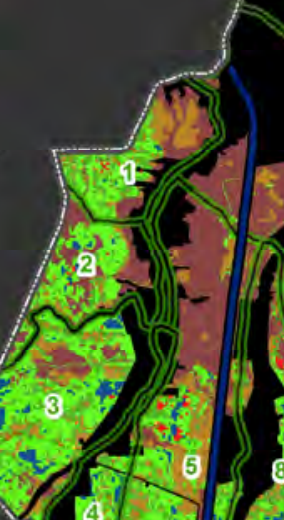
.

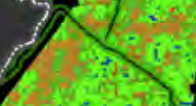

(1)

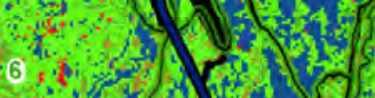

5. 12,15

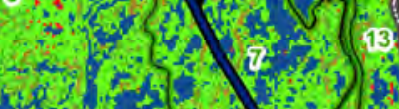

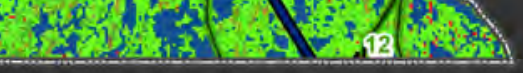

Class

A
B
C
Water

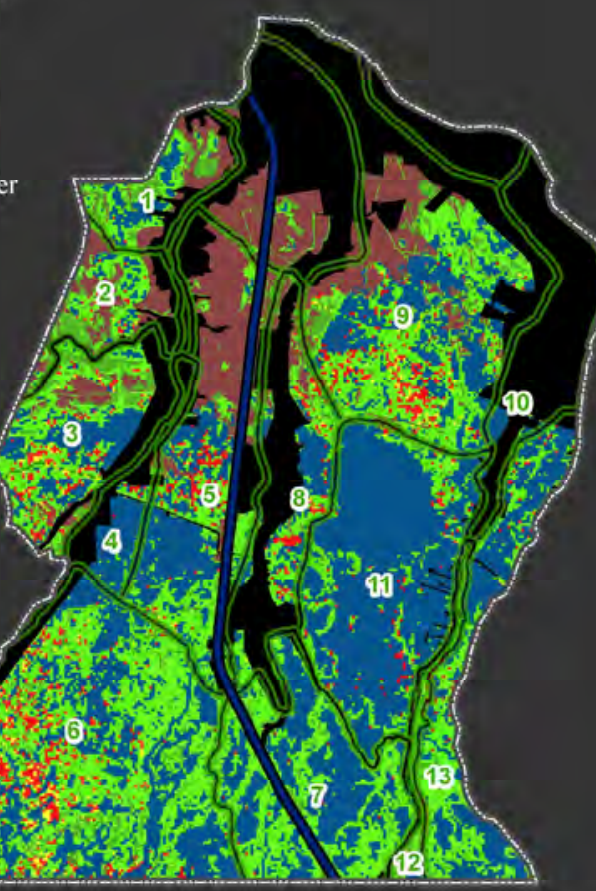

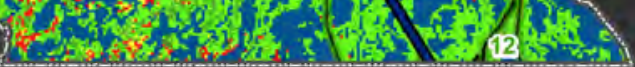

Zo Sale

8. Pelton

8. North Boudreaus

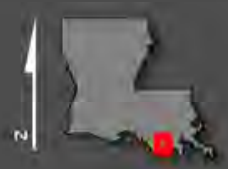

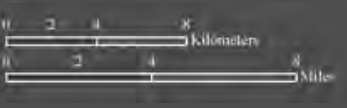

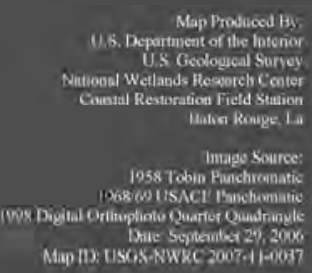

Figure 63. Map of configuration classification (per tile) for 1958, 1968/69, and 1998. Configuration classes (A, typically large connected water patches with linear edge; $B$, typically small disconnected patches with a more random distribution and fewer instances of connection; and C, a combination of subclass A and subclass B) are shown in conjunction with project regions in coastal Louisiana. 
1958-68/69 Configuration change

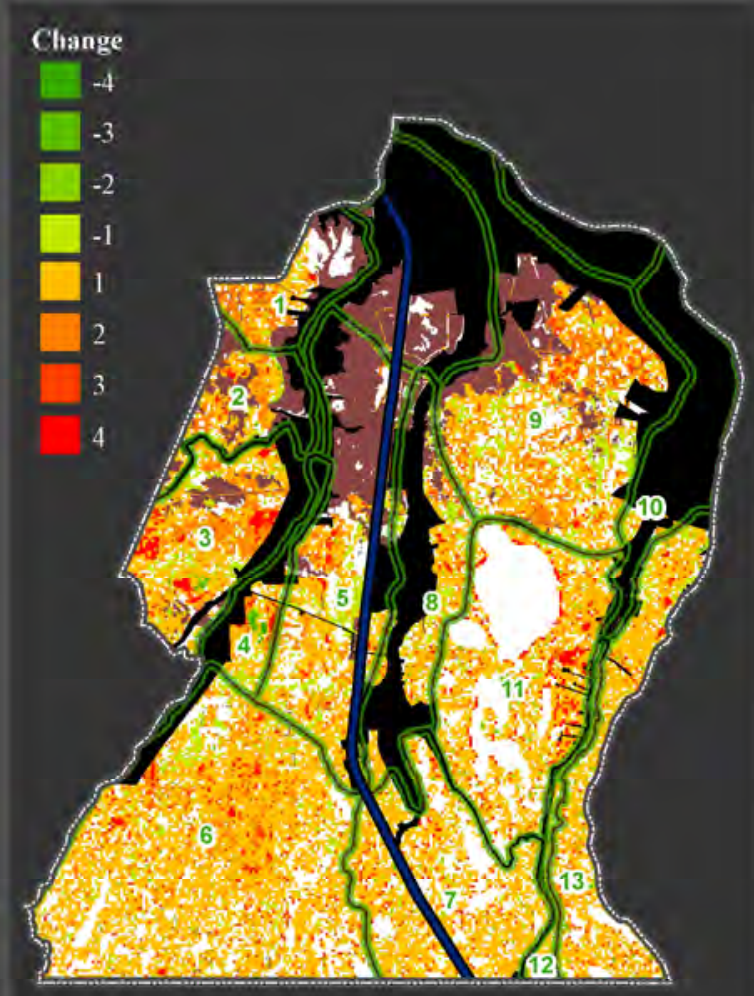

1968/69-98 Configuration change

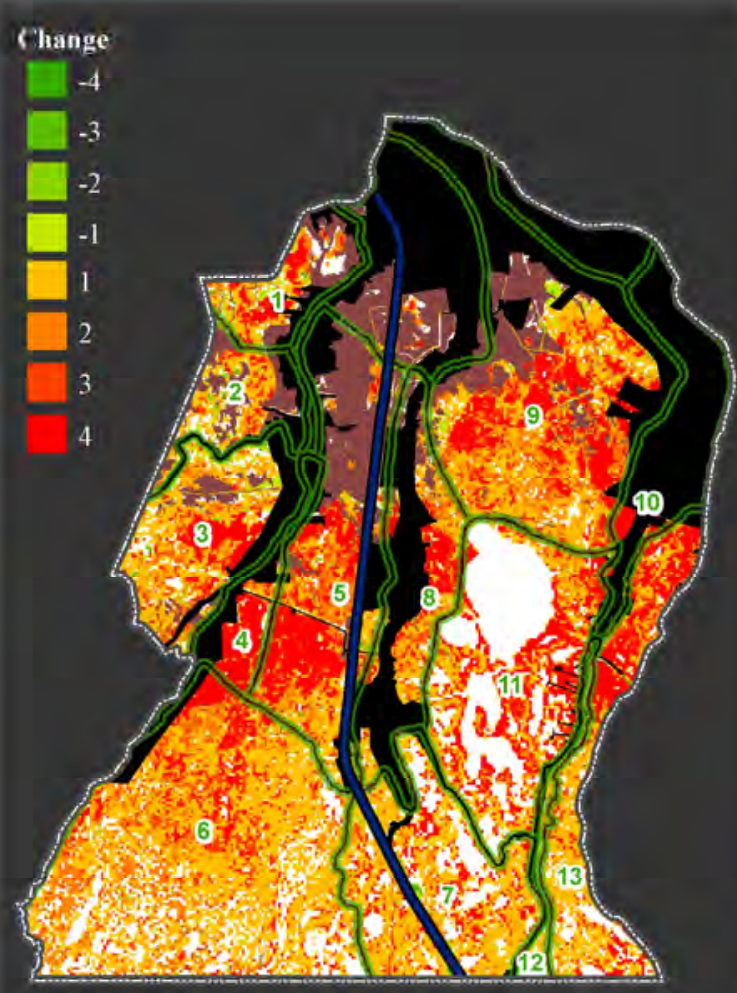

1958-98 Configuration change

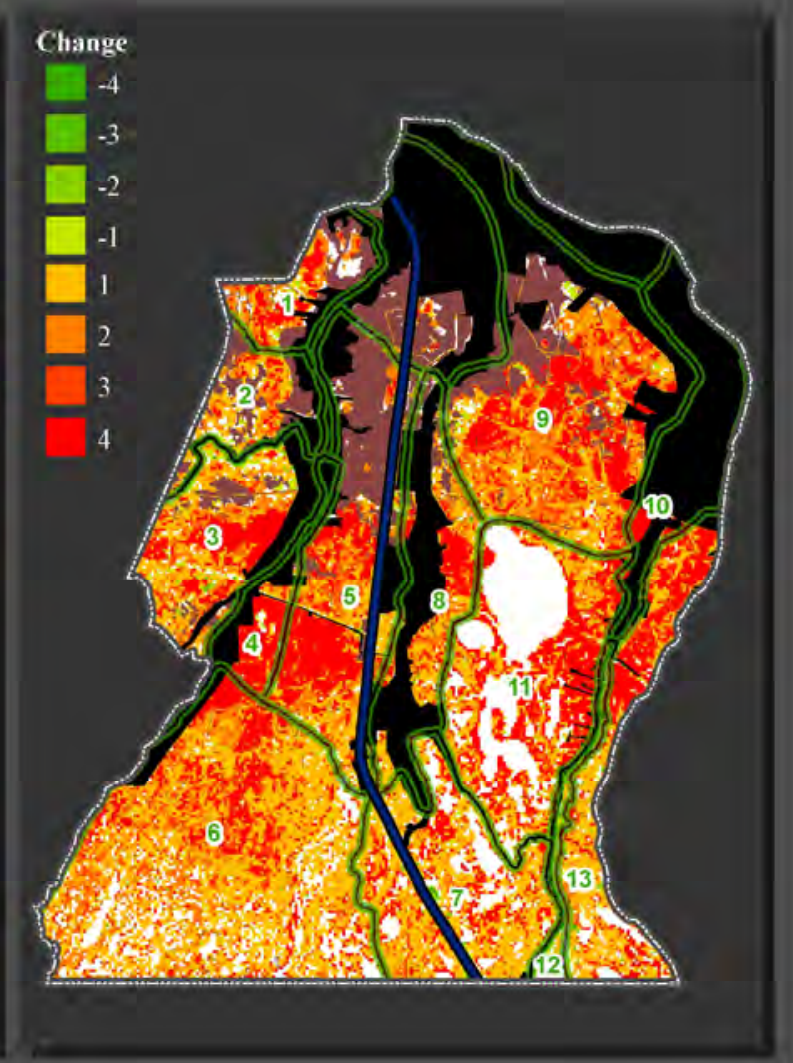

\section{LEGEND}

C.-. Houma Navgation Canal

....... Project boundary

Project regions

Developed/other

Forest

No change

\section{ROJECT REGIONS}

16. Duplantis

2. Hache

3. West Falgout

4. Central Falgout

5. East Falgout
6. Ranbro

76. Sale

8. Pelton

Q. North Boudreaux
10. Klondyke

116. South Boudreaus

12. Petite Caillou

13. La Cache
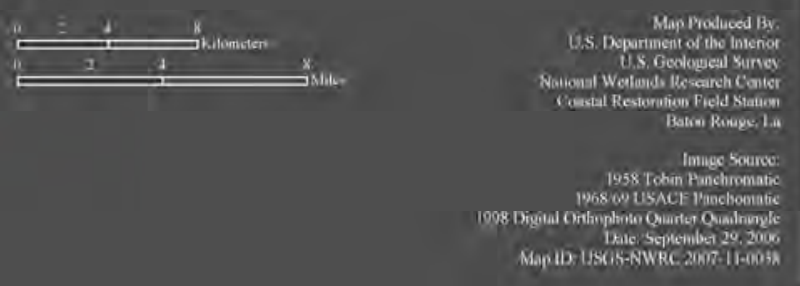

Figure 64. Map of configuration difference per tile among 1958, 1968/69, and 1998. Values were assigned to each class $(1=0$, class $A=1$, class $B=2$, class $C=3$, and classes 6 and $7=4$ ), and the difference was calculated by subtracting a previous date from a latter date. Those difference values are shown in conjunction with project regions in coastal Louisiana. 
Table 19. Marsh classes in coastal Louisiana as defined by using the Dozier classification system, which is used for interpretation of aerial photography.

\begin{tabular}{ccccc}
\hline \multicolumn{4}{c}{ Class criteria } \\
\hline Marsh classes $^{1}$ & Percentage of water & Configuration classes & Dozier categories $^{2}$ \\
\hline Solid marsh & $0-10$ percent & and & A, B & $1,2 \mathrm{~A}, 2 \mathrm{~B}$ \\
Degraded marsh & $10-60$ percent & and/or & C & 2C, 3A, 3B, 3C, 4A, 4B, \\
Water & $>60$ percent & & & $4 C, 5 \mathrm{~A}, 5 \mathrm{~B}, 5 \mathrm{C}$ \\
\end{tabular}

${ }^{1}$ From Sasser and others (1986).

${ }^{2}$ From Dozier (1983).

Table 20 shows the number of tiles and total area for each class by date, where each fragmentation class is grouped according to its general marsh condition (degree of degradation). Table groupings show that, between 1958 and 1968/69, changes were already occurring in the distribution of marsh classes; however, by 1998, a large shift from solid marsh $(<10$ percent water) to open water (>60 percent water) occurred. Between 1958 and 1968/69, solid marsh declined by

Table 20. Summary of fragmentation class groupings for solid marsh (less than 10 percent water), degraded marsh (10-60 percent water), and water (greater than 60 percent water) in coastal Louisiana for three time periods.

\begin{tabular}{|c|c|c|c|c|c|c|}
\hline & \multicolumn{2}{|c|}{1958} & \multicolumn{2}{|c|}{1968} & \multicolumn{2}{|c|}{1998} \\
\hline Class & No. of tiles & Area $\left(\mathrm{km}^{2}\right)$ & No. of tiles & Area $\left(\mathrm{km}^{2}\right)$ & No. of tiles & Area $\left(\mathrm{km}^{2}\right)$ \\
\hline 1 & 15,164 & 236.9 & 12,675 & 198.0 & 3,692 & 57.7 \\
\hline $2 \mathrm{~A}$ & 3,137 & 49.0 & 3,041 & 47.5 & 1,419 & 22.2 \\
\hline $2 \mathrm{~B}$ & 46 & 0.7 & 56 & 0.9 & 173 & 2.7 \\
\hline Total solid & 18,347 & 286.6 & $\overline{15,772}$ & 246.4 & 5,284 & 82.6 \\
\hline $2 \mathrm{C}$ & 216 & 3.4 & 188 & 2.9 & 184 & 2.9 \\
\hline $3 A$ & 5,416 & 84.6 & 5,620 & 87.8 & 4,029 & 63.0 \\
\hline 3B & 26 & 0.4 & 23 & 0.4 & 181 & 2.8 \\
\hline $3 C$ & 284 & 4.4 & 216 & 3.4 & 591 & 9.2 \\
\hline $4 \mathrm{~A}$ & 2,850 & 44.5 & 3,483 & 54.4 & 3,751 & 58.6 \\
\hline $4 \mathrm{~B}$ & 14 & 0.2 & 2 & 0.0 & 33 & 0.5 \\
\hline $4 C$ & 75 & 1.2 & 63 & 1.0 & 427 & 6.7 \\
\hline $5 \mathrm{~A}$ & 2,308 & 36.1 & 2,976 & 46.5 & 4,161 & 65.0 \\
\hline $5 B$ & 14 & 0.2 & 3 & 0.0 & 30 & 0.5 \\
\hline $5 \mathrm{C}$ & 114 & 1.8 & 107 & 1.7 & 679 & 10.6 \\
\hline Total degraded & 11,317 & 176.8 & $\overline{12,681}$ & 198.1 & $\overline{14,066}$ & 219.8 \\
\hline 6 & 1,615 & 25.2 & 2,028 & 31.7 & 4,420 & 69.1 \\
\hline 7 & 4,065 & 63.5 & 4,863 & 76.0 & 11,574 & 180.8 \\
\hline Total water & 5,680 & 88.7 & 6,891 & 107.7 & 15,994 & $\overline{249.9}$ \\
\hline Grand total & $\overline{35,344}$ & 552.1 & $\overline{35,344}$ & 552.2 & 35,344 & 552.3 \\
\hline
\end{tabular}


more than 7 percent in the study area. An accelerated decline continued, and by 1998 only 15 percent of the entire landscape was composed of solid marsh. The degraded marsh class (10-60 percent water) steadily increased from 32 , to 35 , to 40 percent of the study area, while the water class increased from 16, to 20, to 45 percent of the study area for the 1958, 1968/69, and 1998 dates, respectively. Not only do these changes, shown in figure 66, illustrate the extreme projectwide shifts from solid marsh to water classes between the 1958 and 1998 dates, but they also illustrate the initial shift to degraded marsh in the western regions (Hache, Falgout, and Rambio) by 1968/69.

Table 21 further illustrates the change in marsh condition between dates for individual project regions. The regions are grouped according to an east-west designation with respect to the Houma Navigation Canal (HNC). The project area consists of six western regions (Central Falgout, Duplantis, East Falgout, Hache, Rambio, and West Falgout), six eastern regions (Klondyke, La Cache, North Boudreaux, Pelton, Petite Caillou, and South Boudreaux), and one region (Sale) that falls both east and west of the HNC. Overall, the frequency (and percentage within regions) of marsh condition classified tiles that fall within the western regions are considerably different from those observed in the eastern regions. The percentage of solid marsh tiles decreased over time from 59, to 46.9 , to 18.1 percent in the western regions and from 49.1 , to 46.4 , to 10.4 percent in the eastern regions for the 1958, 1968/69, and 1998 dates, respectively. The inverse was true for percentage of water tiles in both the western and eastern regions. Minimal increases were observed in the percentage of water tiles in the western regions, 9.9 to 13.7 percent, and eastern regions, 20.5 to 23.5 percent, for 1958 and 1968/69, respectively, but the percentage of those tiles increased significantly to 37.2 and 54.9 percent by 1998 in the western and eastern regions, respectively. Most notable are the different rates at which the solid and degraded tiles change over the TA and OA time periods. For the pre- to postconstruction period, there was an average decrease in solid tiles of 12.3 and 2.5 percent for the western and eastern regions, respectively, while the degraded tile increased by 9.5 percent in the west and decreased 0.06 percent in the east by during the same period. The preconstruction to end-point period saw similar change for the degraded tile in the west and a shift from slightly decreasing during the TA period to slightly increasing for the OA period. With a range of 10-13 percent, the separation in average percent difference for solid tiles between the western and eastern regions during the OA period remained relatively constant; however, these regions experienced significant decreases over time. These trends, and their variations across classes and regions, are indicative of marshes that were at different phases along the degradation scale. By 1958, a difference existed between the areas east and west of where the HNC would be dredged. The preconstruction western region marshes were more stable marshes, affected by fewer and more naturally occurring waterways, and overall were farther from the bay and gulf waters. The eastern regions consisted of more degraded and waterdominated marshes, with the marshes in closer proximity to the bay. It is assumed that the advanced degree of degradation of these marshes (in relation to the western region marshes) was influenced by salinity pathways created by closer proximity to the bay, connections between larger natural waterways (for example, Bayou Terrebonne), and channelized pipelines and canals.

In addition to differences by region, the average class-level values for all metrics were assessed to quantify differences in marsh condition with respect to locations east and west of the HNC. Table 22 shows the four primary landscape metrics, their average values by year, and eastwest bearing with respect to the HNC. The PLAND, which measures the amount of water within each tile, shows that the average percentages of water per tile that fell west of the HNC were significantly less than the averages in the east and therefore were less degraded at each of the three time series. Similarly, the LPIs - which were used in part to classify landscape configuration within each tile- have trends similar to those observed in the PLAND averages. 
Table 21. Frequency (and percentage) within year of solid marsh, degraded marsh, and water class tiles within each region in coastal Louisiana for three project dates.

[Dark gray rows indicate regions that are west of the Houma Navigation Canal, light gray rows indicate those that are east of the Houma Navigation Canal (Sale, in the white row, is both east and west of the canal]

Regional marsh condition during the three time periods

\begin{tabular}{|c|c|c|c|c|c|c|c|c|c|}
\hline \multirow[b]{2}{*}{ Region } & \multicolumn{3}{|c|}{1958} & \multicolumn{3}{|c|}{$1968 / 69$} & \multicolumn{3}{|c|}{1998} \\
\hline & Solid & Degraded & Water & Solid & Degraded & Water & Solid & Degraded & Water \\
\hline Central Falgout & $\begin{array}{r}344 \\
(67.32)\end{array}$ & $132(25.83)$ & $\begin{array}{r}35 \\
(6.85)\end{array}$ & $\begin{array}{r}312 \\
(61.06)\end{array}$ & $\begin{array}{r}163 \\
(31.90)\end{array}$ & $\begin{array}{r}36 \\
(7.05)\end{array}$ & $\begin{array}{r}12 \\
(2.35)\end{array}$ & $64(12.52)$ & $\begin{array}{r}435 \\
(85.13)\end{array}$ \\
\hline Duplantis & $\begin{array}{r}772 \\
(78.30)\end{array}$ & 155 (15.72) 59 & $(5.98)$ & $\begin{array}{r}672 \\
(68.15)\end{array}$ & $\begin{array}{c}258 \\
(26.17) 56\end{array}$ & $(5.68)$ & $\begin{array}{r}340 \\
(34.48)\end{array}$ & $\begin{array}{r}328 \\
(33.27)\end{array}$ & $\begin{array}{r}318 \\
(32.25)\end{array}$ \\
\hline East Falgout & $\begin{array}{r}2,292 \\
(73.11)\end{array}$ & 794 (25.33) & $\begin{array}{r}49 \\
(1.56)\end{array}$ & $\begin{array}{r}2,085 \\
(66.51)\end{array}$ & $\begin{array}{r}902 \\
(28.77)\end{array}$ & $\begin{array}{r}148 \\
(4.72)\end{array}$ & $\begin{array}{r}573 \\
(18.28)\end{array}$ & $\begin{array}{r}1,204 \\
(38.41)\end{array}$ & $\begin{array}{r}1,358 \\
(43.32)\end{array}$ \\
\hline Hache & $\begin{array}{r}564 \\
(64.68)\end{array}$ & $298(34.17)$ & $\begin{array}{r}10 \\
(1.15)\end{array}$ & $\begin{array}{r}394 \\
(45.18)\end{array}$ & $\begin{array}{r}444 \\
(50.92)\end{array}$ & $\begin{array}{r}34 \\
(3.90)\end{array}$ & $\begin{array}{r}352 \\
(40.37)\end{array}$ & $\begin{array}{r}369 \\
(42.32)\end{array}$ & $\begin{array}{r}151 \\
(17.32)\end{array}$ \\
\hline Klondyke & $\begin{array}{r}252 \\
(78.50)\end{array}$ & (15.58) 19 & $(5.92)$ & $\begin{array}{r}208 \\
(64.80)\end{array}$ & $\begin{array}{c}87 \\
(27.10) 26\end{array}$ & $(8.10)$ & $\begin{array}{r}110 \\
(34.27)\end{array}$ & $\begin{array}{r}51 \\
(15.89)\end{array}$ & $\begin{array}{r}160 \\
(49.84)\end{array}$ \\
\hline La Cache & $\begin{array}{r}1,190 \\
(39.53)\end{array}$ & $\begin{array}{r}1,400 \\
(46.51)\end{array}$ & $\begin{array}{r}420 \\
(13.95)\end{array}$ & $\begin{array}{r}1,244 \\
(41.33)\end{array}$ & $\begin{array}{r}1,292 \\
(42.92)\end{array}$ & $\begin{array}{r}474 \\
(15.75)\end{array}$ & $\begin{array}{r}404 \\
(13.42)\end{array}$ & $\begin{array}{r}1,117 \\
(37.11)\end{array}$ & $\begin{array}{r}1,489 \\
(49.47)\end{array}$ \\
\hline North Boudreaux & $\begin{array}{r}3,642 \\
(82.98)\end{array}$ & 704 (16.04) 43 & $(0.98)$ & $\begin{array}{r}3,484 \\
(79.38)\end{array}$ & $\begin{array}{c}833 \\
(18.98) 72\end{array}$ & $(1.64)$ & $\begin{array}{r}599 \\
(13.65)\end{array}$ & $\begin{array}{r}2,206 \\
(50.26)\end{array}$ & $\begin{array}{r}1,584 \\
(36.09)\end{array}$ \\
\hline Pelton & $\begin{array}{r}700 \\
(51.51)\end{array}$ & $568(41.80)$ & $\begin{array}{r}91 \\
(6.70)\end{array}$ & $\begin{array}{r}692 \\
(50.92)\end{array}$ & $\begin{array}{r}539 \\
(39.66)\end{array}$ & $\begin{array}{r}128 \\
(9.42)\end{array}$ & $\begin{array}{r}120 \\
(8.83)\end{array}$ & $\begin{array}{r}655 \\
(48.20)\end{array}$ & $\begin{array}{r}584 \\
(42.97)\end{array}$ \\
\hline Petite Caillou & $\begin{array}{r}100 \\
(35.71)\end{array}$ & $124(44.29)$ & $\begin{array}{r}56 \\
(20.00)\end{array}$ & $\begin{array}{r}116 \\
(41.43)\end{array}$ & $\begin{array}{r}102 \\
(36.43)\end{array}$ & $\begin{array}{r}62 \\
(22.14)\end{array}$ & $\begin{array}{r}137 \\
(48.93)\end{array}$ & $\begin{array}{r}88 \\
(31.43)\end{array}$ & $\begin{array}{r}55 \\
(19.64)\end{array}$ \\
\hline Rambio & $\begin{array}{r}4,529 \\
(48.85)\end{array}$ & $\begin{array}{r}3,265 \\
(35.22)\end{array}$ & $\begin{array}{r}1,477 \\
(15.93)\end{array}$ & $\begin{array}{r}3,413 \\
(36.81)\end{array}$ & $\begin{array}{r}4,028 \\
(43.45)\end{array}$ & $\begin{array}{r}1,830 \\
(19.74)\end{array}$ & $\begin{array}{r}1,332 \\
(14.37)\end{array}$ & $\begin{array}{r}4,569 \\
(49.28)\end{array}$ & $\begin{array}{r}3,370 \\
(36.35)\end{array}$ \\
\hline Sale & $\begin{array}{r}1,031 \\
(27.87)\end{array}$ & $\begin{array}{r}1,614 \\
(43.63)\end{array}$ & $\begin{array}{r}1,054 \\
(28.49)\end{array}$ & $\begin{array}{r}974 \\
(26.33)\end{array}$ & $\begin{array}{r}1,550 \\
(41.90)\end{array}$ & $\begin{array}{r}1,175 \\
(31.77)\end{array}$ & $\begin{array}{r}509 \\
(13.76)\end{array}$ & $\begin{array}{r}1,423 \\
(38.47)\end{array}$ & $\begin{array}{r}1,767 \\
(47.77)\end{array}$ \\
\hline South Boudreaux & $\begin{array}{r}1,126 \\
(22.84)\end{array}$ & $\begin{array}{r}1,504 \\
(30.51)\end{array}$ & $\begin{array}{r}2,299 \\
(46.64)\end{array}$ & $\begin{array}{r}887 \\
(18.00)\end{array}$ & $\begin{array}{r}1,444 \\
(29.30)\end{array}$ & $\begin{array}{r}2,598 \\
(52.71)\end{array}$ & $\begin{array}{r}121 \\
(2.45)\end{array}$ & $\begin{array}{r}830 \\
(16.84)\end{array}$ & $\begin{array}{r}3,978 \\
(80.71)\end{array}$ \\
\hline West Falgout & $\begin{array}{r}1,583 \\
(68.44)\end{array}$ & 669 (28.92) 61 & (2.64) & $\begin{array}{r}1,140 \\
(49.29)\end{array}$ & $\begin{array}{r}943 \\
(40.77)\end{array}$ & $\begin{array}{r}230 \\
(9.94)\end{array}$ & $\begin{array}{r}476 \\
(20.58)\end{array}$ & $\begin{array}{r}1,116 \\
(48.25)\end{array}$ & $\begin{array}{r}721 \\
(31.17)\end{array}$ \\
\hline Other & & 269 & & & 269 & & & 269 & \\
\hline Total & 18,125 & 11,277 & 5,673 & 15,621 & 12,585 & 6,869 & 5,085 & 14,020 & 15,970 \\
\hline East total & $\begin{array}{r}7,010 \\
(49.06) \\
\end{array}$ & $\begin{array}{r}4,350 \\
(30.45) \\
\end{array}$ & $\begin{array}{r}2,928 \\
(20.49) \\
\end{array}$ & $\begin{array}{r}6,631 \\
(46.41) \\
\end{array}$ & $\begin{array}{r}4,297 \\
(30.07) \\
\end{array}$ & $\begin{array}{r}3,360 \\
(23.52) \\
\end{array}$ & $\begin{array}{r}1,491 \\
(10.44) \\
\end{array}$ & $\begin{array}{r}4,947 \\
(34.62) \\
\end{array}$ & $\begin{array}{r}7,850 \\
(54.94) \\
\end{array}$ \\
\hline West total & $\begin{array}{r}10,084 \\
(59.01) \\
\end{array}$ & $\begin{array}{r}5,313 \\
(31.09) \\
\end{array}$ & $\begin{array}{r}1,691 \\
(9.9) \\
\end{array}$ & $\begin{array}{r}8,016 \\
(46.91) \\
\end{array}$ & $\begin{array}{r}6,738 \\
(39.43) \\
\end{array}$ & $\begin{array}{r}2,334 \\
(13.66) \\
\end{array}$ & $\begin{array}{r}3,085 \\
(18.05) \\
\end{array}$ & $\begin{array}{r}7,650 \\
(44.77) \\
\end{array}$ & $\begin{array}{r}6,353 \\
(37.18) \\
\end{array}$ \\
\hline
\end{tabular}

The cohesion and clumpy values were significantly less in the western tiles than in the eastern tiles for both the preconstruction and end-point dates; however, the reverse was observed in the postconstruction data. This variation in trend was due to the initial deterioration of stable marsh in the west, resulting in sharper increases in water patch formation, aggregation, and connectivity. Though the eastern marshes were less affected by the initial influence of the construction and maintenance of the Houma Navigation Canal, the long-term exposure of higher salinities in the fresher marshes, and the shoreline erosion in the more saline marshes, propelled the eastern marshes to landscapes classified as highly degraded marsh and water by the end-point date. 
Table 22. Average primary metric values by year and by orientation to the Houma Navigation Canal in coastal Louisiana.

[PLAND, percentage of landscape; LPI, largest patch index; Cohesion, cohesion of water patch; Clumpy, clumpiness of water patch]

1958

$1968 / 69$

1998

\begin{tabular}{lrrrrrr}
\hline Metric & West & East & West & East & West & East \\
\hline PLAND & 19.17 & 29.10 & 25.05 & 32.18 & 47.89 & 59.85 \\
LPI & 17.10 & 27.03 & 22.96 & 30.18 & 42.60 & 55.40 \\
Cohesion & 71.77 & 74.58 & 81.43 & 80.21 & 92.90 & 93.66 \\
Clumpy & 0.69 & 0.72 & 0.79 & 0.77 & 0.88 & 0.89 \\
\hline
\end{tabular}

Table 23 utilizes the 1958 category 1 tiles as an indicator class and illustrates how those tiles changed over the TA and OA time periods. In general, the landscape was relatively solid in 1958, with 44 percent of all project tiles being classified as category 1 . Sixty-four percent of those tiles remained class 1 through 1968/69, while only 17 percent of the original category 1 remained by 1998. Additionally, approximately 47 and 23 percent of the tiles that were class 1 in 1958 changed to degraded marsh by 1968/69 and 1998, respectively. Table 23 also shows that, of the tiles that were class 1 in 1958, only 1 percent of them changed to water class by 1968/69 and that 29 percent were classified as water in 1998. Ultimately this indicator class further illustrates the shift from stable marsh in 1958 to degraded marsh and water-dominated landscapes by 1968/69 and 1998. 


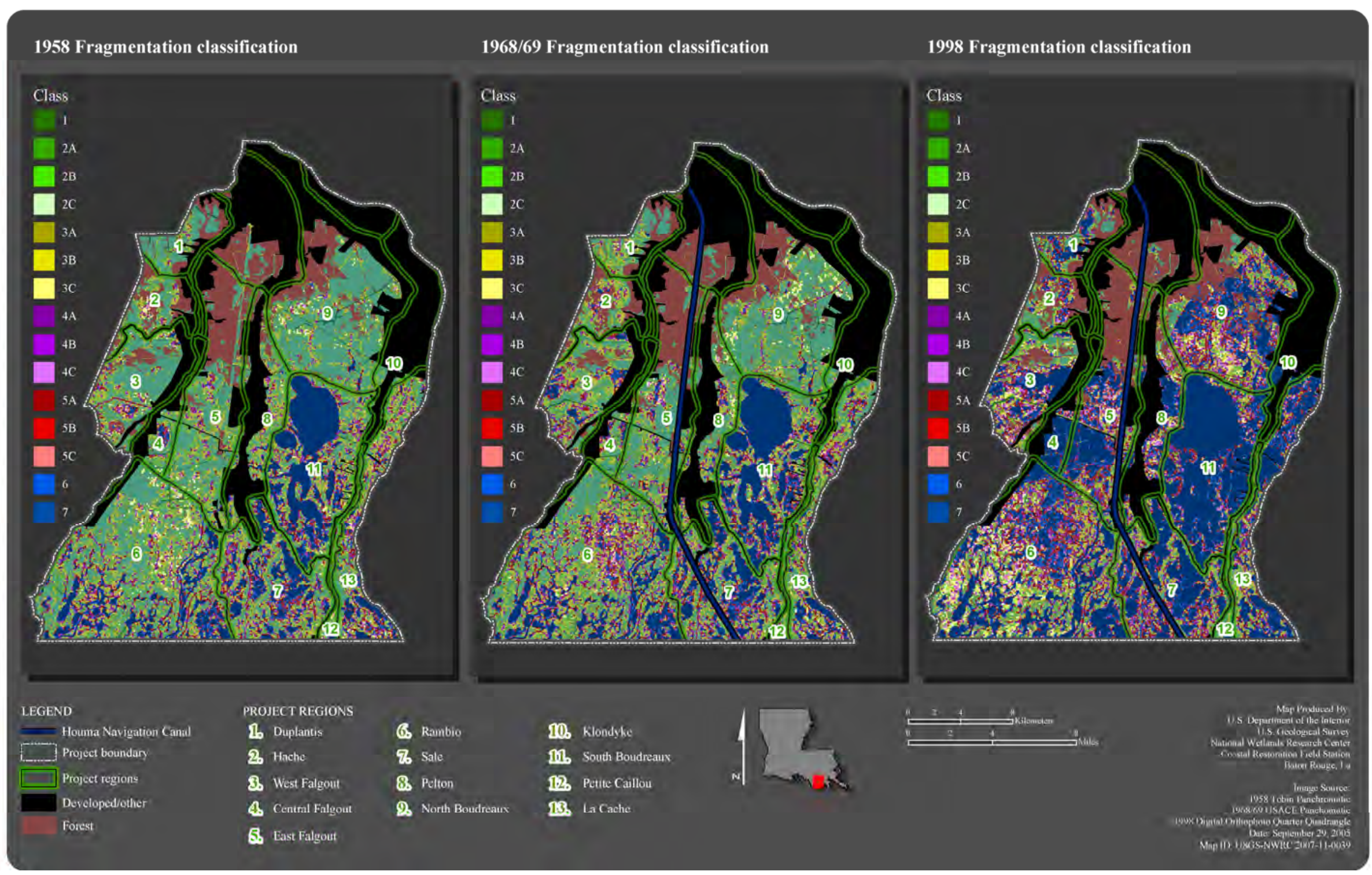

Figure 65. Map of fragmentation classification (per grid tile) for 1958, 1968/69, and 1998. The two tier classes (category and configuration) are shown in conjunction with project regions in coastal Louisiana. 
1958 Marsh degradation classification

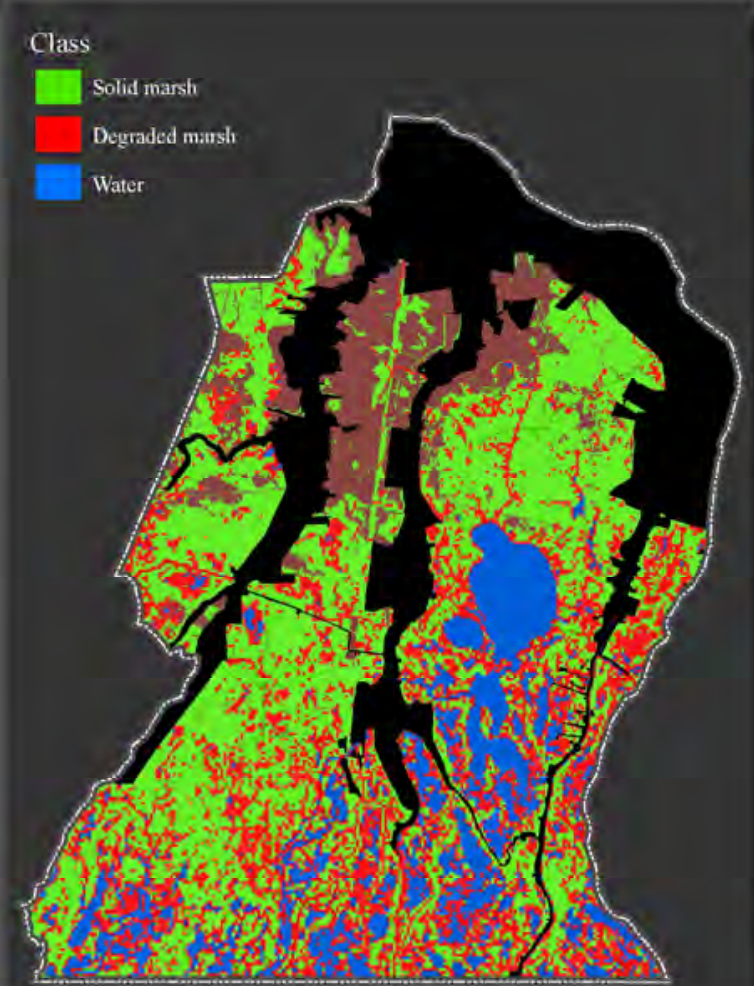

LEGEND
- Houma Navigation Ganal

Project boundar

Developed/other

Fonst
1968/69 Marsh degradation classification

Class

Loblid inarsh

Degraded marsh

Water
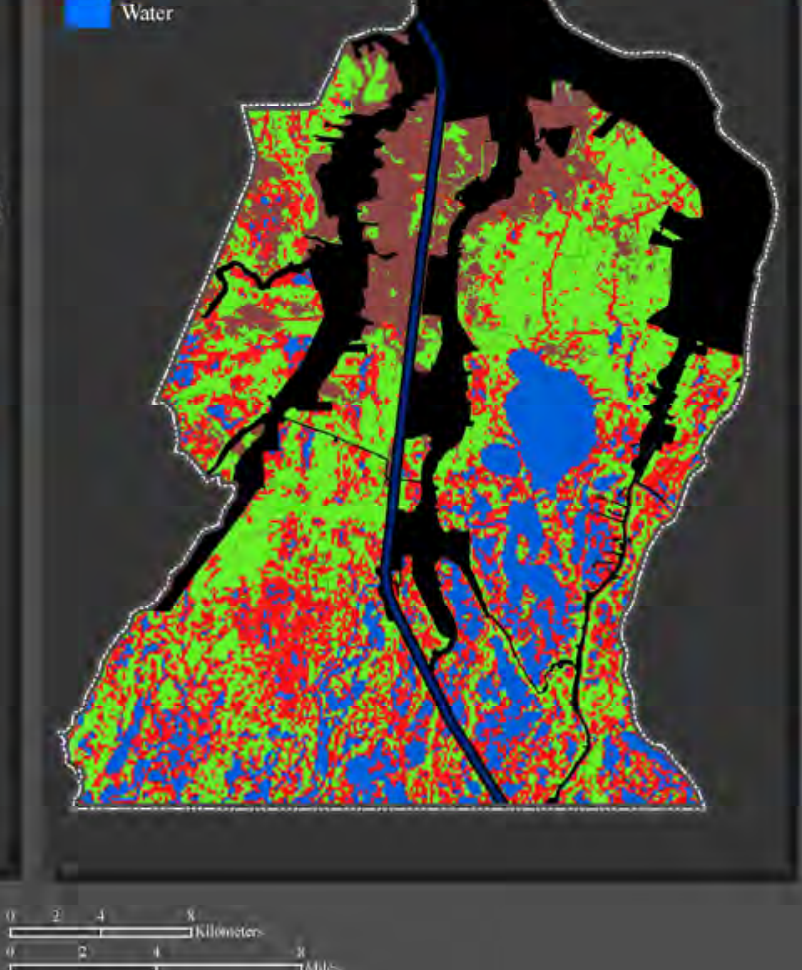

1998 Marsh degradation classification

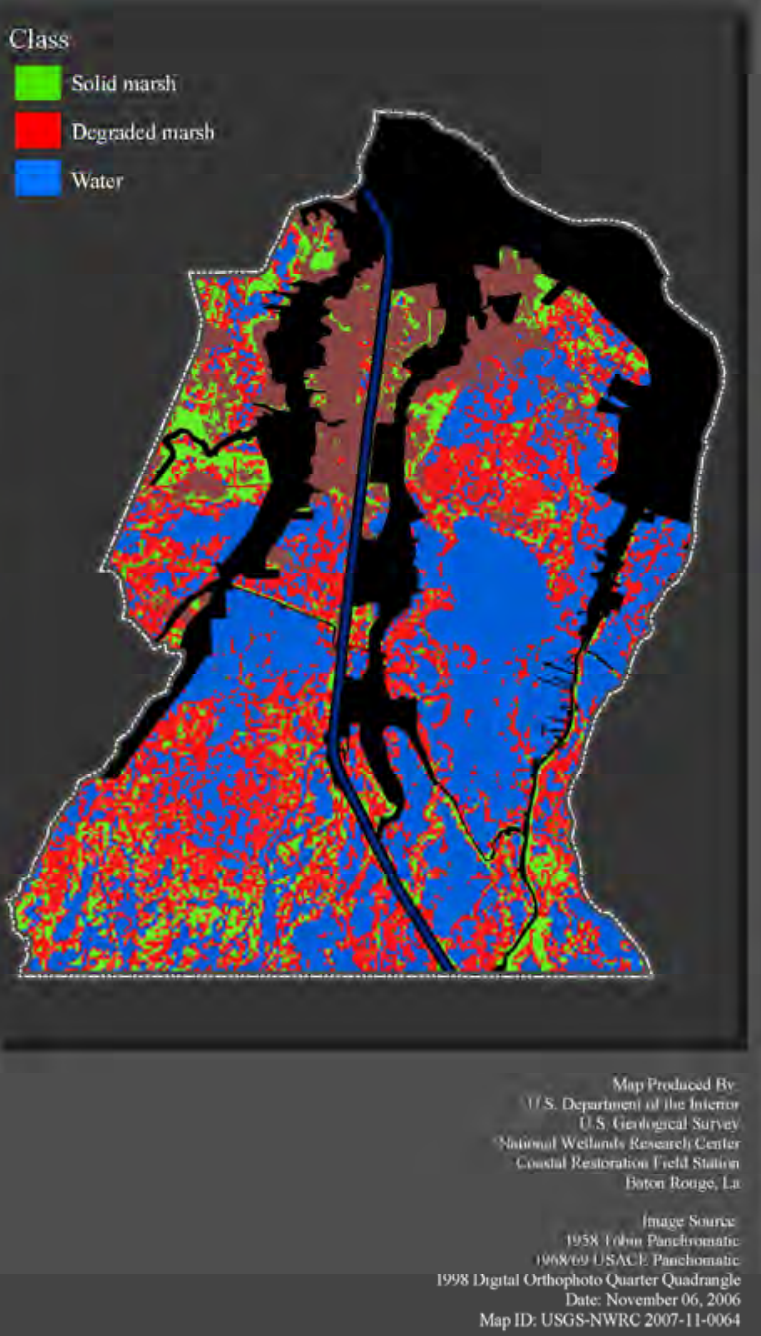

Figure 66. Map of marsh degradation classification (per grid tile) for 1958, 1968/69, and 1998. The marsh degradation classesthree levels of marsh condition: solid marsh $(1,2 \mathrm{~A}, 2 \mathrm{~B})$, degraded marsh $(2 \mathrm{C}, 3 \mathrm{~A}, 3 \mathrm{~B}, 3 \mathrm{C}, 4 \mathrm{~A}, 4 \mathrm{~B}, 4 \mathrm{C}, 5 \mathrm{~A}, 5 \mathrm{~B}, 5 \mathrm{C})$, and water $(6$, 7)-are shown in conjunction with project regions in coastal Louisiana. 
Table 23. Change in classification from 1968 to 1998 for all 1958 class 1 tiles for coastal Louisiana study.

[Counts in the columns represent the values in 1968, and the 1998 classification is represented across the rows. Bold values represent tiles that remained the same between 1968 and 1998 ( 1 tile $=15,625$ square meters). Dashes represent no tiles]

\begin{tabular}{|c|c|c|c|c|c|c|c|c|c|c|c|c|c|c|c|c|}
\hline \multirow{2}{*}{$\begin{array}{c}1998 \\
\downarrow\end{array}$} & \multicolumn{15}{|c|}{ Change matrix } & \multirow[b]{2}{*}{$\begin{array}{l}1998 \\
\text { total }\end{array}$} \\
\hline & $\begin{array}{r}1968 \\
1\end{array}$ & $\overrightarrow{2 A}$ & 2B & 2C & 3A & 3B & $3 C$ & 4A & 4B & 4C & 5A & $5 B$ & $5 C$ & 6 & 7 & \\
\hline & 2,040 & 171 & 4 & 12 & 189 & - & 7 & 87 & 1 & 0 & 42 & - & - & 19 & 1 & 2,573 \\
\hline $2 A$ & 744 & 125 & 2 & 7 & 73 & - & 1 & 14 & - & 1 & 7 & - & - & - & - & 974 \\
\hline 2B & 89 & 10 & 1 & 1 & 8 & - & - & 2 & - & - & - & - & - & - & - & 111 \\
\hline $2 \mathrm{C}$ & 105 & 9 & - & - & 14 & - & - & 1 & - & 1 & 1 & - & - & - & - & 131 \\
\hline $3 A$ & 1,572 & 361 & 4 & 16 & 337 & - & 19 & 46 & - & 1 & 21 & - & - & 7 & 1 & 2,385 \\
\hline $3 B$ & 98 & 7 & - & 1 & 11 & - & 3 & 1 & - & & 1 & - & - & - & - & 122 \\
\hline 30 & 341 & 53 & - & 4 & 26 & - & 2 & - & - & 1 & 1 & - & - & - & - & 428 \\
\hline 4A & 1,046 & 242 & 4 & 20 & 315 & 2 & 12 & 75 & - & 3 & 17 & - & 2 & 6 & 3 & 1,747 \\
\hline 4B & 11 & 1 & - & - & 4 & - & - & - & - & - & - & - & - & - & 1 & 17 \\
\hline $4 C$ & 171 & 41 & 3 & 4 & 35 & - & - & 2 & - & - & 1 & - & - & - & - & 257 \\
\hline $5 A$ & 924 & 186 & 5 & 16 & 303 & 2 & 20 & 165 & - & 3 & 56 & - & 2 & 7 & 2 & 1,691 \\
\hline $5 B$ & 7 & 2 & - & - & - & - & - & 1 & - & - & 1 & - & - & - & - & 11 \\
\hline $5 C$ & 172 & 42 & - & 7 & 61 & - & 5 & 18 & - & 2 & 7 & - & 1 & 2 & - & 317 \\
\hline 6 & 929 & 181 & 12 & 19 & 260 & 3 & 20 & 132 & - & 8 & 94 & - & 8 & 25 & 4 & 1,695 \\
\hline 7 & 1,426 & 276 & 4 & 26 & 396 & 7 & 31 & 159 & - & 10 & 161 & - & 11 & 113 & 85 & 2,705 \\
\hline total & 9,675 & 1,707 & 39 & 133 & 2,032 & 14 & 120 & 703 & 1 & 30 & 410 & - & 24 & 179 & 97 & 15,164 \\
\hline
\end{tabular}




\section{Connectivity Assessment}

The degree of connectivity and distance from primary waterways may influence movement of water both into and out of interior estuarine marshes and can subsequently affect salinity patterns and vegetation distributions. As a means of quantifying the distance and degree of influence that the Houma Navigation Canal (HNC) has on marsh degradation, a 3-km interval buffer array (fig. 67) was used to describe the change in marsh density, shape, and connectivity within each buffer. In addition, the 1968 vegetation zones (Chabreck and others, 1968) were used as the standard for subsetting grid tiles for all years and in conjunction with landscape statistical analyses and classifications to determine the change in marsh condition by vegetation salinity zones. All tiles that were located within areas that were classified as forested or developed were excluded from both the buffer and vegetation zone analyses.

\section{Buffer Zone}

Changes in marsh condition and landscape pattern were analyzed for each project buffer and coastal marsh vegetation zone. Buffers that represented an array of consecutive zones (3-km intervals from the HNC, table 24) were used to examine the effects of the HNC and subsequent salinity intrusion on marsh condition and changes. Though the project area extends to approximately $18 \mathrm{~km}$ from the $\mathrm{HNC}$, the $15-\mathrm{km}$ and $18-\mathrm{km}$ buffers contained an inadequate number of tiles and were excluded from all buffer zone analyses. Figure 68 shows the number of grid tiles within each buffer and the percentage of those tiles that were classified as solid marsh, degraded marsh, or open water. Respectively, buffers 3, 6, 9, and 12 accounted for 22, 28, 28, and 15 percent of the 35,344 tiles that were classified within the project area. The buffers contained higher percentages of solid marsh tiles in 1958 (between 49 and 57 percent) than in 1998, which contained between 11 and 20 percent. There was less solid marsh in buffer 6 than in all other buffers in 1958 (only slightly less than buffer 3), but there was a higher percentage of solid marsh in buffer 6 than in all 1968/69 and 1998 buffers. Overall, there was a slight increase in the number of degraded marsh tiles between 1958 and 1968/69 and a more observable increase by 1998 .

Buffers 3 and 12 had higher percentages of degraded marsh in 1958 and 1968/69 than did buffers 6 and 9 but only slightly greater percentages than buffer 9 by 1998. Conversely, buffers 6 and 9 contained higher percentages of water classified tiles in 1958 and 1968/69, but rapid conversion to water during the TB time period drew buffer 12 near the end-point percentage for buffer 9 .

Table 24. Explanation of buffer intervals in Houma Navigation Canal project area in coastal Louisiana.

\begin{tabular}{cc}
\hline Buffer & Distance from canal \\
\hline $3 \mathrm{~km}$ & $0-3 \mathrm{~km}$ \\
$6 \mathrm{~km}$ & $3-6 \mathrm{~km}$ \\
$9 \mathrm{~km}$ & $6-9 \mathrm{~km}$ \\
$12 \mathrm{~km}$ & $9-12 \mathrm{~km}$ \\
$15 \mathrm{~km}$ & $12-15 \mathrm{~km}$ \\
$18 \mathrm{~km}$ & $15-18 \mathrm{~km}$ \\
\hline
\end{tabular}




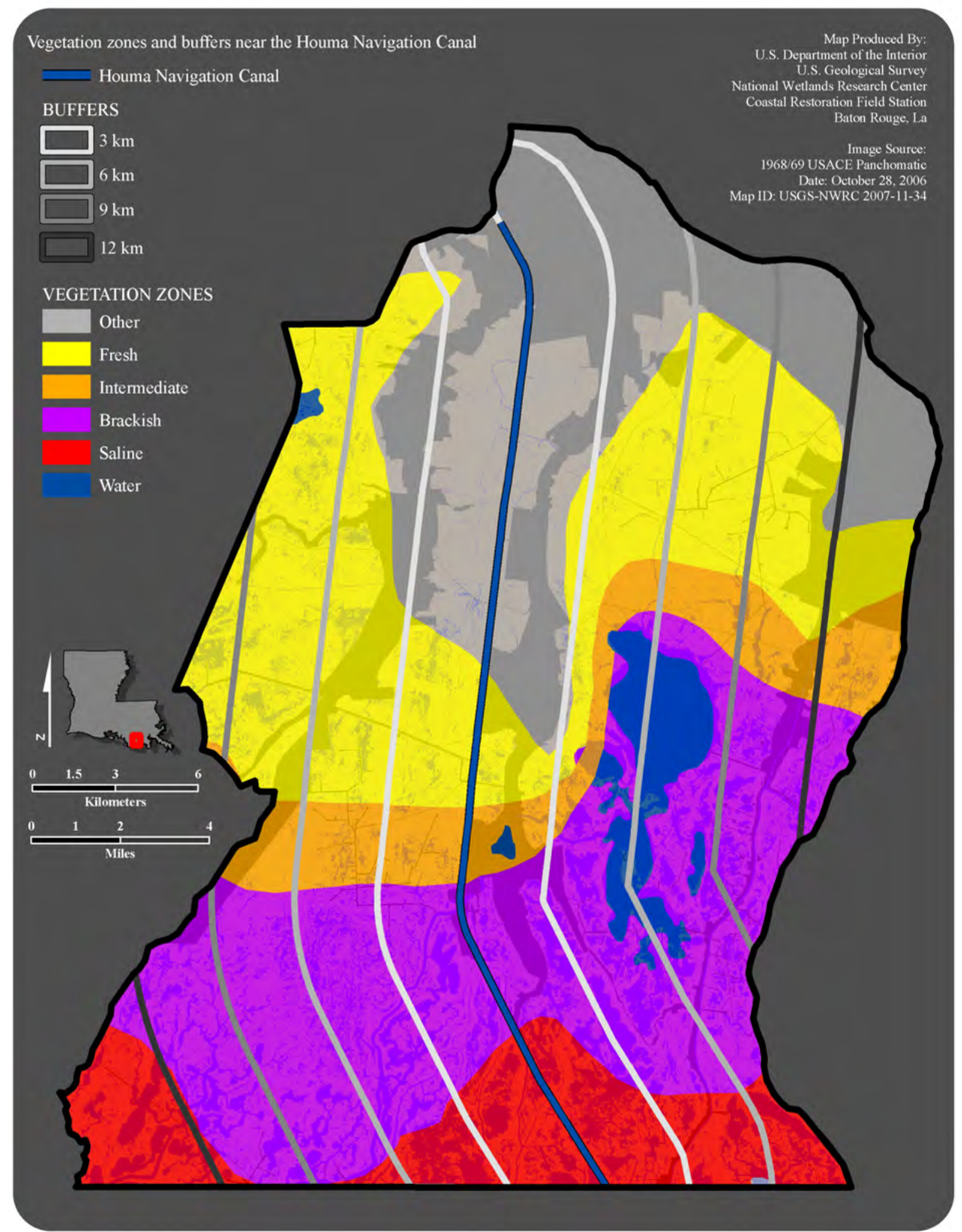

Figure 67. Map of buffers (3-km intervals from the Houma Navigation Canal) and vegetation zones (Chabreck and others, 1968) within the canal project area in coastal Louisiana. The base map is the 1968 land and water analysis image. 
In general, though buffers 6 and 12 were the most and least degraded buffers in 1958, respectively, by 1998 they were the most degraded (highest percentage of water and lowest percentage of solid marsh) buffers, followed closely by buffer 9 and less closely by buffer 3 .

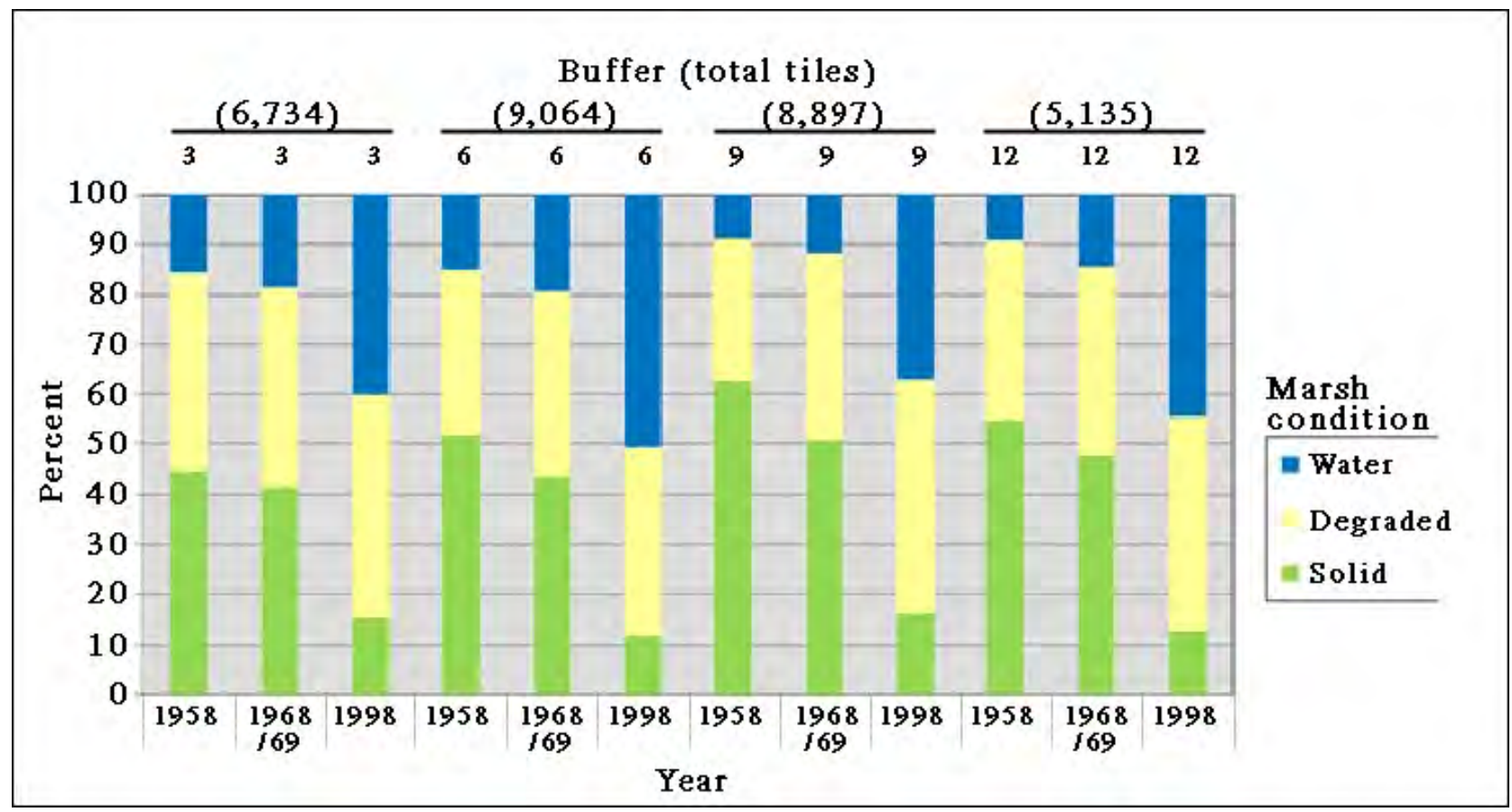

Figure 68. Tile summary for each buffer, by year, along with totals for each buffer zone in coastal Louisiana.

Changes in primary metric values were assessed for all four buffers across the three project dates. A Duncan's multiple range test (SAS, 1990c) was performed to compare LPI, cohesion, and clumpy value means to determine how the marsh landscape changed with respect to distance or influence from the Houma Navigation Canal. The cohesion and clumpy analyses produced nearly identical output; therefore, only the results from LPI and cohesion results are illustrated in figures 69 and 70, respectively. Figure 69 shows that within 1958 only buffer 12 had average LPI value that was significantly different ( $\mathrm{p}$-value <0.05) from all other buffers. By 1968/69 there were significant increases in average LPI values in all buffers except buffer 3. By this postconstruction date, buffer 6 had a significantly higher average LPI value, and buffer 12 was significantly lower than all other buffers. The largest patch averages for 1998 exhibited significant increase over all 1958 and 1968/69 buffers. Within this end-point date, buffers 6 and 12 showed the largest increase in average LPI, while buffer 9 underwent the smallest increase. Among all the 1998 buffers, only buffer 6 was significantly different from the others. In general, the average LPI was highest in buffer 6 for all three dates; however, the rate of change between dates was greatest in buffer 12 . 


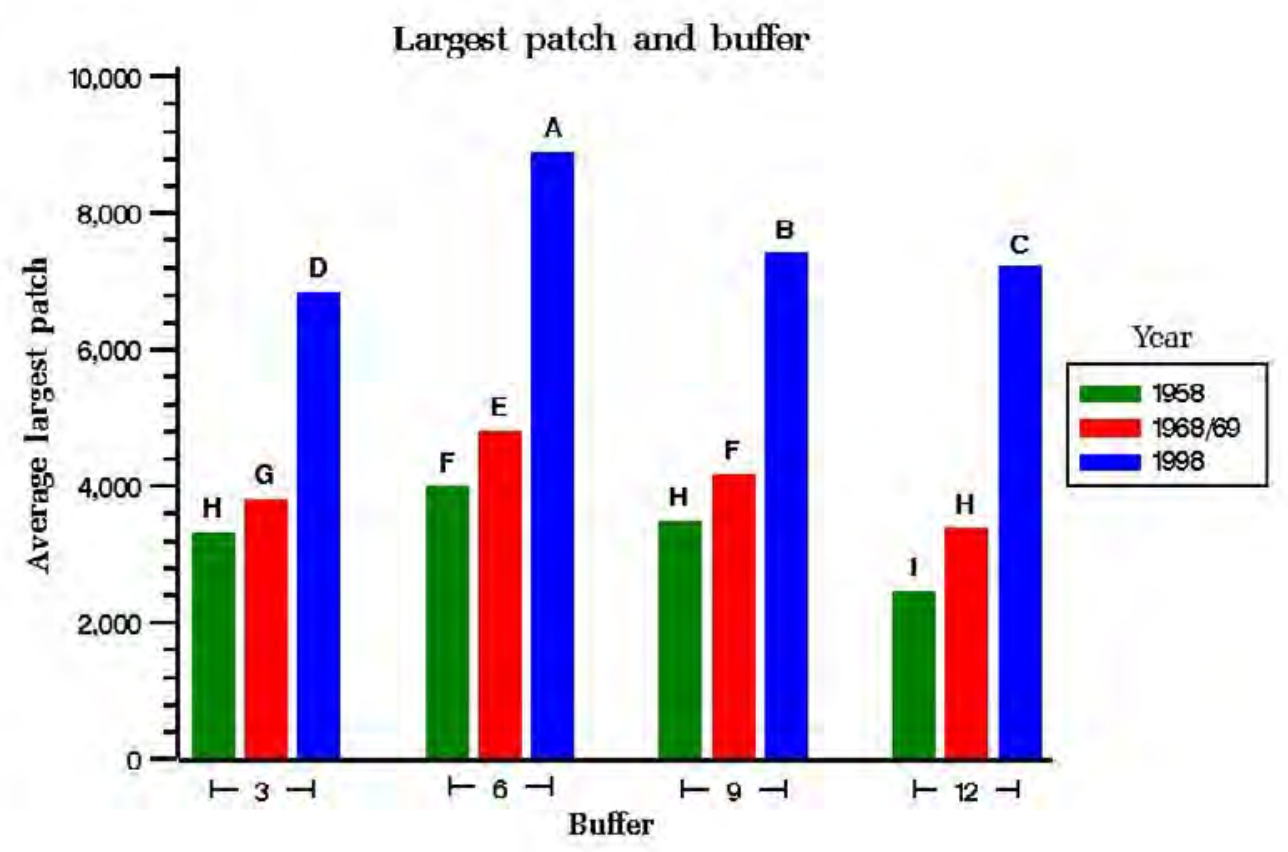

Figure 69. Average largest patch per tile, in square meters, for buffers within the Houma Navigation Canal project area in coastal Louisiana. Data are shown for three dates: preconstruction (1958), postconstruction (1968/69), and end date (1998). Bars with the same letter above them are not significantly different ( $p$-value $>0.05$ ) as determined by Duncan's multiple range test.

The cohesion analysis (as illustrated in fig. 70) showed that buffers 9 and 12 had average cohesion values that were significantly different ( $\mathrm{p}$-value $<0.05$ ) from buffers 3 and 6 . The average cohesion for buffer 9 was the lowest in 1958, followed by buffer 12, and the maximum averages were observed in buffers 3 and 6. By 1968/69 there were significant increases in average cohesion values for buffers 6, 9, and 12. The within-year comparison for all 1968/69 data showed that all buffers were significantly different from each other. Finally, the 1998 data showed significant increases in cohesion values compared to both 1958 and 1968/69, for all buffers. These increases resulted average cohesion values ranging from 88 to 96 . Buffers 6 and 12 were not significantly different from each other and buffer 9 was not significantly different from buffer 12 . However, buffer 3 was significantly different from all other buffers.

These analyses show that prior to the construction of the Houma Navigation Canal (HNC) there was less variation in average largest patch size across all buffers. In addition, the minimum and maximum LPI values of the preconstruction buffers were significantly smaller for nearly all buffers and dates. The mid-distance buffers ( 9 and 12) showed the greatest increase in largest patch size from preconstruction to end-point dates. Similarly, these buffers exhibited significantly lower cohesion values than did the interior buffers ( 3 and 6 ) for the preconstruction date. The 1968/69 and 1998 buffers were significantly different for nearly all buffers between dates but not significantly different for nearly all buffers within specific dates. Figure 69 shows that a parabolic trend in largest patch values was present for all dates, with minimum values located in buffers 3 and 12 and the maximum values located in buffers 6 and 9 . Figure 70 shows varying trends by date, where the minimum preconstruction cohesion value was found in buffer 9 and in buffers 3 and 12 for postconstruction; by 1998 — which had the majority of its buffers approaching the upper 
limits - the minimum average cohesion value was found in buffer 3. These analyses show that, though the HNC may have an influence on marsh degradation, the degree and distance of that influence are not discernable through change in largest patch indices and cohesion values.

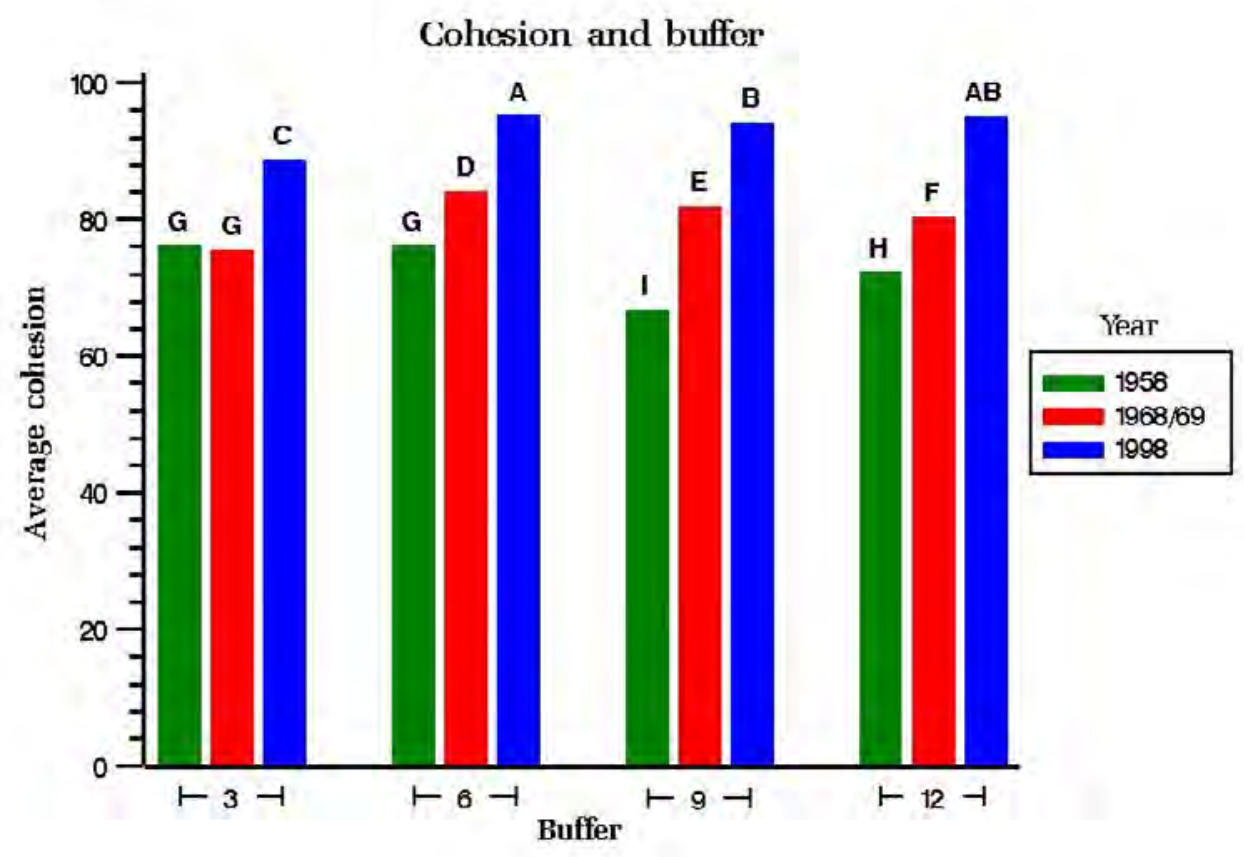

Figure 70. Average cohesion value per tile for buffers within the Houma Navigation Canal project area in coastal Louisiana. Data are shown for three dates: preconstruction (1958), postconstruction (1968/69), and end date (1998). Bars with the same letter above them are not significantly different as determined by Duncan's multiple range test.

\section{Vegetation Zone}

Vegetation surveys were taken in 1949, 1968, 1978, 1988, and 1997 across the Louisiana coast. O'Neil (1949) classified the northern portion of the study area from Lake de Cade east to Bayou Grand Caillou and then arcing north of Lake Boudreaux as floating freshwater marsh (fig. 3). The area directly south of this was classified as floating three-cornered grass marsh, dominated by Schenoplectus olneyi, that graded into fresh maidencane marsh, dominated by Panicum hemitomon, with a thin band of excessively drained salt marshes, dominated by wiregrass (Spartina patens), oystergrass (Spartina alterniflora), or black rush (Juncus roemerianus) on the east and west corners of the study area. By 1968, Chabreck and others (1968) identified the marshes as mostly fresh and brackish, with a thin band of intermediate in between. The salt marsh line encroached into the area formerly identified as brackish. Chabreck and Linscombe (1978) designated only the most northern regions of the study area flanking the Houma area as fresh marshes, with intermediate claiming the rest of the marsh previously identified as fresh. The brackish and saline boundaries were similar to those from 1968. The boundaries for each marsh 
type moved slightly north by 1988; however, by 1997 the intermediate marsh had increased in area, encroaching southward into the 1988 brackish marsh. Some of the vegetation changes that occurred over time are worth noting. For example, the intermediate vegetation zone in 1968 included areas that were classified as brackish in 1978 and then as intermediate again in 1997 (fig. 71). Another area designated as fresh in 1968 was classified as intermediate in both 1978 and 1997. The interesting point about these changes is that these areas are within what is now classified as a hotspot located south of Falgout Canal.

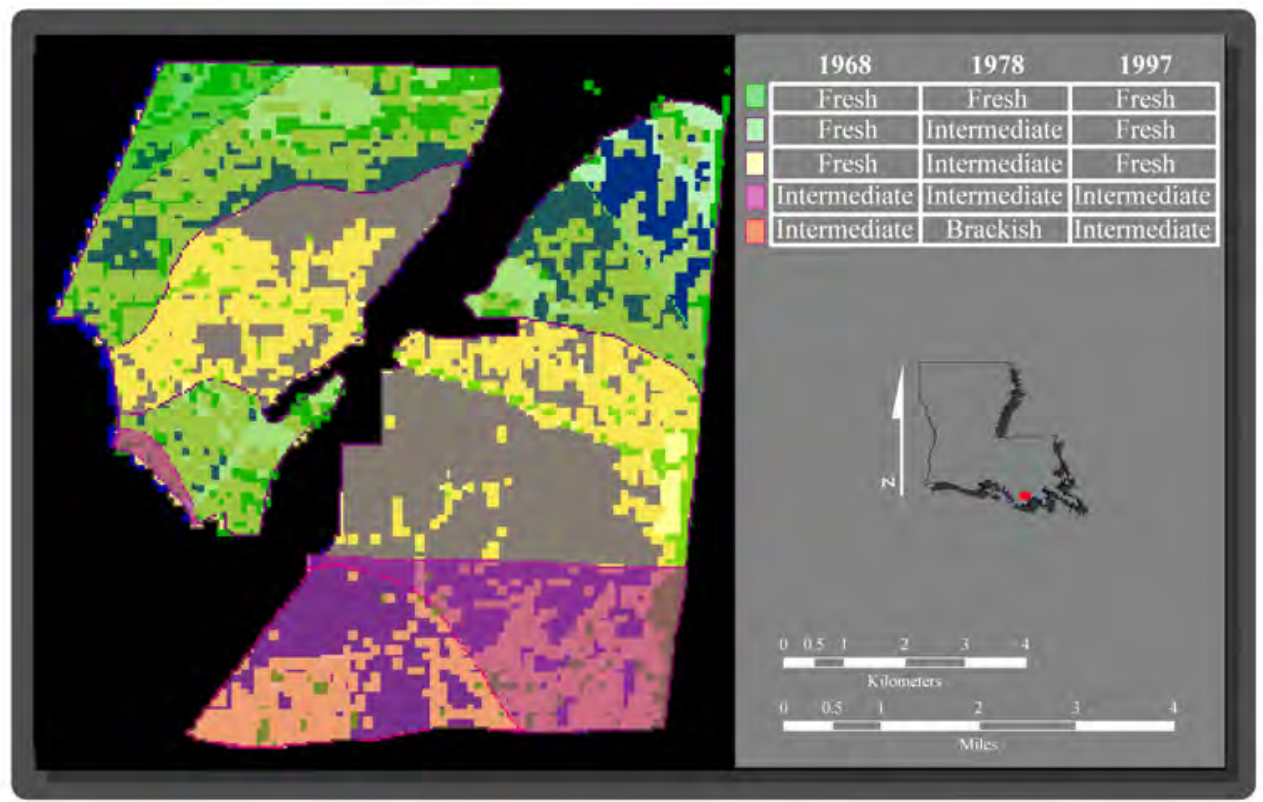

Figure 71. A section of the 1998 land change image with a vegetation change layer derived from a U.S. Geological Survey classification of coastal Louisiana marshvegetation types. Solid areas beneath the vegetation layer represent open water. This figure illustrates higher loss in areas that were fresh in 1968 and became intermediate by 1978 and those that were intermediate in 1968, were classified as brackish in 1978, and were reclassified as intermediate in 1997.

Figure 72 shows both the total number of tiles per vegetation zone and the proportion of those tiles by marsh condition and year for each zone. The project area was divided into four vegetation zones: brackish (13,592 tiles), fresh (9,683 tiles), intermediate (3,481 tiles), and saline (5,512 tiles). Overall, the fresh vegetation zone had the largest percentage of solid marsh and lowest percentage of water for all three dates. Though the more saline zones (brackish and saline) exhibited the largest percentages of water and lowest percentages of solid marsh (significantly different from fresh and intermediate zones) for 1958 and 1968/69, the percentages were not significantly different for the intermediate, brackish, and salt zones by 1998. Figure 72 shows that, at a minimum, the vegetation zones exhibited a slight decrease in percentage of solid marshes between 1958 and 1968/69 and significant decreases by 1998. The fresher marshes had the largest overall decreases in percentage of solid marsh, with 60 and 58 percent reductions in solid marsh for the intermediate and fresh zones, respectively. The reverse was true for water percentages, where a slight increase occurred between pre- and postconstruction and significant increases occurred by the end date. In the fresh and intermediate zones, increases in degraded marsh for the OA period also occurred. The percentages of degraded marsh in the fresh and intermediate zones increased 
from approximately 23 and 27 percent of these marsh areas to approximately 43 and 47 percent, respectively. These fresh and intermediate zones, which also account for the largest increases in water over time, contain the degradation hotspots that are identified in the land change analysis.

Both the brackish and salt marshes incurred land loss over the OA time interval, but the marsh loss was not as drastic. In 1958 much of these marshes were already degrading by means of bank and shoreline erosion, as opposed to the fresh and intermediate vegetation types which were composed mostly of solid marsh (fig. 72). In the brackish and salt vegetation types, the degraded marsh area remained relatively constant, accounting for approximately 40-44 percent of those vegetation types each year. The brackish and saline zones included more water area in 1958 than did the fresh and intermediate types and continued each year to have a higher frequency of water tiles until 1998, when the intermediate vegetation type had similar percentages of water. In addition to the interior marsh degradation, shoreline and bank erosion (near streams and ponds) occurred throughout the brackish and salt marshes.

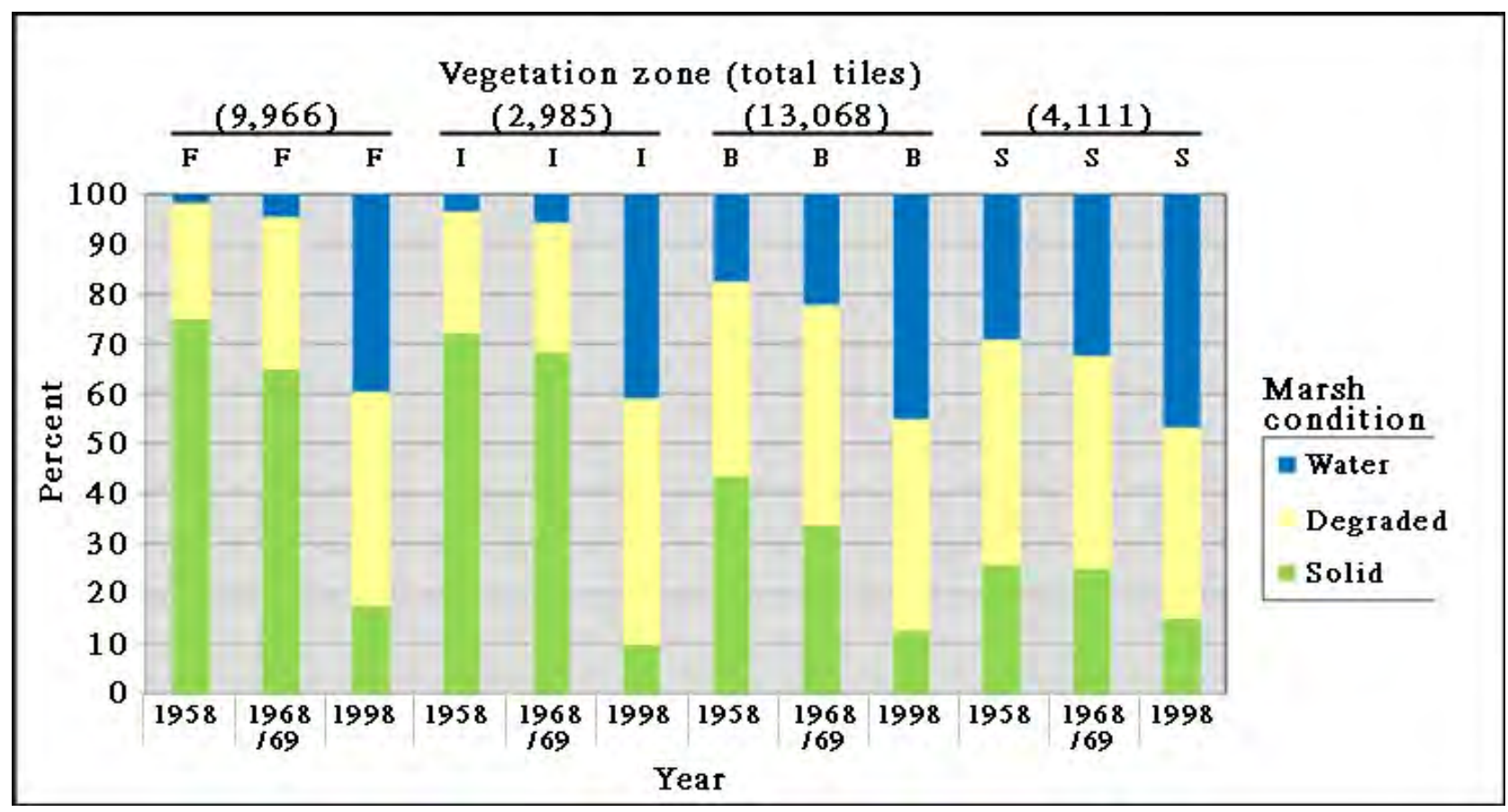

Figure 72. Percentage of tiles in each marsh condition class by vegetation type $(\mathrm{F}$, fresh; I, intermediate; B, brackish; and S, saline) in 1968 (Chabreck, 1972), along with the total number of tiles per vegetation type in coastal Louisiana.

Analogous to the buffer analysis, changes in primary metric values also were assessed for four vegetation zones across the three project dates. The same Duncan's multiple range test (SAS, 1990c) was performed on all LPI, cohesion, and clumpy values for comparing vegetation zones and project dates within the Houma Navigation Canal project area. The cohesion and clumpiness analyses produced identical output; therefore, to avoid the redundancy, only the results of LPI and cohesion are provided in figures 73 and 74, respectively. Figure 73 shows increases in average largest patch size for the preconstruction (1958) date when progressing from the fresh to more 
saline marsh zones. All zones had significantly different ( $p$-value $<0.05$ ) average LPI values in 1958, with mean largest patch sizes of $960 \mathrm{~m}^{2}$ (fresh), 1,265 $\mathrm{m}^{2}$ (intermediate), 3,844 $\mathrm{m}^{2}$ (brackish), and $5,900 \mathrm{~m}^{2}$ (salt). Similar trends were observed in the $1968 / 69$ postconstruction data, where there were significant increases in LPI for all zones; however, the within-year comparison resulted in fresh and intermediate zones that were not significantly different from each other. The same general trend continued in the 1998 data, where all within- and between-year comparisons were significantly different for all zones. Overall, the general rate of change increased with movement from more saline to fresh zones. This movement is evident in the change in LPI values for the OA period (1958-98), where those changes were 2,215 $\mathrm{m}^{2}$ (salt), 3,900 $\mathrm{m}^{2}$ (brackish), 5,870 $\mathrm{m}^{2}$ (intermediate), and $5,843 \mathrm{~m}^{2}$ (fresh) for the indicated zones.

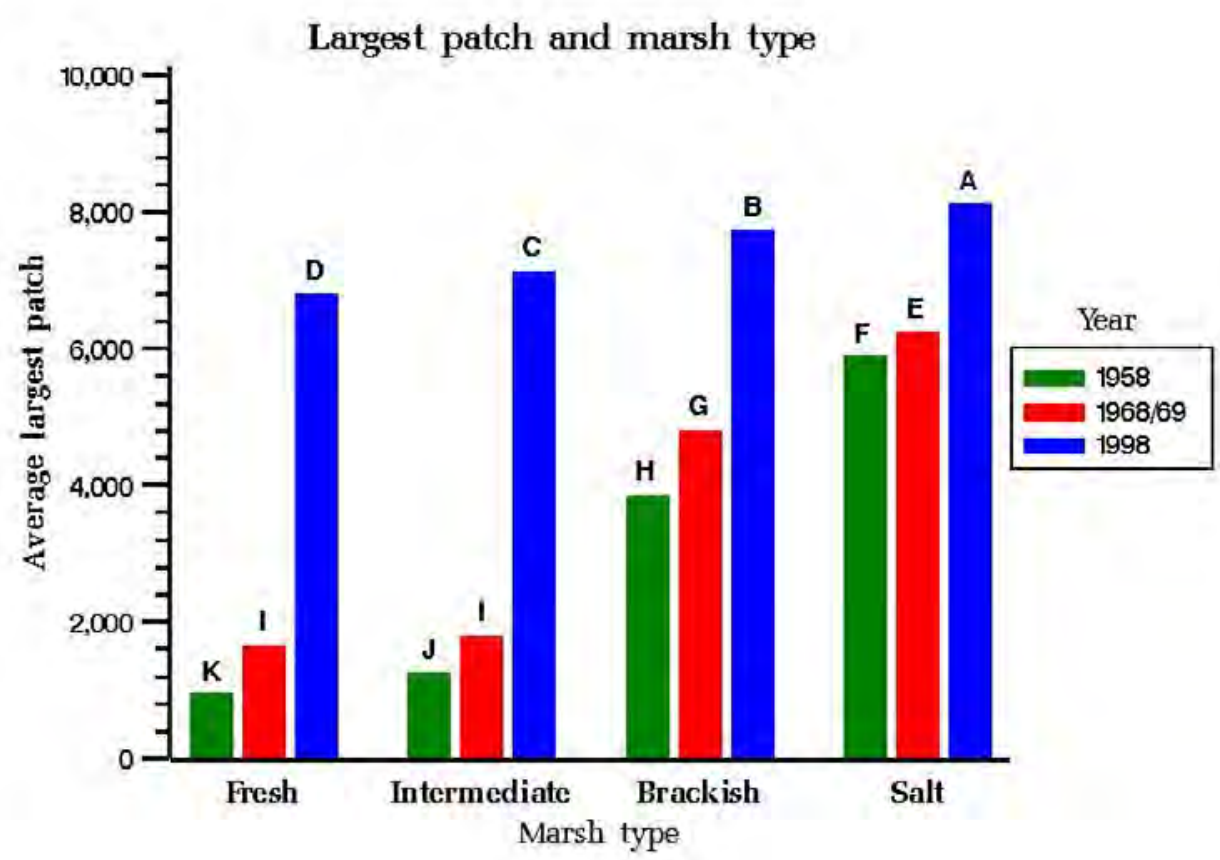

Figure 73. Average largest patch per tile, in square meters, for vegetation zones within the Houma Navigation Canal project area. Data are shown for three dates: preconstruction (1958), postconstruction (1968/69), and end date (1998). Bars with the same letter above them are not significantly different $(p$-value $>0.05)$ as determined by Duncan's multiple range test.

Figure 74 shows the average cohesion index values for the four vegetation zones and across the three project dates. The cohesion metric value is a measurement that indicates the connectedness of water patches within a tile. These results are similar to those observed with the average largest patch assessments. There was a significant increase in average cohesion value with movement from the fresh to saline zones for both 1958 and 1968/69, with the largest within-year difference of neighboring zones occurring between the intermediate and brackish marsh zones. The end-date (1998) data show that, though the fresh zone is significantly different from both the brackish and saline zones and though the intermediate zone is significantly different from the 
brackish zone, the range of values between all 1998 marsh zones is considerably less than that observed in the two previous dates. In all, the maximum changes in average cohesion value occurred in the fresher vegetation zones across all three project dates. These values, which measure the connectedness of water within the marsh, show that in 1958 the water patches had a more natural random distribution and less connectivity in the fresher marshes and highly aggregated and connected patches in the brackish and saline marshes. By 1968, those random distributions in the fresh and intermediate marshes began to degrade, and the water within those marshes began to connect and aggregate. Ultimately, the 1998 values for the fresh and intermediate marshes were comparable to those for the 1958 brackish and saline zones.

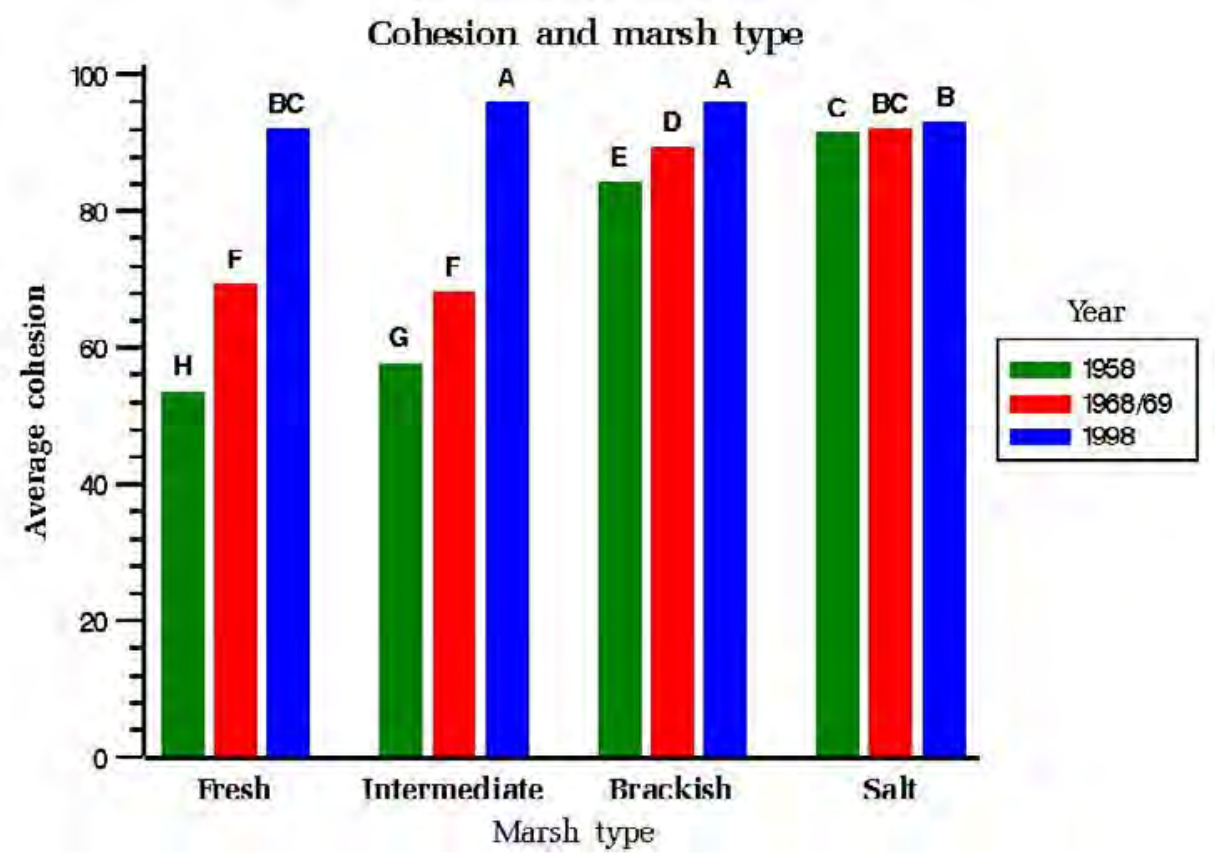

Figure 74. Average cohesion index per tile for four vegetation zones within the Houma Navigation Canal project area in coastal Louisiana. Data are shown for three project dates: preconstruction (1958), postconstruction (1968/69), and end date (1998). Bars with the same letter above them are not significantly different ( $p$-value > 0.05 ) as determined by Duncan's multiple range test.

\section{Buffer-by-Vegetation Analysis}

\section{Fresh Vegetation Type}

Figure 75 shows the marsh classification in the fresh vegetation type by buffer zones and years. Preconstruction data showed that the majority of project landscape that was classified as fresh vegetation was located in buffers 6 and 9. For both the pre- and postconstruction dates, respectively, the fresh vegetation zones within buffers 3, 6, 9, and 12 contained between 74 and 66 percent solid marsh and between 24 and 28 percent degraded marsh. By 1998 buffers 3, 6, and 12 had significant increases in water tiles ( 40 percent or more), while the conversion to water in buffer 
9 was less intense over the same period. Degraded marsh represented between 20 and 29 percent of fresh zone for all buffers in 1958. By 1968, 28-33 percent of the buffer zones were characterized by degraded marshes, with a concomitant reduction in solid marsh. Though these increases in degraded marsh tiles were relatively slight for the TA period, significantly larger increases were observed by 1998. The largest changes within the fresh zone buffers in the TA period occurred between the solid and degraded marshes, with slight increases in the percentages of water. By 1998, large increases were apparent in the number of degraded marsh and water classified tiles. The changes in this vegetation zone are indicative of marsh that was primarily solid for the pre- and postconstruction dates but saw rapid disintegration of marsh and conversion to open water by 1998 .

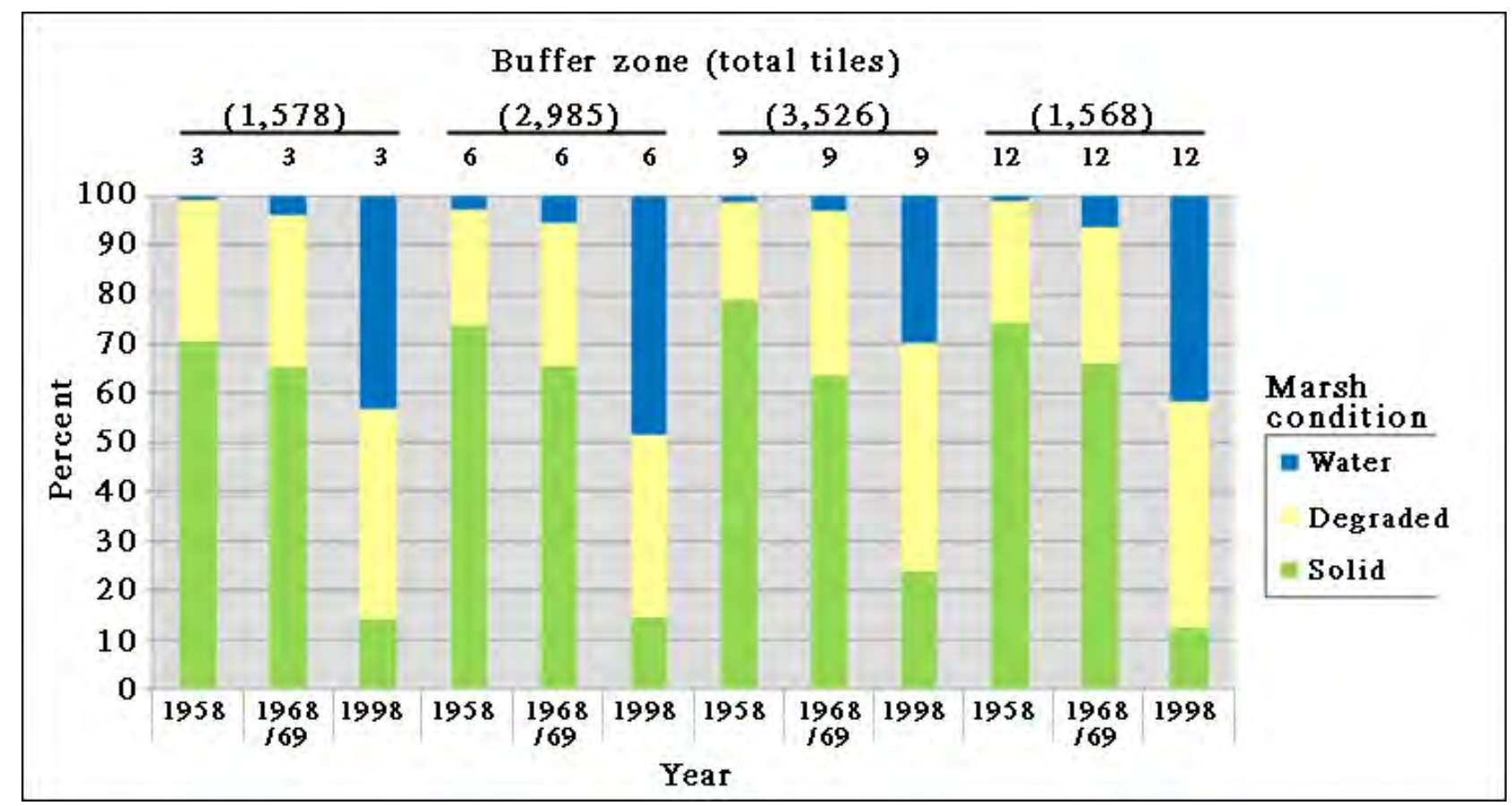

Figure 75. Marsh classification in the fresh vegetation type by buffer zones and years in coastal Louisiana.

\section{Intermediate Vegetation Type}

Figure 3 shows that in 1968 the intermediate vegetation zone encompassed only a narrow swath of the landscape; therefore, the numbers of tiles within this zone are relatively small. As shown in figure 76, all of the buffer zones except zone 12 consisted of at least 95 percent marsh (solid and degraded) in both 1958 and 1968/69, while buffer zone 12 consisted of slightly less solid and degraded marsh in the same two years. In all buffers, solid marsh was the largest component, approximately 63 percent, of the intermediate zone in 1958 and 1968/69. By 1998, the water component increased in every buffer zone, as did the degraded marsh. The greatest increases in water classified tiles were seen in buffers 6 and 12, where water accounted for 53 and 46 percent, respectively. While the extent of the increases found in buffers 6 and 12 are important, the location of these buffers-by-vegetation zones within the project landscape may be most significant. The locations of these segments are located within hotspots, which are identified in the land change 
analysis. Buffer 6 is located in hotspot 2 near the Central/East Falgout and Rambio region boundary, while buffer 12 is located in hotspot 4 (eastern side of the Houma Navigation Canal) in the interdistributary basin between Bayou Petit Caillou and Bayou Terrebonne.

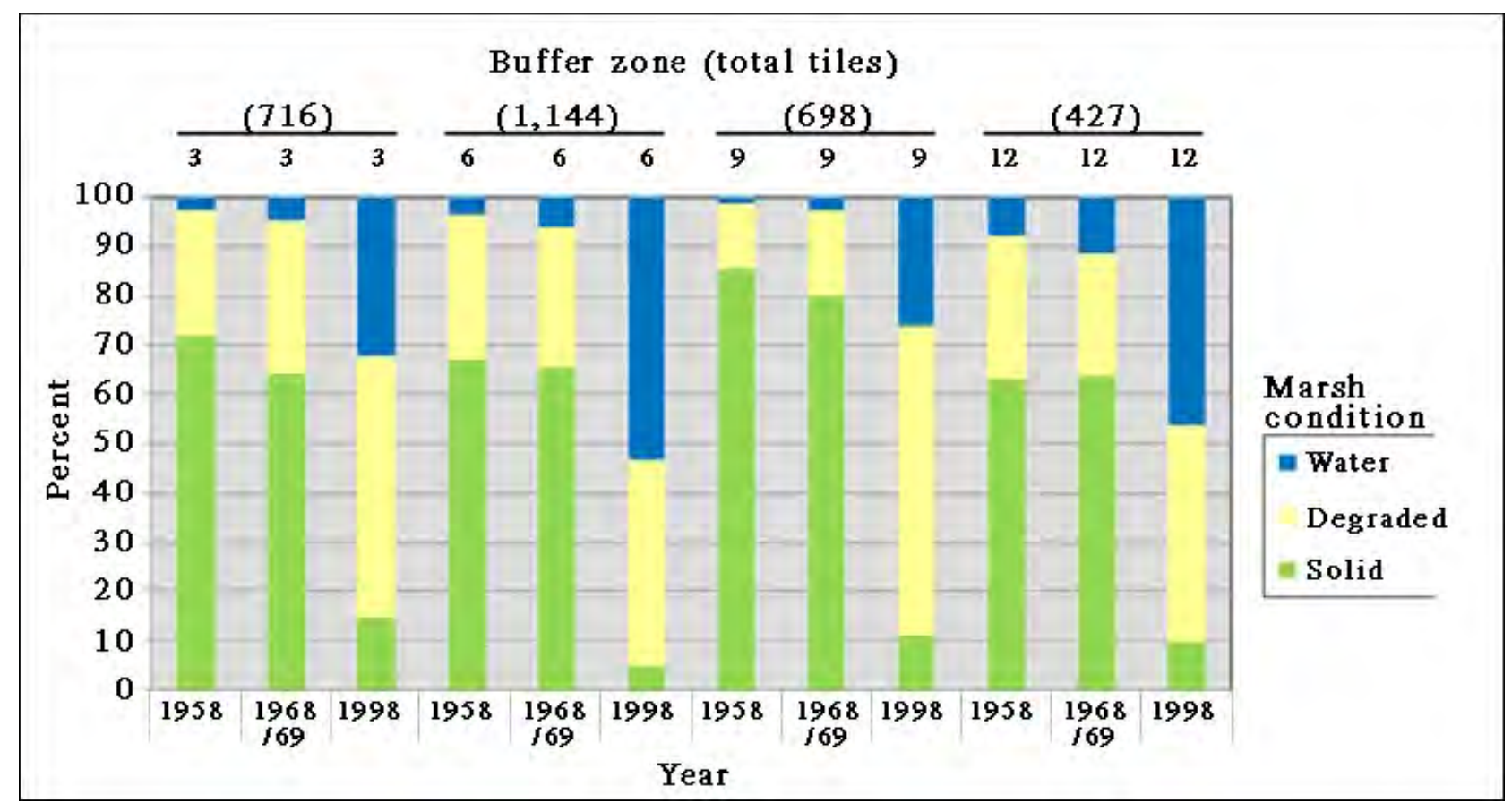

Figure 76. Marsh classification in the intermediate vegetation type by buffer zones and years in coastal Louisiana.

\section{Brackish Vegetation Type}

As stated previously, the brackish zone as a whole contained less than 50 percent solid marsh in 1958. The percentage of solid marsh ranged from less than 40 percent for buffers 3 and 6 to 51 percent (the largest percentage) for buffer 9 (fig. 77). The percentages for buffers 6 and 9 may be skewed slightly since this portion of the brackish zone contains Lake Boudreaux and surrounding water bodies. These water areas did not contribute to the buffer-by-zone classification because they were classified as water in the vegetation type layer; however, the area surrounding these water bodies did fragment into degraded marsh or open water by 1998, leaving 12 percent or less solid marsh in the eastern portion of both buffers 6 and 9. Also contributing to the decrease in solid marsh were the northeast portions of buffers 6 and 9 , which were designated as solid marsh in 1958, became heavily degraded by 1968, and changed to water class by 1998. In 1958 buffers 3 through 12 had significantly higher percentages of water within the brackish zone than in the fresh and intermediate zones combined. Therefore, the changes in percentages of water over time were not as great in the brackish vegetation zone as in those fresher zones. 


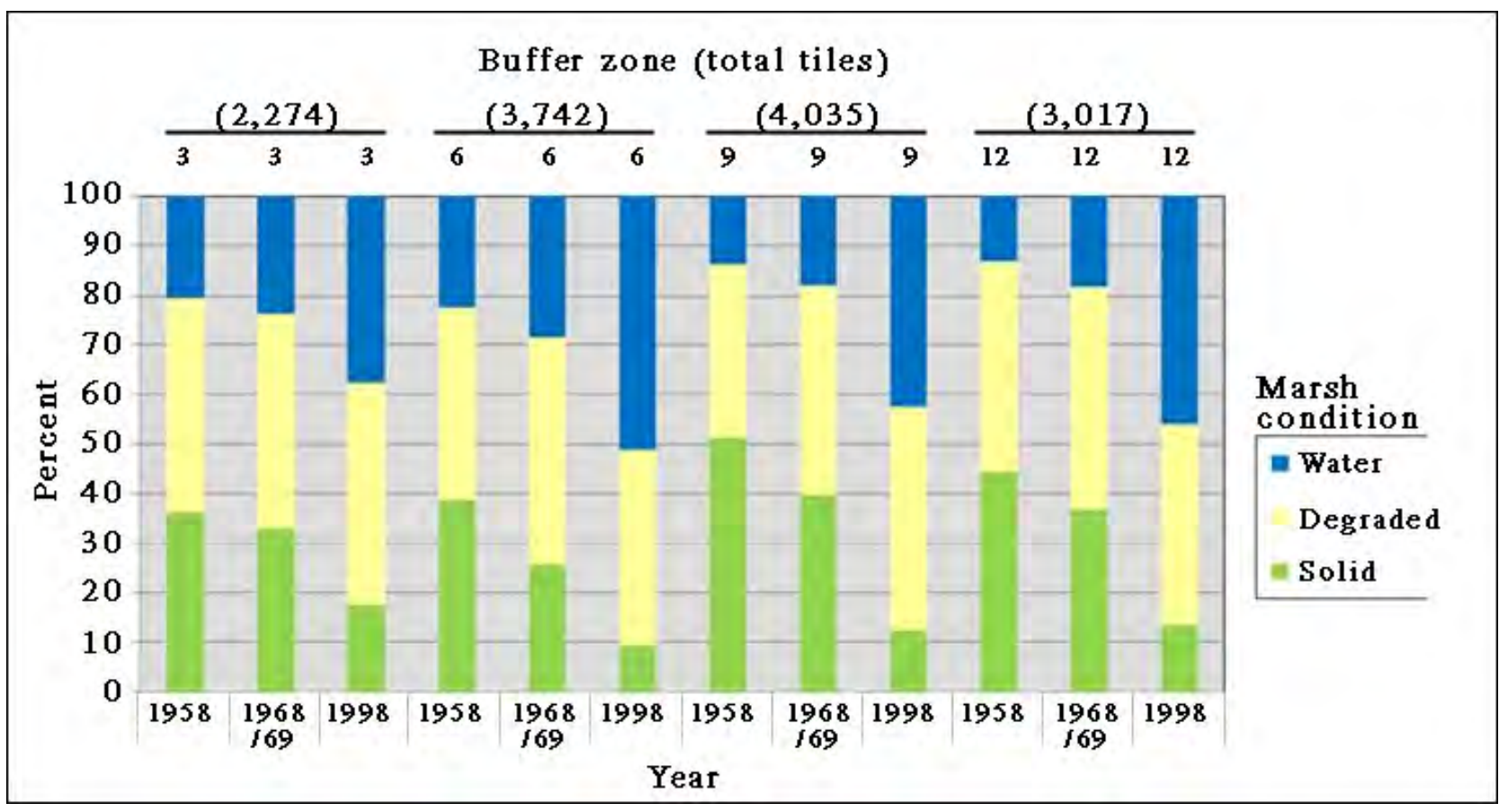

Figure 77. Marsh classification in the brackish vegetation type by buffer zones and years in coastal Louisiana.

\section{Saline Vegetation Type}

The three largest buffer-by-saline zones (buffers 3, 6, and 9) each had less than 27 percent solid marsh in 1958, experienced only slight change by 1968, and had less than 18 percent solid marsh by 1998 (fig. 78). Each buffer had at least 32 percent degraded marsh in every year. Of all of the saline buffers, buffer 12 was the only one to have less than 25 percent water in 1958 and less than 42 percent water in 1998. Across all years, buffers 6 and 9 contained the lowest percentages of solid marsh and the highest percentages of water tiles. The patterns in these regions were strongly affected by shoreline and bank erosion. Though buffers 3, 6, and 9 decreased in percentage of degraded tiles over the OA period, buffer 12 experienced a significant increase over that period. 


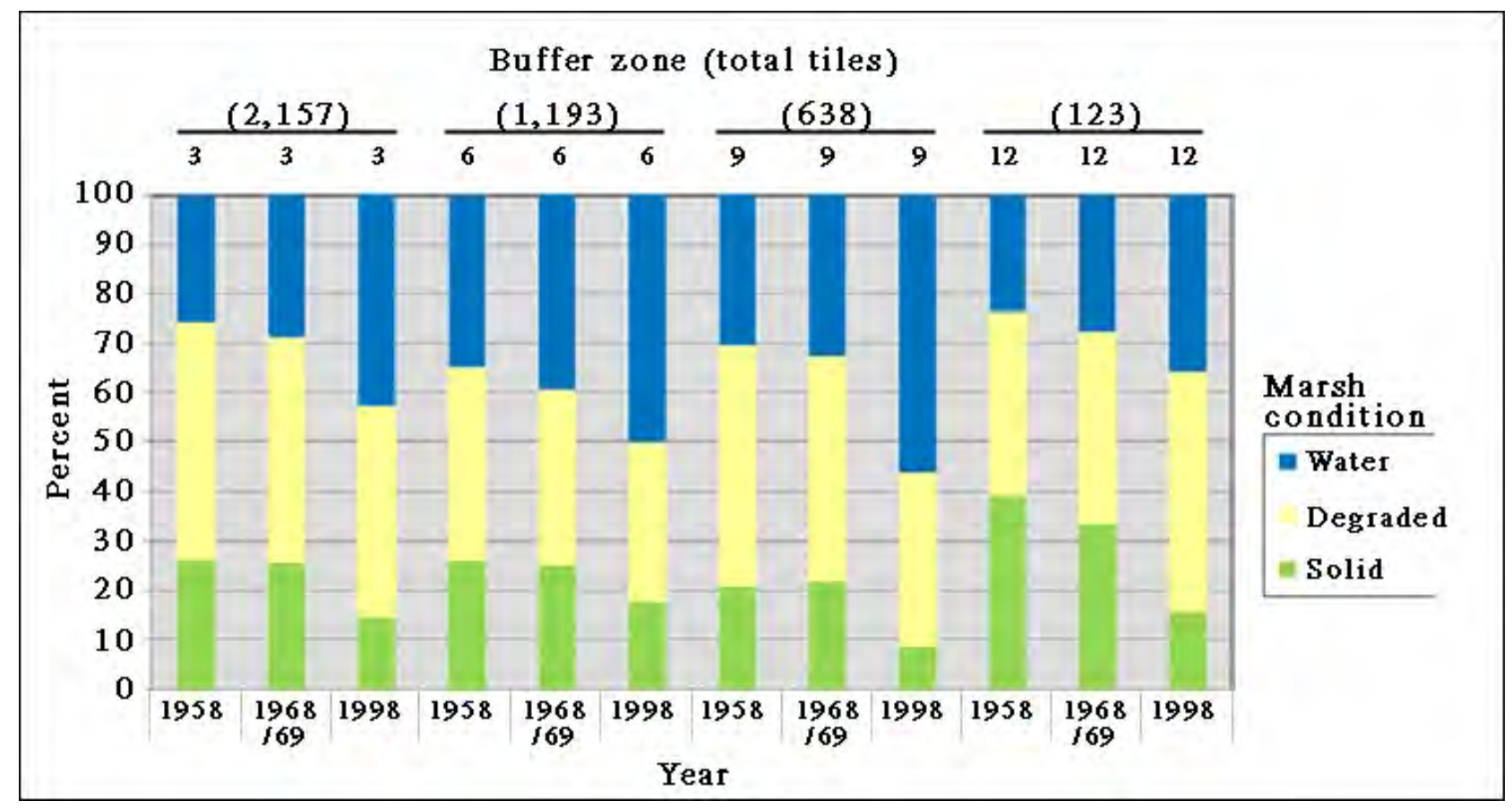

Figure 78. Marsh classification in the salt vegetation class by buffer zones and years in coastal Louisiana.

\section{Summary of Buffer-by-Vegetation Interactions}

Fresh and intermediate vegetation zones were over 65 percent solid marshes in 1958 and 1968. By 1998 these landscapes contained less than 18 percent solid marsh, having deteriorated to degraded marsh and water. Buffer zones 3 and 6 in the fresh and intermediate vegetation types included portions of hotspot 2 (south of Falgout Canal). The fresh vegetation type in buffer zones 3 and 6 were classified as fresh in 1958 and intermediate in 1968 and 1998. The intermediate vegetation portion of buffer 6 was classified as intermediate in 1958, brackish in 1978, and then intermediate again in 1998. Buffer zone 3 in the intermediate zone, which showed less conversion from solid marsh to open water, was classified as intermediate in all three dates. The majority of the salt and brackish vegetation zones were already degraded by 1958 . Most of the degradation noted in these two vegetation types occurred in areas that were already open water. Buffer zone 6 within the brackish marsh was solid in 1958, degraded in 1968, and open water in 1998. Buffer zones 3 through 12 in the brackish marsh, east of the Houma Navigation Canal and south of Lake Boudreaux, became open water by 1998 .

\section{Hotspots of Landscape Change}

Though the patterns of land loss differ spatially within the study area, there were four areas of extensively degraded marsh within the project landscape. These areas-or "hotspots"-are defined as relatively large areas that displayed significant change of one or more landscape metric 
values. It is interesting to note that all four hotspots were located near the intermediate-brackish confluence. Figure 79 shows the four hotspots in relation to the FRAGSTATS category and configuration classification differences. These are the differences between the 1958 and 1998 classes (values were assigned to both the category and configuration classes [configuration class assigned values: class $1=1$, class $A=2$, class $B=3.5$, class $C=5$, and classes 6 and $7=4$ ], all category and assigned configuration values were multiplied by 2 and summed by tile, and the difference was calculated by subtracting a previous date from a latter date, and those within-year values are summed prior to calculating the change over time). This figure gives an overall representation of marsh condition and degradation from start to end-point dates.

Hotspot 1, which is located west of Bayou du Large on the north side of Falgout Canal, was characterized as floating fresh marsh dominated by canouche (Panicum hemitomon) in 1949, characterized as fresh marsh comprising fresh maidencane marsh (dominated by Panicum hemitomon), fresh bulltongue marsh (dominated by Sagittaria lancifolia), and oligohaline mix marsh (dominated by Sagittaria lancifolia) (Visser and others, 1996) in 1968, and shifted to predominantly intermediate marsh by 1978 and 1997. This hotspot was a solid fresh floating marsh in 1958, became degraded marsh by 1968, and exhibited a significant negative change in PLAND, LSI, LPI, and PD values between the preconstruction and end-point dates. The clumpy and cohesion values increased between 1958 and 1968/69 but then underwent a significant negative change by 1998 , with the areas designated as fresh maidencane marsh in 1968 becoming open water. On its east side, the initial marsh degradation and loss in hotspot 1 may be related to natural impoundment on the east by Bayou du Large and by the manmade Falgout Canal in the south and Minors Canal in the west. Both Lake de Cade and Falgout Canal may also be conduits of higher salinity water. On the west side of this hotspot, initial loss occurred in areas of levee flank depressions. Ultimately this area, which was solid marsh in 1958, became predominantly open water by 1998, including larger areas of open water bodies. In 1978, the area was classified as intermediate (Chabreck and others, 1978), indicating increased salinity within the area. With intermediate vegetation persisting in 1988, salinity stress is probably a factor that contributed to the marsh degradation and loss in this area. Work by Morton and others (2005) and Gagliano (1999) indicated a fault trace east/west along Falgout Canal in our study area, cutting across the southern edge of Lake Boudreaux. Another trace splits from this trace west of the Houma Navigation Canal, veering to the northeast along the area north of Lake Boudreaux. Morton and others (2006) also depicted oil and gas fields in the areas which correspond to hotspots of land loss. 


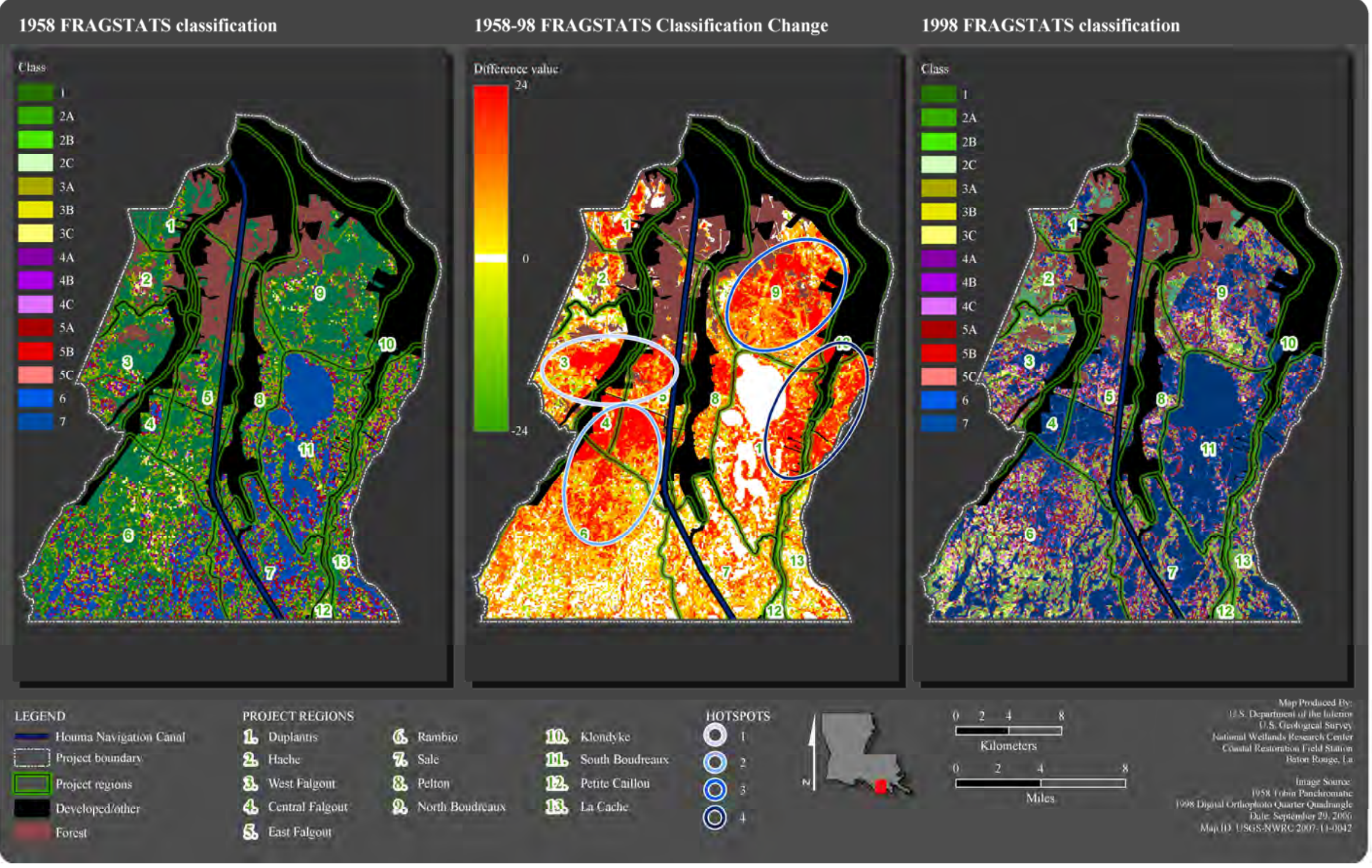

Figure 79. Fragmentation difference per tile between 1958 and 1998 . Values were assigned to each category class (category and assigned configuration values multiplied by 2 ), assigned to each configuration class (class $1=1$, class $A=2$, class $B=3.5$, class $C=5$, and classes 6 and $7=4$ ), and summed by tile, and the difference was calculated by subtracting a previous date from a latter date. Values are shown in conjunction with project regions in coastal Louisiana. 
Morton and others (2005) collected vibracores from near the center of each of five wetland-loss hotspots in the vicinity of our study area. One of the sites (DeLarge) is in the area of our hotspots 1 and 2, which are located south of Falgout Canal, and another one is in the area of our hotspot 4. From these cores, facies and stratigraphic layers were matched to determine a subsidence estimate of approximately $70 \mathrm{~cm}$ between marsh and the sunken marsh layer. Morton and others (2006) theorize that the areas of greatest land loss and subsidence were controlled by the coupling between reservoir compaction and slip along growth faults when sufficiently large volumes of fluid were removed from the subsurface, with loss occurring next to the fault zone and not necessarily directly over the top of the reservoir, explaining why there may not be a direct correlation between identified fields and hotspots of land loss.

There are other possible mechanisms for marsh substrate submergence. In studies of more saline marshes, Nyman and others (1993) found that the marsh surface sinks approximately $10 \mathrm{~cm}$ when marsh plants die. Gosselink and Sasser (1995) postulated that a sudden decrease in marsh elevation might be caused by either a collapse or decomposition of the structure of the marsh's root system when stressed enough.

Historical vegetation data available for some of the area within hotspot 1 indicated a fresh maidencane marsh within the area of loss (Chabreck, 1972; Visser and others, 1996). When stressed, fresh maidencane marsh responds differently than do attached marshes. First, the thickness of a floating marsh mat does not have to keep up with sea-level rise because the mat floats at or near the water surface. Mats approximately $50 \mathrm{~cm}$ thick float above the underlying substrate at a depth that varies with the ambient water level. Fresh maidencane marsh has been shown to be adversely affected by salinities as low as 1.5-3 ppt (Willis and Hester, 2004). Stress on these marshes resulting in lowered production or death of the highly organic mat could also result in the collapse and submergence of the marsh mat to the underlying firm substrate. The loss or decrease in mat buoyancy of a floating marsh could cause a greater decrease in elevation than in an attached marsh, depending upon the depth to the underlying firm substrate. It seems unlikely that fault reactivation or fluid withdrawal/faulting coupling caused most of the loss in hotspot 1; the more likely explanation for the loss was stress by impoundment exacerbated later by salinity stress.

Hotspot 2, which is east of Bayou du Large and just slightly southeast of hotspot 1, was designated as floating three-cornered grass marsh in 1949 (O’Neil, 1949) and by 1968 was classified as fresh and intermediate marsh in the north and brackish marsh in the south (Chabreck and others, 1968). Visser and others (1996) classified the stations on the transect in the northernmost section as oligohaline mix marsh and fresh bulltongue marsh vegetation types. The floating three-cornered grass marsh described by O'Neil in 1949 was likely a mat formed originally by the high productivity of Panicum hemitomon, then undergoing a transition to other species such as three-cornered grass in response to stresses to the marsh. O'Neil (1949) described floating three-cornered grass marshes as having a weak mat that would most probably collapse under stress. Between 1958 and $1968 / 69$, this hotspot was mainly composed of classes 1 through 4A, with a small distribution of classes 5A through 7. In 1965, landscape features described as "rips" in the marsh surface, which compare to those found in floating marshes that are affected by hurricanes (Evers and others, 2007), were evident within hotspot 2. These features provide further evidence that this hotspot included floating marsh. In aerial imagery taken during the flooding of 1973, some of this marsh was under water or had already converted to open water. Vegetation survey shows that hotspot 2 was intermediate (north) 
and brackish marsh (south) in 1978, but by 1997 this region was classified as predominantly intermediate marsh. At the same time the brackish marsh was encroaching into the area where the vegetation bordering the Houma Navigation Canal (HNC) at the same latitude was classified as intermediate. However, it seems unlikely that higher salinity water came directly out of the HNC into these marshes, but there may have been another conduit for it, such as the Falgout Canal and even possibly Lake de Cade. The change in shape, density, and connectivity metric values are less comprehensive in this area than in hotspots 1 and 3; however, the areas in which there was negative change are significantly greater than the average change project wide. As with the other hotspots, hotspot 2 shifted from relatively solid marsh in 1958 to an area that was $>60$ percent water by 1998. An area that was classified as freshwater floating marsh again became either open water or degraded marsh. Because of the character of the hotspot 2 vegetation over time and other evidence, it seems unlikely that fault reactivation or fluid withdrawal/faulting coupling caused most of this loss.

Hotspot 3 is an area north of Lake Boudreaux, in the North Boudreaux region, that was predominantly fresh and intermediate in 1968, underwent a significant shift to brackish by 1988, and was classified as intermediate vegetation in 1997 (fig. 3). In 1958 and 1968/69 this area was predominantly solid marsh but ultimately shifted to highly degraded and water classes. Unlike hotspot 2, these marshes were still viable after the Mississippi/Atchafalaya flood of 1973. Vegetation data from Chabreck (1972) indicate that marsh in areas surveyed within hotspot 3 in 1968 was classified as fresh maidencane marsh and fresh bulltongue marsh. By 1998, data from this area indicated an extreme negative change in PLAND, LSI, and cohesion and clumpy values; mid-level shifts of PD values; and significant change of the LPI values towards the north. The portion of this hotspot that became open water by 1998 was classified as freshwater marsh, either fresh maidencane marsh or fresh bulltongue marsh and likely floating marsh, while the southern part of the hotspot denoted degraded marsh composed of oligohaline wiregrass (dominated by Spartina patens) (Visser and others, 1996). Gagliano (1999) has described the degradation and loss in this region as severe and attributed that loss to fault reactivation by phenomena such as the Alaskan earthquake in 1964. Like hotspot 1, hotspot 3 appears to be mostly a freshwater marsh, probably flotant, which may have been stressed by other factors, causing the deterioration of the marsh mat. Evidence of the change to more saline-tolerant vegetation classification points to an influence by salinity and contributed to land-loss in hotspot 3.

Hotspot 4 is located on either side of Bayou Petite Caillou and between Lake Boudreaux and Bayou Terrebonne. This area consisted of floating three-cornered grass marsh and brackish three-cornered grass marsh (dominated by Schoenoplectus americanus) in 1949; intermediate and brackish marsh in 1968, 1978, and 1997; but was predominantly brackish marsh in both 1988 and 2001. Hotspot 4 was the only hotspot that was not classified as solid marsh in 1958. This hotspot, which was stippled with small water patches in 1958, experienced both enlargement of existing patches and the creation of new ones by 1968 and shifted to predominantly solid water by 1998 . Between 1958 and 1968, this hotspot experienced only moderate increases in the south, but by 1998 the northwest regions underwent intense increases in PD. Only the northern portion of hotspot 4 experienced measurable change in LSI, with a shift to less complex shape in the northeast across all dates and a shift to more complex in the northwest by 1998. Small changes were observed in clumpy value across all dates, with few select sections experiencing significant increases. The clumpy values underwent both decreases (along 
Bayou Petite Caillou) and increases (between Petite Caillou and Lake Boudreaux) for the pre- to postconstruction time period but experienced more extreme increases by the endpoint date. Ultimately, this area, which was already experiencing marsh fragmentation in 1958, shifted extensively to highly degraded marsh or open water by 1998 . This hotspot is near/within two oil/gas fields, one of which also includes a marsh studied previously (Madison Bay, Sasser and Evers, 1995). In a study funded by Barataria Terrebonne National Estuary Program (BTNEP), Sasser and Evers (1995) identified a submerged marsh (an area of marsh visible beneath the water surface and surrounded by nonflooded marsh) in an area east of Bayou Terrebonne in the Madison Bay area between 1969 and 1972 that became open water between 1978 and 1985. Madison Bay is also an area where Morton and others (2006) collected vibracores and found like facies offset by approximately $70 \mathrm{~cm}$. It seems likely that fluid withdrawal/faulting coupling was a major factor in the loss in hotspot 4. 


\section{Synthesis}

\section{Salinity-Coastwide}

Based upon analysis of daily salinity data within the Louisiana coastal zone, the overall coastal salinity pattern exhibited seasonal fluctuations, as well as large-scale fluctuations (usually from frontal passage influence), but typically remained above 15-20 ppt. Generally, the overall inland salinity pattern is characterized by a more pronounced seasonal change from low salinities (0-2 ppt) to moderate salinities (5-10 ppt). The presence of short duration pulses or "spikes" up to 15-20 ppt also are apparent. These spikes are the result of meteorological forcing (strong frontal passages). A typical inland station on a large channel in coastal Louisiana is characterized by low salinities ( $0-1 \mathrm{ppt})$ most of the time with short duration, high salinity (approximately $15 \mathrm{ppt}$ ) spikes from meteorological forcing (strong frontal passages). Additionally, on the Houma Navigation Canal (HNC), spikes were evident after major maintenance dredging events.

Overall, the coastal waters have a mean salinity of 15-20 ppt, which decreases fairly rapidly moving inland away from the gulf. The inland water bodies in the eastern part of the State tend to have higher salinity than do the inland water bodies in the western part of the State. The coastal salinities in Louisiana exhibit interannual variability, which is inversely related to Mississippi River discharge (Wiseman and others, 1990b).

At those stations within the Louisiana coastal zone that had statistically significant trends (42 of 44, or 95 percent), salinity increases occurred at 27 of the stations (64 percent), and salinity decreases occurred at 15 (36 percent) of the stations. Changes in salinity over time were small, with 74 percent being increases or decreases of less than $2 \mathrm{ppt}$, over the period of record. The long-term salinity trends explain less than 10 percent of the variance at most ( 72 percent) of the stations. It is interesting and probably indicative of the physiographic differences between Louisiana's eastern Deltaic Plain region and the western Chenier Plain region that, although there is no coherent coastwide trend of increasing or decreasing salinity, there is a consistent salinity increase for the internal basins of the Chenier Plain.

\section{Salinity-Houma Navigation Canal Area}

Analysis of daily and hourly salinity data within the Houma Navigation Canal (HNC) area indicated the following regarding salinity duration and salinity events or pulses. With the exception of the 1999-2000 drought, there does not appear to be any obvious pattern in increasing salinity levels closely following the completion of the canal, except for the immediate increase in salinity spikes during completion of construction in 1961. The data from Bayou Grand Caillou at Dulac does show a longer term trend of increasing salinity levels. This pattern is similar to the pattern observed at the Houma Water Treatment Plant. A possible explanation for these patterns is based on the dredging history of the HNC, where dates of maintenance dredging correspond fairly closely to the salinity peaks in Bayou Grand Caillou and HNC. It appears that the dredging events opened up a deeper route from the HNC to Crozier and into Grand 
Bayou Caillou, but it also may be a result of the general breakup of the marsh in the area, resulting in greater exchange of bay water.

Water levels have a fairly high correlation ( $>0.7$ at 7 of 10 stations), indicating that the water level patterns in this area are driven mostly by the coastal water levels. The salinity levels show much lower correlations $(<0.5$ at 7 of 10 stations), indicating that the salinity of the Terrebonne Bay waters is not the entire driving force for the more interior locations. Although high coastal water levels result in high water levels throughout the system, high salinity at the coast does not always result in high salinity at the inland stations.

There is an indication of salinity increase in the HNC as opposed to the stations on either side, both of which show decreases. Salinity decrease along a coast-inland gradient exhibited the lowest values in the HNC, indicating that salt water can intrude further inland in this straight canal. Based upon an analysis of salinity pulse characteristics during the fall of 2003 at a distance inland of about $40 \mathrm{~km}$, the station in the HNC has a significantly higher salinity when compared to a station at a similar distance inland in Bayou Grand Caillou (5.5 ppt versus $1.8 \mathrm{ppt}$ ). Closer to the coast (about $20 \mathrm{~km}$ ), the salinity in the HNC (13.3 ppt) is significantly higher than the salinity in Bayou Terrebonne (6.1 ppt) but not significantly higher than the salinity in Bayou Grand Caillou (10.3 ppt).

Salinity pulse analysis for the entire year of 2003 indicated an average duration of 4.8 days at the HNC station, which was significantly lower than the value of 7.3 days at the Bayou Grand Caillou station. However, the mean pulse magnitudes $10.5 \mathrm{ppt}$ (at the HNC station) and 11.0 (at the Bayou Grand Caillou station) were not significantly different. These data indicate that the higher salinity waters associated with the pulses tend to remain longer in the Bayou Grand Caillou system. The duration difference may be due to the influence of fresh water entering the HNC through its connection to the Gulf Intracoastal Waterway. Regression analysis indicates that discharge explains almost 50 percent of the observed salinity pulses in the HNC.

The construction of the HNC may have provided a salinity pathway to the marshes west of the HNC, particularly the marshes in "hotspots" 1 and 2 in the Falgout Canal area. These areas also were impounded by numerous spoil banks, which may have exacerbated any saltwater intrusion problems. Although the available salinity data are insufficient to conduct statistical correlations, there was close agreement between salinity changes and specific dredging events of the HNC.

\section{Salinity and Connectivity}

Salinity data from the Bayou Grand Caillou station at Dulac indicated a major shift to higher salinity levels around 1975 (there was a slight increase postconstruction). This time period coincides with the first full maintenance dredging of the full length of the Houma Navigation Canal (HNC) (6.30 million $\mathrm{m}^{3}$ ) that occurred between 1972 and 1974. The marshes in this area (east of the canal) also show a shift from fresh marsh prior to construction of the canal (completed approximately 1962) to intermediate marsh by 1978. This vegetation shift may be a result of the general breakup of the marshes east of the canal, which was quite extensive by 1978, as opposed to a direct impact of the channel. 
The salinities at Bayou Grand Caillou were high enough prior to construction of the HNC to impact the fresh floating marshes in the areas west of the canal; however, the connections between the marshes west of the canal and the Bayou Grand Caillou station at Dulac were mainly smaller, sinuous channels with limited water exchange. Once the HNC was constructed and after maintenance dredging, the connections between the HNC and Bayou Grand Caillou were found to be efficient (U.S. Army Corps of Engineers, 1975). The construction of the HNC resulted in increases in connectivity between the marshes west of the canal and the lower portion of Bayou Grand Caillou (south of Dulac), which was essentially replaced by the lower portion of the HNC. This increase in connectivity between marshes may have allowed higher salinity waters to reach the marshes west of the HNC, particularly those areas just north and south of Falgout Canal (hotspot areas 1 and 2). These areas also became impounded by numerous canal spoil banks, which may have exacerbated any salinity intrusion events since water would be held in these impounded areas for greater lengths of time (Swenson and Turner, 1987).

\section{FRAGSTATS Method Assessment}

Three methods were assessed for potential development and implementation of landscape fragmentation and configuration analyses. The FRAGSTATS grid system was the method selected because of its class-level metrics, output reproducibility, and potential as a packaged management tool. The FRAGSTATS system was found to be a useful tool in determining the composition and configuration of marsh and water in the study area tiles. Individual landscape metrics were used to determine the percentage and rate of land change and the shifts in density, shape, and cohesiveness of water within the marsh. Individual metrics also were combined into a classification system on the basis of the Dozier (1983) and Evers and others (1991) manual classification schemes, which allowed for the categorization of marsh based on the percentage of water present and the type and degree of degradation within the tile landscape.

Though the FRAGSTATS method provided many advantages over other systems, it is not without limitations. These limitations include the inability to account for patch type adjacency, the time intensive nature of the required land-water analysis, and the overall scale specificity of the technique. Through modification and further evaluation of the FRAGSTATS method, however, solutions to many of these limitations are possible. Long term, the FRAGSTATS grid system provides reliable landscape evaluation capabilities and, with the use of higher quality imagery, should evolve into a historic and predictive tool for assessing ecological processes.

\section{Landscape Assessments}

Wetland loss rates for coastal Louisiana and the Terrebonne basin (Barras, 2006; Barras and others, 2003) were compared to the long- and short-term rates of the Houma Navigation Canal (HNC) study area that were quantified by using FRAGSTATS. These results suggest that the HNC. study area was losing land at a significantly faster rate than both the marshes of coastal Louisiana (all periods) and the other highly degraded 
neighboring marshes within the Terrebonne basin (TB and OA periods). Overall, 37 percent $\left(176.56 \mathrm{~km}^{2}\right)$ of the project area marsh was lost by 1998 .

Project-scale marsh density, shape, and connectivity metrics were computed for three project dates $(1958,1968 / 69$, and 1998). In general, the increases in the projectwide average configuration (PLAND, LPI, LSI) and connectivity metric (cohesion and clumpy) values are indicative of a marsh that transitioned from a solid and less complex landscape, with high levels of marsh connectivity, to a highly complex and degraded landscape with increased water connectivity.

By 1958, significant differences were observed in quantity and configuration of marsh located in areas east and west of the proposed HNC. The preconstruction western region marshes were more stable marshes, affected by fewer and more naturally occurring waterways, and were therefore less hydrologically connected to the higher salinity waters of Terrebonne Bay and the Gulf of Mexico. The eastern regions contained marshes that were either in closer proximity, or had direct connectivity, to the Gulf of Mexico and therefore consisted of more degraded and water-dominated landscapes. It is assumed that the advanced degree of degradation of these marshes (in relation to the western region marshes) was influenced by the closer proximity to the Gulf of Mexico in the south and by connections between larger natural waterways (for instance, Bayou Terrebonne) and channelized pipelines and canals in the north.

As a means of quantifying the distance and degree of influence that the HNC had on marsh degradation, a 3-km interval buffer array was used to describe the changes in primary metric values across the three project dates. The patterns across landscape metrics varied, and it was difficult to discern direct relationships on the basis of proximity to the HNC. Even though the HNC may have an influence on marsh degradation, these analyses show that the degree and distance of that influence is not discernible through change in class-level landscape metric values.

The project area was assessed by using both existing vegetation surveys (O'Neil, 1949; Chabreck and others, 1968; Chabreck and Linscombe, 1978, 1988, 1997; Linscombe and others, 2001) and degradation class (via average landscape metric value) for each vegetation zone (zone extent standardized by using the 1968 survey). The surveys revealed a general northerly shift of higher salinity marshes, where the southern portions of the fresh and intermediate zones transitioned to intermediate and brackish vegetation respectively. These fresher vegetation zones experienced the most significant increases in average primary metric values (PLAND, LPI, cohesion and clumpy) - and therefore suffered the greatest decrease and increase in solid and degraded marsh, respectively - for all three time periods. Ultimately, the 1998 values for the fresh and intermediate marshes were comparable to those for the 1958 brackish and saline zones.

The vegetation zones within buffers show a lot of variability. The results appear to be dominated by both the north-south vegetation delineation and by year, but influence based on distance from the HNC is not evident. Similar to the vegetation zone analyses, these results show that fresher marshes were more susceptible to degradation. This degradation was observed in fresh and intermediate marshes where the primarily solid landscapes in the pre- and postconstruction dates converted to degraded marsh or open water by the end date; however, as a result of higher connectivity to the Gulf of Mexico and subsequent shoreline and bank erosion, the brackish and saline marshes had higher percentages of water in 1958 and therefore experienced lower levels of degradation than the fresh and intermediate zones by 1998 . The inability to differentiate effects based on distance from the HNC could be a result of influence from Bayou Terrebonne in the east. 
Hotspots were defined as areas that experienced extensively degraded marsh and were distinguished by using significant change in landscape metric values. There were four hotspots within the project area, all of which were located near the intermediate to fresh and brackish boundaries. Hotspots 1 and 2 show some of the larger changes in metric value between 1958 and 1968/69. These changes are evident in PLAND values located in hotspot 1, west of Bayou du Large and within a linear band east of Bayou du Large, where there is a trenasse (A small manmade trench through a swamp or marsh an area ) into floating fresh marsh, and in hotspot 2, in the northern section of the Rambio region. The cohesion, $\mathrm{PD}$, and clumpy values represent more of the relative disposition of water patches within the marsh. The changes in the metrics between 1958 and 1968/69 show the early sign of deterioration and shifts in configuration within the marsh. These areas of intense configuration change-which were more prevalent than the PLAND changes observed in hotspots 1,2, and 3-were most intense to the west of Bayou du Large in hotspot 1, throughout all of hotspot 3, and near the most northern and southern sections of hotspot 2. Hotspot 2 also experienced decreases in configuration along the spoil bank and levee of the channelized Falgout Canal. These decreases in configuration are landscapes that transitioned to aggregated land, disconnected water, and reduced patch density in relatively solid marsh. The larger change in shape metrics as related to change in percentage of water alludes to the floating nature of the vegetation in these hotspots.

The changes in hotspots 1 and 2 during the TA period coincide with the channelization of the HNC and Falgout Canal. Construction of the HNC was completed in 1962, and the widening and straightening of the attached Falgout Canal can be observed in as early as 1963 photography. Records show that the original Falgout Canal, which was a modest trenasse created and used for local recreational navigation, was dredged from a depth of approximately $0.76 \mathrm{~m}$ to $2.74 \mathrm{~m}$ and widened to approximately $27.43 \mathrm{~m}$. Though these canals were constructed and enhanced to provide navigable routes for shipping, recreation, and oil and gas usage, they produced unexpected negative effects to the surrounding marsh. These canals provided a deep water channel by which high salinity waters were transported north into fresher marsh and water systems. The overall tile and regional statistics show the significantly different conditions of the marsh located east and west of the HNC. The accelerated deterioration of the marshes west of the HNCcoincides with the construction of that canal and the widening and deepening of the Falgout Canal. This HNC-to-Falgout Canal pathway was able to efficiently deliver higher salinity waters to the fresh and intermediate marshes located west of theHNC. Within hotspots 1 and 2, the effect on the landscape was twofold; an increase in salinity and alteration of hydrology led to impoundment and the eventual shift and deterioration of the marsh.

The hotspots located east of the HNC underwent very different land loss and configuration change when compared to hotspots 1 and 2 and between hotspots 3 and 4 . Hotspot 4, which experienced greater land loss by 1968/69 than did hotspot 3, underwent only minimal configuration change over that period. The opposite was true for hotspot 3 by 1968/69, though by 1998 all hotspots underwent significant change in both configuration and extent of water within the landscape. The causes and/or progression of these changes, however, were different both east and west of the HNC and between hotspots 3 and 4 . Hotspots 1, 2, and 3 were affected by increased salinity and altered hydrology via the HNC and its distributaries. Hotspot 3 experienced land loss at a slower rate than did hotspots 1 and 2 because of its proximity to preexisting natural channels, 
which were capable of delivering higher salinity waters before the construction of the HNC. Hotspot 4 was primarily a brackish marsh during the OA period and was therefore less affected by higher salinity waters. As mentioned previously, studies by Sasser and Evers (1995) and Morton and others (2006) show that this hotspot is located within two oil and gas fields, and therefore, its minimal configuration change and rapid conversion to water can be linked to fluid withdrawal and faulting coupling.

\section{Acknowledgments}

The authors would like to thank the Minerals Management Service's Project Officers Susan Childs and Herb Leedy and the USGS Program Officer Gary Brewer for funding support and technical guidance on this project. We especially thank Craig Conzelmann and Bill Sleavin for supplying data management and application help and John Barras for his invaluable advice. Assistance in both land-water analysis and interpretation was provided by USGS personnel Bill Jones and IAP World Services' personnel Adrienne Garber, Dayna Price, Andy Boudreaux, and Matt Keller. 


\section{References Cited}

Adams, R.D., and Baumann, R.H., 1980, Land building in coastal Louisiana Emergence of the Atchafalaya Bay delta: Baton Rouge, La., Louisiana State University, Center for Wetland Resources, Sea Grant Publication LSU-T-80-02, 26 p., plus appendix.

Barras, J.A., Beville, S., Britsch, D., Hartley, S., Hawes, S., Johnston, J., Kemp, P., Kinler, Q., Martucci, A., Porthouse, J., Reed, D., Roy, K., Sapkota, S., and Suhayda, J., 2003, Historical and projected coastal Louisiana land changes, 1978-2050: U.S. Geological Survey Open-File Report 03-334, 39 p.

Barras, J.A., 2006, Land area changes in coastal Louisiana after the 2005 hurricanes - A series of three maps: U.S. Geological Survey Open-File Report 2006-1274, 3 sheets, available at http://pubs.usgs.gov/of/2006/1274/

Barrett, B.B. and Louisiana Wildlife and Fisheries Commission 1971, Cooperative Gulf of Mexico Estuarine Inventory and Study, Louisiana. Phase II, Hydrology and Phase III, Sedimentology, New Orleans, Louisiana,191 p.

Baumann, R.H., 1987, Physical variables, in Conner, W.H., and Day, J.W., Jr., eds., The ecology of Barataria Basin, Louisiana - An estuarine profile: U.S. Fish and Wildlife Service Biological Report 85(7.13), p. 8-17

Boesch, D.F., Josselyn, M.N., Mehta, A.J., Morris, J.T., Nuttle, W.K., Simenstad, C.A., and Swift, D.J.P., 1994, Scientific assessment of coastal wetland loss, restoration, and management in Louisiana: Journal of Coastal Research, Special Issue 20, 103 p.

Boesch, D.F., ed., 1982, Proceedings of the conference on coastal erosion and wetland modification in Louisiana - Causes, consequences, and options: Washington, D.C., U.S. Fish and Wildlife Service, Biological Services Program, FWS/OBS-82/59, 256 p.

Byrne, P.M., Borengasser, G.D., Muller, R.A., Smith, B.L., and Wax, C., 1976, Barataria Basin - Hydrologic and climatologic processes: Baton Rouge, La., Louisiana State University, Center for Wetland Resources, Sea Grant Publication 3, LSU-T-76-010, $176 \mathrm{p}$.

Chabreck, R.H., 1972, Vegetation, water, and soil characteristics of the Louisiana coastal region: Baton Rouge, La., Louisiana State University, Report No. 664, 72 p.

Chabreck, R.H., Joanen, Ted, and Palmisano, A.W.,1968, Vegetation type map of the Louisiana coastal marshes: Louisiana Cooperative Wildlife Research Unit, Louisiana Wildlife and Fisheries Commission, and Louisiana State University, 1 sheet, scale $1: 100,000$. 
Chabreck, R.H., and Linscombe, R.G., 1978, Vegetative type map of the Louisiana coastal marshes: Baton Rouge, La., Louisiana Department of Wildlife and Fisheries, 1 sheet, scale 1:100,000.

Chabreck, R.H., and Linscombe, R.G., 1988, Vegetative type map of the Louisiana coastal marshes: Baton Rouge, La., Louisiana Department of Wildlife and Fisheries, 1 sheet, scale 1:100,000.

Chabreck, R.H., and Linscombe, R.G., 1997, Louisiana coastal marsh vegetative type map: Baton Rouge, La., Louisiana State University and Louisiana Department of Wildlife and Fisheries, 1 sheet, scale not given.

Chuang, W.S., and Swenson, E.M., 1981, Subtidal water level variations in Lake Pontchartrain, Louisiana: Journal Geophysical Research, v. 86, no. C5, p. 4198-4204.

Dozier, M.D., 1983, Assessment of change in the marshes of southwestern Barataria Basin, Louisiana, using historical aerial photographs and a spatial information system: Baton Rouge, La., Louisiana State University, master's thesis, 102 p.

Evers, D.E., Gosselink, J.G., Sasser, C.E., and Hill, J.M., 1992, Wetland loss dynamics in southwestern Barataria Basin, Louisiana, 1945-1985: Wetlands Ecology and Management v. 2, p. 103-118.

Evers, D.E., Gosselink, J.G., and Sasser, C.E., 1991, Wetland and vegetation changes in southwestern Barataria Bay, Louisiana, 1945-1985: Report to Louisiana Offshore Oil Port, Inc., LSU-CEI-91-11., 77 p.

Evers, D.E., Swenson, E.M., Stanton, L., and Sasser, C.E., 2007, Distribution and ecological characteristics of the marshes in the eastern Mississippi River delta plain, Louisiana and the impacts of Hurricane Katrina, 2007: Dallas, U.S. Environmental Protection Agency, Water Quality Protection division, 121 p.

Flynn, K.M., McKee, K.L., and Mendelssohn, I.A., 1995, Recovery of freshwater marsh vegetation after a saltwater intrusion event: Oecologia, v. 103, no. 1, p. 63-72.

Fuller, D.A., Condrey, R.E., Geaghan, J.P., and Barrett, B.B., 1990, An analysis of longterm salinity patterns in the Louisiana coastal zone: Northeast Gulf Science, v. 11, no. 1, p. 11-17.

Fuller, D.A., Gosselink, J.G., Barras, J.A., and Sasser, C.E., 1995, Status and trends in vegetation and habitat modifications, in Reed, D.J., ed., Status and trends of hydrologic modification, reduction in sediment availability, and habitat loss/modification in the Barataria-Terrebonne estuarine system: Thibodaux, La., Barataria-Terrebonne National Estuary Program, BTNEP Publication no. 20, p. 25-76.

Gagliano, S.M., 1999, Faulting, subsidence and land loss in coastal Louisiana, in Louisiana Coastal Wetlands Conservation and Restoration Task Force and Wetlands Conservation and Restoration Authority, Coast 2050 - Toward a sustainable coastal 
Louisiana, the appendices, appendix B-technical methods: Baton Rouge, La., Louisiana Department of Natural Resources, p. 21-72.

Gagliano, S.M., Kwon, H.J., Light, Phillip, and van Beek, J.L., 1970, Summary of salinity statistics, coastal Louisiana stations, 1946-1968: U.S. Army Corps of Engineers Contract DACW 29-69-C-0092, 302 p.

Gagliano, S. M., Light, P., Muller, R., Al-Awady, M., 1973, Water balance in Louisiana estuaries: Baton Rouge, La., Louisiana State University, Center for Wetland Resources, Coastal Resources Unit, Hydrologic and Geologic Studies of Coastal Louisiana, Report no. 3., 177 p.

Gammill, S., Balkum, K., Duffy, K., Meselhe, E., Porthouse, J., Ramsey, E., and Walters, R., 2002, Hydrologic investigation of the Louisiana Chenier Plain: [Main report prepared for the Louisiana Coastal Wetland Planning, Protection and Restoration Act Task Force], Louisiana Department of Natural Resources, at http://www.lacoast.gov/reports/static/HILCP_l.pdf, 135 p., plus appendices.

Geyer, R.A., 1950, The occurrence of pronounced salinity variations in Louisiana coastal waters: Journal of Marine Research, v. ix, no. 2, p. 100-110.

Good, B., Buchtel, J., Meffert, D., Radford, J., Rhinehart, K., and Wilson, R., 1995, eds., Louisiana's major coastal navigation channels: Baton Rouge, La., Louisiana Department of Natural Resources, Coastal Restoration Division, 57 p.

Gosselink, J.G., 1984, The ecology of delta marshes of coastal Louisiana - A community profile: Washington, D.C., U.S. Fish and Wildlife Service, FWS/OBS-84/09, 134 p.

Gosselink, J.G., and Sasser, C.E., 1995, Causes of wetland loss, part 7, in Reed, D.J., ed., Status and trends of hydrologic modification, reduction in sediment availability, and habitat loss/modification in the Barataria-Terrebonne estuarine system: Thibodaux, La., Barataria-Terrebonne National Estuary Program, BTNEP Publication no. 20, p. 203236.

Grasshoff, Klaus, Kremling, Klaus, and Ehrhardt, Manfred, eds.,1999, Methods of seawater analysis: New York, Wiley-VCH, 632 p.

Haan, C.T, 1977, Statistical methods in hydrology: Ames, Ia., The Iowa State University Press, 378 p.

Hart, W.E., and Murray, S.P., 1978, Energy balance and wind effects in a shallow sound: Journal of Geophysical Research, v. 83, no. C8, p. 4097-4106.

Hester, M.W., Mendelssohn, I.A., and McKee, K.L., 1998, Intraspecific variation in salt tolerance and morphology in Pancium hemitomon, and Spartina alterniflora: International Journal of Plant Science, v. 159, no. 1, p. 127-138. 
Hirsch, R.M., Slack, J.R., and Smith, R.A., 1982, Techniques of trend analysis for monthly water-quality data: Water Resources Research, v. 18, no. 1, p. 107-121.

Holm, G.O., Jr., and Sasser, C.E., 2001, Differential salinity response between two Mississippi River subdeltas - Implications for changes in plant composition: Estuaries v. 24, no.1, p. 78-89.

Howard, R.J., and Mendelssohn, I.A., 1999a, Salinity as a constraint on growth of oligohaline marsh macrophytes, I, species variation in stress tolerance: American Journal of Botany v. 86, no. 6 p. 785-794.

Howard, R.J., and Mendelssohn, I.A., 1999b, Salinity as a constraint on growth of oligohaline marsh macrophytes, II, salt pulses and recovery potential: American Journal of Botany v. 86, no. 6 p. 795-806.

Johnson, W.B., and Gosselink, J.G., 1982, Wetland loss directly associated with canal dredging in the Louisiana coastal zone, in Boesch, D.F., ed., Proceedings of the Conference on Coastal Erosion and Wetland Modification in Louisiana - Causes consequences and options: U.S. Fish and Wildlife Service, Biological Services Program, FWS/OBS-82159, p. 60-72

Kjerfve, Bjorn, 1975, Tide and fair-weather effects in a bar-built Louisiana estuary, in Cronin, L.E., ed., Estuarine Research: Geology and Engineering. v. 2, p. 47-62.

Linscombe, G., Chabreck, R.H., and Hartley, S., 2001, Aerial mapping of marsh dieback in saline marshes in the Barataria - Terrebonne Basins [abs.]: Abstracts from "Coastal Marsh Dieback in the Northern Gulf of Mexico: Extent, Causes, Consequences, and Remedies," USGS Information and Technology Report, USGS/BRD/ITR-2001-0003, $31 \mathrm{p}$.

Louisiana Department of Environmental Quality, comp., 1998, Louisiana BasinSubsegments, Geographic NAD83, LDEQ (1999) [subsegments]: Louisiana Department of Environmental Quality.

Louisiana Coastal Wetlands Conservation and Restoration Task Force (LCWCRTF). 2002. Hydrologic Investigation of the Louisiana Chenier Plain: Louisiana Department of Natural Resources, Coastal Restoration Division.

Louisiana Oil Spill Coordinator's Office, 1999, Color Infrared Orthophoto Quarter of Pierre Part Quadrangle, LA, 50:1 MrSID compressed.

McGarigal, Kevin, Cushman, S.A., Neel, M.C., and Ene, Eduard, 2002, FRAGSTATS Spatial pattern analysis program for categorical maps: Amherst, Mass., The University of Massachusetts, [Computer software program] available at www.umass.edu/landeco/research/fragstats/fragstats.html 
McGarigal, Kevin, and Marks, B.J., 1995, FRAGSTATS - Spatial pattern analysis program for quantifying landscape structure: USDA Forest Service General Technical Report PNW-351, 122 p.

McKee, K.L., and Mendelssohn, I.A., 1989, Response of a freshwater marsh plant community to increased salinity and increased water level: Aquatic Botany v. 34, p. 301-316.

Microsoft Corporation, 1994, Microsoft EXCEL User's Guide, Version 5.0: Cambridge, Microsoft Corporation, $786 \mathrm{p}$.

Morton, R.A., Bernier, J.C., Barras, J.A., and Ferina, N.F., 2005, Rapid subsidence and historical wetland loss in the Mississippi delta plain - Likely causes and future implications: U.S. Geological Survey Open-File Report 2005-1216, 116 p.

Morton, R.A., Bernier, J.C., and Barras, J.A., 2006, Evidence of regional subsidence and associated interior wetland loss induced by hydrocarbon production, Gulf Coast region, USA: Environmental Geology, v. 50, no. 2, p. 261-274.

Nyman, J.A., Callaway, J.C., and DeLaune, R.D., 1993, Case study of a rapidly submerging coastal environment - Relationships among vertical accretion, carbon cycling, and marsh loss in Terrebonne Basin, Louisiana. in Burn, P., ed., Proceedings of the International Coastal Symposium, June 6-9, 1993: Hilton Head Island, S.C., p. 452-457.

O'Neil, Ted, 1949, The Muskrat in the Louisiana coastal marshes: New Orleans, Louisiana Department of Wildlife and Fisheries, 152 p.

Orlando, S.P., Jr., Rozas, L.P., Ward, G.H., and Klein, C.J., 1993, Salinity characteristics of Gulf of Mexico estuaries: Strategic Environmental Assessments, Division Office of Ocean Resources Conservation, and Assessment, National Oceanic and Atmospheric Administration, $209 \mathrm{p}$.

Penland, Shea, Wayne, Lynda, Britsch, L.D., Williams, S.J., Beall, A.D., and Butterworth, V.C., 2000, Process classification of coastal land loss between 1932 and 1990 in the Mississippi River delta plain, southeastern Louisiana: U.S. Geological Survey Open-File Report 00-418, at http://pubs.usgs.gov/of/2000/of00-418/, 1 sheet.

Perez, B.C., Day J.W., Jr., Rouse, L.J., Shaw, R.F., and Wang, Menglou, 2000, Influence of Atchafalaya River discharge and winter frontal passage on suspended sediment concentration and flux in Fourleague Bay, Louisiana: Estuarine, Coastal and Shelf Science, v. 50, no. 2, p. 271-290.

Pezeshki, S.R., and DeLaune, R.D., 1993, Effects of soil hypoxia and salinity on gas exchange and growth of Spartina patens: Marine Ecology Progress Series, v. 96, p. 7581 . 
Rounsefell, G.A., 1964, Preconstruction study of the fisheries of the estuarine areas transversed by the Mississippi River-Gulf Outlet project: Fisheries Bulletin, v. 63, p. 373-393.

SAS, 1990a, SAS procedures guide, version 6, (3rd ed.): Cary, NC, SAS Institute, Inc., $705 \mathrm{p}$.

SAS, 1990b, SAS language reference, version 6, (1 ${ }^{\text {st }}$ ed.): Cary NC, SAS Institute, Inc., $1,042 \mathrm{p}$.

SAS, 1990c, SAS /STAT user's guide, release 6.03 (4 ${ }^{\text {th }}$ ed.): Cary, NC, SAS Institute, Inc., $1,028 \mathrm{p}$.

Sasser, C.E., Dozier, M.D., Gosselink, J.G., and Hill, J.M., 1986, Spatial and temporal changes in Louisiana's Barataria Basin marshes, 1945-1980: Environmental Management, v. 10, no. 5, p. 671-680.

Sasser, C.E., and Evers, D.E., 1995, Vignette studies - Local case studies of wetland loss, part 8, in Reed, D.J., ed., Status and trends of hydrologic modification, reduction in sediment availability, and habitat loss/modification in the Barataria-Terrebonne estuarine system: Thibodaux, La., Barataria-Terrebonne National Estuary Program, BTNEP Publication no. 20, p. 202-236.

Sasser, C.E., Evers, D.E., Gosselink, J.G., Holm, Jr., G.O., Swenson, E.M., and Visser, J.M., 2002, Ecological evaluation of the Coastal Wetlands Planning Protection and Restoration Act central and eastern Terrebonne Basin freshwater delivery project: Baton Rouge, La., Louisiana Department of Natural Resources, 113 p.

Sasser, C.E., Swenson, E.M., Evers, D.E., Visser, J.M., Holm, G.O., Jr., and Gosselink, J.G., 1994, Floating marshes in the Barataria and Terrebonne Basins, Louisiana: Baton Rouge, La., Louisiana State University, Coastal Ecology Institute, Center for Coastal Energy and Environmental Resources, LSU CEI 94-02, 120 p.

Schroeder, W.W., and Wiseman, W.J., Jr., 1986, Low-frequency shelf-estuarine exchange processes in Mobile Bay and other estuarine systems on the northern Gulf of Mexico, in Wolfe, D.A., ed., Estuarine variability: New York, Academic Press, Inc., p. 355-367.

Sikora, W.B., and Kjerfve, Bjorn, 1985, Factors influencing the salinity regime of Lake Pontchartrain, Louisiana, a shallow coastal lagoon - Analysis of a long-term data set: Estuaries, v. 8, no. 2, p. 170-180.

Swarzenski, C.M., 2003, Surface-water hydrology of the Gulf Intracoastal Waterway in south-central Louisiana, 1996-99: U.S. Geological Survey Professional Paper 1672, 51 p.

Swenson, E.M., 2003, Assessing the potential climate change impact on salinity in northern Gulf of Mexico estuaries - A test case in the Barataria estuarine system, chap. 
9, in Ning, Z.H., Turner, R.E., Doyle, Thomas, and Abdollahi, K.K., eds., Integrated assessment of the climate change impacts on the Gulf Coast region: Baton Rouge, La., Gulf Coast Regional Climate Change (GRCC), at http://www.usgcrp.gov/usgcrp/Library/nationalassessment/gulfcoast/gulfcoastcomplete.pdf, p. 131-150.

Swenson, E.M., 1980, The general hydrography of the tidal passes of Lake Pontchartrain, Louisiana, in Stone, J.H., ed., Environmental analysis of Lake Pontchartrain, Louisiana, its surrounding wetlands and selected land uses: Baton Rouge, La., Louisiana State University, Coastal Ecology Institute, School of the Coast and the Environment, [Prepared for U.S. Army Corps of Engineers District, New Orleans, Contract Number DACW-29-77-C-0253], p. 157-215.

Swenson, E.M., Evers, D.E., Grymes, J.M. III., 2004, Brown Marsh task II.5, integrative approach to understanding the causes of salt marsh dieback - Analysis of climate drivers: Baton Rouge, La., Louisiana State University, Coastal Ecology Institute, School of the Coast and Environment [Prepared for Coastal Restoration Division, Louisiana Department of Natural Resources, DNR Interagency Agreement Number 2512-01-14.] 204 p.

Swenson, E.M., and Swarzenski, C.M., 1995, Water levels and salinity in the BaratariaTerrebonne estuarine system, part 6, in Reed, D.J., ed., Status and trends of hydrologic modification, reduction in sediment availability, and habitat loss/modification in the Barataria-Terrebonne estuarine system: Thibodaux, La.,Barataria-Terrebonne National Estuarine Program, BTNEP Publication no. 20, p. 129-201.

Swenson, E.M. and Turner, R.E., 1987, Spoil banks - Effects on a coastal marsh waterlevel regime: Estuarine, Coastal and Shelf Science, v. 24, p. 599-609.

Swenson, E.M., and Turner, R.E., 1998, Past, present, and probable future salinity variations in the Barataria estuarine system, [Final report to the Coastal Restoration Division of the Louisiana Department of Natural Resources], Baton Rouge, La., Louisiana State University, Coastal Ecology Institute, 112 p.

T. Baker Smith \& Sons, Inc., and Reed, D.J., 2002, Houma Navigation Canal secondary impacts study: accessed August 21, 2003, at http://www.tpcg.org/planning/pdf/HNC\%20Study.pps\#256,1,HOUMA

Turner, R.E., and Cahoon, D.R., 1988, Causes of wetland loss in the coastal central Gulf of Mexico: Minerals Management Service, Executive Summary OCS Study MMS870120, v. II Technical Narrative, 400 p.

Twilley, R.R., and Barras, J.A., 2004, Formulation of the LCA ecosystem model, in Twilley, R.R., ed., Hydrodynamic and ecological modeling: Louisiana Coastal Area (LAC) - Louisiana Ecosystem Restoration Plan: v.4, appendix C, chap. 2, p. 18-36. 
U.S. Army Corps of Engineers, 2003, Houma Navigation Canal, Louisiana general reevaluation study, channel deepening model study report: U.S. Army Corps of Engineers, New Orleans District, v.p.

U.S. Army Corps of Engineers, 1984, Bayou Grand Caillou navigation improvements, Terrebonne Parish, Louisiana: U.S. Army Corps of Engineers, New Orleans District, p. 338.

U.S. Army Corps of Engineers, 1975, Final composite environmental impact statement for operation and maintenance dredging of four projects located south of the Intracoastal Waterway in Terrebonne Parish, Louisiana: U.S. Army Corps of Engineers, New Orleans District, v.p.

U.S. Geological Survey, 1998, Land cover classification for the Louisiana GAP analysis project: National Wetlands Research Center, U.S. Geological Survey, Biological Research Division, 1998-01-01, 1 sheet, scale 1:100,000.

Van Sickle, V.R., Barrett, B.B., Gulick, L.J., and Ford, T.B., 1976, Barataria Basin Salinity changes and oyster distribution: Baton Rouge, La., Louisiana State University, Center for Wetland Resources, Louisiana Sea Grant, LSU-T-76-002, 52 p.

Visser, J.M., Sasser, C.E., Chabreck, R.H., and Linscombe, R.G., 1996, Marsh vegetation-types of Barataria and Terrebonne estuaries, 1968-present: BaratariaTerrebonne National Estuarine Program, no. 29, 7-10 p.

Visser, J.M., Sasser, C.E., Chabreck, R.H., and Linscombe, R.G., 1998, Marsh vegetation types of the Mississippi River deltaic plain: Estuaries, v. 21, no. 4, p. 818-828.

Visser, J.M., Sasser, C.E., Chabreck, R.H., and Linscombe, R.G., 2002, The impact of a severe drought on the vegetation of a subtropical estuary: Estuaries and Coasts, v. 25, no. 6, p. 1184-1195.

Wang, F.C, 1988, Dynamics of saltwater intrusion in coastal channels: Journal of Geophysical Research, v. 93, no. C6, p. 6937-6946.

Ward, G.H. Jr., 1980, Hydrography and circulation processes of Gulf estuaries $\underline{i n}$ Hamilton, Peter, and. MacDonald, K.B., eds, Estuaries and wetland processes with emphasis on modeling: New York, Plenum Press, p. 183-215.

Williams, S.J., 1995, Louisiana coastal wetlands - A resource at risk: U.S. Geological Survey Information Sheet, accessed March put in day, 2004, at http://marine.usgs.gov/fact-sheets/LAwetlands.html

Willis, J.M., and Hester, M.W., 2004, Interactive effects of salinity, flooding, and soil type on Panicum hemitomon: Wetlands, v. 24, p. 43-50.

Wiseman, W. J., Jr., 1986, Estuarine-shelf interactions, in Mooers, C.N.K., ed. Baroclinic processes on continental shelves: American Geophysical Union, p. 109-115. 
Wiseman, W.J., Jr., and Swenson, E.M., 1988, Analysis of historical data records, in Turner, R.E., and Cahoon, D.R., eds., Causes of wetland loss in the coastal central Gulf of Mexico, chap. 6, v. 2 - Technical Narrative: New Orleans, Mineral Management Service, [Contract no. 14-12-002-30252.ocs Study/MMS 87-0119], 400 p.

Wiseman, W.J., Jr., Swenson, E.M., and Kelly, F.J., 1990a, Control of estuarine salinity by coastal ocean salinity, in Cheng, R.T., ed., Residual currents and long-term transport, coastal and estuarine studies, v. 38: New York, Springer-Verlag, p. 184-193.

Wiseman, W.J., Jr., Swenson, E.M., and Power, James, 1990b, Salinity trends in Louisiana estuaries: Estuaries, v. 13, no. 3, p. 265-271. 


\section{Appendix 1. Salinity Level Plots}
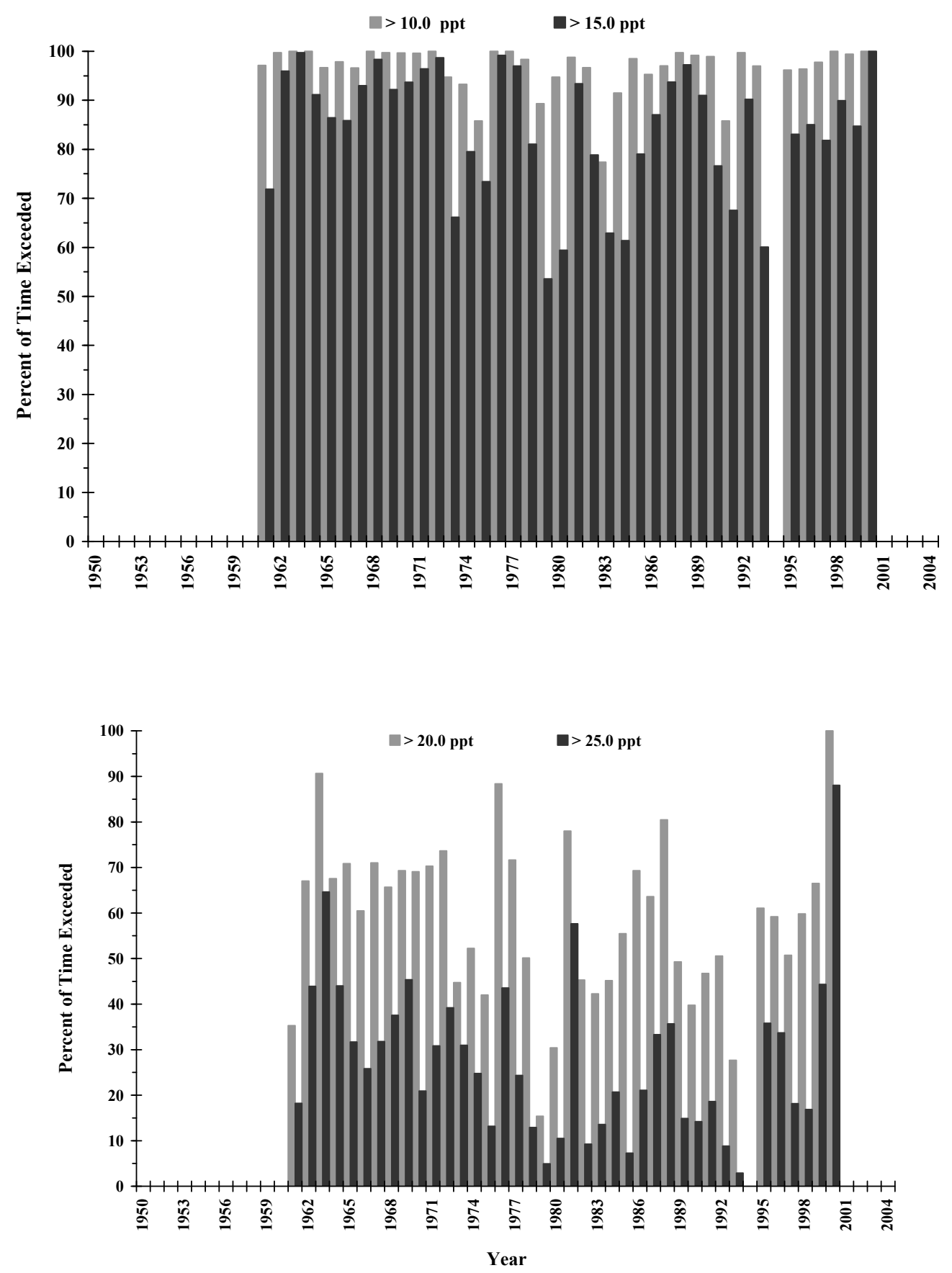

Figure 1-1. Plot of salinity level data for Grand Terre (Louisiana Department of Wildlife and Fisheries station 315). Indicated is the percent of time per year that salinity values exceeded the given threshold values; ppt, parts per thousand. 

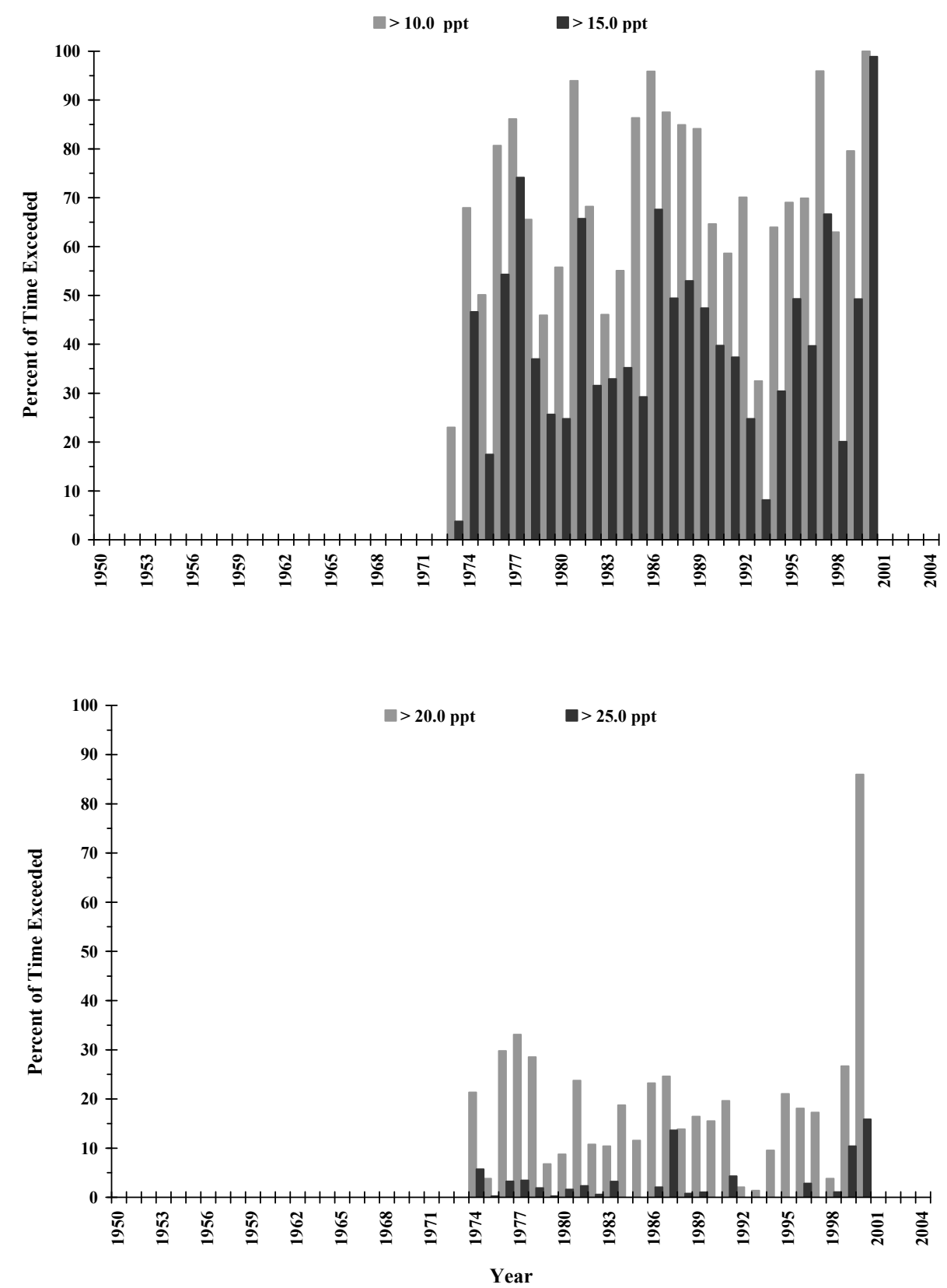

Figure 1-2. Plot of salinity level data for St. Marys Point (Louisiana Department of Wildlife and Fisheries station 317). Indicated is the percent of time per year that salinity values exceeded the given threshold values; ppt, parts per thousand. 

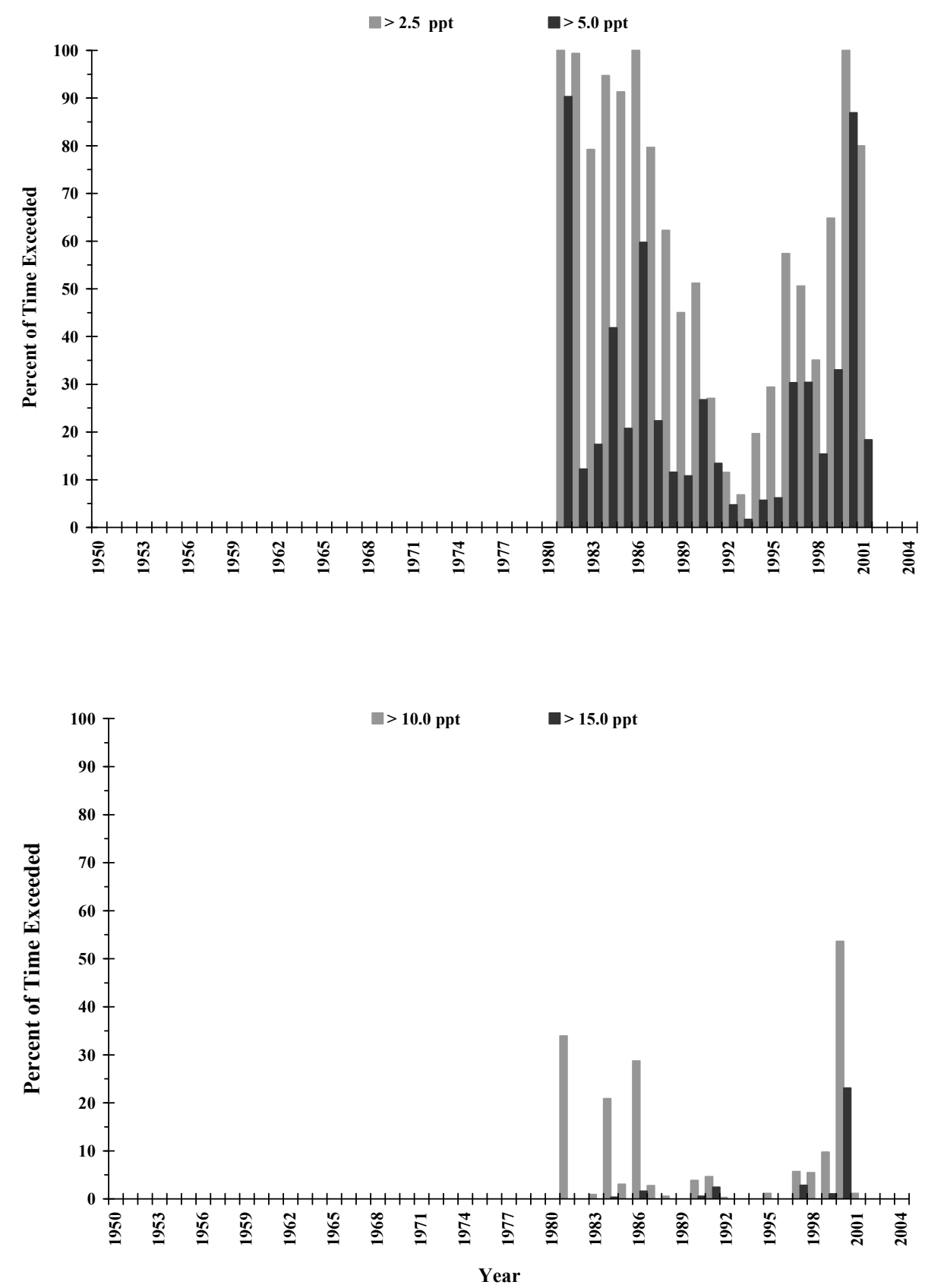

Figure 1-3. Plot of salinity level data for Little Lake (Louisiana Department of Wildlife and Fisheries station 326). Indicated is the percent of time per year that salinity values exceeded the given threshold values; ppt, parts per thousand. 

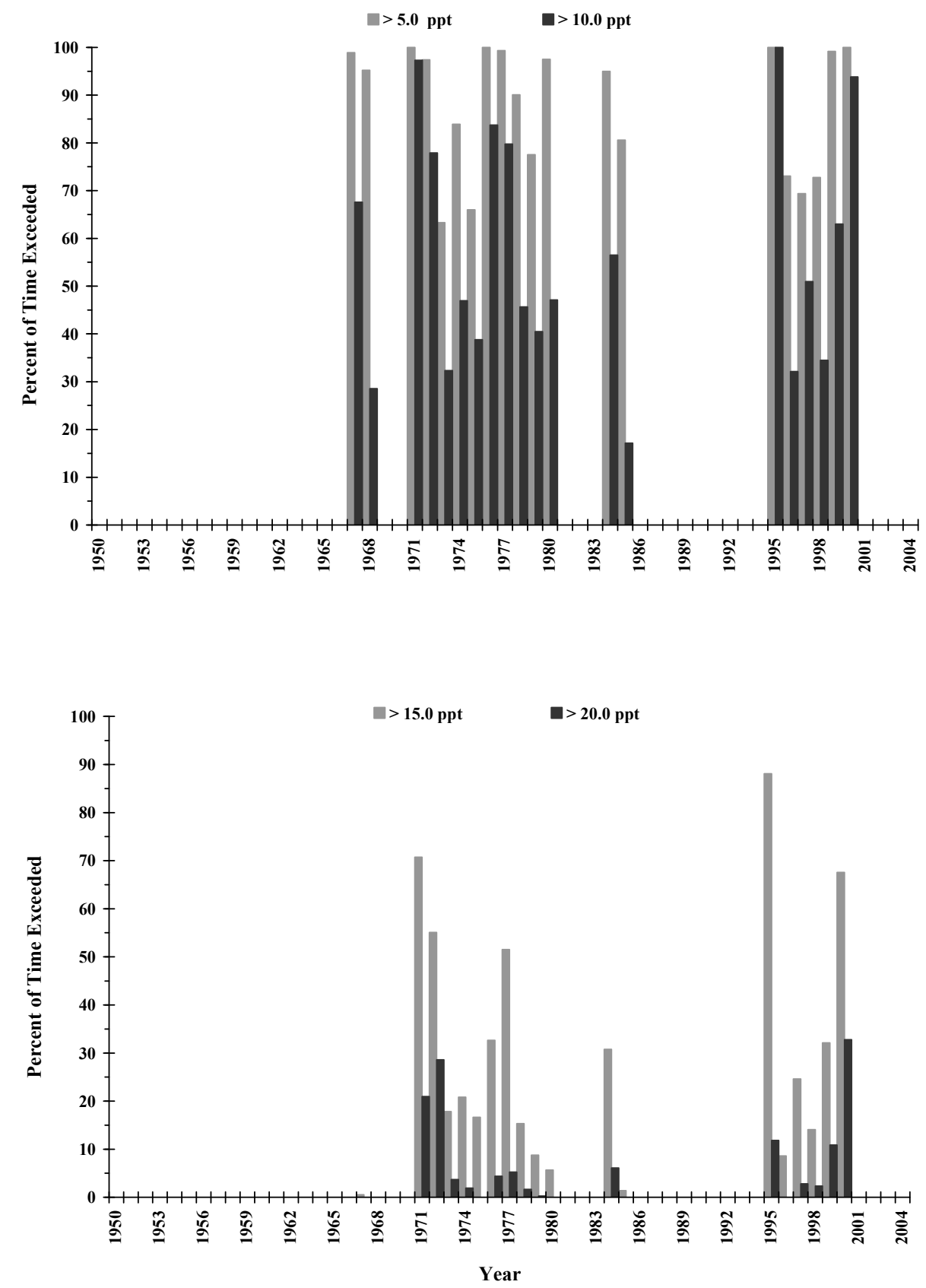

Figure 1-4. Plot of salinity level data for Sister Lake (Louisiana Department of Wildlife and Fisheries station 518). Indicated is the percent of time per year that salinity values exceeded the given threshold values; ppt, parts per thousand. 

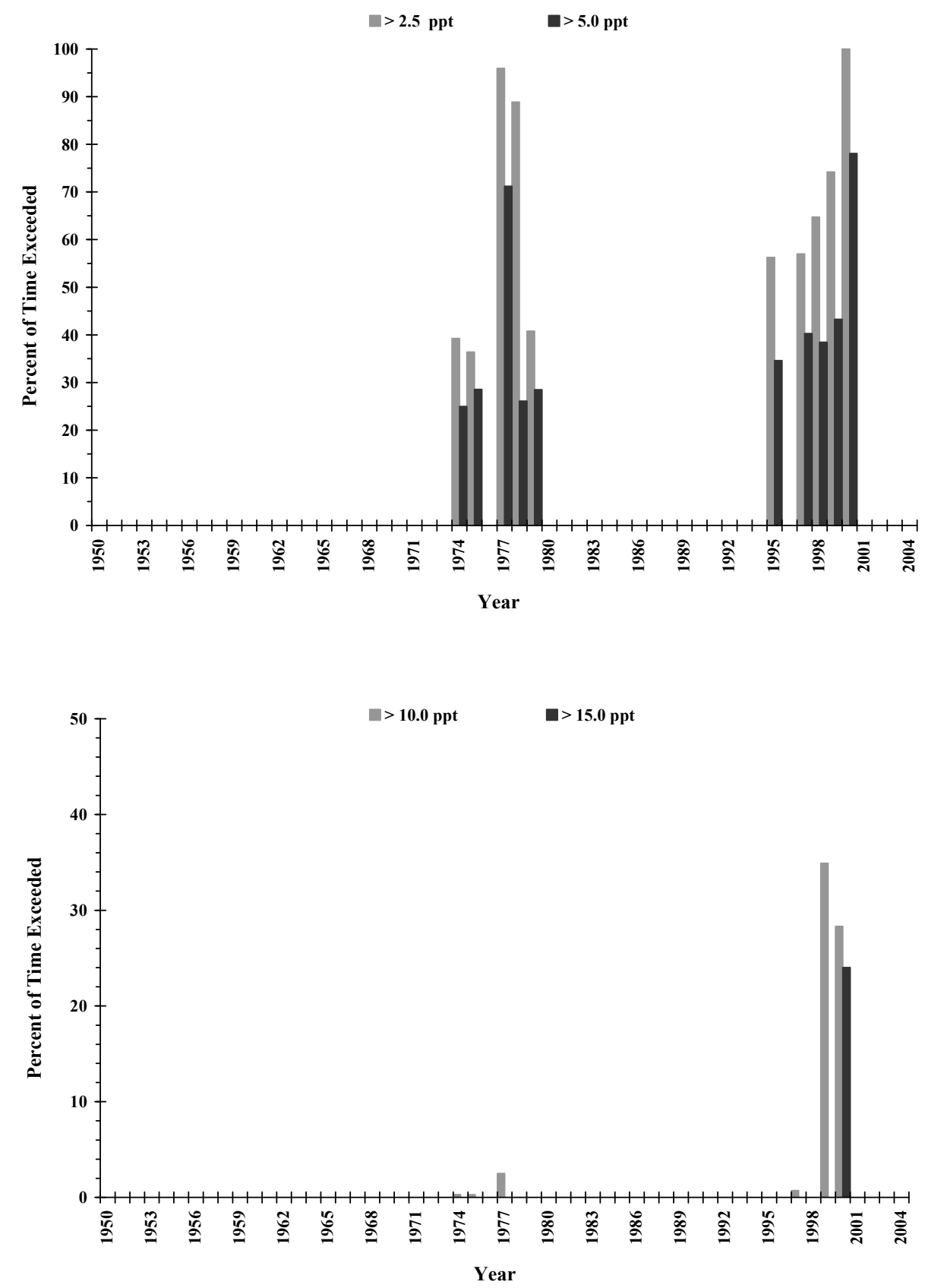

Figure 1-5. Plot of salinity level data for Cypremort Point (Louisiana Department of Wildlife and Fisheries station 619). Indicated is the percent of time per year that salinity values exceeded the given threshold values; ppt, parts per thousand. 

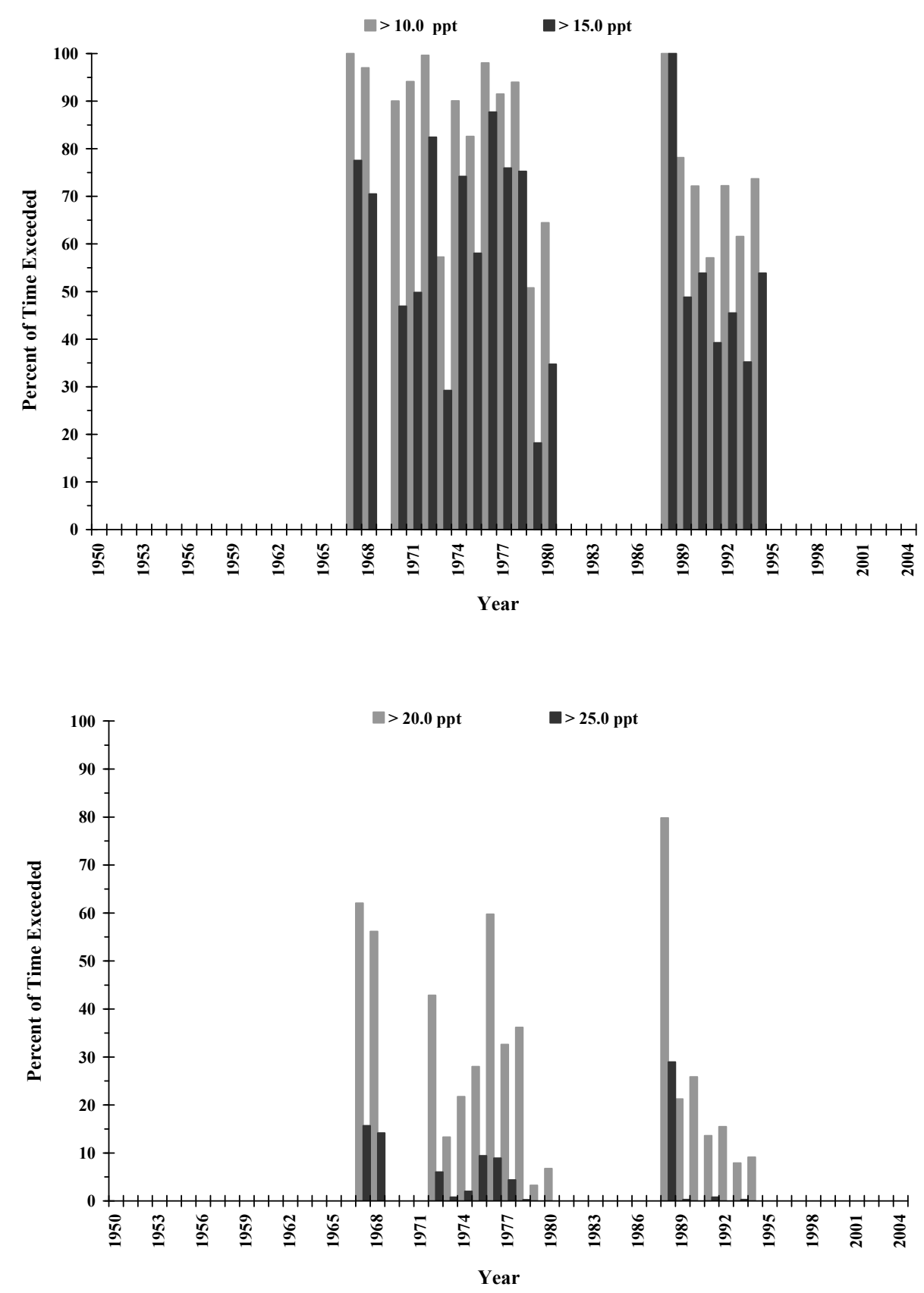

Figure 1-6. Plot of salinity level data for Cameron (Louisiana Department of Wildlife and Fisheries station 719). Indicated is the percent of time per year that salinity values exceeded the given threshold values; ppt, parts per thousand. 

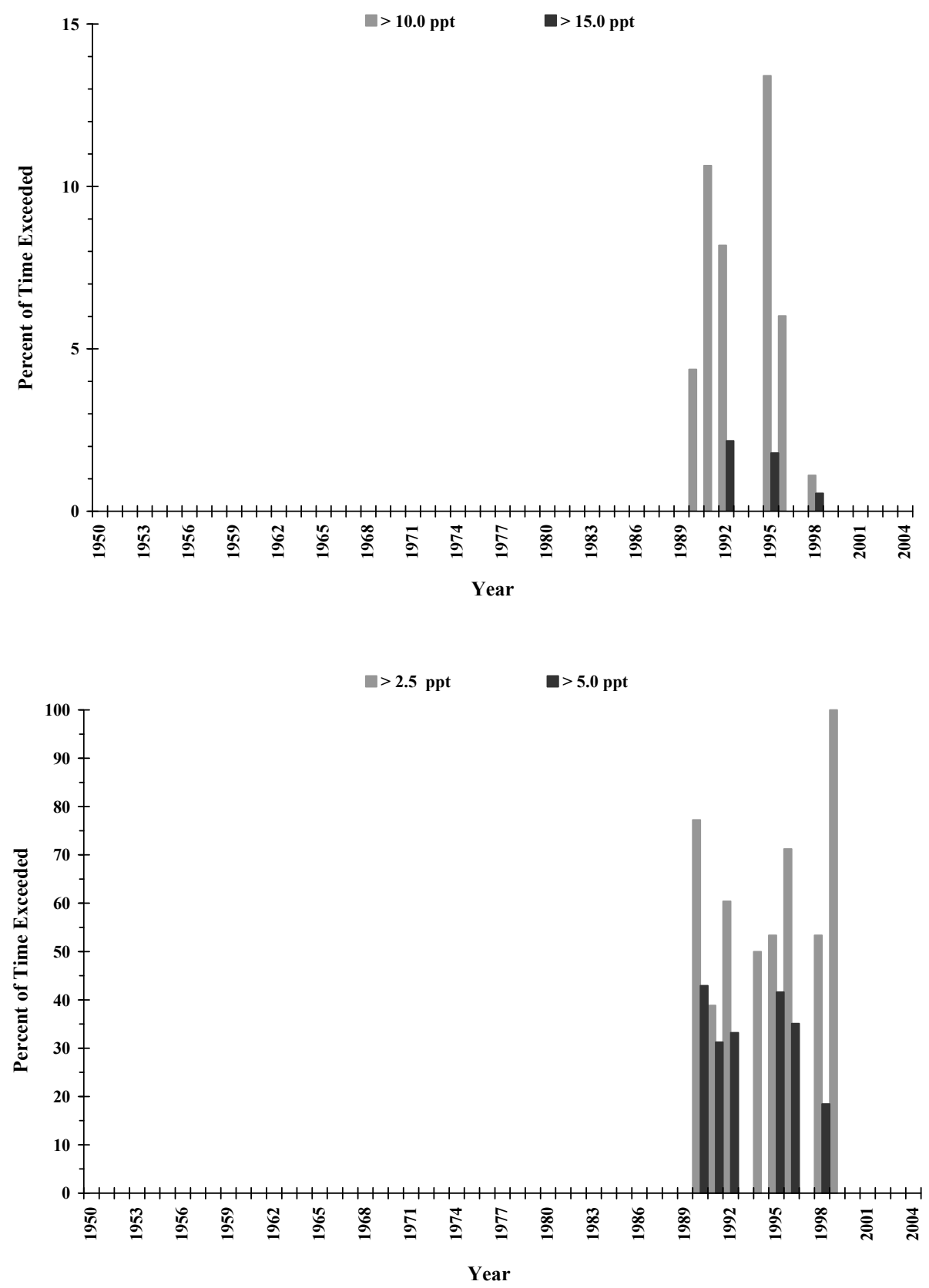

Figure 1-7. Plot of salinity level data for the Mississippi River at Southwest Pass (U.S. Army Corps of Engineers station 01670). Indicated is the percent of time per year that salinity values exceeded the given threshold values; ppt, parts per thousand. 

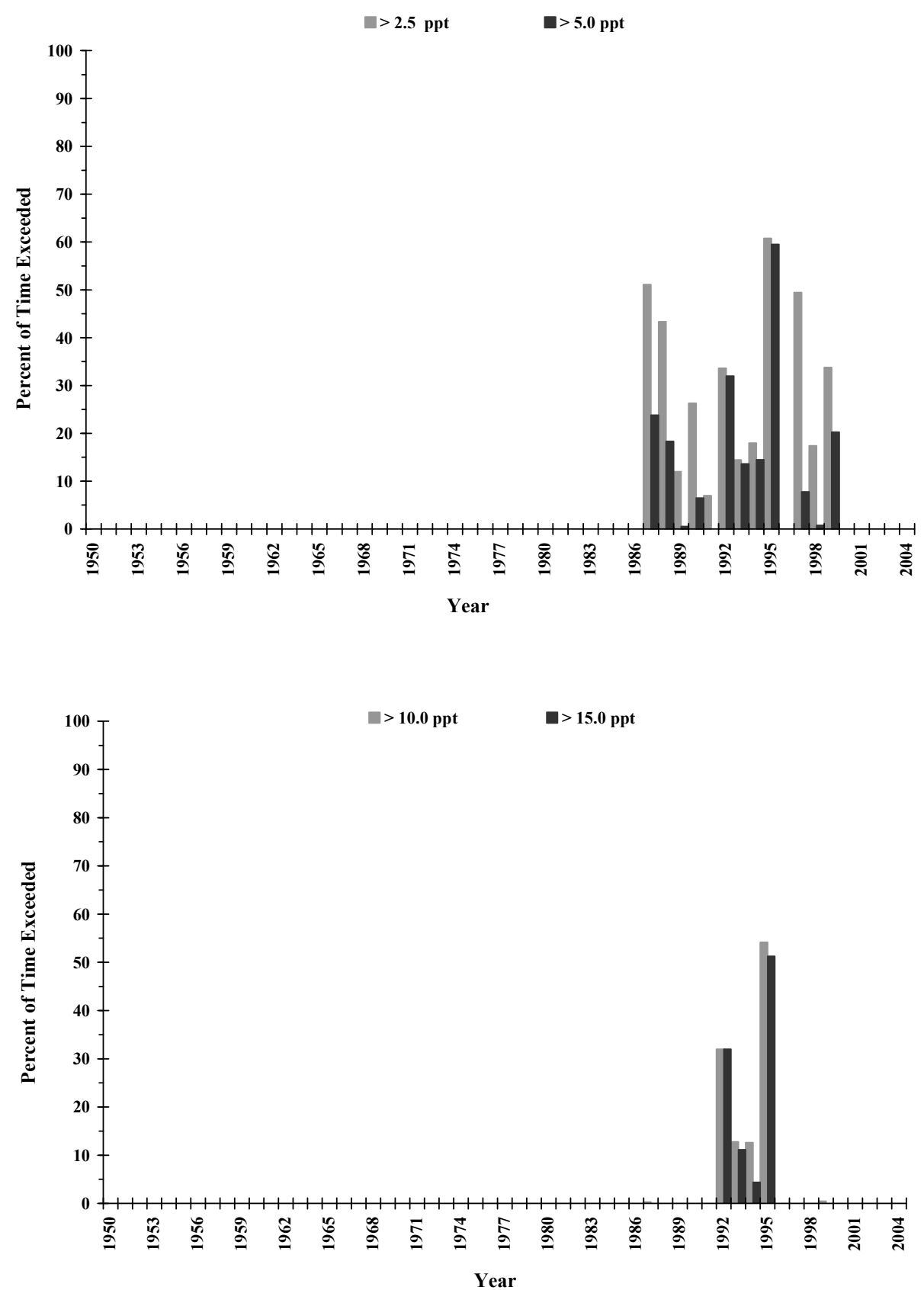

Figure 1-8. Plot of salinity level data for the Mississippi River at Southwest Pass (U.S. Army Corps of Engineers station 67890). Indicated is the percent of time per year that salinity values exceeded the given threshold values; ppt, parts per thousand. 

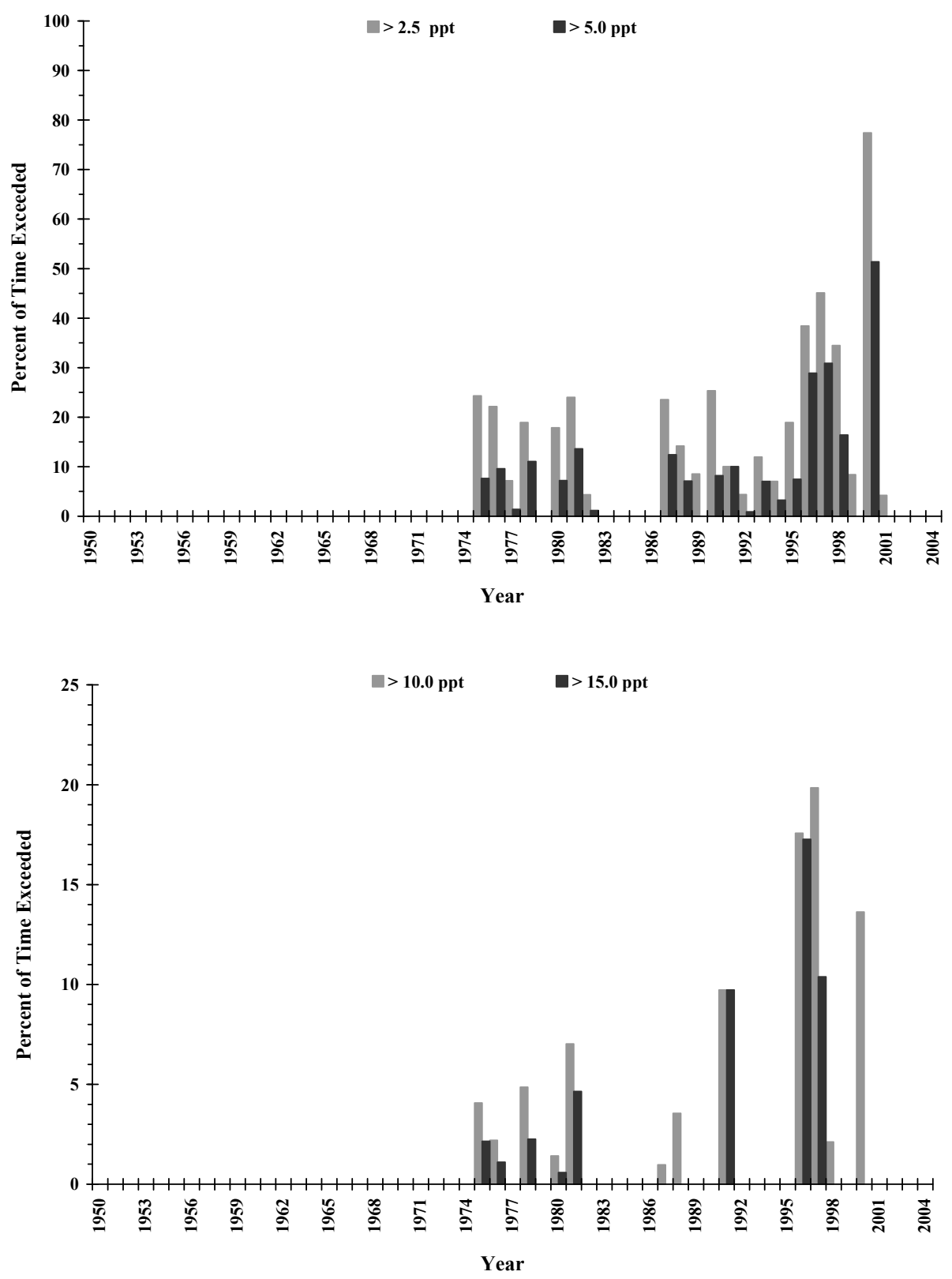

Figure 1-9. Plot of salinity level data for the Mermentau River north of the Catfish Point control structure (U.S. Army Corps of Engineers station 70675). Indicated is the percent of time per year that salinity values exceeded the given threshold values; ppt, parts per thousand. 

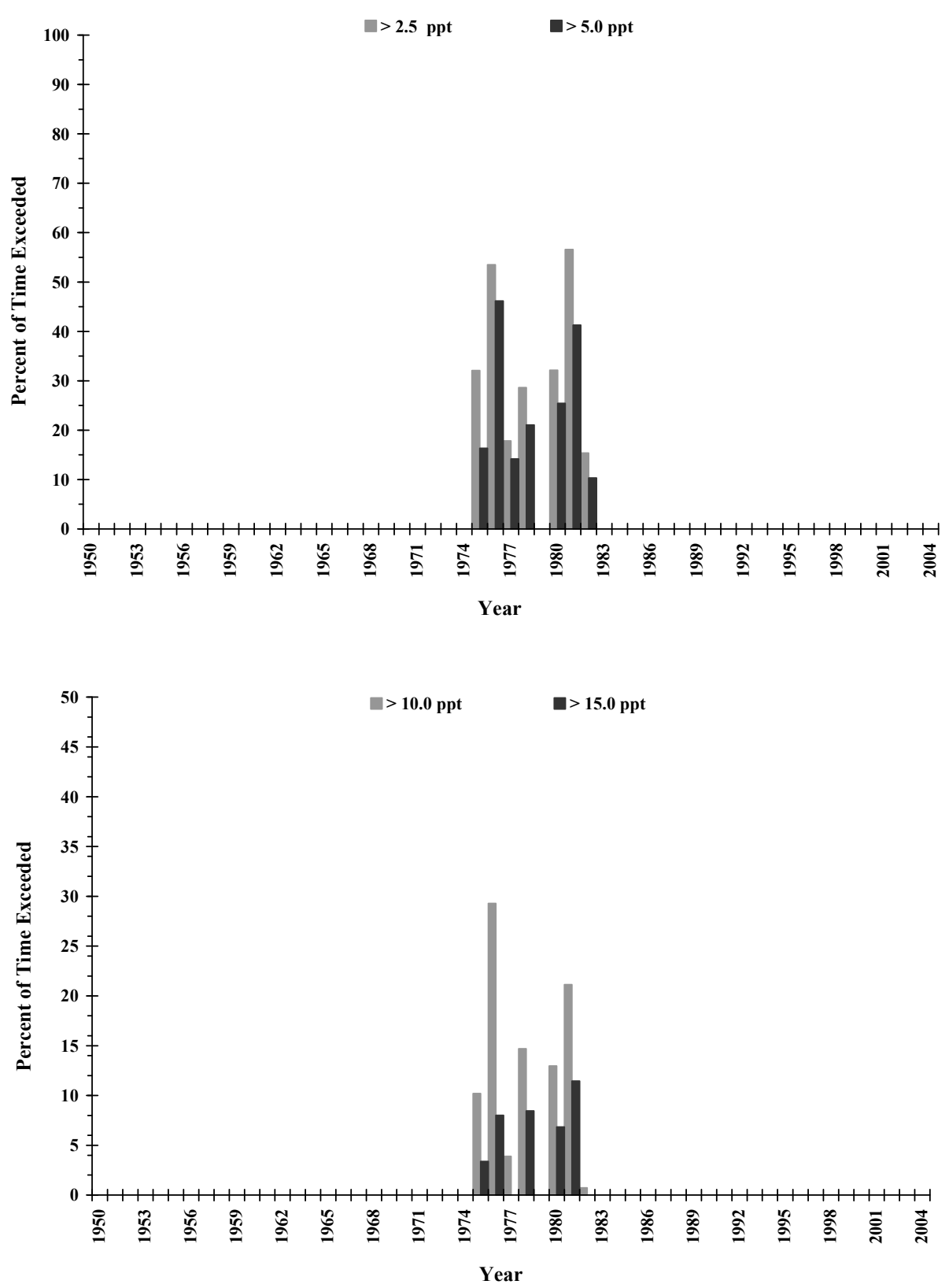

Figure 1-10. Plot of salinity level data for the Mermentau River south of the Catfish Point control structure (U.S. Army Corps of Engineers station 70750). Indicated is the percent of time per year that salinity values exceeded the given threshold values; ppt, parts per thousand. 

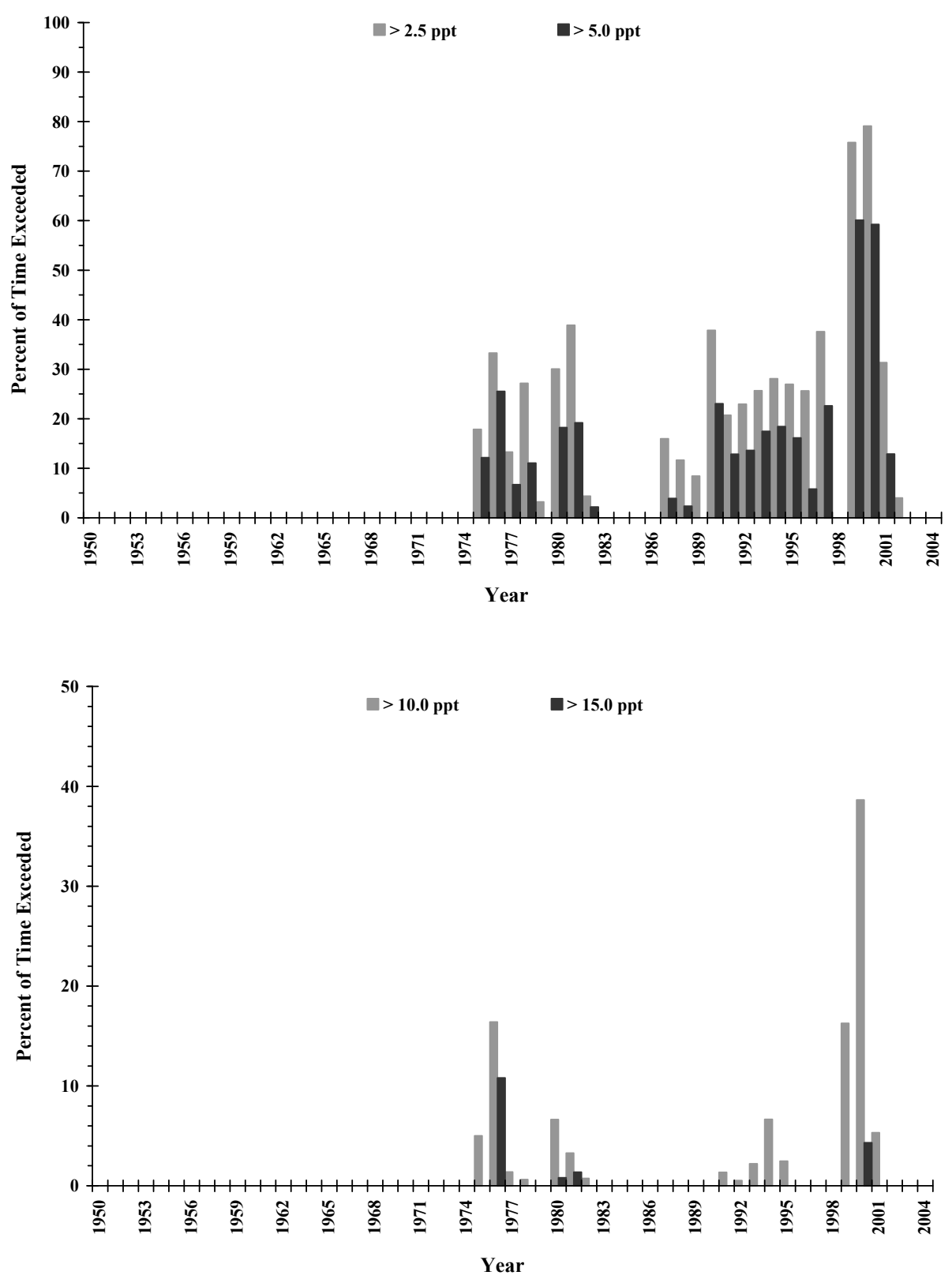

Figure 1-11. Plot of salinity level data for the Calcasieu River saltwater barrier channel at Lake Charles (U.S. Army Corps of Engineers station 73472). Indicated is the percent of time per year that salinity values exceeded the given threshold values; ppt, parts per thousand. 

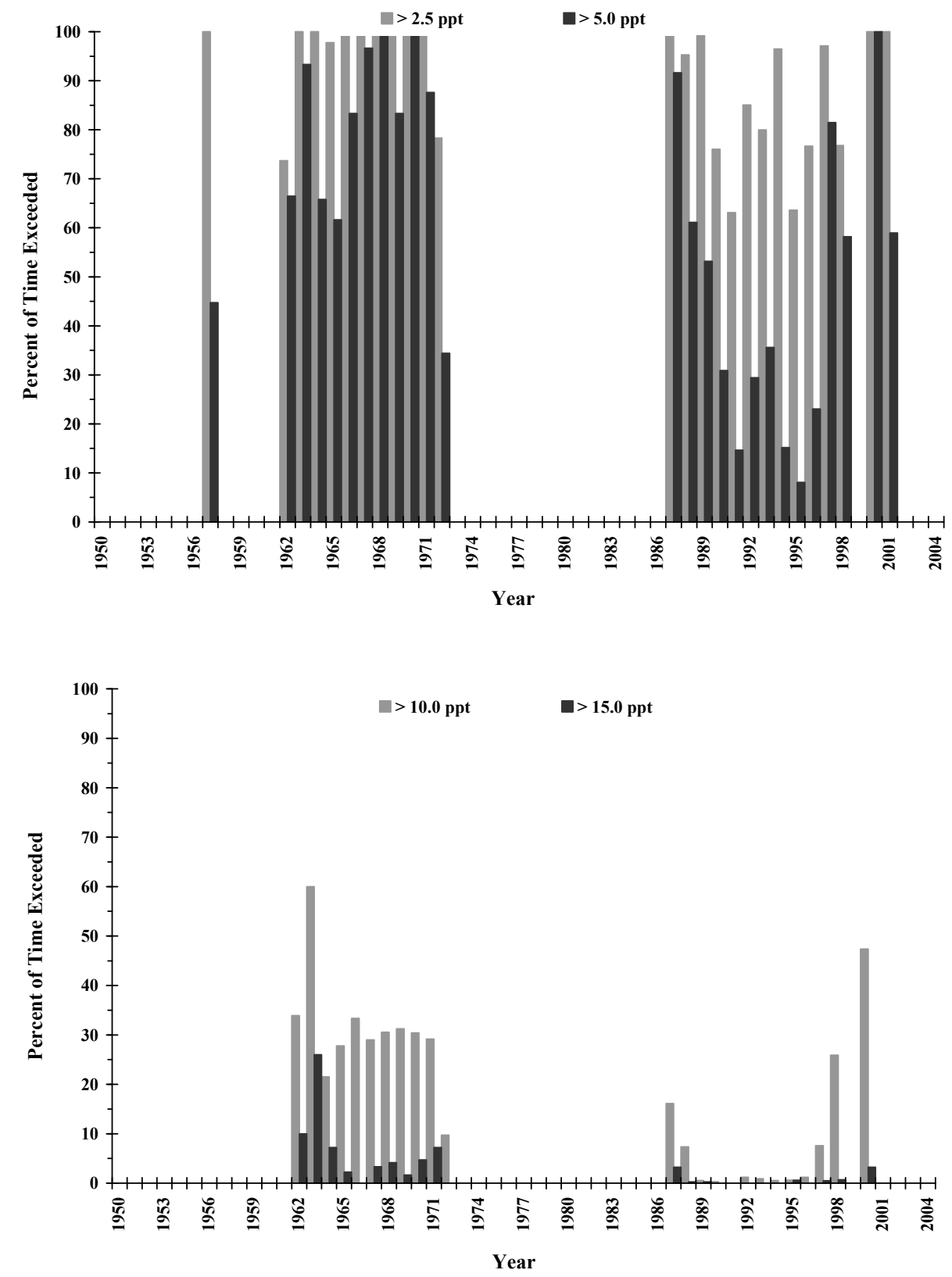

Figure 1-12. Plot of salinity level data for the Inner Harbor Navigation Canal at the Seabrook Bridge (U.S. Army Corps of Engineers station 76060). Indicated is the percent of time per year that salinity values exceeded the given threshold values; ppt, parts per thousand. 

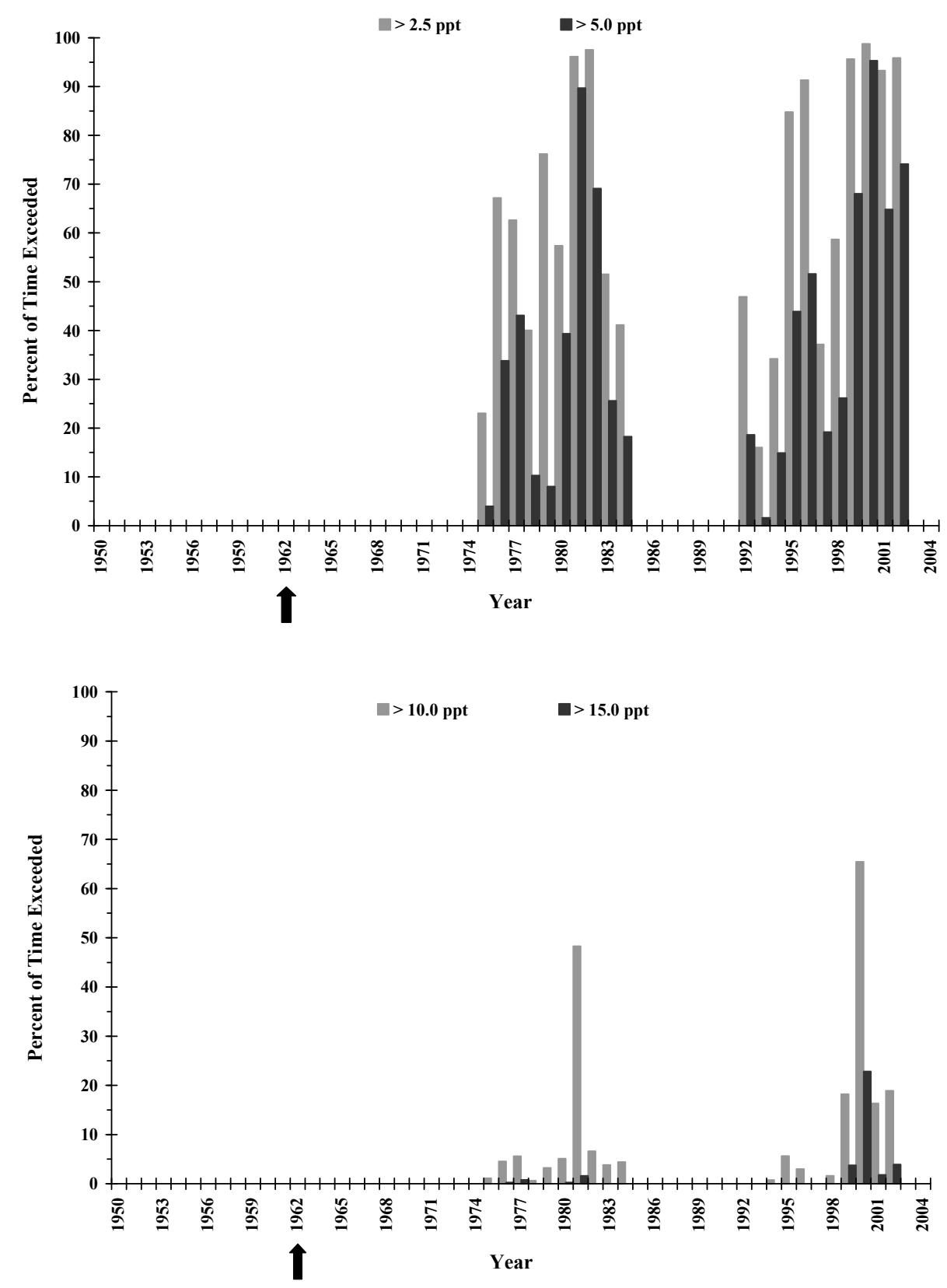

Figure 1-13. Plot of salinity level data for Bayou Petite Caillou near Boudreau Canal (U.S. Army Corps of Engineers station 76303). Indicated is the percent of time per year that salinity values exceeded the given threshold values; ppt, parts per thousand. The completion date for the Houma Navigation Canal is exhibited by the arrow. 

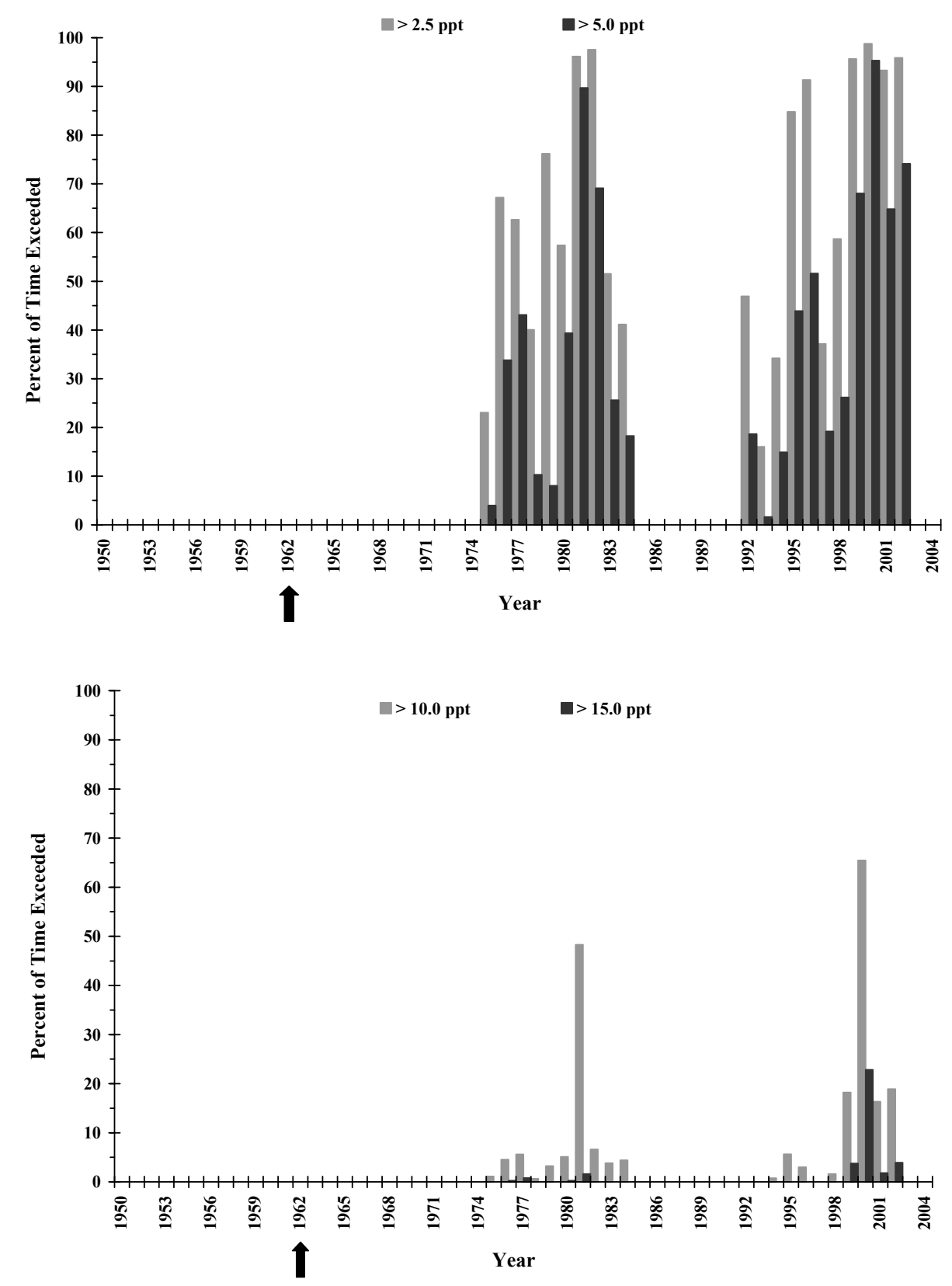

Figure 1-14. Plot of salinity level data for Bayou Petite Caillou at Cocodrie (U.S. Army Corps of Engineers station 76305). Indicated is the percent of time per year that salinity values exceeded the given threshold values; ppt, parts per thousand. The completion date for the Houma Navigation Canal is exhibited by the arrow. 

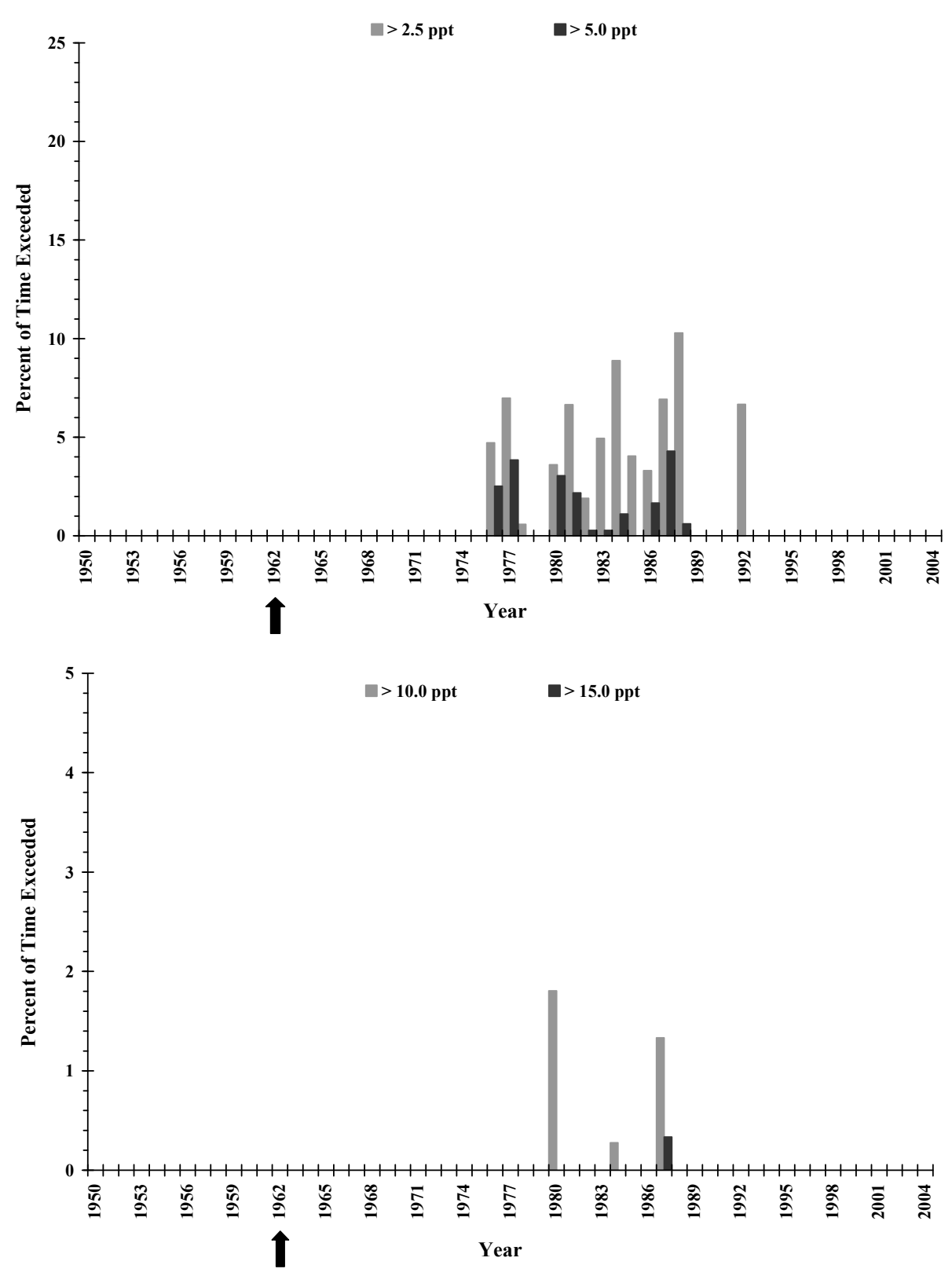

Figure 1-15. Plot of salinity level data for the Gulf Intracoastal Waterway at Houma (U.S. Army Corps of Engineers station 76320). Indicated is the percent of time per year that salinity values exceeded the given threshold values; ppt, parts per thousand. The completion date for the Houma Navigation Canal is exhibited by the arrow. 

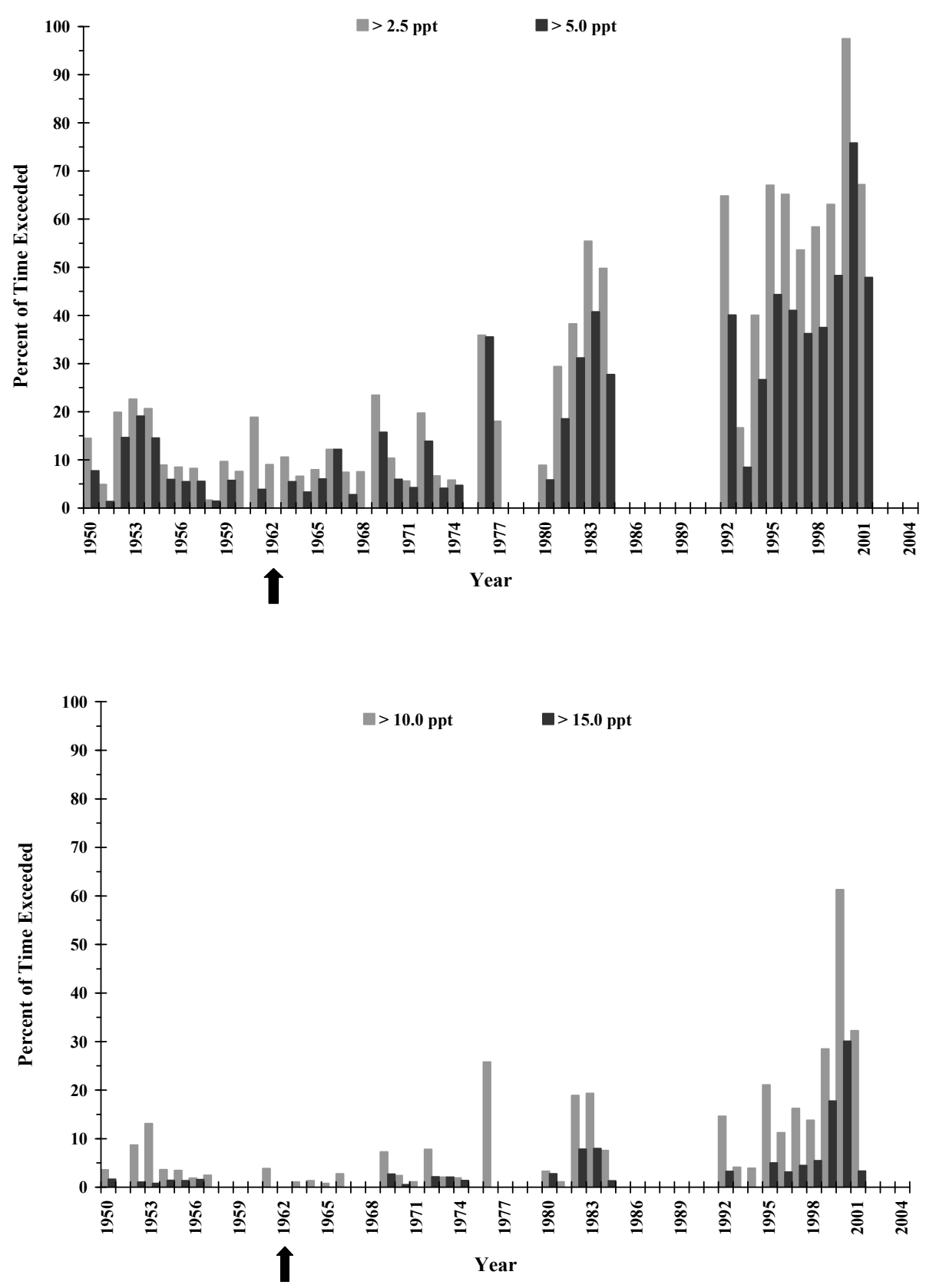

Figure 1-16. Plot of salinity level data for Bayou Grand Caillou near Dulac (U.S. Army Corps of Engineers station 76323). Indicated is the percent of time per year that salinity values exceeded the given threshold values; ppt, parts per thousand. The completion date for the Houma Navigation Canal is exhibited by the arrow. 

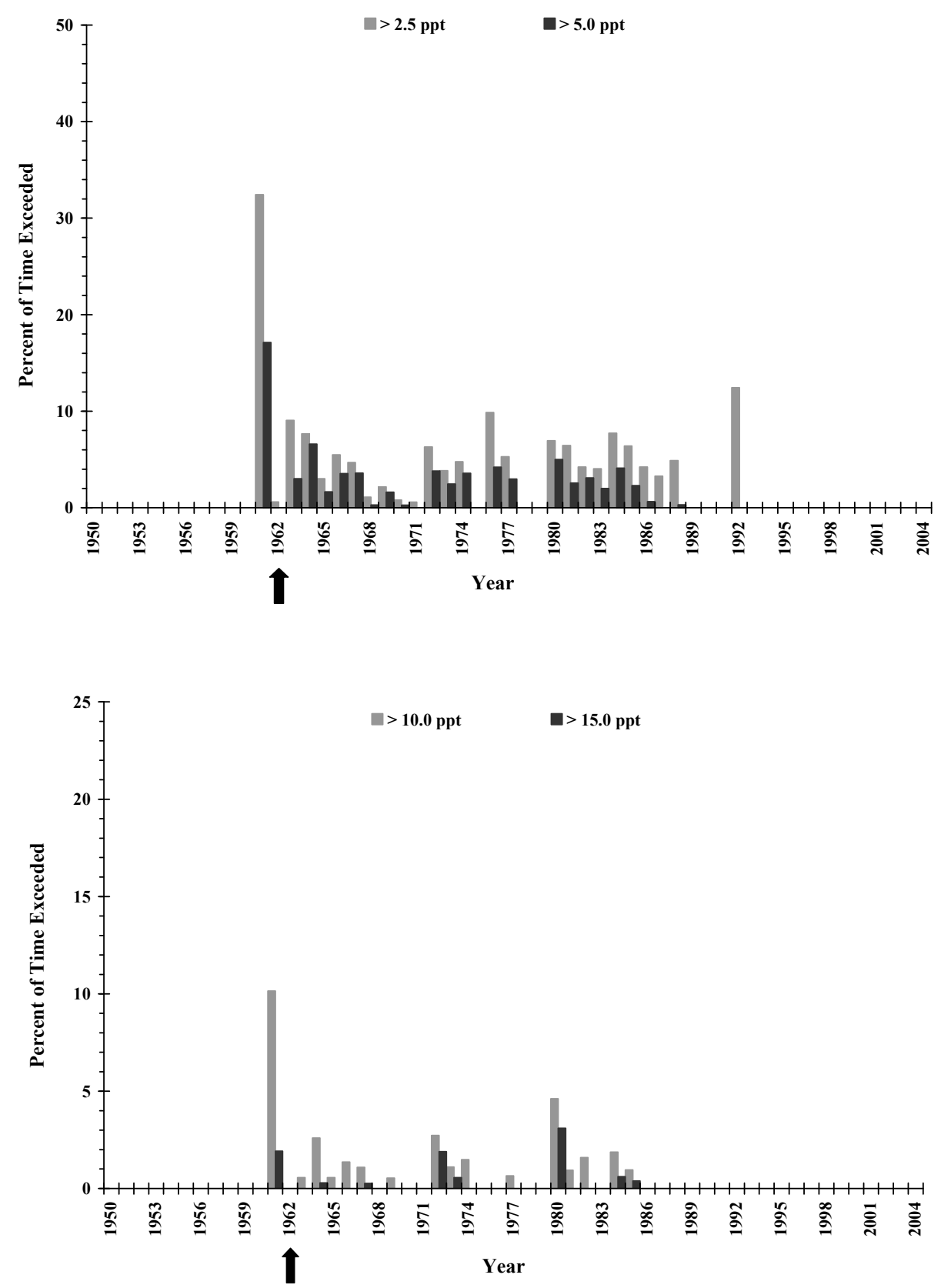

Figure 1-17. Plot of salinity level data for the Houma Navigation Canal near Crozier (U.S. Army Corps of Engineers station 76343). Indicated is the percent of time per year that salinity values exceeded the given threshold values; ppt, parts per thousand. The completion date for the Houma Navigation Canal is exhibited by the arrow. 

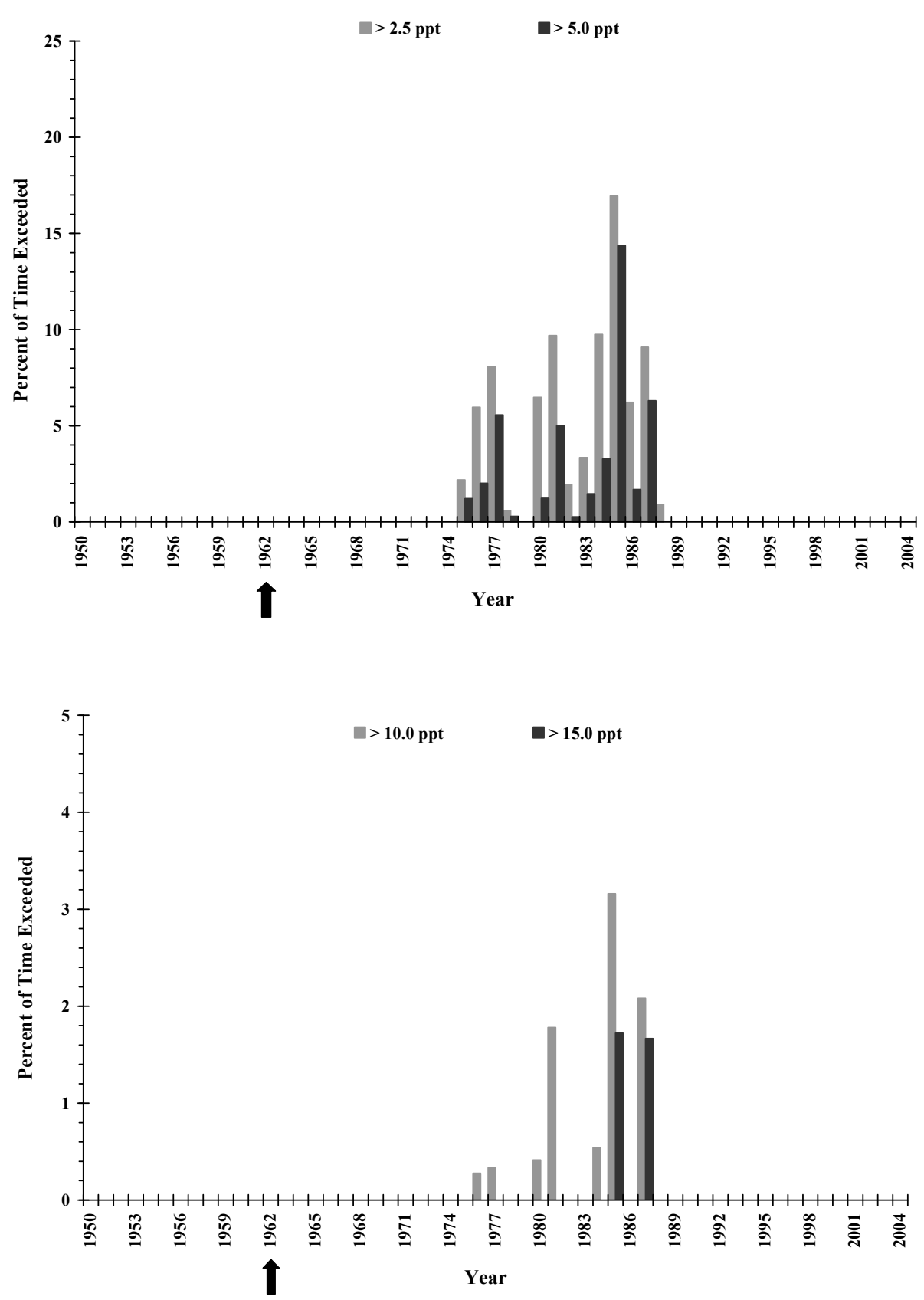

Figure 1-18. Plot of salinity level data for Bayou Terrebonne near Bourg (U.S. Army Corps of Engineers station 76403). Indicated is the percent of time per year that salinity values exceeded the given threshold values; ppt, parts per thousand. The completion date for the Houma Navigation Canal is exhibited by the arrow. 

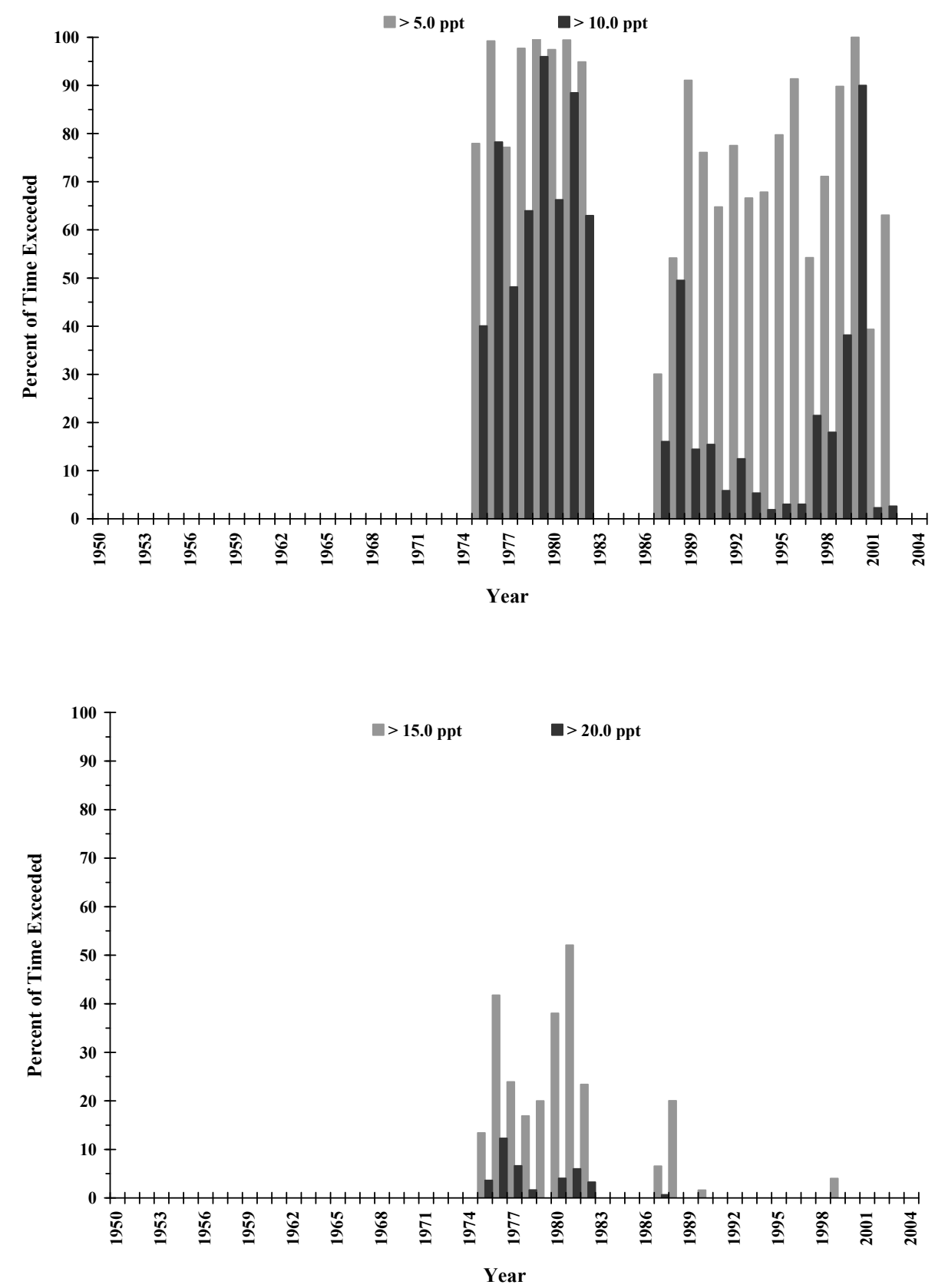

Figure 1-19. Plot of salinity level data for Freshwater Canal north of Freshwater Bayou Locks (U.S. Army Corps of Engineers station 76592). Indicated is the percent of time per year that salinity values exceeded the given threshold values; ppt, parts per thousand. 

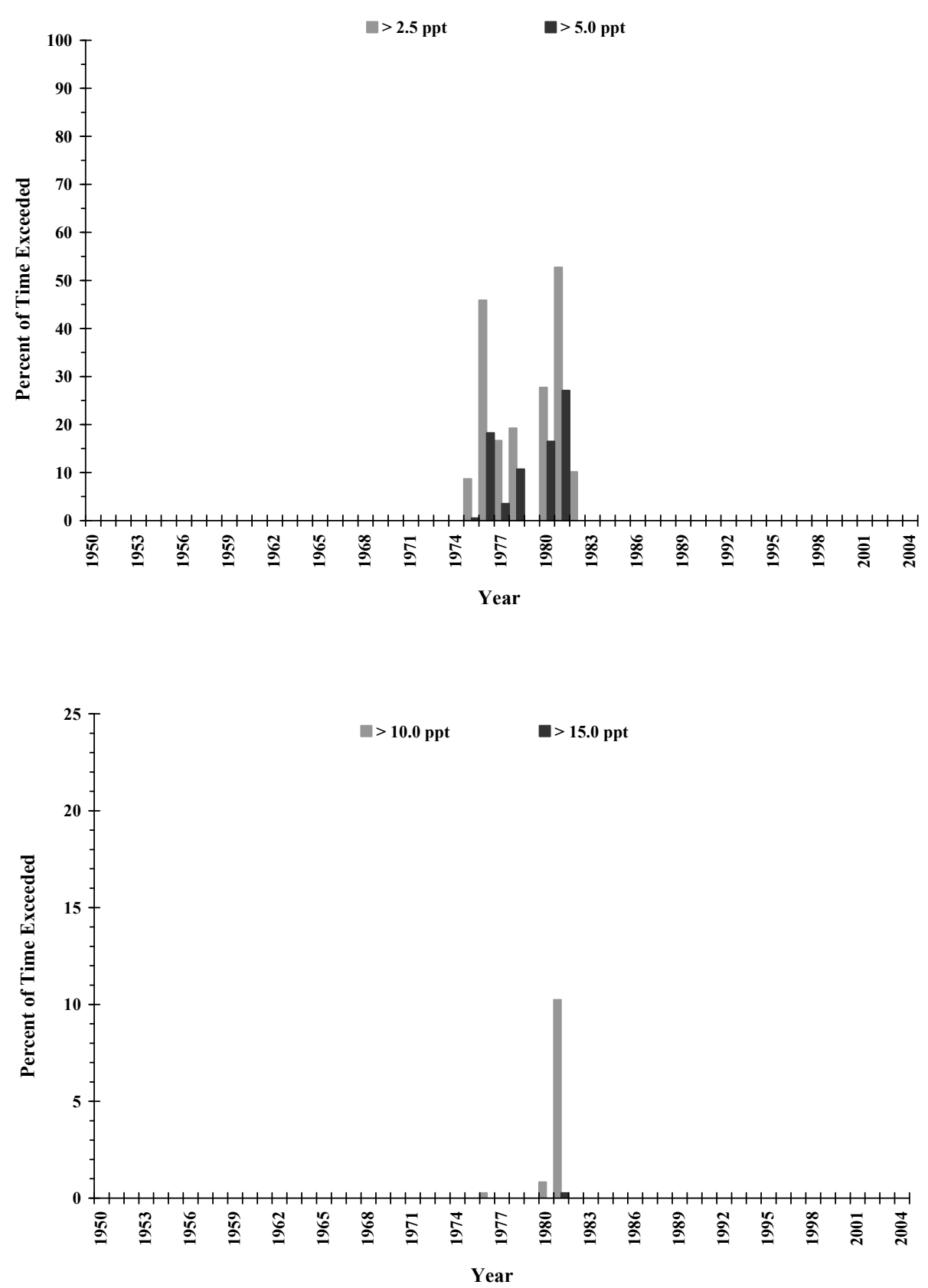

Figure 1-20. Plot of salinity level data for Schooner Bayou east of the control structure (U.S. Army Corps of Engineers station 76600). Indicated is the percent of time per year that salinity values exceeded the given threshold values; ppt, parts per thousand. 

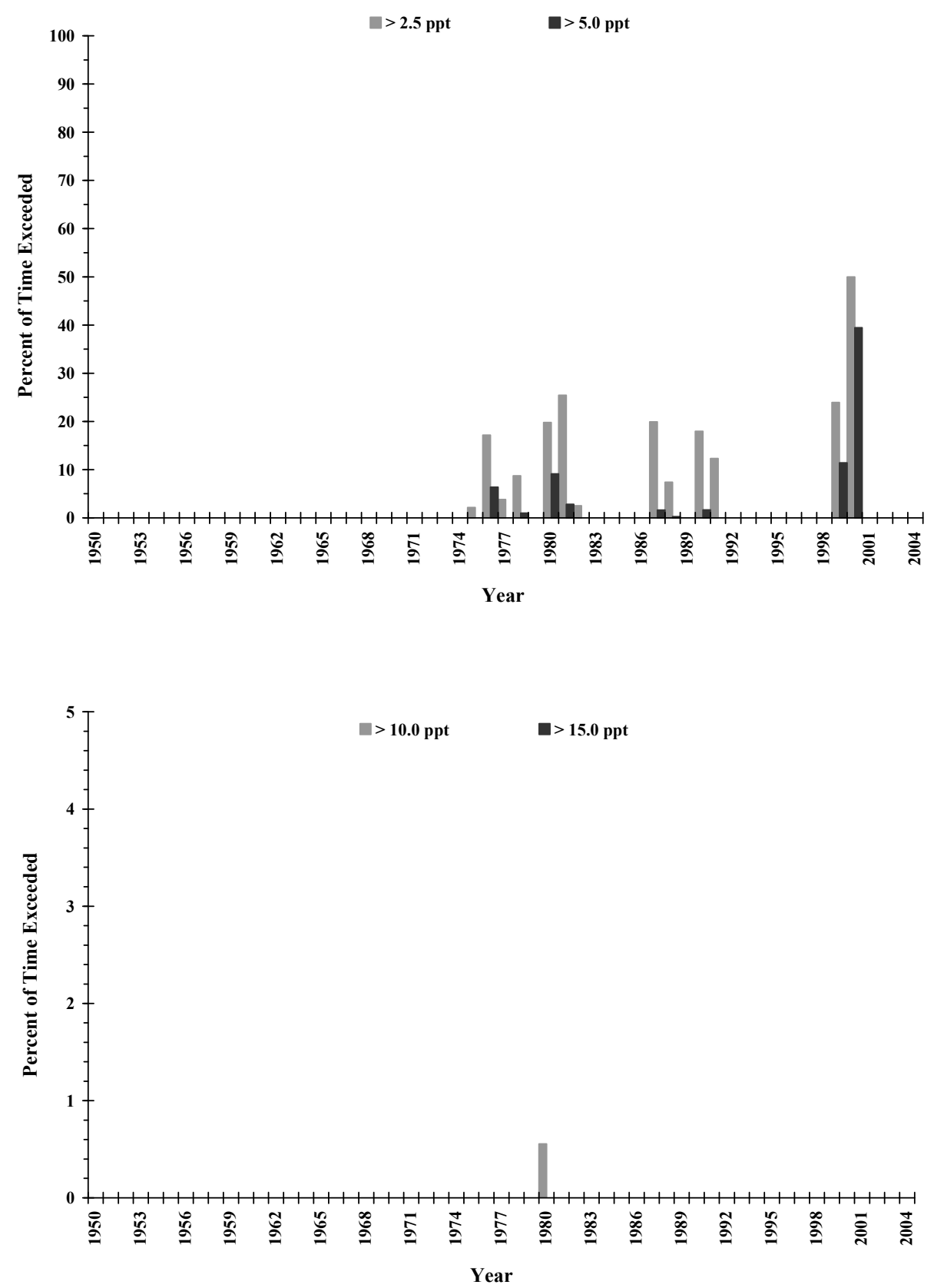

Figure 1-21. Plot of salinity level data for Schooner Bayou west of the control structure (U.S. Army Corps of Engineers station 76680). Indicated is the percent of time per year that salinity values exceeded the given threshold values; ppt, parts per thousand. 

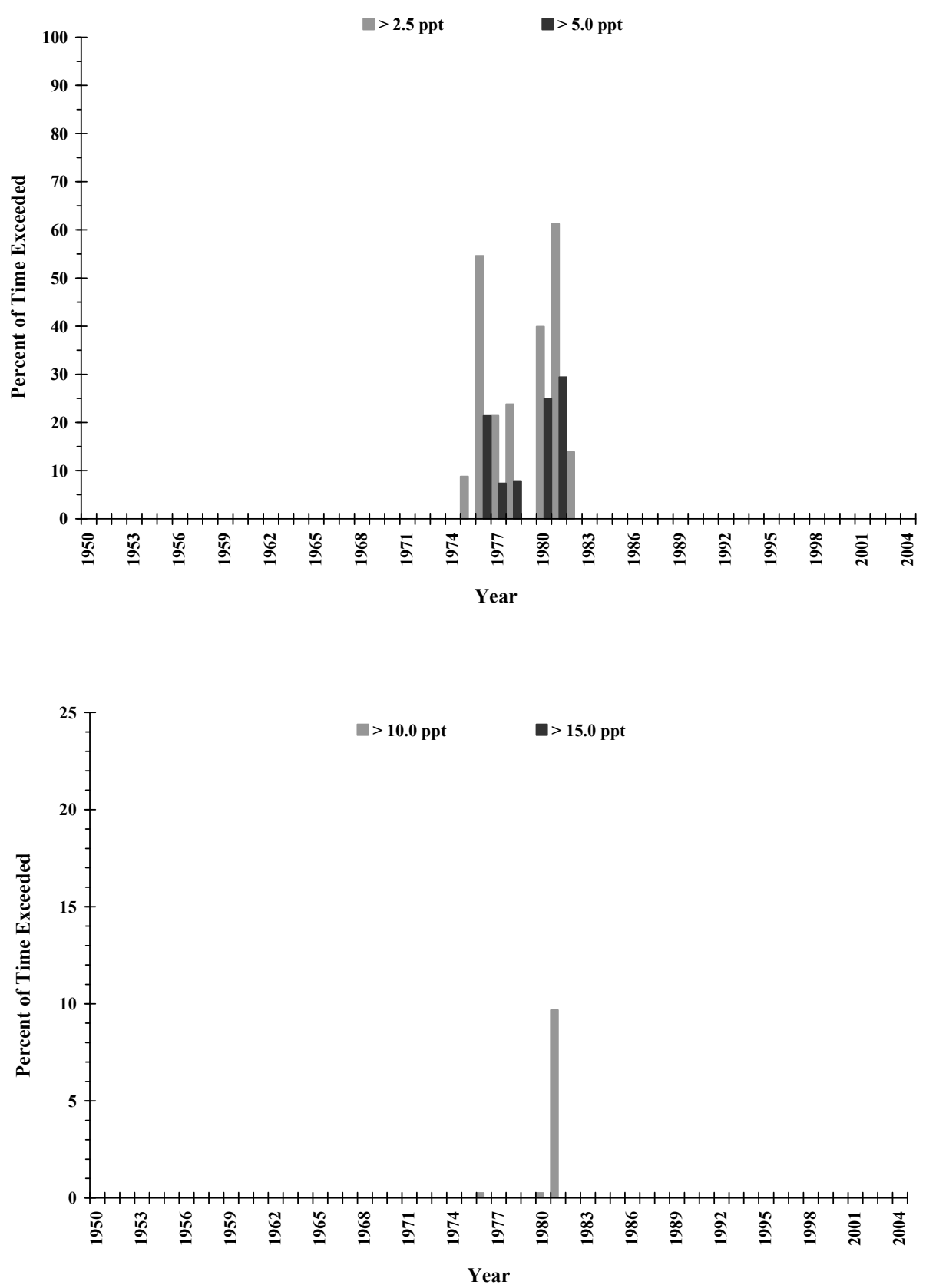

Figure 1-22. Plot of salinity level data for the Intracoastal Waterway east of the Vermilion lock (U.S. Army Corps of Engineers station 76720). Indicated is the percent of time per year that salinity values exceeded the given threshold values; ppt, parts per thousand. 

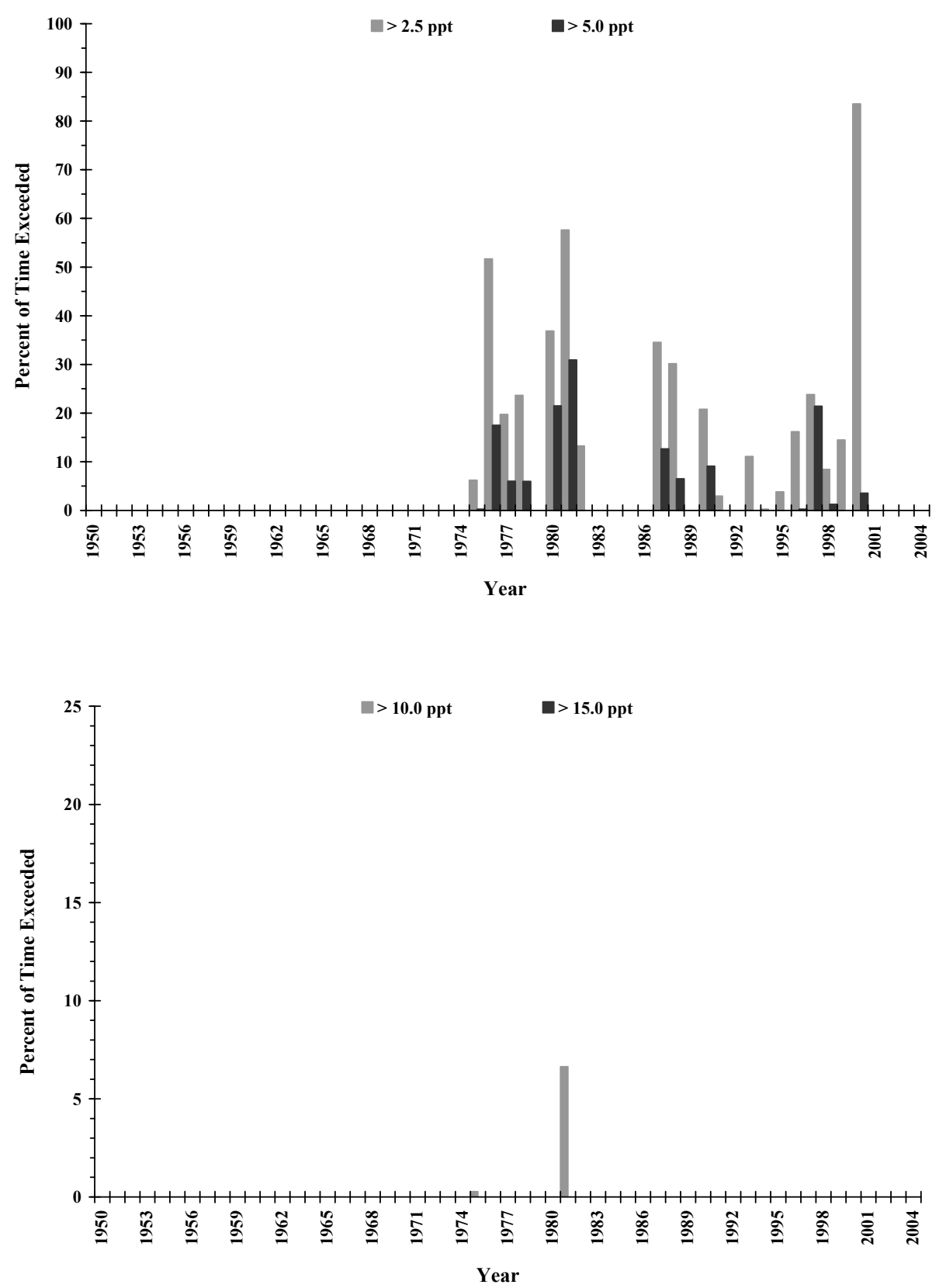

Figure 1-23. Plot of salinity level data for the Intracoastal Waterway west of the Leland Bowman locks (U.S. Army Corps of Engineers station 76800). Indicated is the percent of time per year that salinity values exceeded the given threshold values; ppt, parts per thousand. 


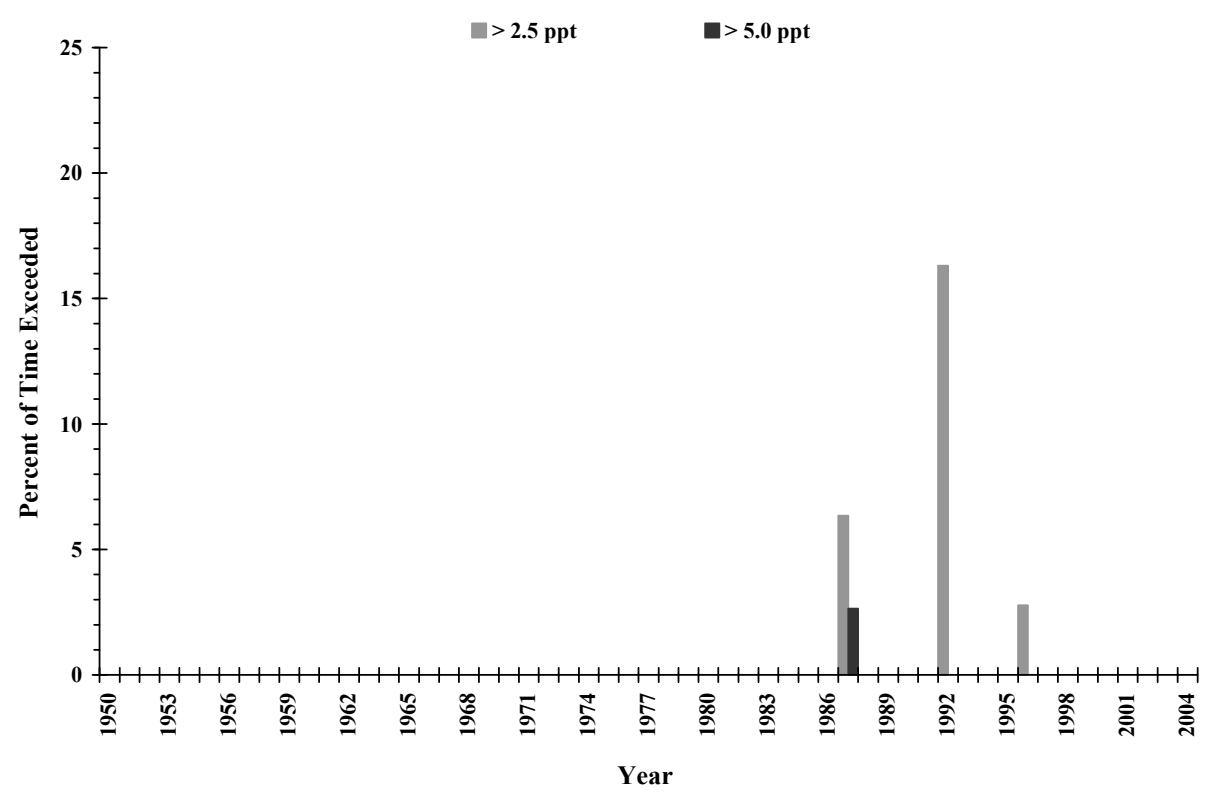

Figure 1-24. Plot of salinity level data for Bayou Blue near Grand Bayou Canal (U.S. Army Corps of Engineers station 81050). Indicated is the percent of time per year that salinity values exceeded the given threshold values; ppt, parts per thousand. 

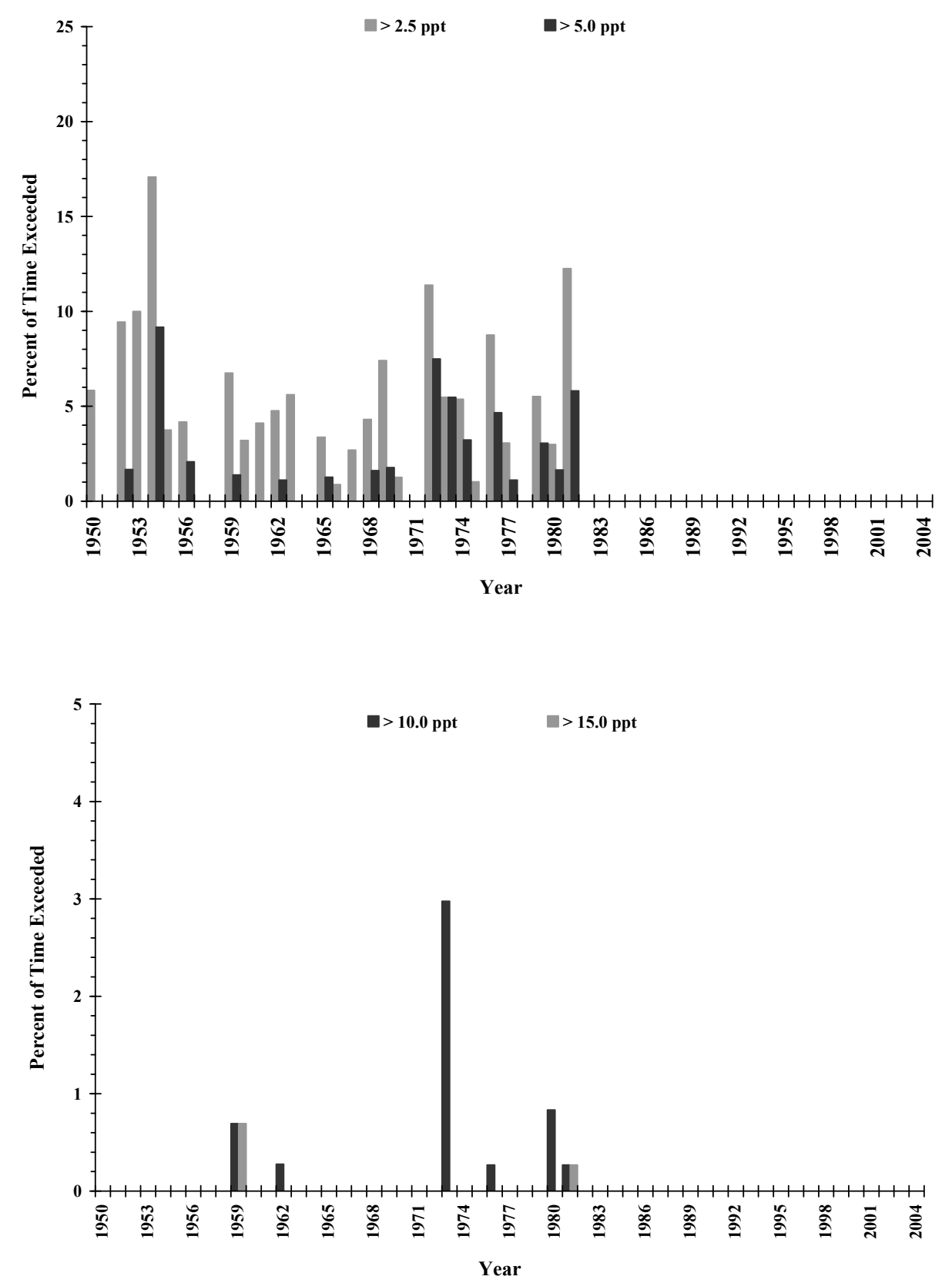

Figure 1-25. Plot of salinity level data for Bayou LaFourche at Larose (U.S. Army Corps of Engineers station 82203). Indicated is the percent of time per year that salinity values exceeded the given threshold values; ppt, parts per thousand. 

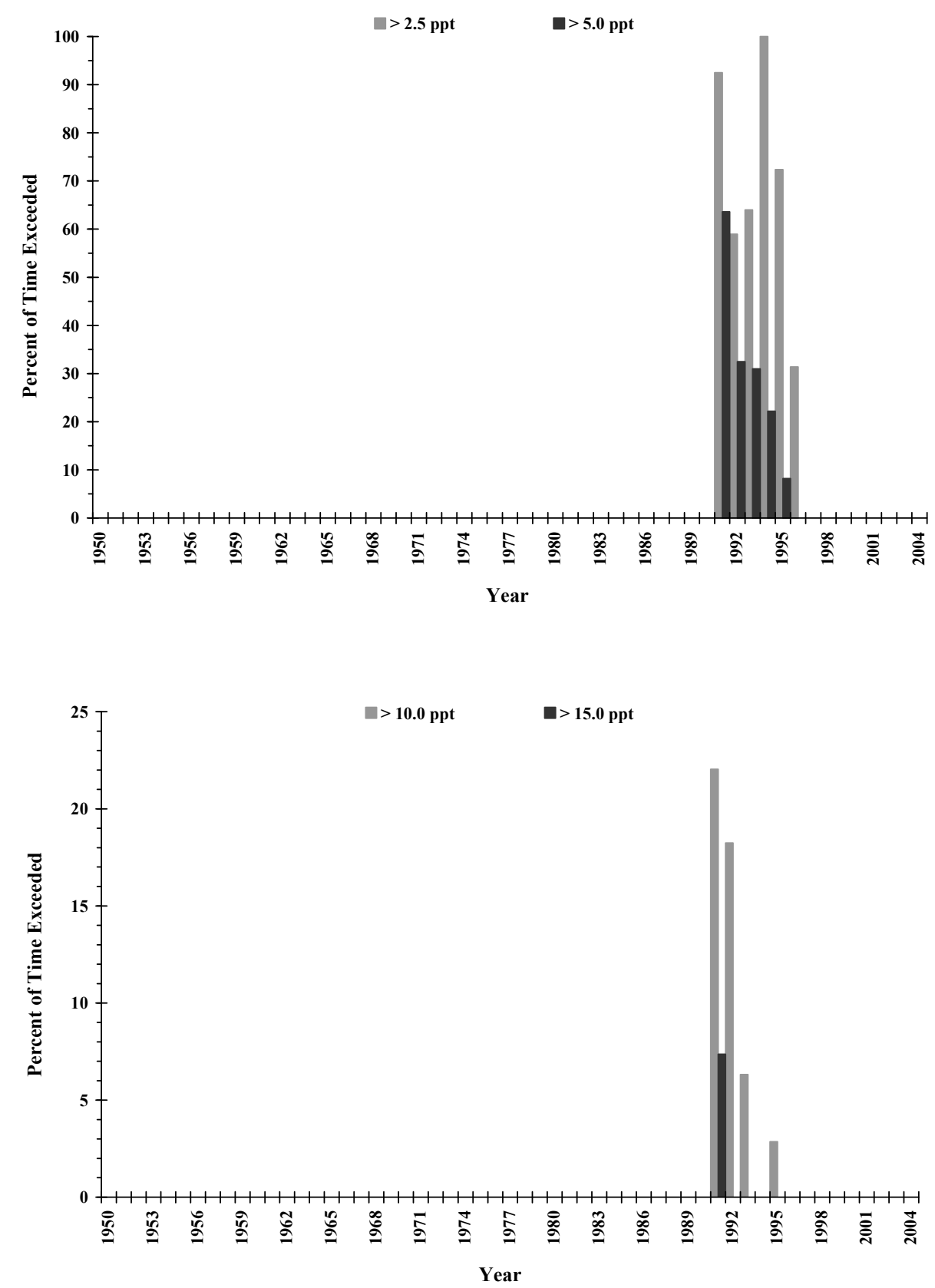

Figure 1-26. Plot of salinity level data for Bayou LaFourche north of the Golden Meadow floodgate (U.S. Army Corps of Engineers station 82250). Indicated is the percent of time per year that salinity values exceeded the given threshold values; ppt, parts per thousand. 

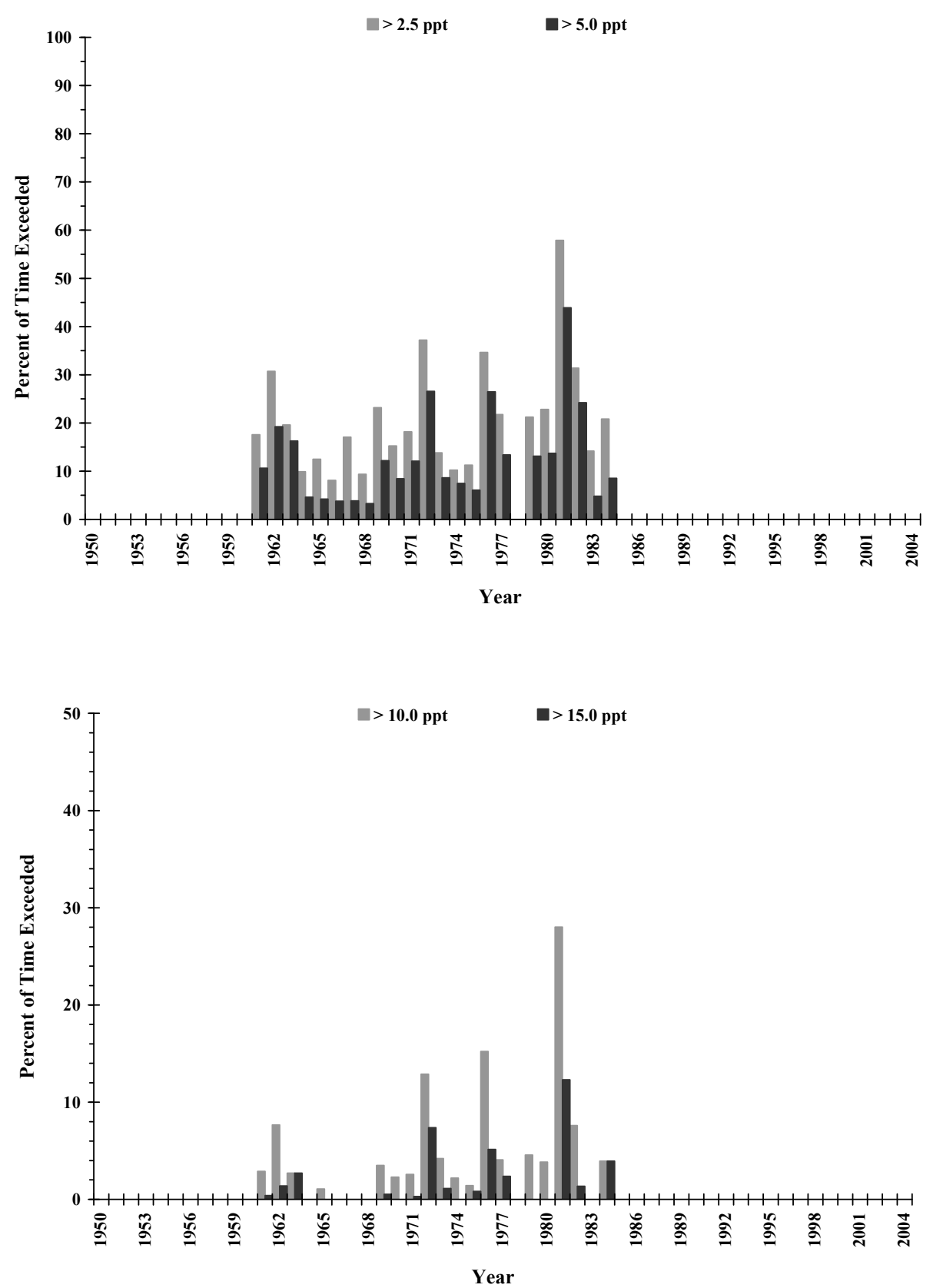

Figure 1-27. Plot of salinity level data for Bayou LaFourche at Galliano (U.S. Army Corps of Engineers station 82300). Indicated is the percent of time per year that salinity values exceeded the given threshold values; ppt, parts per thousand. 

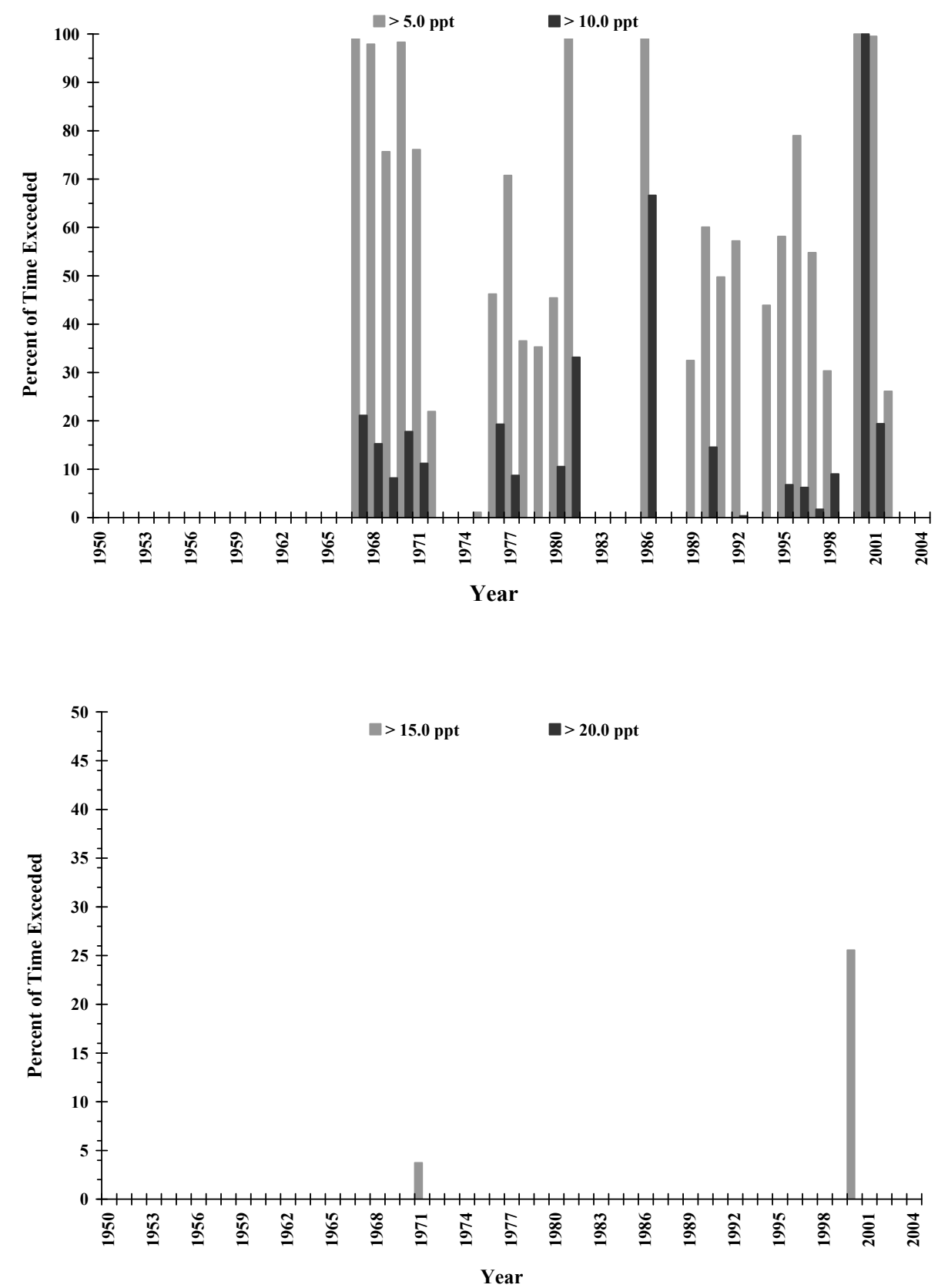

Figure 1-28. Plot of salinity level data for Bayou Barataria at Barataria (U.S. Army Corps of Engineers station 82750). Indicated is the percent of time per year that salinity values exceeded the given threshold values; ppt, parts per thousand. 

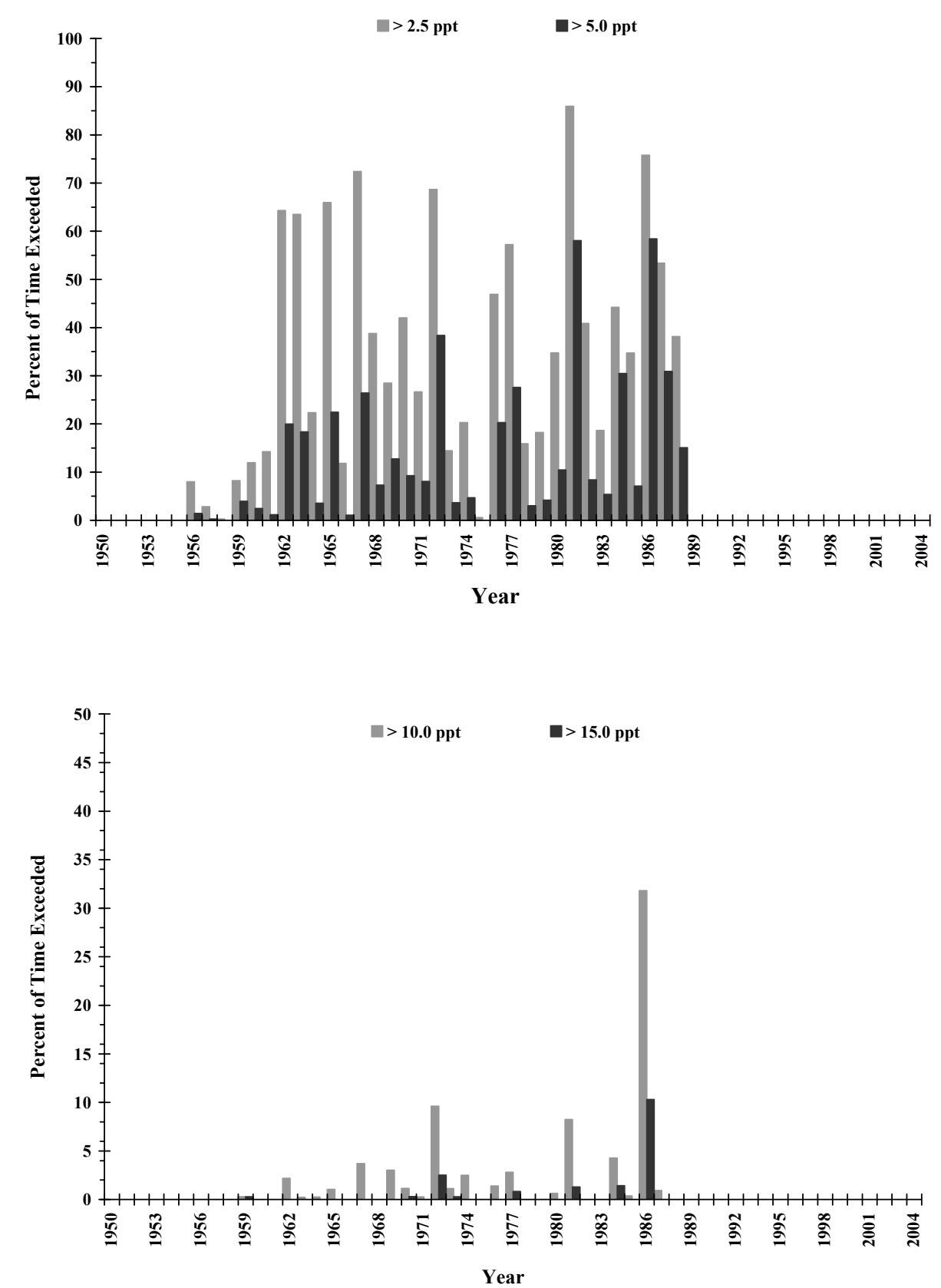

Figure 1-29. Plot of salinity level data for Bayou Barataria at Lafitte (U.S. Army Corps of Engineers station 82875). Indicated is the percent of time per year that salinity values exceeded the given threshold values; ppt, parts per thousand. 


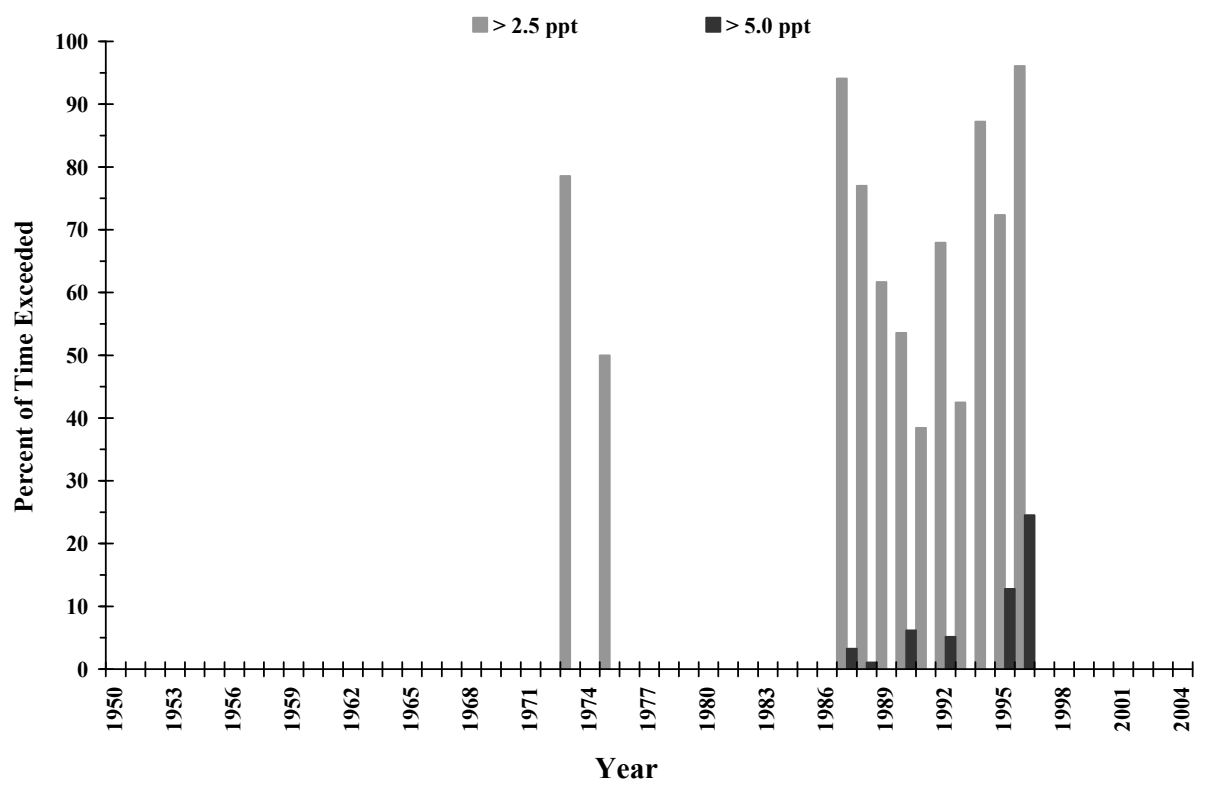

Figure 1-30. Plot of salinity level data for Lake Pontchartrain at midlake (U.S. Army Corps of Engineers station 85600). Indicated is the percent of time per year that salinity values exceeded the given threshold values; ppt, parts per thousand. 

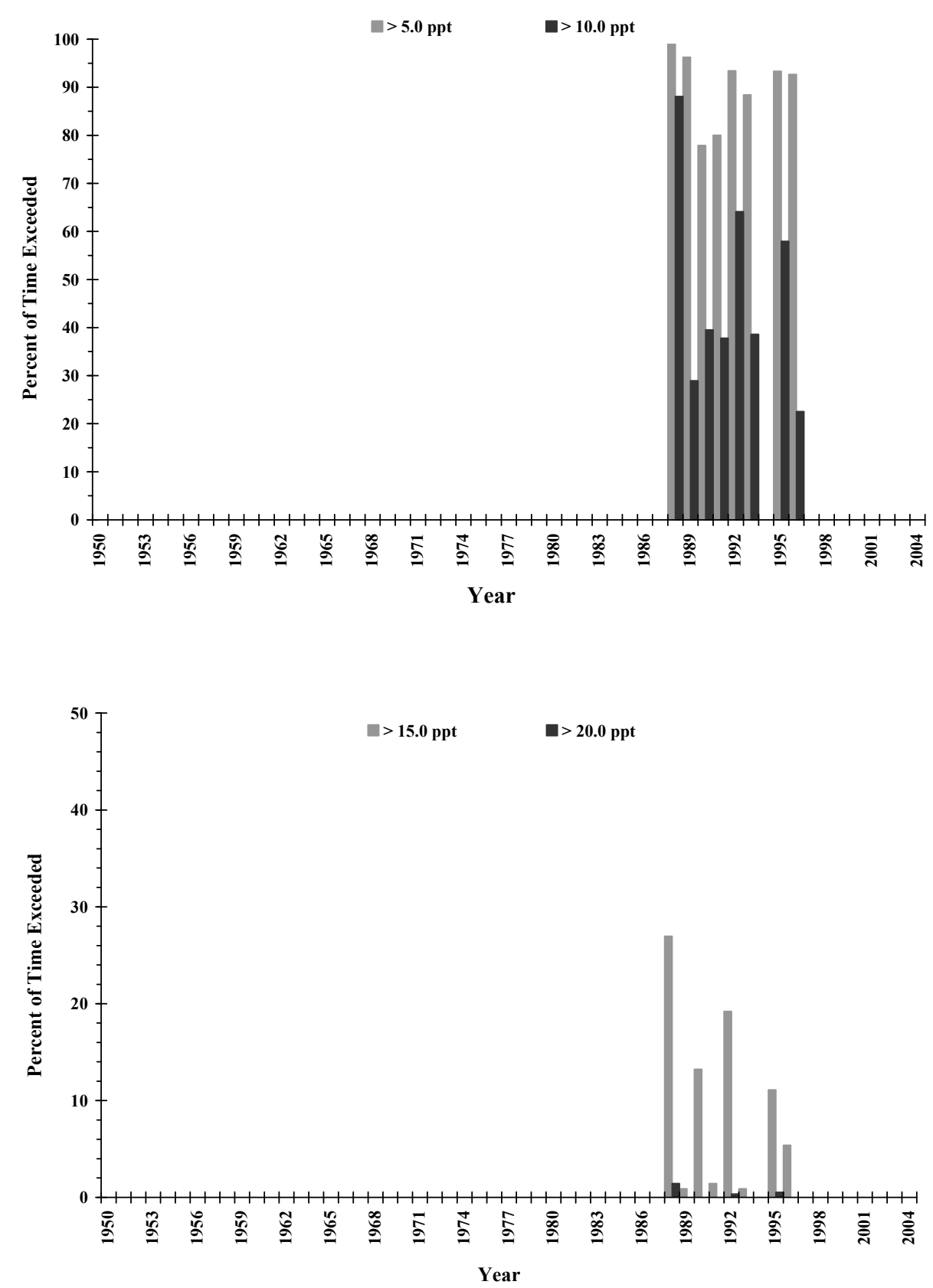

Figure 1-31. Plot of salinity level data for the Mississippi River Gulf Outlet at Shell Beach (U.S. Army Corps of Engineers station 85800). Indicated is the percent of time per year that salinity values exceeded the given threshold values; ppt, parts per thousand. 

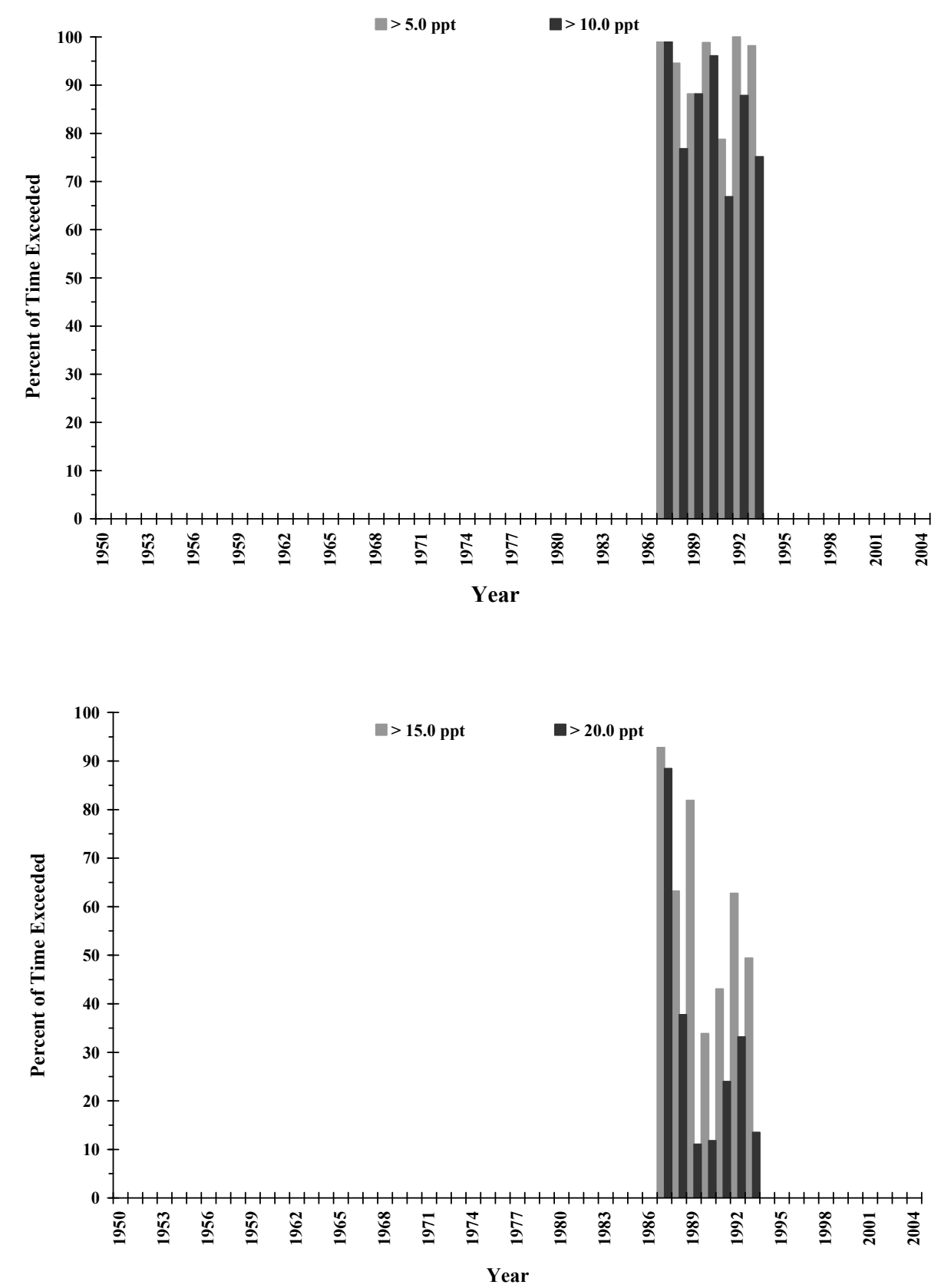

Figure 1-32. Plot of salinity level data for Breton Sound near Garden Island (U.S. Army Corps of Engineers station 85850). Indicated is the percent of time per year that salinity values exceeded the given threshold values; ppt, parts per thousand. 

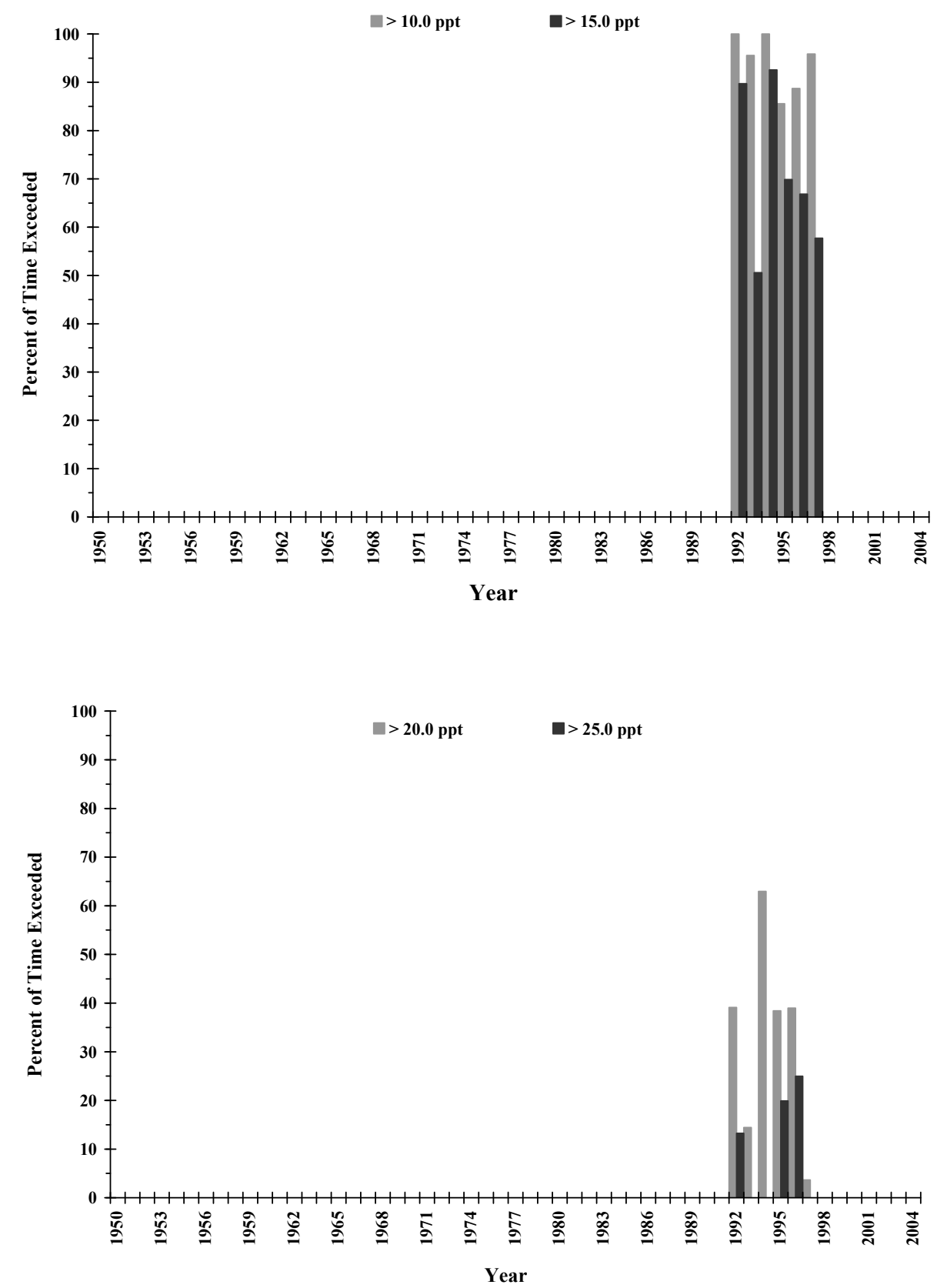

Figure 1-33. Plot of salinity level data for Grand Isle at the Coast Guard Station (U.S. Army Corps of Engineers station 88410). Indicated is the percent of time per year that salinity values exceeded the given threshold values; ppt, parts per thousand. 

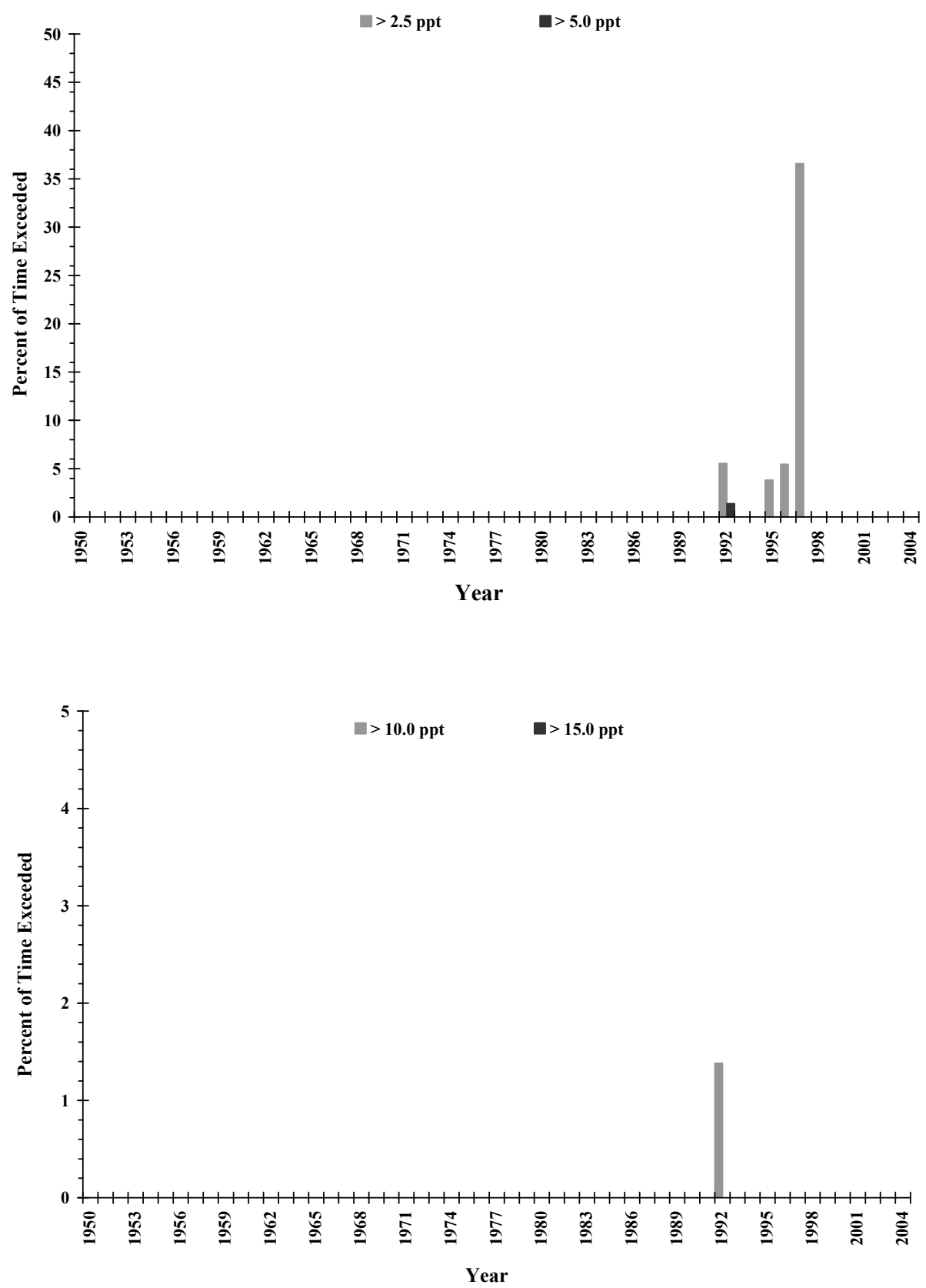

Figure 1-34. Plot of salinity level data for Atchafalaya Bay near Eugene Island (U.S. Army Corps of Engineers station 88550). Indicated is the percent of time per year that salinity values exceeded the given threshold values; ppt, parts per thousand. 

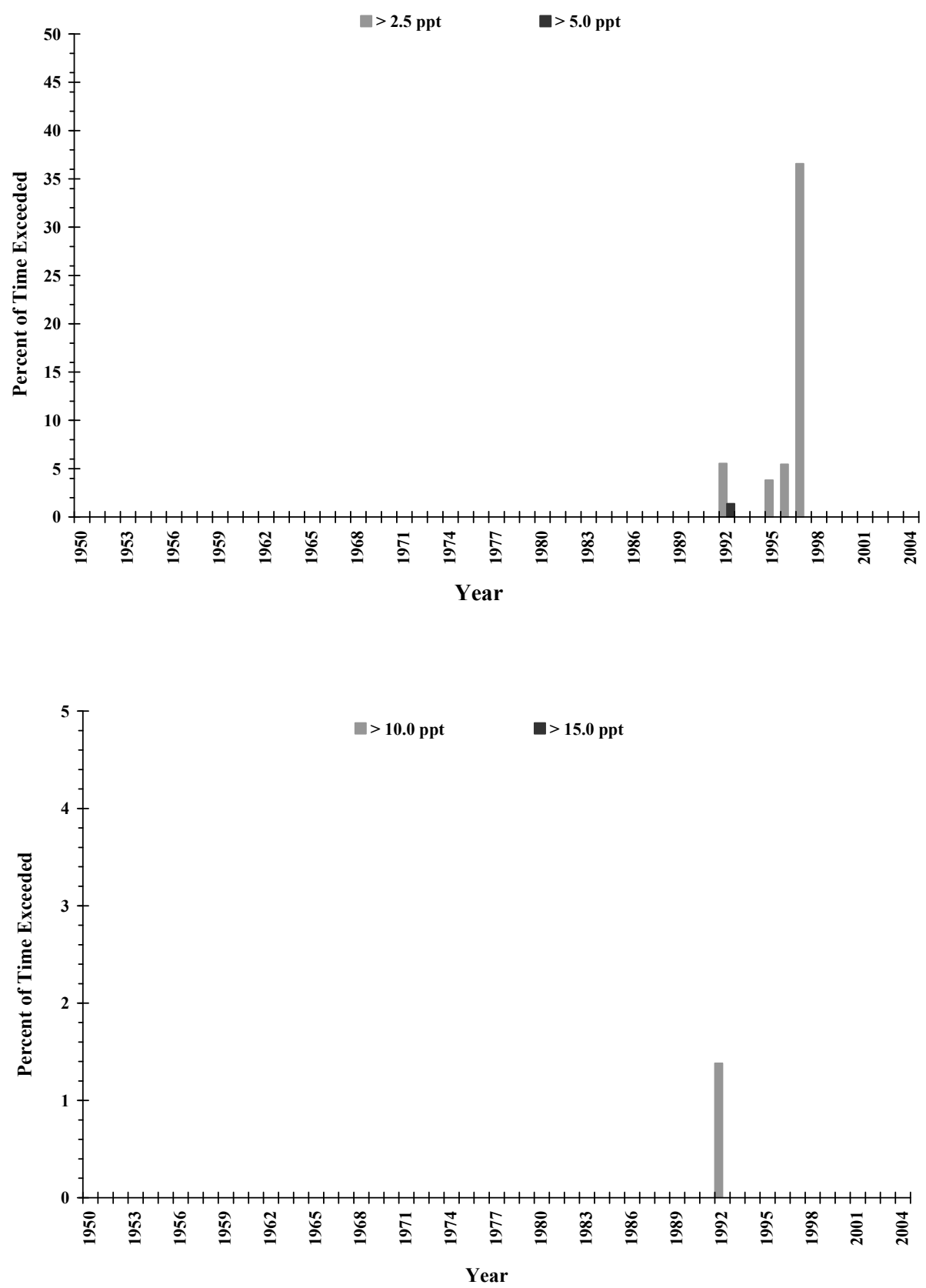

Figure 1-35. Plot of salinity level data for East Cote Blanche Bay at Luke's Landing (U.S. Army Corps of Engineers station 88800). Indicated is the percent of time per year that salinity values exceeded the given threshold values; ppt, parts per thousand. 

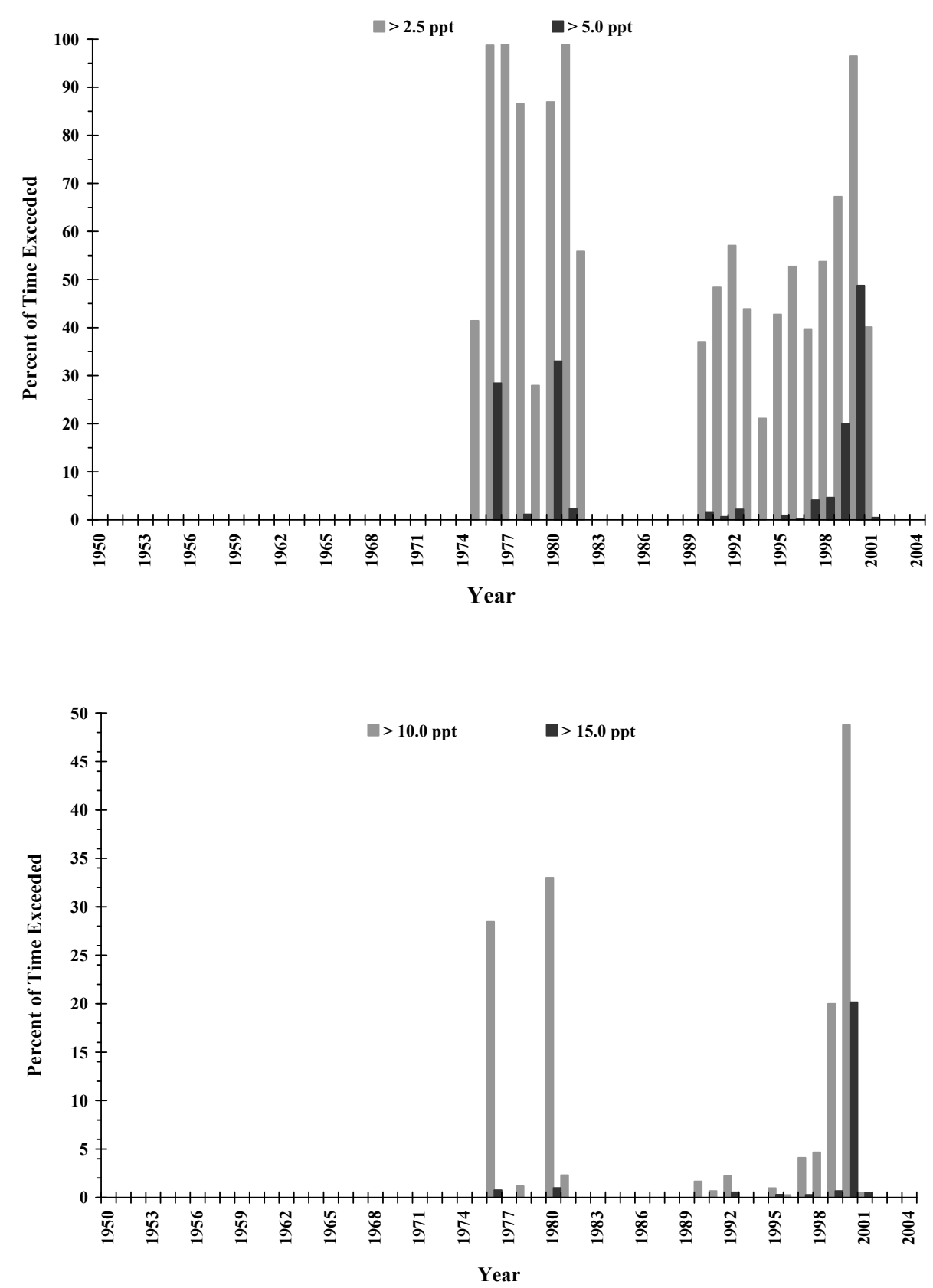

Figure 1-36. Plot of salinity level data for Vermilion Bay at Cypremort Point (U.S. Army Corps of Engineers station 88850). Indicated is the percent of time per year that salinity values exceeded the given threshold values; ppt, parts per thousand.

Salinity was less than $2.5 \mathrm{ppt}$ at the following stations, so no plots were produced:

U.S. Army Corps of Engineers (USACE) 01386, USACE 01420, USACE 01481, USACE 01575, USACE 70600, and USACE 76480. 


\section{Appendix 2. FRAGSTATS Classification Criteria and Thresholds}

1. FRAGSTATS output contains three values for TYPE field $(0,1$, and 2$)$

a. TYPE $=2$ data used in secondary calculations

b. All criteria and sorting applied to TYPE $=1$ records.

2. Create a new field "NEW_PLAND"

a. $=\mathrm{CA} 1 /[\mathrm{CA} 2+\mathrm{CA} 1] * 100$

3. Create a new field "LARGEST_PATCH"

a. $=(\mathrm{LPI} 1 * 1.5625) / 100 * 10000$

4. Create a new field "PD_NEW"

a. $=((\mathrm{NP} 1 /(\mathrm{CA} 1+\mathrm{CA} 2)))$

5. Create a new field "NP/CLUMP"

a. $=$ NP1/CLUMPY 1

6. Sort and separate records by LID

7. Create a new field "WATER"

a. =IF(NEW_PLAND $<5$,"1",IF(NEW_PLAND $<=10$,"2",IF(NEW_PLAND

$<=25, " 3 "$,IF(NEW_PLAND $<=40$,"4",IF(NEW_PLAND

$<=60, " 5 "$, IF(NEW_PLAND <=80,"6",IF(NEW_PLAND <=100,"7","7")))))))

b. Sort and separate records by "WATER" field

8. Create a new field "MARSH"

a. For WATER="2"

i. $=$ IF(AND(LARGEST_PATCH $>=200,($ COHESION $>88.84), A N D(C L U M P Y$ $>0.755), \mathrm{AND}\left(\mathrm{PD} \_N E W<30\right), \mathrm{AND}(\mathrm{NP} / \mathrm{CLUMP}<55.25), \mathrm{AND}(\mathrm{LSI}<8.35)$ ),"

A",IF(AND(LARGEST_PATCH $>200,($ COHESION $>50)$,AND(CLUMPY>0.1)),"C",IF(AND(LARGEST_P

ATCH $<=200,($ COHESION >0),AND(CLUMPY <84)),"B","B")))

b. For WATER=“3”

i. $=$ IF(AND(LARGEST_PATCH $>=400,($ COHESION $>93), A N D(C L U M P Y>0$. 77),AND(PD_NEW<40.7),AND(NP_CLUMP<60),AND(LSI<9)),"A",IF(A ND(LARGEST_PATCH $>400,($ COHESION $>50), A N D(C L U M P Y>0.1)$ ),"C" ,IF(AND(LARGEST_PATCH $<=400,($ COHESION $>0), A N D(C L U M P Y<84)$ )$, " B ", " B ")))$

c. For WATER=“4”

i. $=$ IF(AND(LARGEST_PATCH $>=875$, (COHESION $>96.45), A N D(C L U M P Y$ $>0.79$ ),AND(PD_NEW<53.5),AND(NP_CLUMP < 102),AND(LSI $<9.1)$ ),"A ",IF(AND(LARGEST_PATCH $>=875,($ COHESION $>50), A N D(C L U M P Y>0$ $.1)$ ),"C",IF(AND(LARGEST_PATCH $<875$, (COHESION $>0)$,AND(CLUMP $\mathrm{Y}<84)), " \mathrm{~B}$, ,"B")))

d. For WATER="5"

i. $=$ IF(AND(LARGEST_PATCH $>=2000,($ COHESION $>98.5), A N D(C L U M P Y$ $>=0.84), \mathrm{AND}\left(\mathrm{PD} \_N E W<53.5\right), \mathrm{AND}(\mathrm{NP}$ CCLUMP $\left.<53), \mathrm{AND}(\mathrm{LSI}<8.2)\right)$,"A ",IF(AND(LARGEST_PATCH >=2000,(COHESION $>50)$, AND(CLUMPY> $0.1)$ ),"C",IF(AND(LARGEST_PATCH $<2000,($ COHESION $>0)$,AND(CLU MPY<84)),"B","B")))

9. Create a new field "CLASS"

a. This field will be used to combine the WATER class number to the MARSH subclass letter. 


\section{Glossary}

The definitions below are taken from the following references: The Concise Oxford Dictionary of Ecology, edited by M. Allaby, published by Oxford University Press, Oxford, England, 1994; The Dictionary of Ecology and Environmental Science, edited by H.W. Art, published by Henry Holt and Company, 1993; A Dictionary of Ecology, Evolution, and Systematics, edited by R.J. Lincoln, G.A. Boxshall, and P.F. Clark, published by Cambridge University Press, Cambridge, England, 1982; Glossary of Oceanography and the Related Geosciences with References, by Steven K. Baum, Texas Center for Climate Studies, Texas A\&M University; and Webster's Third New International Dictionary, published by Merriam-Webster, Springfield, Massachusetts, 1961, 1993. Louisiana Coastal Area Ecosystem Restoration: Comprehensive Coastwide Ecosystem Restoration Feasibility Study, Louisiana Coastal Area Ecosystem Restoration Program, U.S. Army Corps of Engineers New Orleans District, Louisiana, 2002.

ASCII (American Standard Code for Information Interchange). A standard code, consisting of 128 7-bit combinations, for characters stored in a computer or to be transmitted between computers.

ARMA (autoregressive moving average). A stochastic process or a model that is used to describe time series data. An ARMA process is a stationary one made up of sums of autoregressive and moving-average components.

BTNEP. Barataria Terrebonne National Estuary Program.

category. Fragmentation class that designates the percentage of water within the defined landscape.

Chenier Plain. An area of coastal Louisiana bordered on the east by Vermilion Bay, on the west by the Sabine River, and on the north by the Pleistocene Ridge (roughly Interstate 10). It is characterized by abandoned beach fronts that parallel the Gulf of Mexico shoreline.

classification. Grouping cells (often by color characteristics) from coregistered rasters to map the location and type of image features (like type of crop, surface cover, and map line type).

class-level metrics. Statistics that are integrated over all the patches of a given type (class). These may be integrated by simple averaging, or through some sort of weighted-averaging scheme to bias the estimate to reflect the greater contribution of large patches to the overall index.

clumpy (clumpiness index). An index that shows the frequency with which different pairs of patch types (including like adjacencies between the same patch type) appear side by side on the map, varying from -1 (totally disaggregated class) to 1 (maximally clumped).

cohesion (patch cohesion index). An index that measures the physical connectedness of the corresponding patch type. Patch cohesion increases as the patch type becomes more clumped or aggregated in its distribution and therefore, becomes more physically connected.

configuration. Fragmentation class that designates the spatial character and arrangement, position, or orientation of the corresponding class type. 
continental shelf. The shallow, gradually sloping seabed around a continental margin, not usually deeper than $200 \mathrm{~m}$ and formed by submergence of part of a continent.

CSV (comma-separated values). A file format used as a portable representation of a database. Each line is one entry or record, and the fields in a record are separated by commas. Commas may be followed by arbitrary space or tab characters, which are ignored.

Deltaic Plain. An area of coastal Louisiana bordered on the west by Vermilion Bay, on the east by the Pearl River, and the north by a line running along the north shore of Lake Pontchartrain, then up the old Pleistocene ridge on the river's present east bank until around the area of Simmsport, and then on a line down to Vermilion Bay.

DOQQ (digital orthophoto quarter quadrangle). A 1:12,000-scale representation of a quarter of the area of a conventional USGS 7.5-minute topographical map produced by using aerial photographs.

easting. A rectangular $(\mathrm{x}, \mathrm{y})$ coordinate measurement of distance east from a north-south reference line, usually a meridian used as the axis of origin within a map zone or projection. False easting is an adjustment constant added to coordinate values to eliminate negative numbers.

ecosystem. A community of organisms and their physical environment that interact as an ecological unit.

Ekman convergence. A zone of convergence of warm surface water caused by Ekman transport, creating a marked depression of the ocean's thermocline in the affected area.

Ekman transport. The natural process by which wind causes movement of water near the ocean surface.

estuary. A semi-enclosed coastal body of water which has a free connection with the open sea and where fresh water derived from land drainage (usually mouths of rivers) is mixed with seawater; often subject to tidal action and cyclic fluctuations in salinity.

evapotranspiration. Loss of water from the soil both by evaporation and by transpiration from plants.

fastlands, The zone extending from the landward limits of wetlands to at least $400 \mathrm{ft}$ inland.

faulting, A fracture in the continuity of a soil or rock formation caused by a shifting or dislodging of the Earth's crust, in which adjacent surfaces are displaced relative to one another and parallel to the plane of fracture.

floating fresh marsh, A term used by O'Neil (1949) to describe a marsh dominated by Panicum hemitomon.

floating three-cornered grass, A term used by O'Neil (1949) to describe a marsh dominated by Schenoplectus olneyi on a floating map. According to O'Neil, muskrat (Ondatra zibethicus ) populations rapidly denude these marshes of the $S$. olneyi, creating extremely rotten broken marsh. 
flotant, A floating marsh that is not anchored to the ground beneath.

FRAGSTATS. A computer software program designed to compute a wide variety of landscape metrics for categorical map patterns.

fresh marsh. Intertidal herbaceous plant community typically found in that area of the estuary with salinity ranging from 0 to 3 parts per thousand.

fresh bulltongue marsh. A term used by Visser and others (1998) to describe a fresh marsh always dominated by Sagittaria lancifolia and frequently codominated by Panicum hemitomon and Eleocharis spp. Ferns (including Thelypteris palustris and Osmunda regalis), Myrica cerifera, and Hydrocotyle spp. are often present also. Bacopa monnieri is absent from this marsh type.

fresh maidencane marsh. A term used by Visser and others (1998) to describe a fresh marsh dominated by Panicum hemitomon.

GAP analysis. The process of identifying and classifying components of biological diversity to determine which components already occur in protected areas and which are not present or are underrepresented in protected areas.

georectification. The digital alignment of a satellite or aerial image with a map of the same area. In georectification, a number of corresponding control points, such as street intersections, are marked on both the image and the map. These locations become reference points in the subsequent processing of the image.

GIS (geographic information system). A combination of computer hardware and software that allows storage and manipulation of information suitable for mapping.

GIWW. Gulf Intracoastal Waterway.

habitat fragmentation, The breaking up of a habitat into unconnected patches of water and land.

hectare (ha). A metric unit of measure for area, equal to 2.47 acres.

HNC. Houma Navigation Canal.

hotspot. Relatively large areas that display significant change in one or more landscape measures: marsh composition, configuration, or density.

HWTP. Houma Water Treatment Plant.

hydrology. The study of the movement of water from the sea through the air to the land and back to the sea; the properties, distribution, and circulation of water on or below the Earth's surface and in the atmosphere.

intermediate marsh. Intertidal herbaceous plant community typically found in that area of the estuary with salinity ranging from 2 to 5 parts per thousand.

Kendall Tau coefficient. A statistic used to measure the degree of correspondence between two rankings and to assess the significance of this correspondence. 
landscape ecology. The distribution of energy, materials, and species in relation to sizes, shapes, numbers, kinds, and configuration of landscape elements or ecosystems.

landscape-level metrics. Metrics that are integrated over all patch types or classes over the full extent of the data (that is, the entire landscape). Like class metrics, these may be integrated by a simple or weighted averaging or may reflect aggregate properties of the patch mosaic.

LDHH. Louisiana Department of Health and Hospitals.

LDNR. Louisiana Department of Natural Resources.

LDWF. Louisiana Department of Wildlife and Fisheries.

location canal. Canals that are primarily dredged within marsh landscapes to provide greater accessibility for oil and gas extraction.

Losco. Louisiana Oil Spill Coordinator's Office.

LPI (largest patch index). An index that quantifies the percentage of total landscape area constituting the largest patch. This index is a simple measure of dominance.

LSI (landscape shape index). The total length of edge involving the corresponding class, given in number of cell surfaces, divided by the minimum length of class edge possible for a maximally aggregated class.

LUMCON. Louisiana Universities Marine Consortium.

marsh. An ecosystem of more or less continuously waterlogged soil dominated by emersed herbaceous plants but without a surface accumulation of peat. A marsh differs from a swamp in that it is dominated by rushes, reeds, cattails, and sedges, with few if any woody plants, and differs from a bog in that it has soil rather than peat as its base.

MCD (marsh configuration difference). The change in marsh configuration metric value from one observed temporal data point to another.

metric. A standard or a statistic for measuring or quantifying something else.

MMS. Minerals Management Service.

mosaic. A large image assembled from segments. Each segment may come from a different source and have a different cell size and angle of orientation, but all the segments must be geometrically rectified and calibrated to a common coordinate framework.

MRGO. Mississippi River-Gulf Outlet.

NAVD88 (North American Vertical Datum of 1988) A geodetic reference for elevations, created by the National Geodetic Survey (NGS) to replace the National Geodetic Vertical Datum (NGVD) 29. This new datum was published in 1991 and incorporates vertical datums used on the Great Lakes. It is adjusted on the basis of field work prior to 1929 as well as surveys as recent as 1988. 
northing. A rectangular $(\mathrm{x}, \mathrm{y})$ coordinate measurement of distance north from an east-west reference line, usually the Equator or other parallel used as the axis of origin for a map zone or projection. False northing is an adjustment constant added to coordinate values to eliminate negative numbers.

NP (number of patches). A metric combination that provides a quasi density-by-shape value that is used to separate the class configurations that are approaching the metric threshold.

OA (overall time period). A term that refers to all project data that were created, and analyses that were performed, in relation to the preconstruction (1958) and end-point (1998) dates of the Houma Navigation Canal.

ocs. Outer Continental Shelf.

oligohaline wiregrass. A term used by Visser and others (1998) to describe an intermediate marsh dominated by Spartina patens and frequently codominated by Scirpus americanus.

panchromatic. An image collected in the broad visual wavelength range but rendered in black and white.

PD (patch density). An index that calculates the number of patches of the corresponding patch type, divided by total grid-tile landscape area and excluding all nonwater and marsh patches.

PLAND (percentage of landscape). The percentage the landscape made up of the corresponding patch type.

POR (period of record). The length of time that data were collected or were available.

ppt (parts per thousand). The ratio of the amount of the substance of interest to the amount of that substance plus the amount of the substance it is in.

QA/QC. quality assurance/quality control.

raster. A single, related, two-dimensionally grouped set of numbers of a single data type. Each number represents the value of some parameter. Its position in the group represents its relative position to the other values. A raster object is a raster that is stored in a raster vector converted (RVC) project file.

resample. To interpolate cell values in a raster object and create a raster with larger or smaller cells.

SAIC. Science Applications International Corporation.

salt marsh. Intertidal herbaceous plant community typically found in that area of the estuary with salinity ranging from 12 to 32 parts per thousand.

SAS. Statistical analysis system. 
salinity. A measure of the total concentration of dissolved salts in water. The salinity of ocean water is in the range of 33-38 parts per thousand.

scale. The distance ratio measured on a map to that distance measured on the ground between the same two points.

subsidence. The process of the sinking or settling of a land surface or a crustal elevation because of natural or artificial causes.

TA (time period A). A term that refers to all project data that were created, and analyses that were performed, in relation to the preconstruction (1958) and postconstruction (1968/69) dates of the Houma Navigation Canal.

TB (time period B). A term that refers to all project data that were created, and analyses that were performed, in relation to the postconstruction (1958) and end-point (1998) dates of the Houma Navigation Canal.

TCA (total class area). A measure of landscape composition; specifically, how much of the landscape is composed of a particular patch type.

TIFF (Tagged Image File Format). A container format for storing images, including photographs and line art.

TM (Landsat Thematic Mapper). One of the Earth-observing sensors introduced in the Landsat program. TM sensors feature seven bands of image data (three in visible wavelengths, four in infrared), most of which have 30-m resolution.

trenasse. A small manmade trench through a swamp or marsh an area.

topography. The natural and constructed relief of an area.

USACE. U.S. Army Corps of Engineers.

USEPA STORET. The U.S. Environmental Protection Agency (EPA) data management system that contains water quality information for the Nation's waters.

USGS. U.S. Geological Survey.

vector. An object made up of three different types of elements that can have associated attributes: (1) points, which are single sets of coordinates that define a point feature (such as a well); (2) lines, which are curvilinear strings of coordinates that define a curved line (such as a stream); and (3) polygons, which are collections of lines that inscribe an area (such as a lake), as well as a fourth type of element, nodes, which are necessary to maintain vector topology.

vector grid. A network of parallel and perpendicular lines superimposed on a map and often used for referencing or processing of additional data.

wetland. A general term applied to land areas which are seasonally or permanently waterlogged, including lakes, rivers, estuaries, and freshwater marshes; an area of low-lying land submerged or inundated periodically by fresh or saline water. 